\title{
Filtros para Objetos ${ }^{1}$
}

José de Oliveira Guimarães

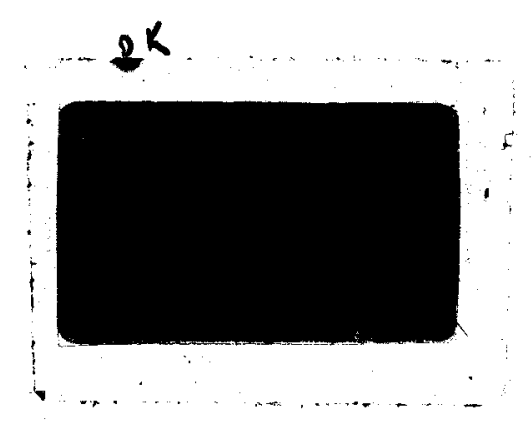

Tese apresentada no Instituto de Física de São Carlos, da Universidade de São Paulo, para obtenção do título de Doutor em Física Aplicada, subárea Física Computacional.

Orientador: Prof. Dr. Paulo Cesar Masiero

São Carlos

1996

${ }^{1}$ Esta tese recebeu suporte financeiro do CNPq, processo No. 200466-94.1 
Guimarães, José de Oliveira

Filtros para Objetos/Guimarães, José de Oliveira

- São Carlos, 1996.

$159 \mathrm{p}$. los, 1996.

Tese (Doutorado) - Instituto de Física de São Car-

Orientador: Prof. Dr. Paulo Cesar Masiero

1. Linguagens de Programação. 2. Engenharia de Programação.

I. Título 


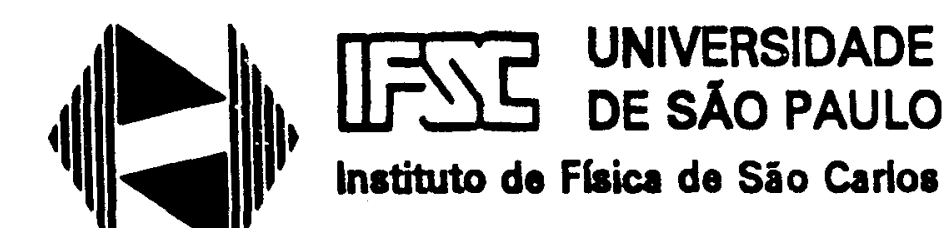

Av. Dr. Carlos Botelho, 1465

CEP 13560-250 - Sảo Cartos - SP Brasil

Fone (016) 272-6222

Fax (016) 272-2218

MEMBROS DA COMISSÃO JULGADORA DA TESE DE DOUTORADO DE JOSÉ DE OLIVEIRA GUIMARÃES APRESENTADA AO INSTTTUTO DE FÍSICA DE SÃO CARLOS, UNIVERSIDADE DE SÃO PAULO, EM 22/04/1996.

COMISSÃO JULGADORA:

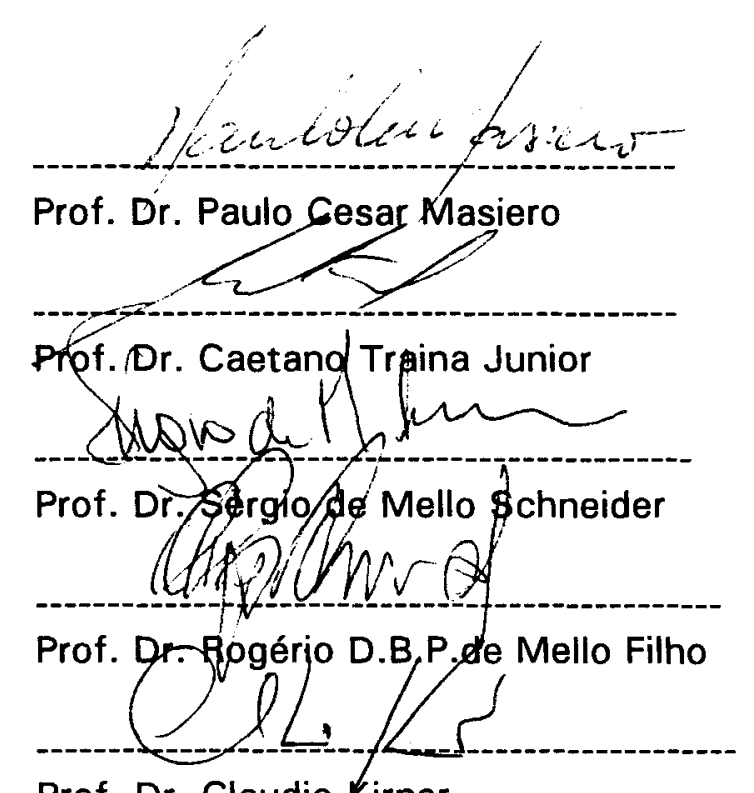

Prof. Dr. Claudio Kirner 


\section{DEDICATÓRIA}

Esta tese é dedicada a meus pais, Belchior e Dalila. 


\section{AGRADECIMENTOS}

Agradeço

- Aos meus orientadores, Paulo Cesar Masiero e Ralph Johnson, pelo suporte no desenvolvimento desta tese;

- Aos brasileiros que conheci em Urbana-Champaign, dentre eles, a Flávio, Rogério Gaúcho, Rogério Cearence, Georgios, Paulo, José, Miledi, Amir, Everton, Cangibrina. As intermináveis noitadas de truco em companhia destas pessoas tornaram a minha estada em Champaign muito agradável;

- Aos americanos que conheci em Urbana-Champaign. Em particular, a Joseph Yoder, Jason e sua mãe Becky, Judy Tolliver, Leanna, Michael, David, Tamara Livingston, Clara Castelo, Ian Chai, Thomas Overbye, Jo, Tim, Bonnie, Jeff Bong, John Martinez, Pat e Bob Felts. Todas estas pessoas me ajudaram imensamente a melhorar o meu Inglês, a entender a cultura americana e resolver problemas do dia a dia;

- Aos professores e funcionários do departamento de computação, que forneceram suporte para este trabalho. Em particular, agradeço ao professor Zorzo, que ministrou disciplinas que, de outra forma, seriam ministradas por mim;

- A meus pais, que compreenderam as visitas menos freqüentes devido ao doutorado. 


\section{Sumário}

1 Introdução 1

1.1 Problemas com Programação Orientada a Objetos . . . . . . . . . 1

1.2 Algumas Definições Básicas . . . . . . . . . . . . . 3

1.3 Filtros e Shells . . . . . . . . . . . . . . . 4

1.4 Padrões de Apresentação e Organização da Tese . . . . . . . . . 8

2 Visão de Classe $\quad \mathbf{1 1}$

2.1 Introdução . . . . . . . . . . . . . . . . . . . 11

2.2 Alguns Exemplos de Problemas . . . . . . . . . . . . . . . . . 11

2.3 O Esboço de uma Solução . . . . . . . . . . . . . . . . . 14

2.3.1 Solução com Herança . . . . . . . . . . . . . . . 17

2.3 .2 A Solução Geral . . . . . . . . . . . . . . . . 20

2.4 Definição de Visão de Classe . . . . . . . . . . . . . . . 24

2.5 Uma Otimização da Substituição da Atribuição . . . . . . . . . . 34

2.5 .1 Caso Simples ... . . . . . . . . . . . . 34

2.5.2 Caso Polimórfico . . . . . . . . . . . . . 35

2.5 .3 Caso Geral . . . . . . . . . . . . . . . . 35

2.6 Algumas Restrições no Uso de Visão de Classe . . . . . . . . . . 38

2.7 Solução dos Problemas . . . . . . . . . . . . . . . . . . . . . 40

2.8 Implementação . . . . . . . . . . . . . . . . . . . . 44 44

2.9 Trabalhos Relacionados . . . . . . . . . . . . . . 45

$\begin{array}{llr}3 & \text { Adaptadores } & \mathbf{4 7}\end{array}$

3.1 Introdução . . . . . . . . . . . . . . . . . . . 47 47

3.2 Alguns Exemplos de Problemas . . . . . . . . . . . . . . . 47

3.3 O Esboço de uma Solução . . . . . . . . . . . . . . . . . 51

3.4 A Definição de Adaptadores . . . . . . . . . . . . . . 52

3.4 .1 A Análise da Classe Adaptadora . . . . . . . . . . . 52

3.4.2 Quando um Objeto Filtro Deve Ser Adicionado . . . . . . 55

3.4.3 Quando Filtros Redundantes são Removidos . . . . . . . . 57

3.4 .4 Caso Geral . . . . . . . . . . . . . . . 61

3.4.5 Restrições nas Definições de Adaptadores . . . . . . . . . . 63

3.4.6 Limites no Número de Objetos Filtro . . . . . . . . . . . . 64

3.5 Solução dos Problemas . . . . . . . . . . . . . . . 66 65

3.6 Implementação . . . . . . . . . . . . . . . . . . . . . . . . . . . . 66

3.7 Trabalhos Relacionados . . . . . . . . . . . . . 66 
4 Extensão de Classe $\quad 68$

4.1 Introdução . . . . . . . . . . . . . . . . . . . . . . . . . . 68

4.2 Alguns Exemplos de Problemas . . . . . . . . . . . . . . . . 68

4.3 A Definição de Extensão de Classe . . . . . . . . . . . . . . . . . . 70

4.4 Solução dos Problemas . . . . . . . . . . . . . . . . 73

4.5 Implementação . . . . . . . . . . . . . . . . . 78

4.6 Trabalhos Relacionados . . . . . . . . . . . . 78

5 Shell Dinâmico $\quad 81$

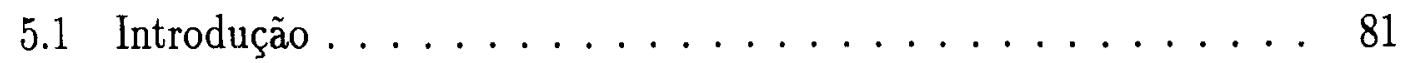

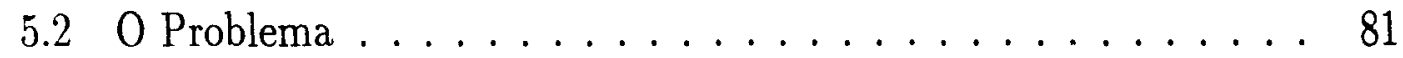

5.3 O Esboço de uma Solução . . . . . . . . . . . . . . . . . . . . 82

5.4 A Especificação de Shell Dinâmico . . . . . . . . . . . . . 83

5.5 Prova da Correção Estática de Tipos . . . . . . . . . . . . . . . 87

5.6 A Solução do Problema . . . . . . . . . . . . . . . . . 88

5.7 Implementação . . . . . . . . . . . . . . . . . . . . . . . . 94

5.8 Trabalhos Relacionados . . . . . . . . . . . . . . 95

6 Extensão Dinâmica $\quad 97$

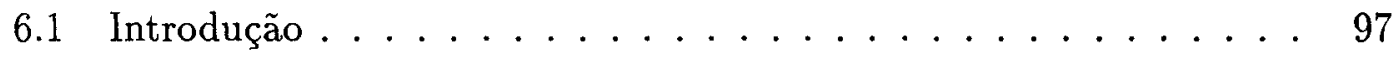

6.2 A Definição de Extensão Dinâmica . . . . . . . . . . . . . 97

6.3 A Prova de Correção de Tipos . . . . . . . . . . . . . . . . 100

6.4 Implementação . . . . . . . . . . . . . . . . . . . . . 101

6.5 Trabalhos Relacionados . . . . . . . . . . . . . . . 102

7 Relacionamentos Entre Shells 104

8 Reflexão Computacional e as Construções Shell 107

8.1 Introdução . . . . . . . . . . . . . . . . . . 107

8.2 Modelos Reflexivos Existentes . . . . . . . . . . . . . . . 107

8.3 Alguns Exemplos de Uso de Reflexão . . . . . . . . . . . . . . . 109

8.4 Problemas com os Modelos Meta-classe e Meta Objeto . . . . . 110

8.5 Discussão Sobre Shells e Reflexividade . . . . . . . . . . . . 110

9 Conclusão $\quad 113$

9.1 Considerações Gerais . . . . . . . . . . . . . . . . . . . . 113

9.2 Contribuições desta Tese . . . . . . . . . . . . . . . 115

9.3 Pesquisas Futuras . . . . . . . . . . . . . . . . . . 118

$\begin{array}{lr}\text { Bibliografia } & \mathbf{1 2 1}\end{array}$

$\begin{array}{lr}\text { A Um Modelo de Linguagem } & \mathbf{1 2 7}\end{array}$

A.1 Introdução . . . . . . . . . . . . . . . . . 127

A.1.1 Características Básicas . . . . . . . . . . . . . . 127

A.1.2 Tipos, Mensagens e Polimorfismo . . . . . . . . . 131

A.1.3 Representação de Classes . . . . . . . . . . . . . . . . 136

A.1.4 Outras Facilidades da Linguagem ... . . . . . . 137 
A.3.1 Definição . . . . . . . . . . . . . . . 140

A.3.2 Uma Extensão a Classes Parametrizadas . . . . . . . . . 143

B A Gramática da Linguagem $\quad 151$

$\begin{array}{ll}\text { C Glossário } & \mathbf{1 5 4}\end{array}$ 


\section{Lista de Figuras}

1.1 Objeto $\mathcal{Q}$ coberto por um shell com métodos r e s . . . . . . 5

1.2 Objeto $\mathcal{Q}$ coberto por shell com métodos m e p . . . . . . . 5

1.3 Um shell NewStore para a classe Store . . . . . . . . . . . 7

1.4 O filtro $\mathcal{F}$ e a variável a fazem referência ao objeto $\mathcal{Q} \ldots \ldots$

2.1 Classes A e B onde B é subtipo de A . . . . . . . . . . . . 12

2.2 Referência a um filtro em tempo de execução . . . . . . . . . . . 15

2.3 Um filtro para objetos de Box . . . . . . . . . . . . 16

2.4 Possíveis filtros para objetos Box em tempo de execução . . . . . . 17

2.5 O uso de filtros das superclasses . . . . . . . . . . . . . . . . . 18

2.6 Uma hierarquia de classes . . . . . . . . . . . . . . . 19

2.7 O uso de vários objetos filtro em seqüência . . . . . . . . . 20

2.8 Algoritmo abstrato para encontrar os filtros para uma atribuição . 21

2.9 Sintaxe da definição de um filtro que pertence à visão de classe para classe B . . . . . . . . . . . . . . . . 22

2.10 Algoritmo para encontrar os filtros para objetos da classe B que são referenciados em Q . . . . . . . . . . . . . . 23

2.11 Algoritmo para criar classes normais usando as classes filtro . . . 24

2.12 Algoritmo para criar uma classe normal a partir de uma classe filtro 25

2.13 A classe CreateClass $(G->\beta) \ldots \ldots 25$

2.14 Algoritmo que retorna a classe criada por CreateClass em tempo de compilação . . . . . . . . . . . . . . . 26

2.15 Instruções que substituem a atribuição $v:=\operatorname{Exp} \ldots \ldots . . \ldots 26$

2.16 Algoritmo para descartar objetos filtro de um objeto . . . . . . . 27

2.17 Algoritmo para criar objetos filtro para uma atribuição . . . . . . 28

$2.18 \mathrm{Um}$ objeto da classe CreateClass $\left(G_{1}->\beta_{1}\right) \ldots \ldots 28$

2.19 A seqüência de objetos filtro referenciados por $\mathrm{v} \ldots \ldots . . . . .29$

2.20 Algoritmo para descobrir se uma atribuição precisa de objetos filtro 35

2.21 Algoritmo para descobrir a necessidade de objetos filtro na presença de polimorfismo . . . . . . . . . . . 36

2.22 Instruções que substituem a atribuição $v:=\operatorname{Exp} \ldots \ldots 36$

2.23 Algoritmo que substitui uma atribuição por instruções que irão colocar ou remover objetos filtro em tempo de execução . . . . . . 37

2.24 A divisão de um sistema em regiões para uma subclasse . . . . . . 39

2.25 Programa que usa as classes StringE e StringR . . . . . . . . . . 41

2.26 Classes filtro para classes StringR e StringE . . . . . . . . . . . . 42

2.27 Programa com testes inseridos pelo compilador . . . . . . . . . . 43 


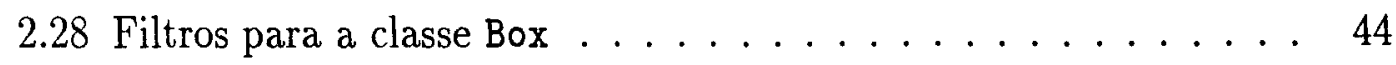

3.1 Um filtro para transformar objetos Pessoa em objetos Person . . 48

3.2 Um adaptador para converter objetos do tipo B para objetos do tipo A ..................... 51

3.3 Algoritmo para criar uma classe normal a partir de uma classe adaptadora . . . . . . . . . . . . . . . 52

3.4 Algoritmo para encontrar métodos a serem adicionados a uma classe adaptadora . . . . . . . . . . . . . . . 53

3.5 Objeto $\mathcal{Q}$ coberto por filtros $\mathrm{h}_{1} \ldots \mathrm{h}_{r}$, que é chamado $\mathcal{P} \ldots \ldots \quad 55$

3.6 Hierarquia de tipos com filtros para converter objetos do tipo $T$. 56

3.7 Algoritmo para encontrar o filtro mais específico para $S \ldots \ldots . .58$

3.8 Ambiguidade na escolha do filtro para $S \ldots \ldots \ldots \ldots \ldots$

3.9 Algoritmo ShellTypeSafe . . . . . . . . . . . . . . . . . 59

3.10 Alguns tipos e seus adaptadores . . . . . . . . . . . . . 59

3.11 Sequêencia de objetos filtro para um objeto do tipo $U \ldots \ldots$. . 60

3.12 Algoritmo que encontra o modo correto de converter $\mathcal{P}$ para o tipo $T 62$

3.13 Um ciclo de tipos equivalentes . . . . . . . . . . . . . 65

3.14 Filtros para tipos type(Pessoa) e type(Estudante) . . . . . 66

4.1 Sintaxe para uma extensão de classe . . . . . . . . . . . 70

4.2 Representação da herança criada pela instanciação de uma extensão de classe . . . . . . . . . . . . . . . . . . . . 71

4.3 Extensão de classe para a classe Car . . . . . . . . . . 74

4.4 Extensão de classe Eaddall com método addall . . . . . . . . 75

4.5 Extensão de classe Eunion com método union . . . . . . . . 76

4.6 Extensão de classe Eunion para estruturas de dados que armazenam objetos de qualquer tipo . . . . . . . . . . . . . . . 77

4.7 Classes mixins feitas com classes parametrizadas . . . . . . . . 79

5.1 Sintaxe para um shell dinâmico . . . . . . . . . . . . 82

5.2 Shells são colocados sobre a1 e a2 . . . . . . . . . . . . 83

5.3 Antes e depois de um objeto shell ser colocado sobre um objeto da classe A . . . . . . . . . . . . . . . . . . 84

5.4 Algoritmo para substituir "object" por "super(A)" . . . . . 84

5.5 Algoritmo para colocar um shell dinâmico sobre o objeto a . . . 85

5.6 Faça todas as variáveis que se referem a obj(a) referirem-se a

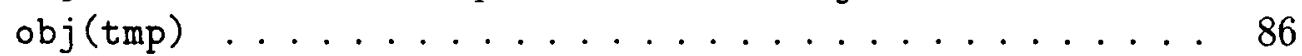

5.7 Algoritmo para remover um objeto shell de um objeto . . . . . . 86

5.8 O comando caseclass usado conjuntamente com remove . . . . 86

5.9 A classe Client . . . . . . . . . . . . . . . . 88

5.10 Um shell para objetos da classe Client . . . . . . . . . . 89

5.11 Um exemplo de uso de shell dinâmico . . . . . . . . . . . 91

5.12 Classes Light e Controllight . . . . . . . . . . . . . . . . 92

5.13 Solução do problema parte-todo com shell dinâmico . . . . . . . 93

5.14 Uma simulação de shell dinâmico . . . . . . . . . . . . . . 95 
6.1 Antes e depois de uma extensão para a classe A ser criada dinamicamente . . . . . . . . . . . . . . 97

6.2 Sintaxe para extensão dinâmica . . . . . . . . . . . . 98

6.3 Algoritmo para colocar uma extensão dinâmica sobre uma classe . 99

6.4 Um objeto da classe $\mathrm{B}_{0}^{\prime} \ldots \ldots \ldots . \ldots . \ldots . \ldots 99$

6.5 Antes e depois de um shell ser colocado em $\mathcal{Q} \ldots \ldots$. . . . . . . 100

6.6 Um erro em tempo de execução . . . . . . . . . . . . . . 101

7.1 Algoritmo para calcular todos os tipos relacionados a $T \ldots 105$

7.2 Uma hierarquia de tipos . . . . . . . . . . . . 105

A.1 Sintaxe para a declaração de uma classe . . . . . . . . . . . . . 128

A.2 Sintaxe para a declaração de um método . . . . . . . . . . . . 128

A.3 Uma classe na linguagem usada nesta tese . . . . . . . . . . . . . 129

A.4 Método que usa valor de retorno múltiplo . . . . . . . . . . 129

A.5 Exemplo de uso de variáveis . . . . . . . . . . . . . . 130

A.6 Herança de classes e referência a um objeto . . . . . . . . . . 130

A.7 A classe D herda A duas vezes . . . . . . . . . . . . . 130

A.8 Uma classe para armazenar objetos inteiros . . . . . . . . . . . . 131

A.9 Representação de um objeto da classe B. A classe B herda de A . . 139

A.10 Algoritmo para procurar por um método para responder a uma mensagem . . . . . . . . . . . . . . . 141

A.11 Classe String conforma com HasEqual . . . . . . . . . . . . 142

A.12 Sintaxe para uma classe parametrizada . . . . . . . . . . . 143

A.13 Algoritmo para instanciar uma classe parametrizada A . . . . . . 144

A.14 Uma classe parametrizada que é um vetor de matrizes . . . . . . . 145

A.15 Uma classe Matrix parametrizada com o tipo dos elementos da matriz . . . . . . . . . . . . . . . . 145

A.16 Classes INT e REAL que conformam com Number . . . . . . . . 146

A.17 Classes que conformam com Matrix [INT] e Matrix [REAL] . . . . 147

A.18 Algoritmo para emparelhar classes . . . . . . . . . . . . . . . . 149 


\section{RESUMO}

Esta tese propõe cinco construções para linguagens orientadas a objetos. Algumas delas podem ser implementadas por meio de pré-processadores. Estas construções são: visão de classe, adaptador, extensão de classe, shell dinâmico e extensão dinâmica. Todas elas são baseadas no conceito de filtro, que é um objeto que intercepta as mensagens enviadas a um outro objeto. Visão de classe permite corrigir interpretações incorretas da semântica de uma classe no código de outras classes. Um filtro é usado para traduzir as mensagens para o significado correto. Adaptadores permitem mudar o tipo de um objeto através de um filtro e são usados para acoplar classes que, de outra forma, seriam incompatíveis quanto a tipos. Extensâo de classe permite adicionar métodos e variáveis de instância a classes sem a necessidade de edição do código fonte destas. Shell dinâmico e extensão dinâmica possuem algumas das características de meta-objetos e meta-classes, respectivamente. Eles formam um modelo reflexivo estaticamente tipado. Shell dinâmico permite redirecionar todas as mensagens enviadas a um objeto e extensão dinâmica permite substituir métodos de uma classe em tempo de execução. Todas as construções são originais, podem ser adicionadas em uma linguagem estaticamente tipada sem danificar o sistema de tipos e resolvem alguns problemas descritos na literatura de orientação a objetos.

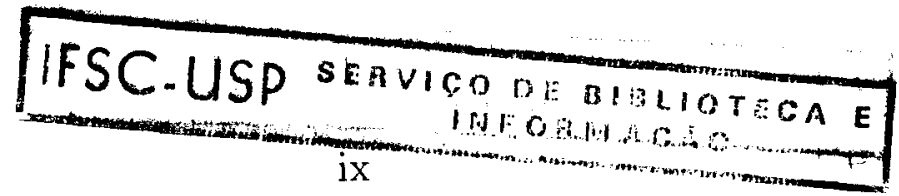




\begin{abstract}
This thesis proposes five constructions for object-oriented languages. Some of them can be implemented using a preprocessor. These constructions are: class view, adapter, class extension, dynamic shell, and dynamic extension. All of them are based in the concept of filter, that is an object that intercepts the messages sent to another object. Class view allows to correct misinterpretations about the semantics of a class in code of other classes. A filter is used to translate the messages to the correct semantics. Adapters allow to change the type of an object through a filter and are used to glue type incompatible classes. Class extension allows to add methods and instance variables to classes without editing the source code of these classes. Dynamic shell and dynamic extension have some of the characteristics of metaobjects and meta-classes, respectively. They compose a statically typed reflective model. Dynamic shell allows to redirect all messages sent to an object and dynamic extension allows to replace methods of a class at run time. All constructs are original and can be added to a statically typed language. They solve some problems described in the object-oriented literature.
\end{abstract}




\section{Capítulo 1}

\section{Introdução}

\subsection{Problemas com Programação Orientada a Objetos}

Programação orientada a objetos possui três características principais: encapsulamento, herança e polimorfismo. Encapsulamento consiste no agrupamento de dados e de comportamento (métodos) em uma única abstração chamada classe. Herança permite criar uma subclasse mais específica que a superclasse. Se um programador precisar de uma classe similar, mas de algum modo diferente de uma classe existente, ele pode herdar uma classe e redefinir alguns métodos em uma subclasse. Então o código da superclasse é reusado na subclasse.

Os parâmetros de um procedimento polimórfico $P$ podem pertencer a mais de um tipo. O código de $\mathrm{P}$ é reusado para cada tipo. Se não houver nenhum polimorfismo e se $P$ precisasse ser invocado com parâmetros de várias classes, o programador deveria construir vários procedimentos similares a $\mathrm{P}$ como parâmetros pertencentes a cada uma destas classes.

Embora programação orientada a objetos tenha conseguido aumentar a produtividade dos programadores [1], há alguns problemas com este paradigma, citados a seguir.

- Hierarquias de herança extensas tornam impossível a utilização de linguagens orientadas a objeto sem boas ferramentas para desenvolvimento de software. Hierarquias extensas tornam difícil descobrir a quais mensagens um objeto de uma dada classe pode responder por causa dos métodos herdados das superclasses.

- Programas orientados a objeto fragmentam o código em métodos muito pequenos. Para compreender um método, o programador deve percorrer uma longa seqüência de chamadas a métodos, a qual é complicada por herança e ligação dinâmica [2].

- Taenzer et al. [3] descrevem o problema "Yoyo", semelhante ao problema do item anterior. Segundo estes autores, a ligação dinâmica de métodos dificulta não só a elaboração de programas, como também o entendimento do código fonte. Uma mensagem enviada para self dentro de uma classe 
pode causar uma busca por um método em uma subclasse da classe onde está o envio da mensagem; o algoritmo de busca por método procura por um método das subclasses para as superclasses. O programador confunde-se com estas ligações dinâmicas. ${ }^{1}$

- Classes reusáveis são difíceis de serem projetadas [4] [5] [6]. Reuso não é obtido simplesmente porque usamos programação orientada a objetos. Classes reusáveis só são obtidas depois de um cuidadoso projeto e sucessivas reorganizações das hierarquias de classes.

- Herança múltipla introduz vários problemas, tais como violação de encapsulamento [7] [8] e duplicação de variáveis de instância em subclasses [9]. Ela também contribui para o aumento da complexidade do programa. Estas questões são discutidas no Apêndice A.

- Polimorfismo funciona somente se a interface do objeto que alguém pretenda utilizar for exatamente igual à interface requerida. É comum existir um tipo com funcionalidade idêntica à de um outro tipo, mas com uma interface diferente, provavelmente porque eles foram codificados por diferentes programadores.

- Objetos especiais de uma classe não são permitidos na maioria das linguagens orientadas a objeto, ou seja, objetos que possuam alguns métodos ${ }^{2}$ diferentes dos métodos de sua classe. Objetos especiais podem ser implementados mudando-se a classe dos objetos em tempo de execução, que é um tipo de mudança não suportada pela maioria das linguagens orientadas a objeto atuais.

- Não se consegue adicionar código a uma hierarquia de classes sem editá-la, usualmente introduzindo erros no programa. Um trabalho recente de Ossher e Harrison [10] sugeriu "extension" como um mecanismo para adicionar código a classes existentes sem modificar o código fonte delas.

- Reflexão computacional é a habilidade de um programa examinar e modificar alguns aspectos de si mesmo em tempo de execução. Esta facilidade tem sido implementada principalmente em linguagens não tipadas, com algumas exceções, tais como Open $\mathrm{C}++$ [11] e Oberon-2 [12]. Open $\mathrm{C}++$, uma extensão a $\mathrm{C}++$, e Oberon- 2 possuem algumas deficiências no suporte à reflexividade porque esta facilidade não foi prevista no projeto inicial da linguagem. De fato, do nosso conhecimento nenhuma linguagem orientada a objetos estaticamente tipada foi projetada desde o início para suportar reflexividade.

\footnotetext{
${ }^{1} \mathrm{Na}$ terminologia usada em $\mathrm{C}++$, são virtuais todos os métodos a que nos referimos nesta tese.

${ }^{2}$ Estamos nos referindo ao corpo do método diferente. A interface (assinatura) do método deve ser a mesma porque de outra forma haveria erros de tipo.
} 


\subsection{Algumas Definições Básicas}

Nesta tese será usada uma linguagem com um sistema de tipos semelhante ao da linguagem POOL-I [13]. Embora esta linguagem seja descrita no Apêndice A, teceremos alguns comentários sobre as suas características fundamentais e sobre alguns conceitos de orientação a objetos.

Uma classe define um conjunto de variáveis de instância e métodos. A seção pública de uma classe, visível fora da classe, define apenas métodos. Assim, objetos da classe são manipulados apenas por meio de envio de mensagens (métodos) e nunca pelo acesso direto às suas variáveis de instância.

O tipo de uma classe é o conjunto de assinaturas de seus métodos. A assinatura de um método é o seu nome, tipo dos parâmetros e tipo do valor de retorno, se houver. Se uma classe Store definir os métodos

proc put ( $\mathrm{px}$ : integer ); ...

proc get () : integer; ...

(e apenas eles), o seu tipo será

$\{$ put (integer), get () : integer \}

Onde se espera um objeto de um tipo, pode-se passar objetos de um subtipo. Um tipo $S$ será subtipo de um tipo $T$ se $S$ possuir pelo menos as assinaturas de métodos de $T$, isto é, $T \subset S$. Deste modo, o método

proc $\mathrm{m}$ ( $\mathrm{s}$ : Store)

pode aceitar como parâmetros objetos de qualquer classe que possua os métodos put (integer) e get (): integer.

Uma variável s declarada como do tipo Store é, na verdade, um ponteiro para objetos da classe Store. São ponteiros todas as variáveis cujos tipos são classes, como na maioria das linguagens orientadas a objeto. ${ }^{3}$ Por isso, dizemos que uma variável referencia um objeto, que é equivalente a dizer que uma variável "aponta para" um objeto.

Linguagens baseadas em delegação não possuem classes, possuem apenas objetos. Um objeto é declarado de maneira semelhante a uma classe nas linguagens convencionais. Objetos são criados a partir de cópia dos objetos existentes. Por exemplo,

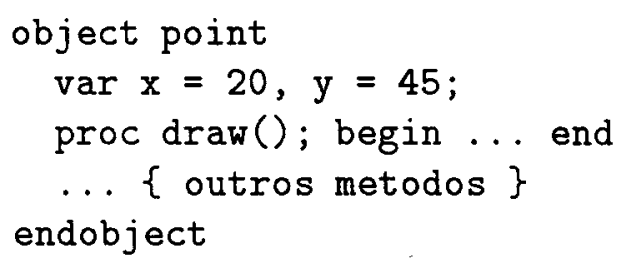

poderia ser a declaração de um objeto point. As variáveis são declaradas sem a citação do seu tipo. Novos pontos são criados como

$$
a:=\text { point.copy }() ;\{\text { cria copia de point }\}
$$

Herança é implementada através de variáveis de instância. Um objeto pode possuir uma variável especial que designa um outro objeto que desempenha o papel de sua superclasse. Assuma que esta variável se chame super. Quando

\footnotetext{
${ }^{3}$ Variáveis cujos tipos são um dos tipos básicos, como integer e real, não estão incluídas.
} 
uma mensagem é enviada a um objeto, o sistema de tempo de execução procura pelo método correspondente entre os métodos do objeto. Se nenhum método for encontrado, a mensagem será enviada ao objeto referenciado por super. Dizemos que a mensagem é delegada ao objeto referenciado por super. Um método é executado em resposta a um envio de mensagem a um objeto. Este objeto pode ser referenciado dentro do método usando a palavra self. Quando um mensagem é delegada a super e um método do objeto superclasse é executado, este pode enviar uma mensagem a self. Neste caso, self refere-se ao objeto inicial e não ao objeto referenciado por super.

Em

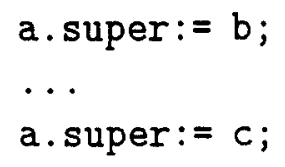

é atribuído ao objeto a duas superclasses, objetos b e c, em diferentes pontos do programa. Em linguagens com delegação, um objeto pode mudar a sua superclasse em tempo de execução, como neste exemplo.

O sistema de tempo de execução é composto por algoritmos presentes no código executável de um programa que não foram codificados pelos programadores. Dentre as funções do sistema de tempo de execução, podemos citar: alocar memória para variáveis locais de subrotinas, retirar da pilha os parâmetros reais de um chamada de subrotina, fazer coleta de lixo e realizar a buscar por um método quando uma mensagem é enviada.

A maior parte dos algoritmos descritos nesta tese são inseridos pelo compilador no código executável do programa. Assim, a maior parte dos algoritmos descritos fazem parte do sistema de tempo de execução. Por isto, as referências ao sistema de tempo de execução nesta tese referem-se aos algoritmos descritos no texto.

\subsection{Filtros e Shells}

Nesta tese são propostos filtros e shells ${ }^{4}$ como mecanismos de linguagem para tornar a programação orientada a objetos mais fácil de se estender, manter e reusar, resolvendo assim alguns dos problemas descritos na seção anterior. Cinco tipos de filtros são sugeridos. Alguns destes correspondem a técnicas comuns adotadas por programadores de linguagens orientadas a objeto.

$\mathrm{Na}$ definição de filtros/shell será utilizada uma linguagem com um sistema de tipos semelhante ao da linguagem POOL-I [13], descrita no Apêndice A. O objetivo desta tese não é definir uma nova linguagem orientada a objetos, mas sim propor várias construções relacionadas a classes, tipos e incompatibilidades entre elas. Portanto, a linguagem descrita no Apêndice A possui um conjunto mínimo necessário de características. Algumas delas (atribuição múltipla, procedimentos e comando caseclass) fazem parte da linguagem apenas para facilitar os exemplos dados na tese. Outras estão na linguagem (herança múltipla, variáveis globais, métodos e variáveis de classe) para torná-la tão completa quanto possível.

\footnotetext{
${ }^{4} \mathrm{Na}$ impossibilidade de encontrar uma tradução adequada para shell, usaremos esta palavra em Inglês.
} 


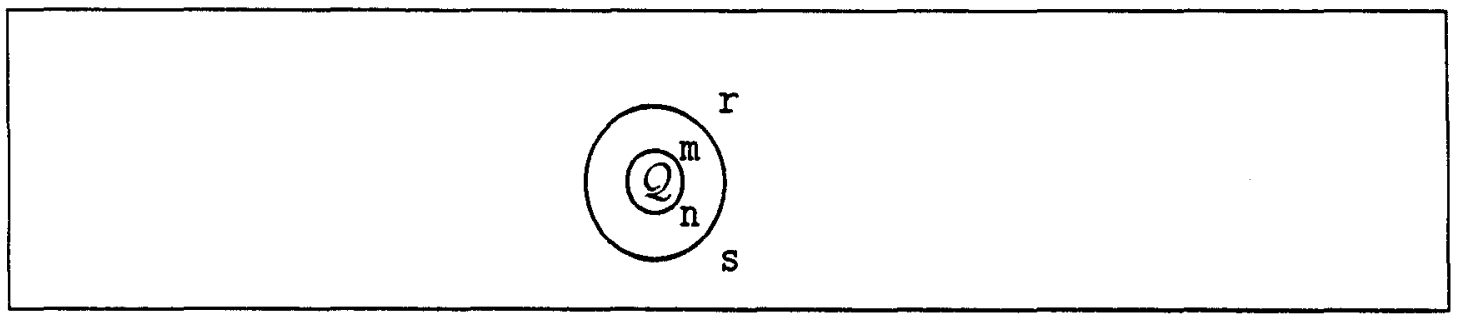

Figura 1.1: Objeto $\mathcal{Q}$ coberto por um shell com métodos $\mathbf{r}$ e $\mathbf{s}$

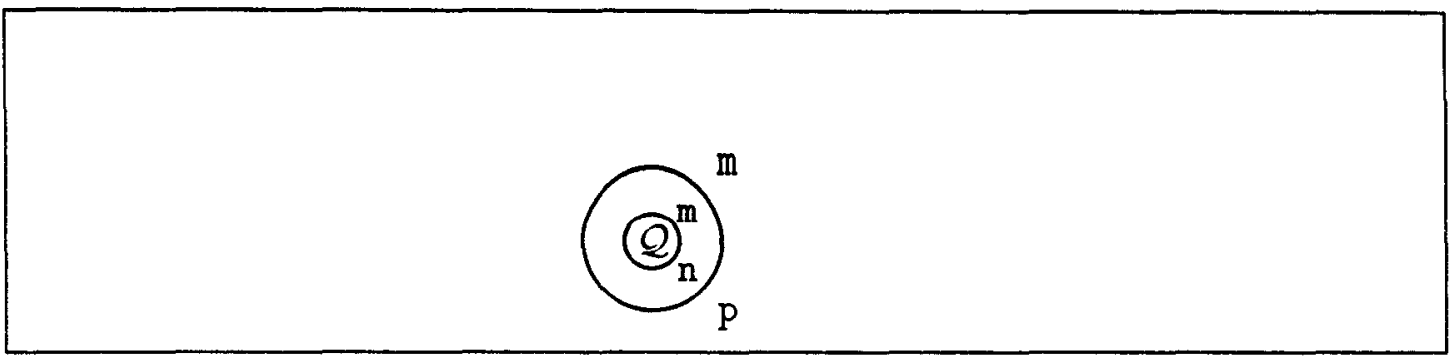

Figura 1.2: Objeto $\mathcal{Q}$ coberto por shell com métodos $\mathrm{m}$ e $\mathrm{p}$

A idéia principal desta tese é colocar um shell ao redor de um objeto, mudando o seu tipo e/ou comportamento. Um shell é uma camada de métodos e variáveis de instância. Qualquer mensagem enviada para um objeto com um shell é primeiramente interpretada pelo shell. Não existindo nenhum método correspondente à mensagem no shell, a mensagem é delegada ao objeto. Qualquer mensagem enviada a self dentro do objeto faz com que a busca pelo método apropriado comece no shell. Então, este mecanismo é semelhante a delegação. De fato, shells permitem que uma linguagem baseada em classes possua algumas facilidades de linguagens baseadas em delegação [14] [15] [16] [17] [18] sem perder sua correção estática de tipos.

Um shell pode redirecionar a mensagem enviada a ele para um método do objeto com outro nome, executar seu próprio código sem usar o objeto e executar seu próprio código chamando mais de um método do objeto. O shell interpreta o ambiente do mundo externo para que ele possa ser compreendido pelo objeto. Isto é ilustrado pela Figura 1.1 onde os nomes de mensagens $r$ e s são transladados para m e $\mathrm{n}$, respectivamente. $\mathrm{O}$ shell da Figura 1.2 responde às mensagens $\mathrm{m}$ e $\mathrm{p}$ e o objeto responde a $\mathrm{m}$ e $\mathrm{n}$. Como as mensagens não entendidas pelo shell são delegadas para o objeto, o objeto shell da Figura 1.2 pode entender as mensagens $\mathrm{m}, \mathrm{n}$ e p.

Shells resolvem incompatibilidades entre as semânticas de várias classes, alteram simultaneamente o comportamento de vários objetos, permitem polimorfismo apesar de incompatibilidades de tipo e resolvem alguns outros problemas relacionados com interfaces de classes (tipos). Todos os problemas solucionados por shells relacionam-se com incompatibilidades de tipos e semântica.

Esta idéia resulta em cinco construções e iremos assumir que elas serão parte da linguagem, embora algumas construções possam ser implementadas por meio de pré-processadores, não exigindo alterações na linguagem. De qualquer forma, as mesmas regras, restrições e algoritmos empregados nas construções de linguagem seriam usados pelos pré-processadores. 
Quando um programador descobre ser necessário colocar um shell ao redor de um objeto, de um conjunto de objetos ou de todos os objetos de alguma classe, ele procura o shell apropriado à situação. De outro modo, ele deveria modificar o código, o que tende a introduzir erros no programa.

Nesta tese, assumimos que um shell possui uma referência ao objeto coberto por ele. Os métodos do shell podem enviar mensagens a este objeto através da palavra-chave object. Um envio de mensagem "object.m(...)", em um método de um shell, ordena ao sistema de tempo de execução que faça uma busca pelo método $\mathrm{m}$ no objeto coberto pelo shell. Então, esta palavra-chave não pode ser usada em um método de uma classe normal. Ela também não pode ser usada como uma variável do lado esquerdo ou direito de uma atribuição, exceto em envios de mensagens.

Um shell rudimentar pode ser feito com classes, como mostrado na Figura 1.3. Um objeto da classe Store ${ }^{5}$ pode armazenar um objeto integer, o qual pode ser obtido e iniciado pelos métodos get e put. Um objeto da classe NewStore cobre um objeto de Store quando o método setShellof é chamado:

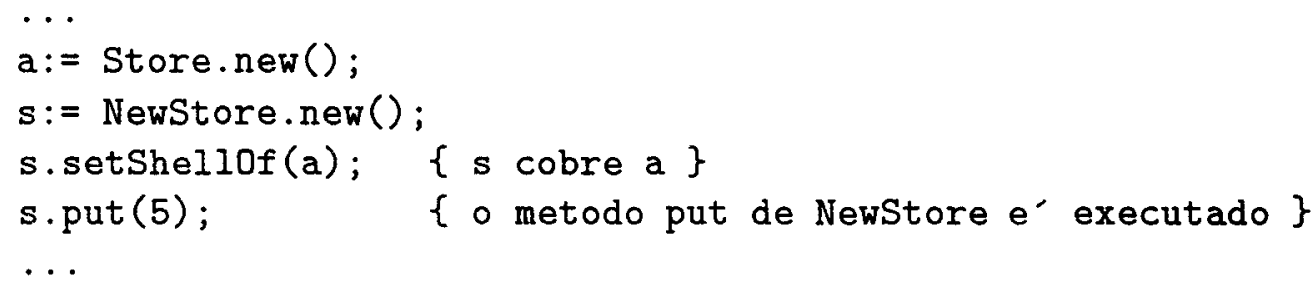

O código acima cria um shell que é colocado ao redor do objeto referenciado por a. Depois o método put do shell (classe NewStore) é executado. Os métodos de NewStore podem manipular o objeto.

Não é exato dizer que um shell é colocado ao redor do objeto. De fato, a variável a continua a referir-se ao objeto sem o shell. O shell é percebido somente pela variável s. O que acontece é que um filtro é colocado entre a variável s e o objeto, como mostrado na Figura 1.4. Nesta figura, o círculo é o objeto de Store e o filtro, representado como um retângulo de bordas arredondadas, é composto pelos métodos de NewStore. Note que a variável a refere-se ao objeto, não ao filtro.

Embora o significado geral das palavras "filtro" e "shell" seja o mesmo, usaremos "filtro" se puder existir uma variável que refira-se diretamente ao objeto sem se referir a um objeto filtro, como a variável a da Figura 1.4. Será usado "shell" quando o oposto for verdadeiro, isto é, cada variável que necessite fazer referência ao objeto de fato faça referência ao objeto filtro que se refere ao objeto. Portanto, a única referência ao objeto está no filtro. Esta definição captura o significado intuitivo de "shell": alguma coisa que cobre completamente outra.

\footnotetext{
${ }^{5}$ Esta tese foi redigida originalmente em Inglês devido ao estágio do autor na Universidade de Illinois at Urbana-Champaign. Decidimos manter os exemplos em Inglês para facilitar a atualização simultânea das versões da tese nas duas línguas. A versão em Inglês tem sido citada em artigos submetidos para publicação e ficará disponível em um diretório público na Universidade de Illinois, podendo ser obtida por FTP.
} 


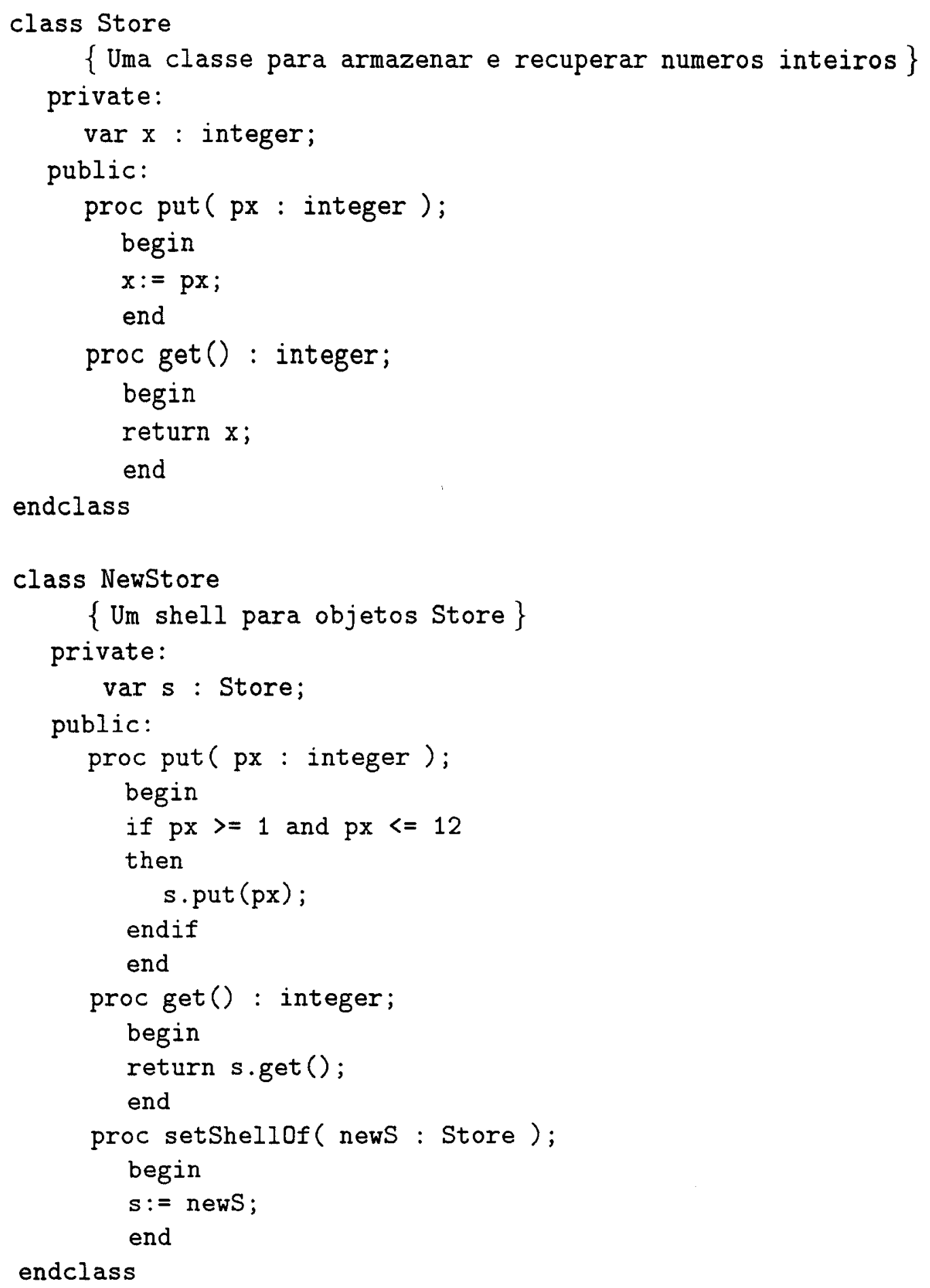

Figura 1.3: Um shell NewStore para a classe Store 


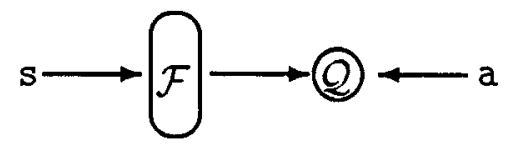

Figura 1.4: $\mathrm{O}$ filtro $\mathcal{F}$ e a variável a fazem referência ao objeto $\mathcal{Q}$

Uma classe que define um shell (ou filtro) será chamada de "classe shell" ("classe filtro") ou, simplesmente, "shell" ou "filtro". Um objeto de uma classe shell (ou classe filtro) é um objeto shell (objeto filtro). No exemplo da Figura 1.4, $\mathcal{F}$ é um objeto filtro e a classe NewStore é uma classe filtro.

No exemplo da Figura 1.3, a classe NewStore não pode ser considerada como subtipo da classe Store porque ela restringe o limite do parâmetro px do método put. Se um objeto de NewStore for usado onde se esperaria um objeto de Store, o código talvez tente usar put com um número inteiro 13 , causando um comportamento errôneo.

É um erro do programador criar uma classe que é sintaticamente um subtipo de outra mas não é semanticamente um subtipo, como as classes NewStore e Store. Como será mostrado nesta tese, com shells isto pode não ser classificado como um erro.

O programador pode declarar variáveis de instância em um filtro/shell, mas elas devem ser usadas com cuidado. As variáveis de instância dos filtros não devem duplicar or substituir os dados do objeto. Se isto ocorrer, os métodos do filtro/shell utilizarão as variáveis de instância do filtro/shell ao invés de enviar mensagens para o objeto. Portanto, os dados do objeto não serão atualizados pelas mensagens enviadas para o objeto. Então, se o objeto filtro/shell for removido (o que pode ocorrer em alguns tipos de shells), os dados do objeto podem estar inválidos e ser utilizados quando os métodos do objeto forem executados. Métodos e variáveis da seção shar ${ }^{\epsilon}$ não são permitidos em algumas construções shell descritas nesta tese.

Esta tese provará que colocar um filtro em um objeto não introduz nenhum erro de tipos. $\mathrm{O}$ argumento usado é que um filtro possui um tipo que é subtipo do tipo do objeto ao qual ele fará referência. Um objeto filtro, digamos $\mathcal{F}$, e o objeto a que ele se refere, $\mathcal{Q}$, podem ser considerados como um único objeto cujo tipo é type $(\mathcal{F}) \cup \operatorname{type}(\mathcal{Q})$, que é type $(\mathcal{Q})$, pois type $(\mathcal{F}) \subset \operatorname{type}(\mathcal{Q})$. Em conseqüência, fazer uma variável que se refere a um objeto $\mathcal{Q}$ referir-se a um objeto filtro é o mesmo que fazê-la referir-se a um outro objeto que possui o mesmo tipo que $\mathcal{Q}$, o que naturalmente não introduz erros de tipos.

\subsection{Padrões de Apresentação e Organização da Tese}

Nesta tese serão usadas:

\footnotetext{
${ }^{6}$ Componentes compartilhados por todos os objetos de uma classe - veja Apèndice A.
}

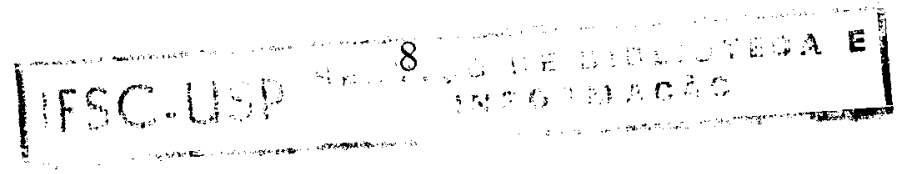


- letras maiúsculas do início do alfabeto (A, B, C, D, E, F, G) para nomes de classes. Algumas vezes o nome de uma classe será usado como se ele fosse um tipo. Leia Apêndice A para detalhes;

- letras maiúsculas em itálico do fim do alfabeto $(T, U, V, W)$ para nomes de tipos;

- as letras minúsculas $\mathrm{m}, \mathrm{n}$ para nomes de métodos;

- as letras maiúsculas P e Q para nomes de procedimentos;

- letras minúsculas do início e do fim do alfabeto ( $a, b, t, u, x)$ para nomes de variáveis. $\mathrm{O}$ nome da classe ou tipo da variável consiste na letra maiúscula correspondente. Por exemplo, a variável a é uma variável da classe A;

- as letras minúsculas $k, m, n, p, q$ para índices;

- as letras gregas $\alpha, \beta, \gamma, \delta$ para regiões do programa compostas por classes e procedimentos;

- letras caligráficas $(\mathcal{P}, \mathcal{Q})$ para nomes de objetos.

Esta tese é organizada como se segue. O capítulo 2 define visão de classe, que resolve o problema da interpretação incorreta da semântica de uma classe no código de outra classe. Por exemplo, visão de classe pode corrigir o código que usa uma classe Box como se ela usasse metros como unidade de medida quando, de fato, Box adota centímetros. Filtros são usados para corrigir a semântica dos objetos.

Adaptadores, propostos no Capítulo 3, facilitam o uso conjunto de classes incompatíveis com relação a tipos. Se um método exigir como parâmetro um objeto do tipo $T$, pode-se usar como parâmetro real um objeto cujo tipo não seja um subtipo de $T$, mas que possui a mesma funcionalidade de $T$. Extensão de classe, definida no Capítulo 4, permite colocar um shell ao redor de uma classe antes da compilação do programa. Esta construção pode mudar os métodos da classe sem a necessidade de sua edição. Shell dinâmico, definido no Capítulo 5, permite colocar e remover um shell ao redor de um único objeto em tempo de execução. O shell desempenha o papel de um meta-objeto [19] [20], podendo ser usado para implementar objetos especiais e algumas construções de linguagem.

O Capítulo 6 define extensão dinâmica, que permite colocar um shell ao redor de uma classe em tempo de execução. Ela possui algumas das características de meta-classes [21]. As restrições dos relacionamentos entre os shells são tratados no Capítulo 7.

O Capítulo 8 define e discute reflexão computacional, que consiste na habilidade de um programa representar e alterar alguns aspectos de si mesmo em tempo de execução. Shells dinâmicos e extensôes dinâmicas possuem muitas características de outras construções reflexivas e podem ser adicionados em uma linguagem estaticamente tipada.

O Capítulo 9 apresenta a conclusão da tese e pesquisas futuras a serem realizadas com shells. O Apêndice A define uma pequena linguagem usada nesta 
tese, juntamente com a representação de objetos e um algoritmo de busca por um método. Os dois últimos apêndices, $\mathrm{B}$ e $\mathrm{C}$, descrevem a gramática da linguagem e um glossário de termos usados neste trabalho.

Ao final de cada um dos capítulos que descrevem cada construção shell, há uma seção de implementação e outra de trabalhos relacionados. Decidimos colocar estas seções nos capítulos que descrevem cada construção a fim de facilitar a leitura da tese. 0 leitor conhecerá as técnicas de implementação sugeridas e os trabalhos semelhantes logo após a descrição de cada construção, diminuindo a necessidade de reler as definiçôes dos shells.

Todas as construções propostas nesta tese não introduzem erros de tipo na linguagem. Isto é provado após a definição de cada shell usando a representação de objetos definida na Seção A.2. A seção de implementação de cada um dos capítulos que descrevem os shells sugere uma implementação diferente daquela da Seção A.2. O objetivo desta seção é mostrar que shells podem ser implementados eficientemente. 


\section{Capítulo 2}

\section{Visão de Classe}

\subsection{Introdução}

Uma visão de classe é um tipo de filtro usado quando diferentes clientes ${ }^{1}$ de uma classe levantam diferentes hipóteses sobre a semântica da classe. Por exemplo, um cliente supõe que um método retorna um tamanho em centímetros, mas outro assume que o tamanho é medido em milímetros. Um programa pode ser dividido em regiões, onde o código de cada região faz o mesmo conjunto de suposições sobre a classe. O programador deve definir uma visão de classe para esta classe, que consiste em um conjunto de filtros, um para cada região.

Sempre que um objeto de uma classe for referenciado por uma variável em uma região, um filtro será colocado entre a variável e o objeto. Assim, a região passará a usar o objeto através do filtro que corrige a interpretação incorreta da classe naquela região. Quando a referência for passada de uma região a outra, o filtro será removido e outro, específico para a região para onde a referência for passada, será usado. Deste modo, os objetos são sempre usados corretamente no programa.

\subsection{Alguns Exemplos de Problemas}

Berlin [39] argumenta que o maior problema com reuso de software não é a qualidade dos subsistemas que compõem o sistema, mas sim as incompatibilidades entre os seus subsistemas. Ela menciona cinco áreas de conflito entre subsistemas. Uma delas é manipulação de erro. Haverá um conflito se dois subsistemas apontarem erros de maneiras diferentes. Por exemplo, um sistema poderia usar valor de retorno de função ou parâmetros para sinalizar erros, enquanto o outro adota sinalização de exceções. Se o primeiro utilizar o segundo, haverá situações em que uma exceção será sinalizada e não manipulada. Por exemplo, suponha que duas classes para manipulação de cadeias de caracteres, digamos StringR e StringE, feitas por diferentes programadores, possuam o método proc $\operatorname{dup}()$ : ArrayChar

\footnotetext{
${ }^{1}$ Clientes de uma classe são os procedimentos e outras classes que declaram variáveis e parâmetros desta classe.
} 


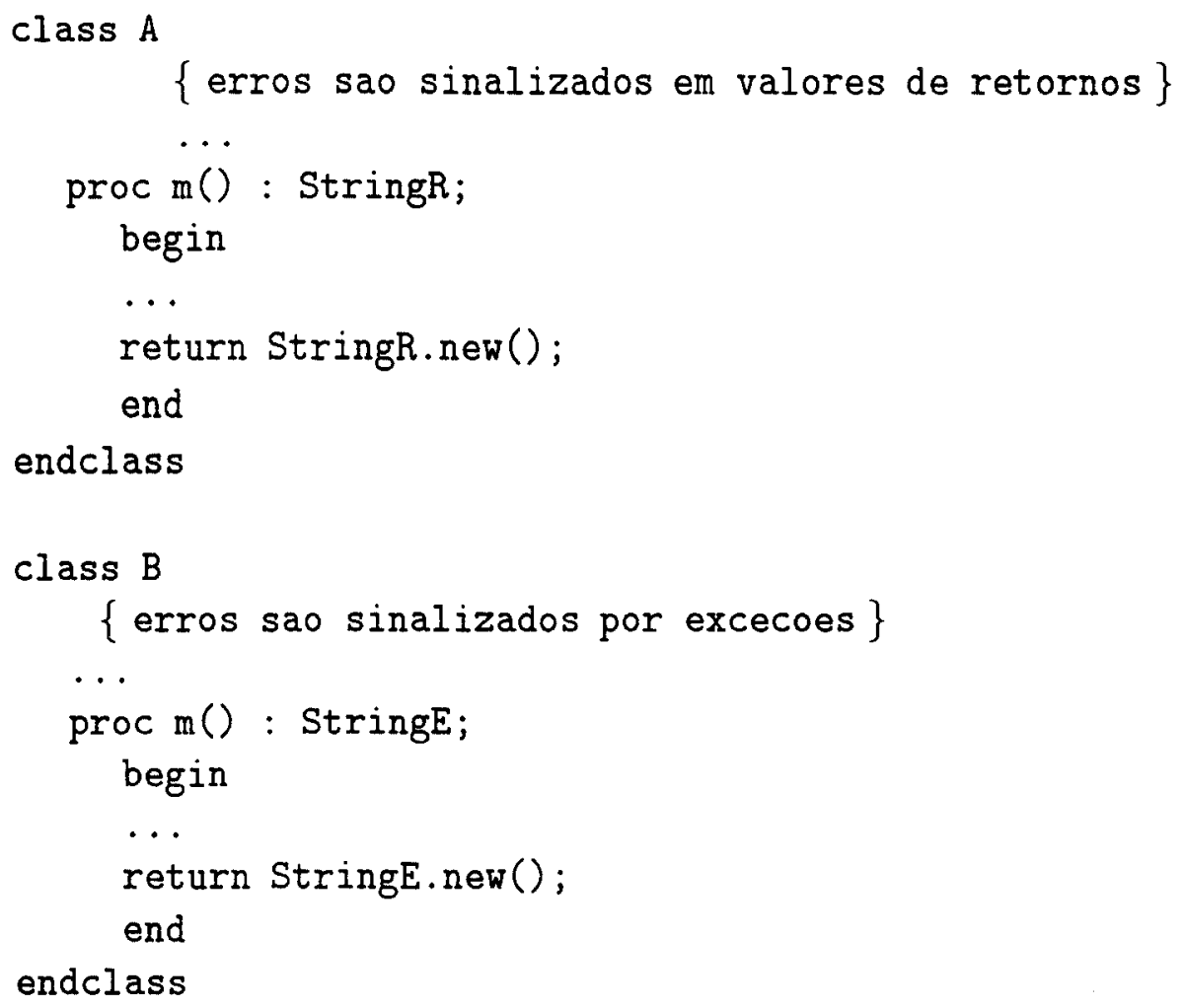

Figura 2.1: Classes A e B onde B é subtipo de A

Este método retorna uma cópia, alocada dinamicamente, da cadeia de caracteres armazenada no objeto na forma de um vetor de caracteres. Ambas as classes trabalham juntas no mesmo programa, mas há uma incompatibilidade semântica entre elas relacionada com a manipulação do erro "Acabou a memória disponível para alocação dinâmica". O método dup de StringR retorna nil neste caso e o método dup de StringE sinaliza uma exceção chamada OutofMemory.

Devido ao fato de StringE e StringR possuirem o mesmo tipo, uma variável $s$ do tipo StringR pode referir-se a objetos da classe StringE em tempo de execução. Se o programador utilizar a expressão "s.dup()" como se ela retornasse nil no caso de memória disponível insuficiente, haverá um problema semântico que não pode ser resolvido em tempo de compilação, pois não sabemos a classe do objeto a que $\mathbf{s}$ irá se referir em tempo de execução. De fato, s poderá se referir a um objeto de uma classe e então referir-se a um objeto de outra classe na próxima vez que a expressão "s.dup ()" for avaliada. Não é possível dizer em tempo de compilação qual a classe dos objetos referenciados pela variável $\mathbf{s}$ em tempo de execução.

Usaremos as classes da Figura 2.1 para mostrar uma versão concreta deste exemplo abstrato. No código

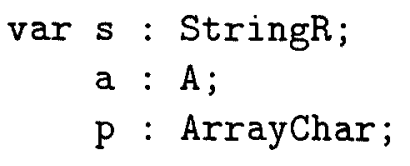




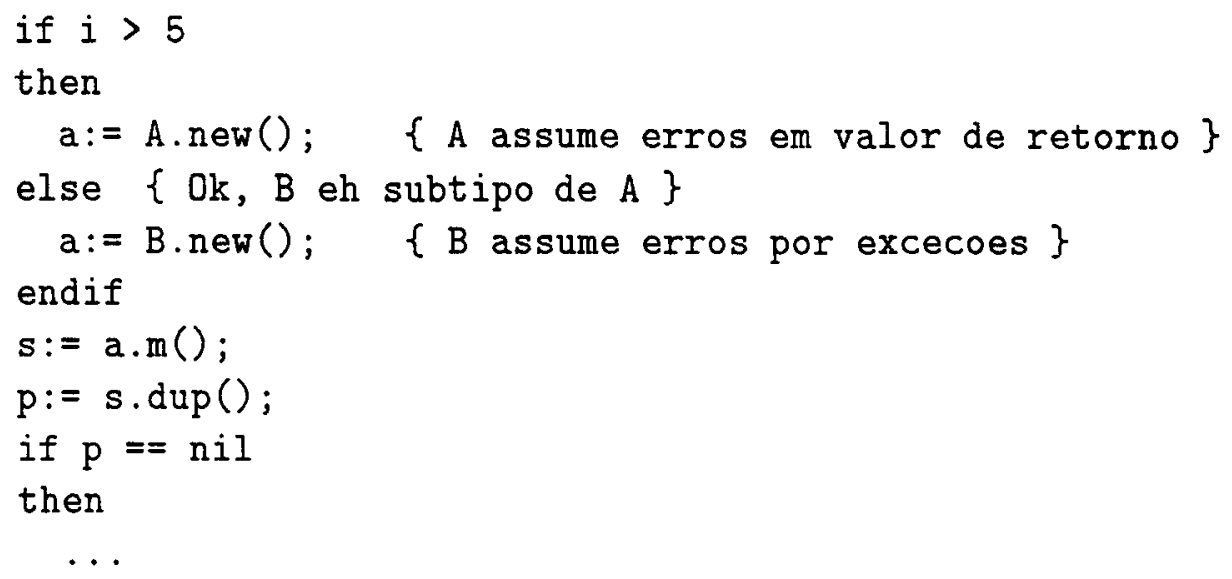

o programador assumiu que "s.dup()" retornará nil se não houver memória disponível suficiente, pois o tipo de s é StringR. Entretanto, a s é associado um objeto retornado por $\mathrm{a} \cdot \mathrm{m}()$ e a variável a pode se referir a objetos que usam valores de retorno ou sinalizam uma exceção em erro. A classe real do objeto a qual a fará referência em tempo de execução será decidida pelo comando if. Em geral, é impossível dizer em tempo de compilação qual ramo (then or else) desta instruçâo será executado em tempo de execução. Então, se a memória disponível para alocação dinâmica do programa se esgotar, a expressão "s.dup ()" poderá retornar nil ou sinalizar uma exceção. Como o código foi escrito considerando-se o primeiro caso, uma exceção pode ser sinalizada e não tratada.

Assumimos que o método $m$ da classe A retorna um objeto da classe StringR (Figura 2.1). Entretanto, este método também pode retornar um objeto da classe StringE, pois estas classes possuem o mesmo tipo. $O$ fato do tipo de $\mathbf{s}$ ser StringR não significa que o programador assumiu que dup retorna nil na falta de memória. Ele pode ter usado a documentação de StringE, visto que estas duas classes possuem o mesmo tipo e deveriam trabalhar juntas.

Outro exemplo de incompatibilidade é a interpretação errada da unidade de medida usada por uma classe. Por exemplo, suponha que exista uma classe Box contendo um método width que retorna o comprimento da caixa em centímetros. Um programador entendeu incorretamente o significado da classe Box e criou classes que a usam como se ela empregasse polegadas como unidade de medida. Um outro programador assumiu que Box usa milimetros. Todas estas classes foram combinadas para construir um sistema (programa). Não há nenhum erro de compilação, mas há um erro semântico: a classe Box é interpretada de três modos diferentes. Ela é usada como se ela fornecesse medidas em centímetros, polegadas e milímetros. Os objetos que assumem cada unidade de medida são misturados em tempo de execução. O código que assume que o método width retorna um valor em centímetros pode receber objetos do código que assume polegadas como a unidade de medida deste método. Como é impossível, em tempo de compilação, prever a semântica correta do objeto ao qual uma certa variável fará referência em tempo de execução, não se pode dizer se uma certa variável referir-se-á a objeto de uma semântica específica (por exemplo, polegadas) na execução do programa. Uma variável do tipo Box pode referir-se a um objeto que usa polegadas durante algum tempo e depois referir-se a um objeto que usa centímetros. 
Ambos os problemas descritos anteriormente possuem as mesmas características, relacionando objetos em tempo de execução e semântica: objetos são referenciados por várias partes do código e são incorretamente interpretados. Cada um deles pode ser entendido incorretamente de mais de um modo (centímetro por polegada, polegada por milímetro, etc), várias vezes durante a sua existência, no mesmo pedaço de código ou em várias partes do sistema.

No primeiro problema podem ocorrer erros semânticos no uso de objetos de duas classes, StringR e StringE. No segundo, os erros podem ocorrer somente com objetos de Box. A solução destes problemas através de visão de classe (a construção descrita neste capítulo) é apresentada na Seção 2.7. Para cada classe interpretada incorretamente, uma visão de classe é construída. Assim, são construídas duas visões para o primeiro problema e uma para o segundo.

\subsection{O Esboço de uma Solução}

Nesta seção pretende-se definir com mais detalhes o problema exposto na seção anterior. Primeiramente, será assumido que todos os métodos de uma certa classe C usam outra classe (como a classe Box) com a mesma semântica; isto é, se um método de $\mathrm{C}$ assumir que Box usa polegadas como unidade de medida, então todos os métodos de $\mathrm{C}$ admitirão esta mesma hipótese. Então, não é permitido a um método de $\mathrm{C}$ considerar que o método width da classe Box retorna um valor em polegadas e a outro método de $\mathrm{C}$ considerar que width retorna um valor em centímetros.

Uma região é definida como um conjunto de classes e procedimentos ${ }^{2}$ que assume a mesma semântica para uma dada classe, como Box. Assim, o sistema ${ }^{3}$ é dividido em regiões, cada uma interpretando Box de seu próprio modo. Todo o código de uma região possui a mesma visão de Box e quaisquer duas regiões possuem diferentes interpretações desta classe. O sistema compila sem erros, embora ocorra uma interpretação semântica incorreta. Este erro semântico foi descoberto depois que o sistema estava pronto ou em seus últimos estágios. Então não é compensador programar todo o sistema novamente.

Naturalmente, a divisão do sistema em regiões é realizada para cada classe interpretada incorretamente. Portanto, a divisão para uma classe pode ser (e provavelmente é) diferente da divisão para outra classe. Isto pode ocorrer mesmo entre uma superclasse e suas subclasses, embora com algumas restrições, descritas no final deste capítulo.

O problema originado pela interpretação semântica incorreta pode ser resolvido usando-se filtros para converter um objeto de uma determinada semântica para outra. Os parágrafos seguintes assumem que os filtros são colocados automaticamente pelo compilador e sistema de tempo de execução. Isto será explicado melhor nas seções seguintes.

\footnotetext{
${ }^{2}$ Procedimento são rotinas fora de classes. São o equivalente a funções da linguagem $\mathrm{C}$ ou procedimentos/funções de Pascal.

${ }^{3}$ Sistema é o programa correntemente em uso, consistindo em uma coleção de classes e procedimentos.
} 


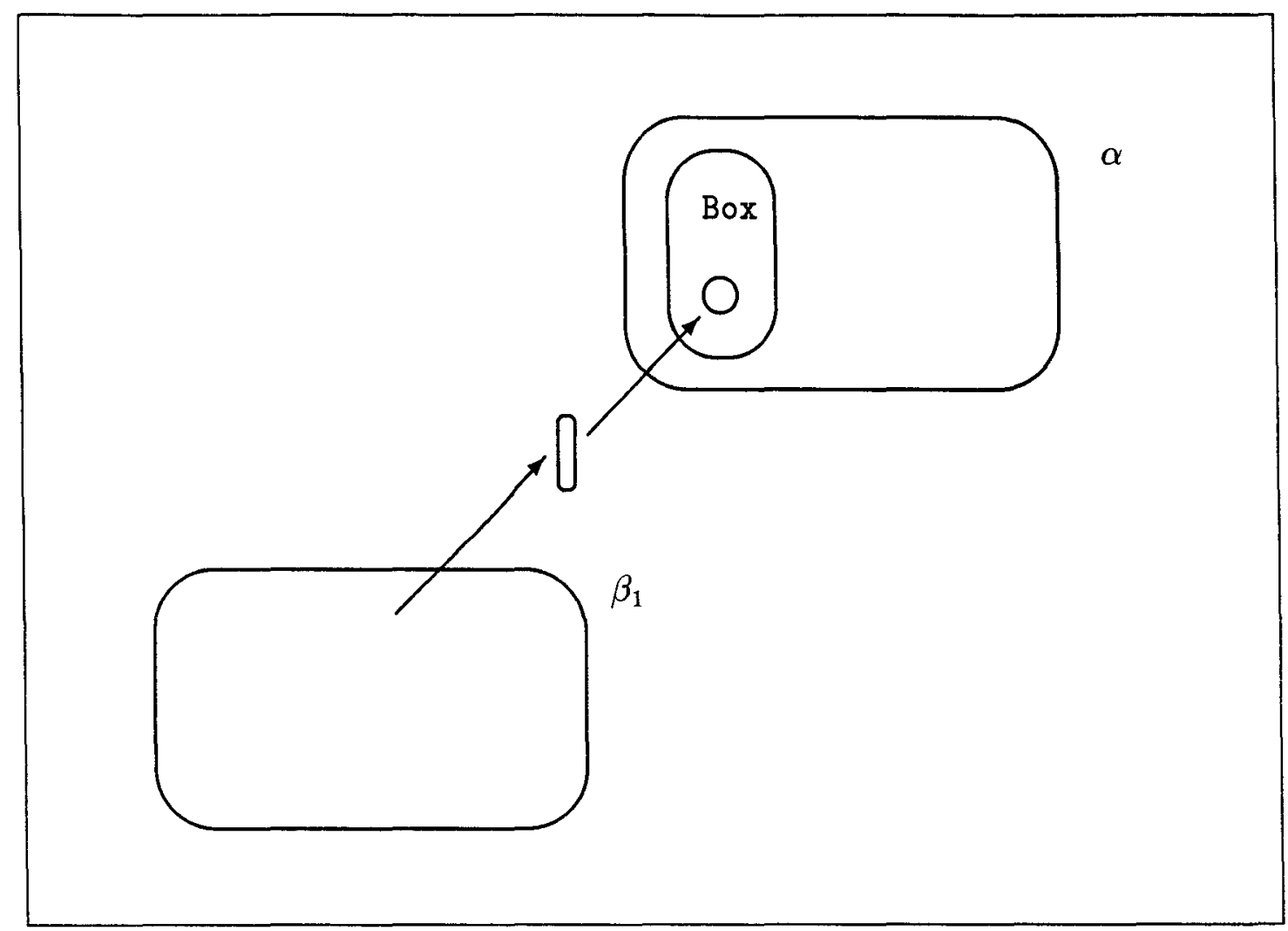

Figura 2.2: Referência a um filtro em tempo de execução

A Figura 2.2 mostra duas regiões, $\alpha$ e $\beta_{1}$, onde $\beta_{1}$ assume que a classe Box usa polegadas como unidade de medida. $O$ código de $\beta_{1}$ possui uma instrução que faz uma variável referir-se a um objeto Box. $O$ sistema de tempo de execução detecta que o código de $\beta_{1}$ interpretaria incorretamente este objeto e coloca um objeto filtro entre a variável e o objeto de Box. ${ }^{4} \mathrm{O}$ filtro é definido pelo programador e similar ao filtro FilterBoxToInch da Figura 2.3. O objeto filtro é representado na Figura 2.2 como um pequeno retângulo vertical com bordas arredondadas e um círculo dentro de uma classe significa um objeto desta classe. As flechas representam referências entre objetos e objetos filtro. Então, há uma variável da região $\beta_{1}$ referindo-se ao objeto filtro, que por sua vez refere-se ao objeto pertencente à classe Box da região $\alpha$. Lembre-se de que a referência do objeto pelo objeto filtro implica que uma mensagem enviada ao objeto filtro será delegada ao objeto se o objeto filtro não possuir o método correspondente.

A situação geral de referências para objetos é mostrada na Figura 2.4. Há filtros 1 e 2 para interpretar objetos de Box como se eles usassem polegadas $\left(\beta_{1}\right)$ e milímetros $\left(\beta_{2}\right)$, respectivamente.

Vamos examinar um exemplo usando a Figura 2.4. A atribuição

$$
\mathrm{a}:=\mathrm{P}() \text {; }
$$

está na região $\beta_{1}$ e $\mathrm{P}$ é um procedimento que retorna um objeto de Box em tempo de execução. Não importa a qual região $\mathrm{P}$ pertença. $\mathrm{O}$ sistema de tempo de

\footnotetext{
${ }^{4} \mathrm{O}$ programador informa, ao definir as classes filtro, quais as regiões do código que interpretam incorretamente uma classe.
} 


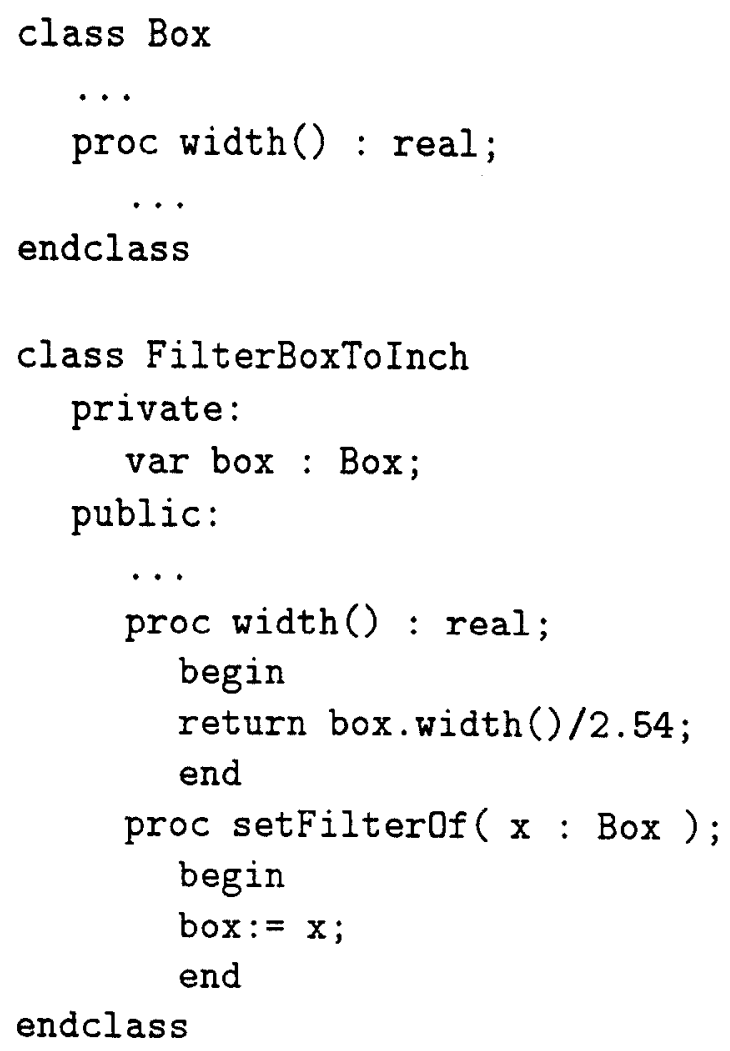

Figura 2.3: Um filtro para objetos de Box 


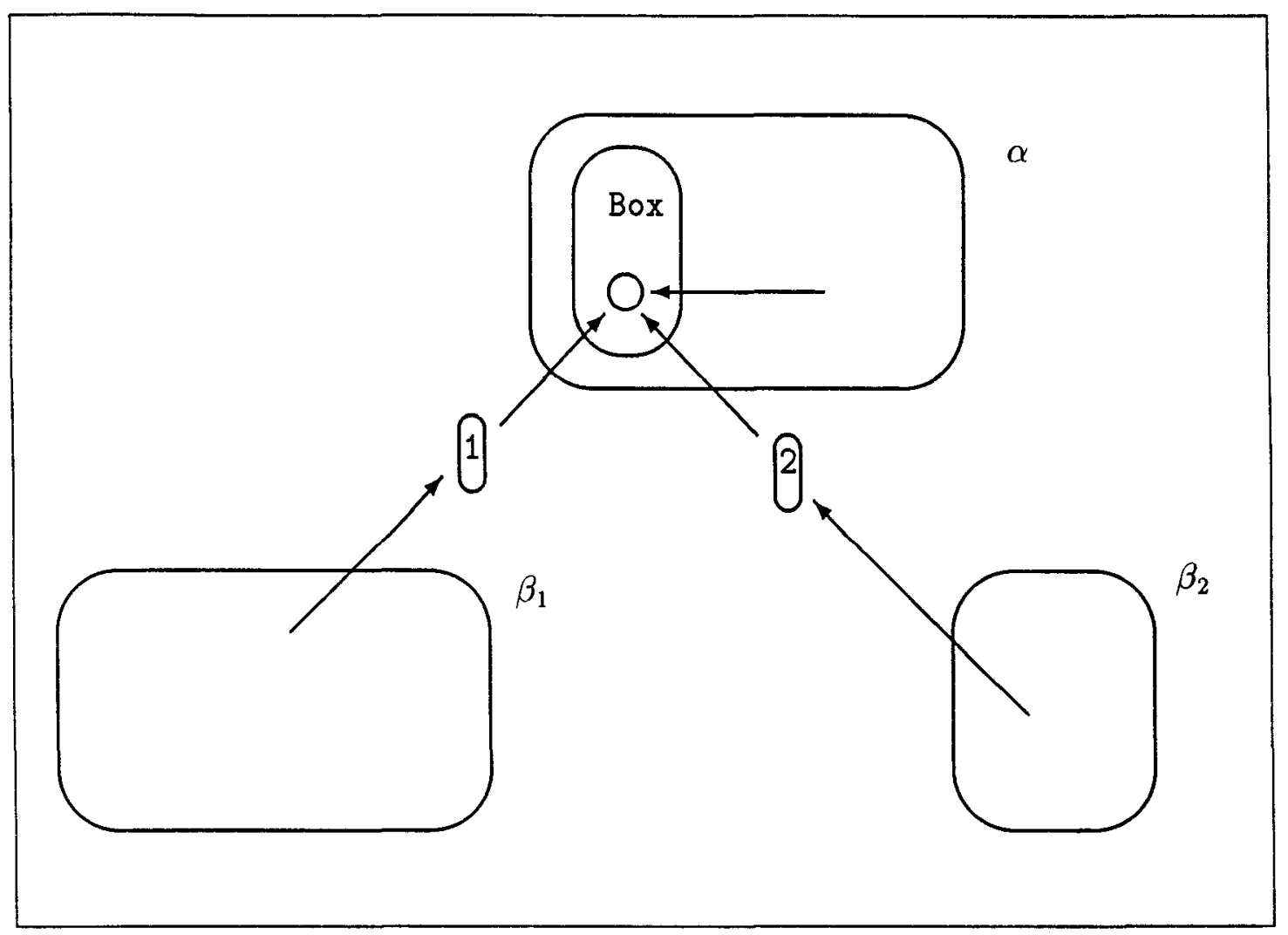

Figura 2.4: Possiveis filtros para objetos Box em tempo de execução

execução faz a referir-se ao objeto filtro 1 e este filtro refere-se ao objeto retornado por P. Qualquer mensagem enviada através de a será redirecionada para o objeto filtro 1. Se ele não possuir o método apropriado, ele delegará a mensagem para o objeto de Box.

$\mathrm{P}$ pode retornar um objeto de qualquer classe, digamos $\mathrm{A}$, com o mesmo tipo que Box. A classe A poderia não ser interpretada incorretamente neste sistema. Então, se $\mathrm{P}$ retornar um objeto da classe $\mathrm{A}$, nenhum filtro será necessário.

Como $\mathrm{P}$ é um procedimento, o compilador sabe a que região ele pertence. Isto não é verdade quando uma expressão b.m() é atribuída a a. A razão é que não se pode dizer, em tempo de compilação, a classe do objeto que b referir-se-á em tempo de execução. Portanto, não se pode dizer a região que o método m pertencerá em tempo de execução. Contudo, isto não é um problema. O filtro a ser usado na atribuição (se algum for necessário) depende somente da região onde a atribuição está e se a expressão retornar um objeto da classe Box ou não.

$O$ lado direito de uma atribuição sempre resulta em uma referência para um objeto, mesmo se a expressão resultante for uma seqüência de filtros que referemse a um objeto. A seqüência de objetos filtro é descartada.

\subsubsection{Solução com Herança}

Suponha que uma classe Window herde de Box e nenhuma visão de classe para Window tenha sido definida. Então, esta classe usará os filtros de sua superclasse. Isto faz sentido porque, se Box foi interpretada incorretamente em uma região, 


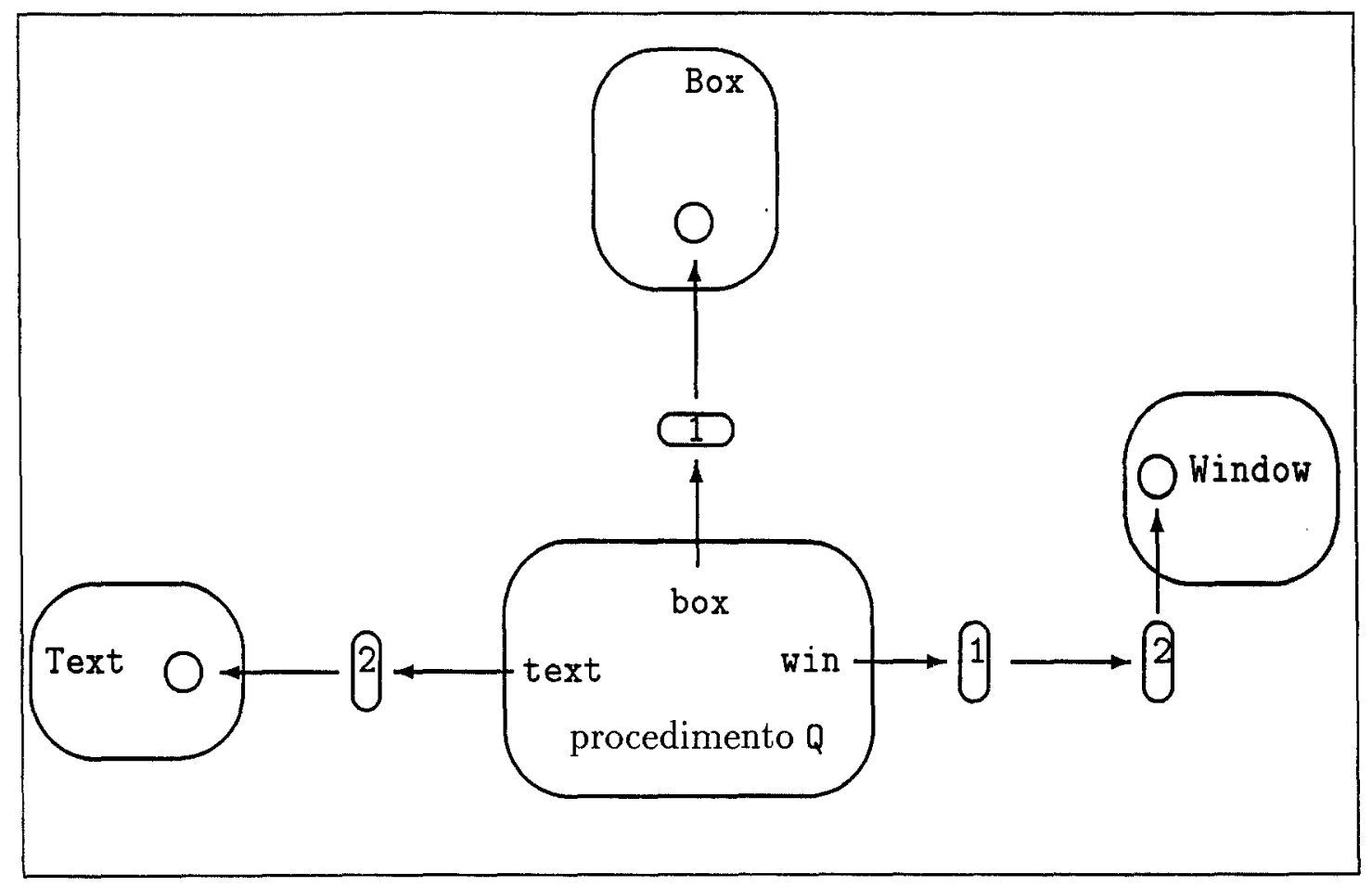

Figura 2.5: 0 uso de filtros das superclasses

assim o foram suas subclasses, pois estas devem seguir a sua semântica.

Naturalmente, se a classe Window definir métodos não herdados de Box que foram interpretados incorretamente em outras regiões, o programador deverá definir filtros especificamente para esta classe.

No exemplo acima, não há nenhum filtro para a subclasse e ela herda de apenas uma superclasse. Uma situação diferente será examinada agora, onde não há filtros para a subclasse, mas ela herda de duas ou mais superclasses que possuem filtros.

Suponha que a classe Window herde das classes Box e Text e:

- não haja nenhum filtro para a classe Window;

- a classe filtro 1 seja usada se uma variável de um procedimento/classe Q referir-se a um objeto da classe Box. Por "usado" queremos dizer que, quando uma variável $\mathrm{v}$ de $\mathrm{Q}$ for referir-se a um objeto da classe Box, o sistema de tempo de execução criará um objeto filtro da classe filtro 1, fará $\mathrm{v}$ referir-se ao objeto filtro e fará o objeto filtro referir-se ao objeto da classe Box;

- a classe filtro 2 seja usada se uma variável do procedimento $Q$ referir-se a um objeto da classe Text.

Em uma atribuição

$$
\text { win: }=P()
$$

dentro de $\mathrm{Q}$, suponha que $\mathrm{P}$ retorne um objeto da classe Window. Considerando que um objeto de Window é também um objeto de Box (porque Window herda de Box), a classe filtro 1 deve ser usada nessa atribuição. Do mesmo modo, um 


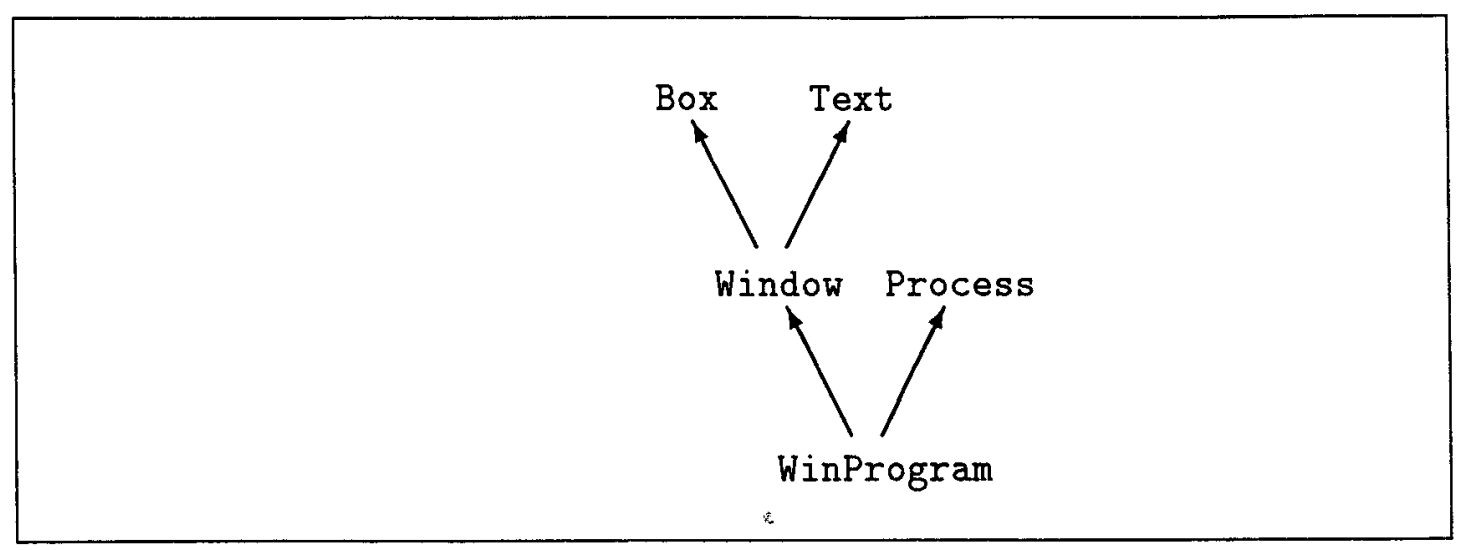

Figura 2.6: Uma hierarquia de classes

objeto Window é também um objeto Text e a classe filtro 2 deve também ser usada. O sistema de tempo de execução gerencia estes dois requerimentos

- criando dois objetos filtros das classes filtro 1 e 2;

- fazendo um objeto filtro referir-se ao outro, criando então uma seqüência de dois objetos filtro. Será visto adiante que não importa qual filtro seja colocado primeiro na seqüência porque eles não possuem métodos em comum;

- fazendo a variável win referir-se ao primeiro objeto filtro da seqüencia e o último referir-se ao objeto da classe Window.

Esta situação é mostrada na Figura 2.5, na qual text e box são variáveis dos tipos Text e Box, respectivamente. Em uma Figura, um círculo dentro de uma classe representa um objeto desta classe.

Observe que os parágrafos acima assumiram que a atribuição win: $=\mathrm{P}()$ está em um procedimento ou classe ao invés de uma região. Isto ocorre porque as superclasses Box and Text podem dividir o sistema em conjuntos diferentes e pode não existir uma região comum entre eles. Então, foi empregado um pedaço de código (procedimento/classe) indivisivel, sendo impossível que parte dele pertença a uma região e outra parte pertença a uma outra região.

Se $Q$ fosse uma região, Box poderia ser interpretado em $Q$ de mais de um modo e não saberíamos qual filtro usar na atribuição. Por este motivo, foi usado uma parte indivisivel para descobrir quais filtros usar.

O exemplo que acabamos de examinar pode ser estendido para um mais complexo, no qual uma classe WinProgram, que não possui classes filtro, herda direta ou indiretamente de várias superclasses que possuem filtros. Considerando que um objeto da classe WinProgram seja também um objeto de cada uma das superclasses de WinProgram, os filtros das superclasses devem ser usados com objetos de WinProgram.

Admita que exista uma atribuição

$$
\text { winprg: }=\mathrm{P}()
$$

em um procedimento $Q$ e que a hierarquia da classe WinProgramé aquela mostrada

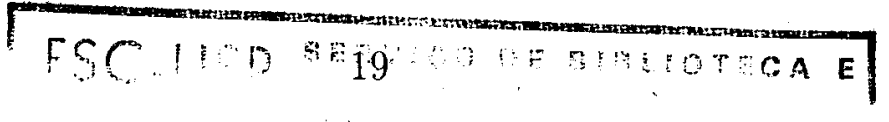




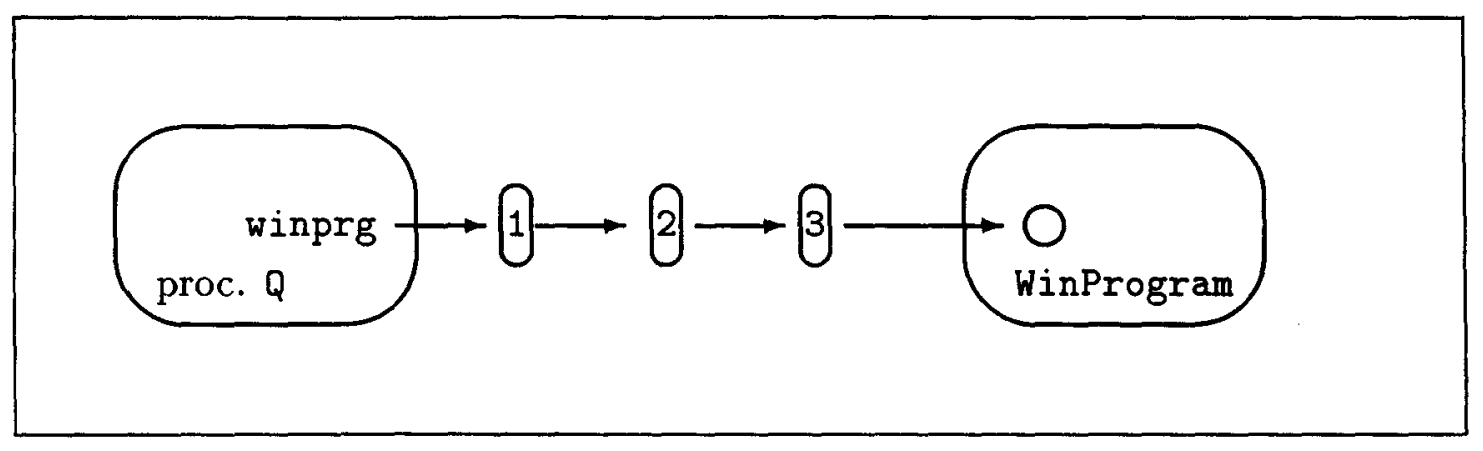

Figura 2.7: $\mathrm{O}$ uso de vários objetos filtro em seqüência

na Figura 2.6. As classes filtro 1, 2 e 3 deveriam ser usadas se uma variável de $Q$ se referisse a objetos de Box, Text e Process, respectivamente.

Se $P$ retornar um objeto de WinProgram, o sistema de tempo de execução procurará filtros nas superclasses Window e Process de WinProgram, pois WinProgram não possui nenhuma classe filtro. A classe Window, por sua vez, não possui classes filtro e isto faz com que o sistema de tempo de execução procure por filtros nas superclasses Box e Text de Window. Os filtros usados são os de Box, Text e Process. Isto é, se uma variável de $Q$, digamos winprg, irá se referir a um objeto de WinProgram, o sistema de tempo de execução usará os filtros que seriam usados se as variáveis de $Q$ se referissem a objetos de classes Box, Text e Process.

Considerando que 1, 2 e 3 são as classes filtro que seriam usadas se objetos de Box, Text e Process fossem referenciados em $Q$, o sistema de tempo de execução fará winprg referir-se a uma seqüência de objetos filtro das classes filtro 1,2 e 3 e fará o último objeto filtro referir-se ao objeto de WinProgram retornado por $P$. Uma representação desta situação é mostrada na Figura 2.7.

Suponha que $Q$ interprete incorretamente somente as classes Box e Text. Então, a classe filtro 3 de Process não será usada quando winprg referir-se a um objecto de WinProgram dentro de $Q$.

Em geral, cada procedimento/classe interpreta classes Box, Text e Process de seu próprio modo, o que significa que uma variável do tipo WinProgram pode referir-se a uma seqüência de zero, um, dois ou três objetos filtro das classes filtro 1,2 e 3 em um total de

$$
\sum_{i=0}^{3}\left(\begin{array}{l}
3 \\
i
\end{array}\right)=8
$$

combinações possiviveis.

\subsubsection{A Solução Geral}

O raciocínio empregado para estes exemplos pode ser generalizado em um algoritmo para encontrar todos os filtros que devem ser usados quando uma variável de um procedimento/classe $Q$ referir-se a um objeto da classe B. Este algoritmo é mostrado na Figura 2.8 e será reescrito em uma forma mais concreta adiante.

Uma visão de classe para uma classe é um conjunto de filtros que permitem que objetos desta classe sejam interpretados corretamente em todas as regiões 


\section{Algoritmo FindFilters $(Q, B)$}

$\{$ Encontre e retorne o conjunto de classes filtro que devem ser usadas quando uma variável do procedimento/classe $Q$ referir-se um objeto da classe B. \}

if existem filtros para a classe B

then

if existe uma classe $B \rightarrow \beta$ definida pelo programador tal que $\mathcal{Q}$ está na região $\beta$. Isto significa que $Q$ está em uma região que interpreta $B$ de um modo diferente de sua semântica original then

return o conjunto unitário composto pelo filtro usado quando uma variável de Q refere-se a um objeto da classe B.

else

$\{Q$ interpreta $B$ usando a semântica correta. Nenhum filtro é necessário. $\}$

return \{\}

endif

else

$\{$ Como não há classes filtro para $B$, use as classes filtro das superclasses $\}$

Sejam $A_{1}, A_{2}, \ldots A_{p}$ as superclasses diretas de $B$.

if $p=0$

then

$$
\text { return }\{\}
$$

else

return

FindFilters $\left(Q, A_{1}\right) \cup$ FindFilters $\left(Q, A_{2}\right) \cup \ldots$

endif

FindFilters $\left(Q, A_{p}\right)$

endif

Figura 2.8: Algoritmo abstrato para encontrar os filtros para uma atribuição 


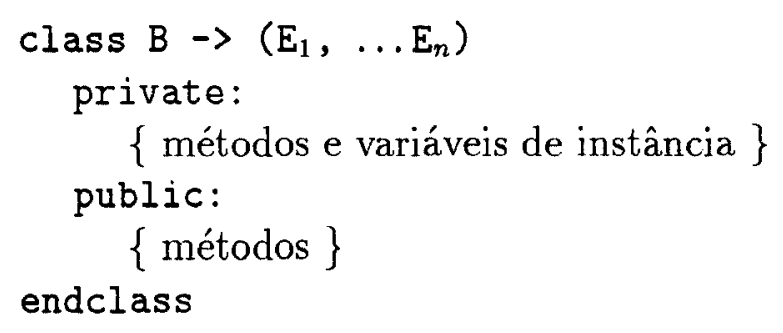

Figura 2.9: Sintaxe da definição de um filtro que pertence à visão de classe para classe B

do programa. O problema que esta facilidade soluciona é o da interpretação da semântica de uma classe de várias maneiras incorretas no código do sistema. Isto é, o sistema está pronto (ou quase pronto) e compilando sem erros, embora, em algumas regiôes do código, uma certa classe tenha sido usada com o significado errado. A mesma interpretação incorreta aconteceu em outras regiões do sistema e então regiões diferentes interpretam a classe de diferentes maneiras.

Para se corrigir o sistema, o programador deve construir uma visão de classe para a classe, que consiste de uma classe filtro para cada região que interpretou incorretamente a classe. A sintaxe para a definição de uma classe filtro é mostrada na Figura 2.9 e será representada como

- (NomeDaClasse, Regiao, VariaveisDeInstancia, Metodos) onde NomeDaClasse é o nome da classe interpretada incorretamente no conjunto Regiao de procedimentos/classes. VariaveisDeInstancia e Metodos possuem o mesmo significado que na representação de classes normais definida no Apêndice A;

- ou como $\mathrm{B} \rightarrow\left(\mathrm{E}_{1}, \ldots \mathrm{E}_{n}\right)$

onde $E_{i}$ representa uma classe ou procedimento. Será usado $B \rightarrow \beta$ como abreviação, onde $\beta$ é a região $\left\{E_{1}, \ldots E_{n}\right\}$.

Deve existir um filtro $\mathrm{B} \rightarrow \beta$ para cada região $\beta$ que interpreta incorretamente a classe $\mathrm{B}$. O conjunto de filtros será chamado de "a visão de classe para B". Como é especificado no Apêndice A, estes filtros são colocados no arquivo shell e não no arquivo do programa.

Cada filtro para $B$ pode definir um subconjunto dos métodos de type(B). Isto é, type $(B \rightarrow \beta) \subset$ type(B). Dois filtros para uma classe podem definir diferentes métodos entre si. Esta característica permite que uma região interprete incorretamente um método de B, enquanto que outra região interpreta este método corretamente.

Suponha que uma variável de um procedimento $Q$ (ou uma variável de um método da classe Q) referir-se-á a um objeto da classe B em tempo de execução e queremos saber quais são as classes dos objetos filtro às quais a variável deve referir-se.

\footnotetext{
${ }^{5}$ As definições de "arquivo shell" e "arquivo do programa" também são dadas no Apêndice A.
} 


\section{Algoritmo FindFilters $(Q, B)$}

$\{$ Encontre e retorne o conjunto de filtros a serem usados quando uma variável de um procedimento/classe $Q$ refere-se a um objeto da classe B \}

if $B$ tem pelo menos um filtro

then

else

$$
\text { return }\{B \rightarrow \beta \mid Q \in \beta\}
$$

$$
\begin{aligned}
& \begin{array}{c}
\text { return } \quad \text { B não possui filtros. Usa os das superclasses }\} \\
U \text { FindFilters }(Q, A)
\end{array} \\
& \text { endif } \\
& \text { A é uma superclasse direta de B }
\end{aligned}
$$

Figura 2.10: Algoritmo para encontrar os filtros para objetos da classe B que são referenciados $\mathrm{em} Q$

Para isto é usado o algoritmo FindFilters da Figura 2.10, que é o algoritmo da Figura 2.8 sob uma forma mais concreta. O sistema de tempo de execução cria um objeto filtro para cada classe filtro retornada por este algoritmo e os organiza em seqüência, cada um referenciando o próximo. A variável referir-se-á ao primeiro objeto filtro e o último filtro referir-se-á ao objeto, como mostrado na Figura 2.7. Isto será melhor definido mais tarde. Agora explicaremos como este algoritmo funciona.

Se houver filtros para classe $B$ e algum for necessário, o filtro empregado será escolhido entre estes. Isto é, se existir um filtro $B \rightarrow \beta$ no qual $Q \in \beta$, o procedimento $Q$ interpreta incorretamente a classe $B$ e portanto este filtro será usado. Se houver filtros para $B$, mas $Q$ não pertencer ao conjunto $\beta$ de nenhum deles $(Q \notin \beta)$, então $Q$ usa a classe $B$ corretamente e nenhum filtro será necessário. Portanto, o algoritmo retornará o conjunto vazio.

Se não houver nenhum filtro para a classe $B$, o algoritmo chama a si mesmo recursivamente para cada superclasse direta de B, se estas existem. Todos os filtros coletados pelas chamadas recursivas são agrupados e retornados pelo algoritmo. Isto faz sentido por duas razões. Primeiro, as chamadas recursivas retornam os filtros que seriam usados se os objetos das superclasses fossem referenciados em Q. Segundo, se uma superclasse necessitar de filtros, ela foi interpretada incorretamente em $Q$ e, se isto aconteceu, a classe B também foi interpretada incorretamente, pois uma subclasse deve seguir a semântica de cada uma de suas superclasses. Então, os filtros das superclasses devem ser usados com os objetos das subclasses.

Uma classe filtro $\mathrm{X} \rightarrow \beta$ pode definir um subconjunto dos métodos da classe $\mathrm{X}$. Assim, os filtros para as superclasses de uma classe não possuem métodos em comum. Se isso ocorresse, também haveriam métodos em comum entre as superclasses, o que é proibido pela linguagem - veja Apêndice A. Portanto, a combinação dos filtros retornados pelo algoritmo FindFilters não resulta em 


\section{Algoritmo CreateAllClasses()}

$\{$ Este algoritmo cria classes para cada classe filtro do arquivo shell usando o algoritmo CreateClass. As classes criadas são colocadas no conjunto AllFilters que será utilizado em tempo de execução. \}

AllFilters: $=\{\}$

For each classe filtro $G \rightarrow \beta$ do arquivo shell do

AllFilters: $=$ AllFilters $U$

$$
\{(G \rightarrow \beta, \operatorname{CreateClass}(G \rightarrow \beta))\}
$$

Figura 2.11: Algoritmo para criar classes normais usando as classes filtro

colisão de métodos, o que significa que os objetos filtro podem ser agrupados em sequiência, cada um referindo-se ao próximo, em qualquer ordem.

\subsection{Definição de Visão de Classe}

Visão de classe será definida usando a representação de objetos da seção A.2.

Assumimos que:

- todas as classes filtro estão no arquivo shell;

- o algoritmo CreateAllClasses da Figura 2.11 é executado antes que o arquivo do programa seja realmente compilado. CreateAllClasses chama CreateClass da Figura 2.12, que usa somente os tipos das classes definidas no arquivo de programa. Os tipos das classes podem ser conhecidos antes da compilação de acordo com a suposição A.1 do Apêndice A.

O algoritmo CreateAllClasses chama CreateClass para cada classe filtro do arquivo shell e insere o par

(classe filtro, CreateClass (classe filtro))

no conjunto AllFilters. CreateClass cria classes normais $\mathrm{X}$ a partir de uma classe filtro $G \rightarrow \beta$ copiando o corpo da classe filtro e trocando o símbolo "object" por "super(G)". A classe X herda de G. Para entender melhor esta função, a Figura 2.13 mostra a classe retornada por $\operatorname{CreateClass}(G \rightarrow \beta)$.

Uma classe filtro $G \rightarrow \beta$ será considerada correta se a classe $X=$ CreateClass $(\mathrm{G} \rightarrow \beta)$ for correta e type $(\mathrm{X})=\operatorname{type}(\mathrm{G})$. A classe retornada por CreateClass é uma classe normal e pode ser compilada usando a definição da linguagem sem shells. G $\rightarrow \beta$ pode chamar métodos de $\mathrm{G}$ pelo envio de mensagens para "object", que são tranformadas em chamadas para os métodos da superclasse, que é G. Então temos a seguinte proposição:

Proposição 2.1 type (G $\rightarrow \beta$ ) é um subconjunto de type(G), onde type (G $\rightarrow \beta$ ) é o tipo da classe filtro $\mathrm{G} \rightarrow \beta$. 
Algoritmo CreateClass ( $\mathrm{G} \rightarrow \beta$ )

$\{$ Este algoritmo retorna uma classe que possui o corpo da classe filtro $G \rightarrow \beta$ e herda G. O símbolo "object" na classe é trocado por "super (G)". \}

Seja G $\rightarrow \beta$ representado como (G, $\beta$, IVs, Ms) de acordo com a representação de classes filtro.

Seja $X$ a classe normal (Xname, $\{G\}, I V s, M s^{\prime},\{\},\{\}$ ) na qual o nome Xname é um nome permitido pelo compilador mas não na linguagem e ele é diferente de qualquer outro nome de identificador no programa.

$M s^{\prime}$ é calculado como se segue:

Ms': $:=\{\}$

For each método (Sign, Text, Status) $\in$ Ms do

Text':= Text

Troque cada símbolo "object" em Text' por "super(G)".

Veja a definição de "símbolo" no Apêndice $\mathrm{C}$

$M^{\prime}:=M s^{\prime} \cup\{($ Sign, Text', Status $)\}$

return X

Figura 2.12: Algoritmo para criar uma classe normal a partir de uma classe filtro

class Xname inherits $G$

$\{$ corpo de G $\rightarrow \beta$ com "object" trocado por "super(G)" \} endclass

Figura 2.13: A classe CreateClass ( $\mathrm{G}->\beta$ ) 
Algoritmo GetClass ( $G \rightarrow \beta$ )

$\{$ Este algoritmo retorna em tempo de execução a classe normal correspondente a $\mathrm{G} \rightarrow \beta$ que foi criada em tempo de compilação por CreateClass $\}$

return $\mathrm{X}$ onde $(\mathrm{G} \rightarrow \beta, \mathrm{X}) \in \mathrm{AllFilters.}$

Figura 2.14: Algoritmo que retorna a classe criada por CreateClass em tempo de compilação

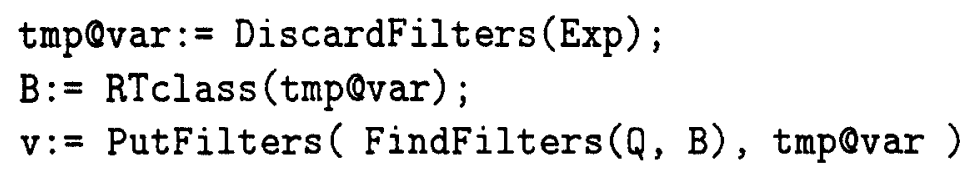

Figura 2.15: Instruções que substituem a atribuição v := Exp

Prova: Admita que $X$ seja CreateClass $(G \rightarrow \beta)$. Então, type(X) = type $(G \rightarrow \beta) \cup$ type $(G)$ pela definição de CreateClass. A classe $X$ somente será considerada correta pelo compilador se type $(X)=$ type $(G)$. Portanto, $\operatorname{type}(G \rightarrow \beta) \subset \operatorname{type}(G)$ porque, de outra forma, type $(X)$ seria diferente de type (G).

O conjunto AllFilters é usado em tempo de execução na chamada do algoritmo GetClass ( $\rightarrow \rightarrow \beta$ ) para recuperar a classe criada por CreateClass correspondente à classe filtro $\mathrm{G} \rightarrow \beta$. O algoritmo GetClass é mostrado na Figura 2.14.

Como filtros de visão de classe são usados em atribuições, uma atribuição $\mathrm{v}:=\operatorname{Exp}$ é definida como os comandos mostrados na Figura 2.15. As variáveis tmp@var e B são temporárias, Q é a classe/procedimento onde esta atribuição está e RTclass, que significa "run-time class", é uma funçao que retorna a classe do objeto a que seu parâmetro real refere-se. DiscardFilters é definido na Figura 2.16 e explicado adiante. Por enquanto, assuma que ele seja a função identidade.

$\mathrm{O}$ algoritmo PutFilters é definido na Figura 2.17 e usa a função GetClass definida na Figura 2.14. O algoritmo PutFilters cria um objeto filtro para cada classe filtro do conjunto $\delta$ retornado por $F$ indFilters $(Q, B)$ (primeiro parâmetro de PutFilters) e faz cada objeto filtro referir-se ao próximo filtro. O último objeto filtro refere-se a $\mathcal{Q}$. Então PutFilters retorna uma referência para o primeiro objeto filtro desta seqüência de objetos.

De acordo com a representação de objetos dada na Seção A.2, um objeto de uma classe B que herda de uma classe A é composto por um subobjeto da classe $B$ que aponta, através da variável super (A), para um objeto da classe $A$. Usando esta representação, um objeto da classe CreateClass $\left(G_{i} \rightarrow \beta_{i}\right)$ é composto por um subobjeto que possui os métodos definidos na classe $G_{i} \rightarrow \beta_{i}$ e por um objeto da classe $G_{i}$. A variável de instância super $\left(G_{i}\right)$ do primeiro subobjeto refere-se 
Algoritmo DiscardFilters $(\mathcal{P})$

$\{\mathcal{P}$ é uma sequiência de $n$ objetos filtro $(n \geq 0)$ que se referem a um objeto $\mathcal{Q}$. Este algoritmo retorna $\mathcal{Q}$, descartando os objetos filtro \}

\{ Este comando if usa o fato de que nomes de classes filtro não são nome permitidos na linguagem, embora eles sejam aceitos pelo compilador $\}$

if o nome da classe do objeto $\mathcal{P}$ é um nome permitido na linguagem

then

$\{$ o objeto $\mathcal{Q}$ foi encontrado $\}$ return $\mathcal{P}$

else

Seja G $\rightarrow \beta$ a classe filtro do primeiro objeto filtro de $\mathcal{P}$.

$\{$ Então este objeto filtro possui uma variável de instância super (G), que é um ponteiro para o próximo objeto filtro ou para um objeto. Esta variável foi inicializada por PutFilters, pois todos os objetos filtro são criados por este algoritmo. $\}$

return DiscardFilters ( $\mathcal{P}$. super $(G))$ endif

Figura 2.16: Algoritmo para descartar objetos filtro de um objeto 
Algoritmo PutFilters $(\delta, \mathcal{Q})$

$\{$ Uma variável irá se referir ao objeto $\mathcal{Q}$ e a classe de $\mathcal{Q}$ é incorretamente interpretada na região onde está a atribuição para esta variável. A interpretação incorreta da classe de $\mathcal{Q}$ é corrigida pelas classes filtro do conjunto $\delta$.

Este algoritmo cria e retorna uma sequiência de objetos filtro, cada um pertencendo a uma classe filtro de $\delta$, de tal modo que cada objeto filtro refere-se ao próximo na seqüência. $\mathrm{O}$ último objeto filtro refere-se a $\mathcal{Q}$. $\}$

$\{$ As funções head e tail tratam $\delta$ como uma lista e retornam o primeiro elemento de $\delta$ e o resto da lista sem o primeiro elemento, respectivamente $\}$

if $\delta=\{\}$

then return $\mathcal{Q}$ else

Seja head $(\delta)$ igual a $G \rightarrow \beta$.

$x:=\operatorname{GetClass}(G \rightarrow \beta)$. new ()

$\{$ Pela definição de GetClass e CreateClass,

GetClass ( $G \rightarrow \beta$ ) herda de $G$ (e somente de $G$ )

$\mathrm{e}$, portanto, o objeto a que $\mathrm{x}$ refere-se possui uma variável de instância super $(G)$. $\}$

x.super $(G):=$ PutFilters $(\operatorname{tail}(\delta), \mathcal{Q})$

return $x$

endif

Figura 2.17: Algoritmo para criar objetos filtro para uma atribuição

objeto da classe $\mathrm{G}_{1} \rightarrow \beta_{1}$ objeto da classe $G_{1}$

Figura 2.18: Um objeto da classe CreateClass $\left(G_{1}->\beta_{1}\right)$ 


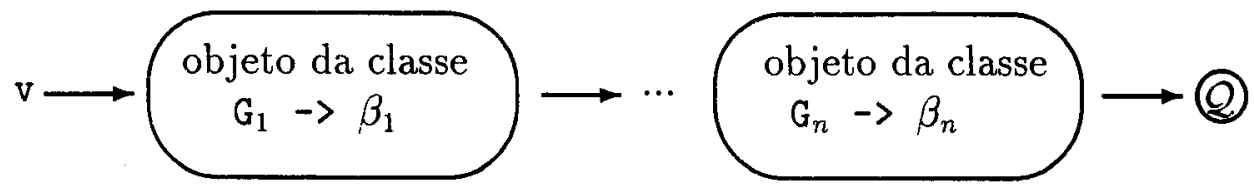

Figura 2.19: A seqüência de objetos filtro referenciados por $\mathrm{v}$

ao segundo - veja Figura 2.18.

Se $\delta=\left\{G_{i} \rightarrow \beta_{i} \mid 1 \leq i \leq n\right\}, \operatorname{PutFilters}(\delta, \mathcal{Q})$ retornará uma seqüência de objetos filtro das classes GetClass $\left(G_{i} \rightarrow \beta_{i}\right), 1 \leq i \leq n$, nos quais o objeto da classe $G_{i}$ foi descartado de cada objeto filtro da classe GetClass $\left(G_{i} \rightarrow \beta_{i}\right)$. $O$ objeto da classe $G_{i}$ é descartado quando é atribuida à variável de instância. super $\left(G_{i}\right)$ do objeto filtro a seqüência de objetos filtro retornada pela chamada recursiva a PutFilters

$$
\text { x.super }(G):=\operatorname{PutFilters}(\operatorname{tail}(\delta), \mathcal{Q})
$$

A seqüência de objetos filtro retornada por $\operatorname{PutFilters}(\delta, \mathcal{Q})$ é mostrada na Figura 2.19.

Baseado no texto acima deduz-se a proposição:

Proposição 2.2 Se um objeto filtro $\mathcal{F}$ pertencer a uma seqüência de objetos filtro retornada por PutFilters e a classe de $\mathcal{F}$ for $\operatorname{GetClass}(G \rightarrow \beta)$, então o tipo de $\mathcal{F}$ será type $(\mathrm{G} \rightarrow \beta)$, o qual é o conjunto de assinaturas de métodos da classe $G \rightarrow \beta$.

Prova: $\mathcal{F}$ é criado por GetClass $(G \rightarrow \beta)$, o qual retorna uma classe que possui os métodos da classe $\mathrm{G} \rightarrow \beta$ e herda de G. Portanto, $\mathcal{F}$ possui um subobjeto que possui métodos da classe $\mathrm{G} \rightarrow \beta$ e um objeto da classe $\mathrm{G}$. Como este último objeto é descartado pela atribuição a super $(G), \mathcal{F}$ possui somente os métodos de $G \rightarrow \beta$, o que prova a proposição.

$O$ algoritmo DiscardFilters da Figura 2.16 toma um parâmetro $\mathcal{P}$. Se $\mathcal{P}$ for um objeto normal (sem objetos filtro), ele será retornado. Caso contrário, ele será um objeto filtro que aponta para alguma outra coisa que pode ser outro objeto filtro ou um objeto. Então DiscardFilters chamará a si mesmo recursivamente usando $\mathcal{P}$. super $(G)$ como parâmetro para descartar os objetos filtro remanescentes, se algum existir. Portanto, DiscardFilters retornará $\mathcal{Q}$ quando ele receber como parâmetro uma seqüência de objetos filtro que se referem a um objeto $\mathcal{Q}$.

Será provado agora que nenhum erro de tipos é introduzido no programa quando os comandos da Figura 2.15 substituem v:= Exp. Lembre-se de que $Q$ é o procedimento/classe onde esta atribuição está, e que B é a classe do objeto que resulta de Exp depois do descarte de todos os objetos filtro.

A idéia básica da correção de tipos desta substituição é simples. As duas primeiras atribuições são corretas porque tmp@var e B podem ser considerados 
sem tipo. Então a substituição será correta se a terceira atribuição, para v, for correta. Na atribuição original para $\mathrm{v}$, o lado direito é Exp, que possui tipo type(B), e é substituído por uma chamada a PutFilters. Então, o que temos que provar é que a chamada a PutFilters retorna um objeto de um subtipo de type(B). Uma prova informal da correção de tipos é apresentada a seguir.

Em PutFilters, cada objeto filtro criado da classe CreateClass (G $\rightarrow \beta$ ) possui um tipo type $(G \rightarrow \beta)$ de acordo com a Proposição 2.2 e type $(G \rightarrow \beta)$ é um subconjunto de type $(G)$ de acordo com a Proposição 2.1. Como G é uma superclasse da classe $B$ (pela definição de FindFilters), temos que type $(G \rightarrow \beta)$ $\subset$ type(G) $\subset$ type(B). Isto é, o tipo de cada objeto filtro é um subtipo de type (B). Portanto, type (B) é o tipo da seqüência de objetos filtro que se referem ao objeto $\mathcal{Q}$ do tipo type (B). Então, o tipo do objeto retornado por PutFilters é type(B), e a atribuição $\mathrm{v}:=\operatorname{PutFilters~(...)~é~corretamente~tipada~porque~}$ $v:=\operatorname{Exp}$ o é.

Serão provadas agora várias proposições usadas na prova de correção de tipos das instruções da Figura 2.15.

Proposição 2.3 Se $\mathcal{R}$ for o objeto retornado por PutFilters (FindFilters $(Q, B)$, tmp@var )

então

$$
\operatorname{type}(\mathcal{R})=\operatorname{type}\left(G_{n} \rightarrow \beta_{n}\right) \cup \operatorname{type}\left(G_{n-1} \rightarrow \beta_{n-1}\right) \cup \ldots \operatorname{type}\left(G_{1} \rightarrow \beta_{1}\right)
$$

onde FindFilters $(\mathrm{Q}, \mathrm{B})=\left\{\mathrm{G}_{i} \rightarrow \beta_{i} \mid 1 \leq i \leq n\right\}$.

Prova: Pela Proposição 2.2, o tipo de cada objeto filtro de $\mathcal{R}$ é type $\left(G_{i} \rightarrow \beta_{i}\right)$, $1 \leq i \leq n$. Uma mensagem enviada a $\mathcal{R}$ causa uma busca por método no primeiro objeto filtro. Se ele não for encontrado lá, a busca continuará no segundo objeto filtro e assim por diante. Então, o conjunto de métodos de $\mathcal{R}$ é a união dos métodos de cada um de seus objetos filtro e do objeto do tipo type(B). Isto prova a proposição. As classes $G_{i}$ são superclasses diretas e indiretas de B.

Proposição 2.4 Seja $\delta=$ FindFilters $(Q, B)$. Então, $\delta=\{\}$ ou para cada $\mathrm{E}$ $\in \delta$, type(E) $\subset$ type(B).

Prova: Esta prova será feita usando-se indução no número de camadas da hierarquia da classe B. A primeira camada é a classe B, a segunda é composta pelas superclasses diretas de B, a terceira pelas superclasses das superclasses diretas de B e assim por diante. Cada passo da indução reduz o número de camadas de um (1). Há dois casos a considerar.

1. A classe $B$ não possui superclasses. Se $B$ possuir um filtro $B \rightarrow \beta$ tal que $Q \in \beta$, FindFilters $(Q, B)$ retornará $\{B \rightarrow \beta\}$. Caso contrário, ele retornará \{\} . Qualquer um dos dois satisfaz a Proposição 2.4, já que type $(B \rightarrow \beta) \subset$ type $(B)$ pela Proposição 2.1 .

2. A classe $B$ possui superclasses $A_{1}, A_{2}, \ldots A_{p}, p \geq 1$. Neste caso, FindFilters $(Q, B)$ retornará: 
- $\{\mathrm{B} \rightarrow \beta\}$ se $B$ possuir filtro $B \rightarrow \beta$ tal que $Q \in B$. Este item satisfaz a Proposição 2.4 porque type $(B \rightarrow \beta) \subset$ type $(B)$.

- Ou $\psi=$ FindFilters $\left(Q, A_{1}\right) \cup$ FindFilters $\left(Q, A_{2}\right) \cup \ldots$ FindFilters $(Q$, $\left.\mathrm{A}_{p}\right)$ caso contrário. Assuma $\delta_{j}=\operatorname{FindFilters}\left(\mathrm{Q}, \mathrm{A}_{j}\right)$ e $\psi=\delta_{1} \cup \delta_{2}$ $\cup \ldots \delta_{p}$.

Aplicando a Proposição 2.4 a $\mathrm{A}_{j}$, temos, para $1 \leq j \leq p$ :

$$
\delta_{j}=\{\} \text { ou, para cada } E \in \delta_{j}, \operatorname{type}(E) \subset \operatorname{type}\left(A_{j}\right) .
$$

type $\left(A_{j}\right) \subset$ type $(B)$ porque $A_{j}$ é uma superclasse de $\mathrm{B}$ e, portanto, $\delta_{j}$ $=\{\}$ ou para cada $E \in \delta_{j}, \operatorname{typ}_{t}(E) \subset \operatorname{type}(B)$.

Então, de acordo com a Proposição $2.5, \psi=\{\}$ ou para cada $E \in \psi$, type(E) $\subset$ type(B).

Então, Proposição 2.4 será verdadeira quando B possuir superclasses.

Como a Proposição 2.4 é válida com (2) ou sem (1) superclasses de B, concluímos que ela é sempre verdadeira.

Proposição 2.5 Seja $\psi=\delta_{1} \cup \delta_{2} \cup \ldots \delta_{p}$ onde $\delta_{j}=\operatorname{FindFilters}\left(\mathbf{Q}, \mathrm{A}_{j}\right)$. Se, para $1 \leq j \leq p, \delta_{j}=\{\}$ ou para cada $\mathrm{E} \in \delta_{j}$, type(E) $\subset$ type(B), então $\psi=\{\}$ ou para cada $\mathrm{E} \in \psi$, type(E) $\subset$ type(B).

Prova: Podemos provar esta afirmação por contradição. Suponha que ela seja falsa. Então $\psi$ não é vazio e há um elemento $E^{\prime} \in \psi$ tal que type $\left(E^{\prime}\right) \not \subset$ type(B). Pela definição de $\psi, E^{\prime}$ pertence a um conjunto $\delta_{k}$ e então type $\left(E^{\prime}\right) \subset$ type(B). Isto contradiz o resultado prévio, o que prova nossa afirmação.

Proposição 2.6 type $(\mathcal{R})=$ type $(B)$

Prova: De acordo com a Proposição 2.3,

$$
\operatorname{type}(\mathcal{R})=\left(\bigcup_{E \in \delta} \operatorname{type}(E)\right) \cup \operatorname{type}(B)
$$

onde $\delta=$ FindFilters $(\mathrm{Q}, \mathrm{B})$ e pela Proposição $2.4, \delta=\{\}$ ou para cada $\mathrm{E}$ $\in \delta, \operatorname{type}(E) \subset$ type $(B)$.

Existe uma união de conjuntos na qual cada um deles é um subconjunto de type(B). Portanto, o lado direito da igualdade é type(B), o que prova a proposição.

Proposição 2.7 A atribuição $\mathrm{v}:=\mathcal{R}$ está corretamente tipada.

Prova: Antes que a atribuição acima aconteça, $\mathcal{R}$ é construído por PutFilters usando a expressão Exp, que pode resultar em

1. um objeto normal $\mathcal{Q}$;

2. uma seqüência de objetos filtro na qual o último filtro refere-se a um objeto $\mathcal{Q}$. Chamaremos esta seqüência de objeto $\mathcal{P}$, que foi criada por uma chamada prévia a PutFilters, pois este é o único algoritmo que cria objetos filtro. 
Se Exp resultar em 2, então type $(\mathcal{P})=\operatorname{type}(\mathcal{Q})$ pela Proposição 2.6 , que diz que o tipo de uma seqüência de objetos filtro é igual ao tipo do último objeto.

Em qualquer caso, 1 ou 2, o tipo do objeto em que Exp resulta é type( $\mathcal{Q})$, que é type (B) porque DiscardFilters (Exp) retorna $\mathcal{Q}$ e B é a classe de $\mathcal{Q}$ (veja Figura 2.15). Então, pelas regras de subtipo da linguagem,

1. type (Exp) $\prec$ type (v) onde type(Exp) e type(v) são os tipos declarados de Exp e v, respectivamente;

2. type(objeto em que Exp resulta) $\prec$ type(Exp)

Isto é, $\operatorname{type}(\mathcal{Q}) \prec \operatorname{type}(\operatorname{Exp})$ ou $\operatorname{type}(\mathcal{P}) \prec \operatorname{type}(\operatorname{Exp})$ pois type $(\mathcal{P})=$ type $(\mathcal{Q})$.

Portanto, type $(B)=\operatorname{type}(\mathcal{Q}) \prec$ type $(\operatorname{Exp}) \prec$ type $(v)$. Pela Proposição 2.6, $\operatorname{type}(\mathcal{R})=\operatorname{type}(B)$ e então type $(\mathcal{R}) \prec \operatorname{type}(v)$. Isto prova a proposição.

Os envios de mensagem para self e para super dentro de $\mathcal{R}$ serão examinados agora para garantir que eles são corretamente tipados.

Como nas proposições anteriores, assuma que $\mathcal{R}$ seja composto por subobjetos dos tipos

$$
\operatorname{type}\left(G_{n} \rightarrow \beta_{n}\right), \ldots \operatorname{type}\left(G_{2} \rightarrow \beta_{2}\right), \operatorname{type}\left(G_{1} \rightarrow \beta_{1}\right), \operatorname{type}(B)
$$

Proposição $2.8 \operatorname{type}\left(G_{i} \rightarrow \beta_{i}\right) \subset \operatorname{type}(\mathrm{B}), 1 \leq i \leq n$.

Prova: Segue diretamente da Proposição 2.4 .

Proposição 2.9 type $(B) \prec \operatorname{type}\left(G_{i}\right)$ ou type $\left(G_{i}\right) \subset$ type $(B), 1 \leq i \leq n$.

Prova: Este resultado se segue do fato de que ou $\left(n=1\right.$ e $\left.G_{1}=B\right)$ ou $G_{i}$ é uma superclasse de B (pela definição de FindFilters).

Proposição 2.10 Considere um subconjunto de $\mathcal{R}$ composto por subobjetos dos tipos

$$
\operatorname{type}\left(G_{j} \rightarrow \beta_{j}\right), \ldots \operatorname{type}\left(G_{2} \rightarrow \beta_{2}\right) \text {, type }\left(G_{1} \rightarrow \beta_{1}\right) \text {, type(B) }
$$

em que $0 \leq j \leq n$. O tipo deste subconjunto é

$$
\operatorname{type}\left(G_{j} \rightarrow \beta_{j}\right) \cup \ldots \operatorname{type}\left(G_{2} \rightarrow \beta_{2}\right) \cup \operatorname{type}\left(G_{1} \rightarrow \beta_{1}\right) \cup \operatorname{type}(B)
$$

que é type(B).

Prova: Este resultado pode ser deduzido da Proposição 2.8.

Proposição 2.11 Nenhum envio de mensagem para super dentro dos métodos de qualquer subobjeto de $\mathcal{R}$ causará erro de tipos em tempo de execução.

Prova: Um subobjeto da classe GetClass $\left(G_{i} \rightarrow \beta_{i}\right)$ possui envios de mensagens para super $\left(G_{i}\right)$, onde esta variável possui tipo type $\left(G_{i}\right)$ (pela definição de CreateClass). PutFilters atribui a super $\left(G_{i}\right)$ uma seqüência de objetos cujos tipos são 


$$
\operatorname{type}\left(G_{i-1} \rightarrow \beta_{i-1}\right), \ldots \operatorname{type}\left(G_{2} \rightarrow \beta_{2}\right), \operatorname{type}\left(G_{1} \rightarrow \beta_{1}\right), \operatorname{type}(B)
$$

e que possui tipo type(B) de acordo com a Proposição 2.10. Como super $\left(G_{i}\right)$ possui tipo type $\left(G_{i}\right)$ e type $(B) \prec$ type $\left(G_{i}\right)$ de acordo com a Proposição 2.9 , a atribuição de super $\left(G_{i}\right)$ é correta quanto a tipos. Portanto, nenhum envio de mensagem para super(NomeClasse) em um método de $\mathcal{R}$ causará erro de tipos em execução.

Agora os envios de mensagem para self em métodos de $\mathcal{R}$ serão examinados. Uma instrução

$$
\mathrm{v} \cdot \mathrm{n}(\ldots)
$$

executada depois de $\mathcal{R}$ ser atribuido a $\mathrm{v}$ pode causar (durante a execução do método n) um envio de mensagem para self:

$$
\text { self.m (...) }
$$

Provaremos que este envio de mensagem é corretamente tipado através das proposições seguintes.

Proposição 2.12 O algoritmo de busca por método encontrará o método m se m $\in$ type (B).

Prova: O sistema de tempo de execução (algoritmo para busca por método definido na seção A.2) começará uma busca por m no primeiro subobjeto de $\mathcal{R}$. A busca continuará, se necessário, através de todos os subobjetos até que o objeto da classe $B$ seja alcançado. $O$ método $m$ será encontrado se ele pertencer a qualquer subobjeto de $\mathcal{R}$ (o que inclui o objeto da classe B), o que é o mesmo que dizer que o método m será encontrado se ele pertencer ao tipo type(B) de acordo com a Proposição 2.10 .

Proposição 2.13 Nenhum envio de mensagem self.m(...) dentro de qualquer subobjeto de $\mathcal{R}$ causará erros de tipo em tempo de execução.

Prova: Este envio de mensagem pode estar em dois lugares em $\mathcal{R}$ :

I. um método de um objeto filtro, que é um método de uma classe $\mathrm{G}_{i} \rightarrow \beta_{i}$

II. um método do último objeto, que é um método da classe B.

Se o envio de mensagem estiver em I, ele será considerado válido pelo compilador se $\mathrm{m} \in \operatorname{type}\left(G_{i}\right)$. Isto se segue do fato de que $G_{i} \rightarrow \beta_{i}$ é transformado em $\mathrm{X}=$ CreateClass $\left(\mathrm{G}_{i} \rightarrow \beta_{i}\right)$, que é correto somente se type $(\mathrm{X})=\operatorname{type}\left(\mathrm{G}_{i}\right)$, por definição. Como $m$ deve pertencer ao tipo da classe onde o envio da mensagem self.m (...) está, ele deve pertencer a type $(X)$ e, portanto, m deve também pertencer a type $\left(G_{i}\right)$. Caso contrário, haveria um erro de compilação de acordo com a definição da linguagem. Então concluímos que $\mathrm{m} \in$ type $\left(\mathrm{G}_{i}\right) \mathrm{e}$, portanto, $\mathrm{m} \in$ type (B) de acordo com a Proposição 2.9.

Se o envio de mensagem self.m( ...) estiver em II, ele será legal em tempo de compilação se $m \in$ type(B). Em qualquer caso, I ou II, o envio de mensagem self.m(...) ocorrerá somente se ele for considerado correto com relação a tipos pelo compilador, o que significa $m \in$ type (B). Entretanto, neste caso um método $m$ será encontrado de acordo com a Proposição 2.12 e, portanto, não haverá nenhum erro de tipos.

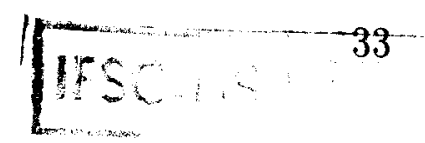


Pode existir um ponteiro w para o subobjeto da classe B de $\mathcal{R}$, pois w pode estar em uma região que interpreta a classe B corretamente. Um envio de mensagem para o subobjeto da classe $B$ não causará nenhum erro de tipos, pois ele é considerado um objeto normal. Ele não possui nenhuma referência aos outros subobjetos.

\subsection{Uma Otimização da Substituição da Atribuição}

\subsubsection{Caso Simples}

Com as definições dadas acima, o sistema de tempo de execução pode trocar cada atribuição do programa pelas instruções da Figura 2.15. Entretanto, isto seria um desperdício de tempo, pois filtros só são usados quando variáveis de algumas partes do código referem-se a objetos de algumas classes.

Algumas atribuições nunca necessitarão de objetos filtro e isto pode ser descoberto em tempo de compilação, diminuindo o número de instruções que devem ser transformadas em uma chamada para PutFilters. As atribuições que podem ser substituídas são da forma

$$
\mathrm{v}:=\operatorname{Exp}
$$

tal que:

- esta instrução está em um um procedimento ou classe Q;

- a expressão Exp pode resultar em um objeto da classe B, onde a classe B é interpretada incorretamente ${ }^{6}$ em Q. Então o objeto da classe B necessitará de objetos filtro.

Assumindo que $T$ seja o tipo declarado de Exp, temos que:

Proposição 2.14 A expressâo Exp pode resultar em um objeto da classe B se e somente se ( $\Longleftrightarrow$ ) type (B) for um subtipo de $T$.

Prova: Provaremos primeiro que Exp poderá resultar em um objeto da classe $B$ se type (B) for um subtipo de $T$ (a parte $\Longrightarrow$ ). A expressão B. new() possui tipo type(B) e, já que type(B) $\prec T$, também é do tipo $T$. Então, se Exp for B. new(), Exp resultará em um objeto da classe $B$.

Provaremos agora que Exp pode resultar em um objeto da classe B só se type(B) for um subtipo de $T$ (a parte $\Longleftarrow$ ). Suponha o contrário: Exp pode resultar em um objeto da classe B no qual type(B) não seja subtipo de $T$. Então uma expressão do tipo $T$ iria se referir a um objeto cujo tipo não é subtipo de $T$. Contudo, isto não pode ocorrer porque o sistema de tipos da linguagem garante que uma expressão ou variável sempre refere-se a um objeto cujo tipo é um subtipo do seu tipo declarado.

\footnotetext{
${ }^{6}$ Por interpretada incorretamente queremos dizer que objetos filtro devem ser usados quando um objeto da classe $B$ for referenciado em $Q$.
} 
Algoritmo NeedFilters $(Q, T)$

$\{$ Há uma atribuição $\mathrm{v}:=$ Exp em um procedimento/classe

Q e o tipo declarado de Exp (determinado estaticamente)

é $T$. Este algoritmo retorna true se esta atribuição

puder necessitar de objetos filtro em tempo de execução.

Caso contrário, retorna false

return $\exists$ classe $B$ tal que type $(B) \prec T$ e FindFilters $(Q, B) \neq\{\}$

Figura 2.20: Algoritmo para descobrir se uma atribuição precisa de objetos filtro

Então o compilador deve procurar por atribuições nas quais uma classe que precisa de filtros seja um subtipo do tipo do lado direito da atribuição. $O$ compilador usa o algoritmo NeedFilters da Figura 2.20 para descobrir se uma atribuição de um procedimento/método $Q$ deve ser convertida para uma chamada para PutFilters. A atribuição deve ser convertida se NeedFilters retorna true.

\subsubsection{Caso Polimórfico}

$\mathrm{O}$ algoritmo NeedFilters assume que $\mathrm{Q}$ e $T$ são conhecidos pelo compilador para cada atribuição. Isto é verdade para $T$, mas não para $Q$, pois a atribuição pode ser uma passagem de parâmetros para um método polimórfico.

Assumindo que a variável aa pode se referir a objetos de várias classes que possuem o método $\mathrm{m}$, em

aa.m(Exp)

é impossível determinar, em tempo de compilação (em geral), qual método m será executado em tempo de execução em resposta a este envio de mensagem. Portanto, o compilador não sabe o parâmetro Q de NeedFilters.

Então, este algoritmo deve ser executado com todas as possíveis situações; isto é, o parâmetro $Q$ deve assumir o valor de todas as classes (pois m pertence a uma classe) a cujos objetos a variável aa puder se referir, que são as classes A tal que type (A) $\prec$ type (aa), onde type (aa) é o tipo declarado de aa.

Isto é feito de uma forma sutil pelo algoritmo PolyNeedFilters da Figura 2.21. Ao invés de executar NeedFilters para cada classe subtipo de type (aa), o algoritmo tenta encontrar uma classe A que seja subtipo de type (aa) e NeedFilters $(A, T)$ seja verdadeiro. Se esta classe existir, a passagem de parâmetros, digamos $v:=\operatorname{Exp}$, deverá ser substituída pela seqüência de instruções mostradas na Figura 2.22.

\subsubsection{Caso Geral}

O algoritmo NeedFilters descobre se objetos filtro precisam ser criados em tempo de execução, mas ele não diz se objetos filtro precisam ser removidos antes da atribuição. Por exemplo, assuma que 
Algoritmo PolyNeedFilters (aa, T)

$\{$ Há um envio de mensagem na qual a variável aa refere-se a um objeto que recebe uma mensagem no qual um objeto do tipo $T$ é parâmetro real. Retorne true se esta passagem de parâmetros puder necessitar de objetos filtro, false caso contrário \}

return $\exists$ classe $A$ tal que type(A) $\prec \operatorname{type}(\mathrm{aa})$ e NeedFilters $(\mathrm{A}, T)=$ true

Figura 2.21: Algoritmo para descobrir a necessidade de objetos filtro na presença de polimorfismo

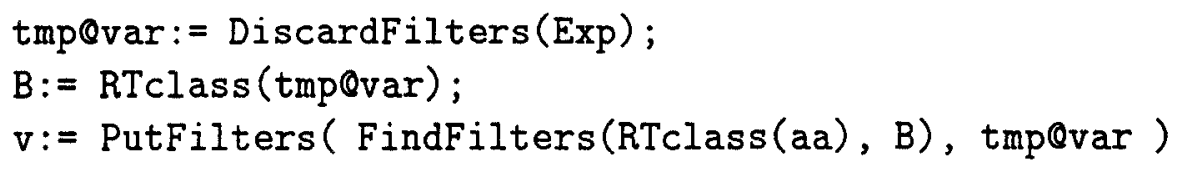

Figura 2.22: Instruções que substituem a atribuição v := Exp

$$
t:=P()
$$

esteja em um procedimento $Q$ que interpreta a classe $B$ corretamente, e que $P$ retorna uma seqüencia de objetos filtro que se referem a um objeto $\mathcal{Q}$ da classe B. Naturalmente, $\mathrm{P}$ está em uma região que interpreta incorretamente a classe B. Neste caso, os objetos filtro devem ser descartados e $\mathcal{Q}$ deve ser atribuído a $t$.

Considerando o caso geral, uma atribuição $\mathrm{v}:=\operatorname{Exp}$, de um procedimento/classe $Q$, pode ter a necessidade de criar objetos filtro para Exp ou de removê-los. Então, o compilador deve analisar todas as atribuições e trocar cada uma delas, se necessário, por código para fazer uma coisa ou outra. Antes da compilação do programa, o compilador percorre o arquivo do programa e executa o algoritmo ReplaceAssignment mostrado na Figura 2.23 para cada atribuição $\mathrm{v}:=\operatorname{Exp}$ do programa, o que naturalmente inclui passagem de parâmetros. Se existir a possibilidade de que $v:=$ Exp necessite de objetos filtro em tempo de execução (NeedFilters ( $Q, T)$ ou PolyNeedFilters(aa, $T$ ) retorna true), o algoritmo substituirá a atribuição por código para criar objetos filtro, o que já foi descrito. Se ambas as chamadas que acabamos de citar retornarem false, a parte else do comando if número I será executada e as proposições abaixo serão verdadeiras.

Proposição 2.15 Se o item 1 for verdadeiro, para cada classe B tal que type(B) $\prec T$, FindFilters $(\mathrm{Q}, \mathrm{B})=\{\}$.

Prova: Se o item 1 for verdadeiro e a parte else for executada, NeedFilters $(Q, T)=$ false e portanto $F i n d F i l t e r s(Q, B)=\{\}$. Isto é, a classe $B$ será interpretada corretamente em $Q$ e portanto ela será interpretada corretamente na região onde a atribuição $\mathrm{v}:=$ Exp se encontra. 


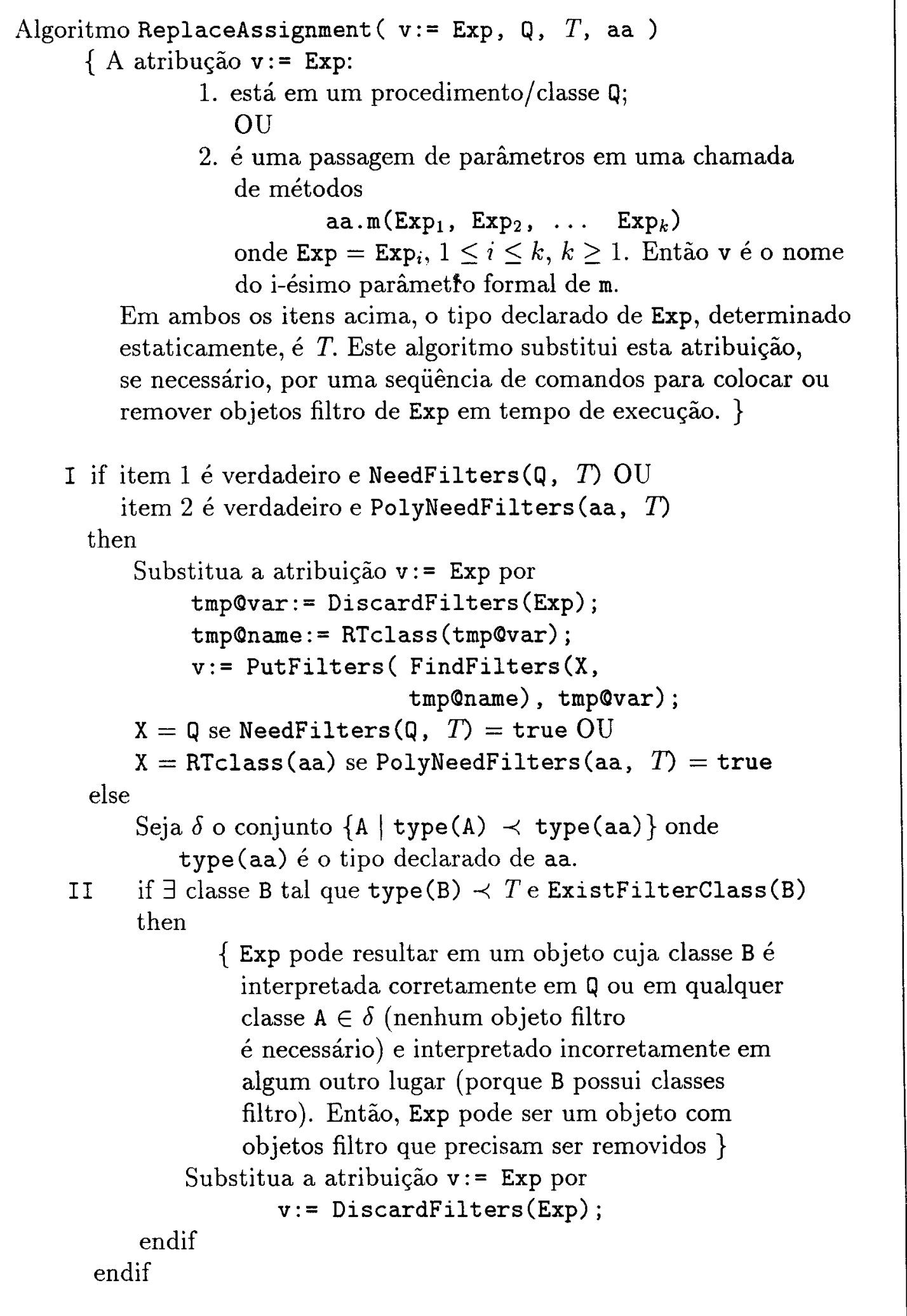

Figura 2.23: Algoritmo que substitui uma atribuição por instruções que irão colocar ou remover objetos filtro em tempo de execução 
Proposição 2.16 Se o item 2 for verdadeiro, para cada classe $\mathrm{A} \in \delta=\{\mathrm{A} \mid$ type $(A) \prec \operatorname{type}(a a)\}, F i n d F i l t e r s(A, B)=\{\}$.

Prova: Se o item 2 for verdadeiro e a parte else for executada, PolyNeedFilters (aa, $T$ ) será falso, o que significa que, para cada classe $B$ tal que type $(B) \prec T$ e para cada classe $A \in \delta, F i n d F i l t e r s(A, B)=\{\}$. Isto é, a classe $B$ será interpretada corretamente em qualquer classe $A \in \delta$ e portanto $B$ será corretamente interpretada na região onde esta atribuição está, que pode ser qualquer método de qualquer classe $A \in \delta$.

Se a expressão booleana do comando if número II for verdadeira, haverá pelo menos uma classe $B^{\prime}$ tal que type $\left(B^{\prime}\right) \prec T$ e existirão classes filtro para $B^{\prime}$ (ExistFilterClass $\left(B^{\prime}\right)==$ true). Então, Exp poderá resultar em um objeto da classe ${ }^{7} B^{\prime}$ com objetos filtro que precisarão ser removidos porque $B^{\prime}$ é interpretada corretamente no código onde a atribuição $v:=$ Exp está de acordo com as Proposições 2.15 e 2.16. Os objetos filtro são removidos em tempo de execução pela instrução dada na parte then do comando if número II. Se Exp resultar em um objeto sem objetos filtro, esta instrução apenas atribuirá Exp a v.

Se as expressões dos ifs número I e II forem falsas, ReplaceAssignment não modificará a atribuição v:= Exp. Em particular, se nenhuma classe subtipo de type (Exp) possuir classes filtro, a atribuição não será modificada.

É possível que:

- a atribuição $\mathrm{v}:=$ Exp possa necessitar de filtros em tempo de execução e é substituída pelas instruções da Figura 2.15;

- em tempo de execução, Exp resulte em um objeto $\mathcal{P}$ composto por objetos filtro que se referem a um objeto $\mathcal{Q}$ da classe C. A classe C é interpretada corretamente no procedimento/classe onde esta atribuição está.

Neste caso, os objetos filtro de $\mathcal{P}$ devem ser removidos e nenhum deve ser criado. Isto é o que as instruções da Figura 2.15 farão. Embora estas instruções tenham sido projetadas para inserir objetos filtro, elas também os removem quando eles não são necessários.

ReplaceAssignment assume que o compilador conhece todos os tipos e todas as classes antes que ele seja chamado. Esta informação é usada em expressões como " $\exists$ classe B tal que type(B) $\prec T$ e ...", na qual todos os subtipos de um dado tipo devem ser analisados. Esta suposição de ReplaceAssignment é correta desde que o compilador, antes de executar este algoritmo, faça uma análise sintática no arquivo do programa para determinar todas as classes e todos os tipos. Isto é possível de acordo com a suposição A.1 do Apêndice A (página 136).

\subsection{Algumas Restrições no Uso de Visão de Classe}

Variáveis globais são permitidas na linguagem, mas há restrições em seu uso com visão de classes. É proibido a existência de variáveis globais do tipo $T$ se houver

\footnotetext{
${ }^{7}$ Pois $T$ é o tipo declarado de Exp e type $\left(B^{\prime}\right) \prec T$.
} 

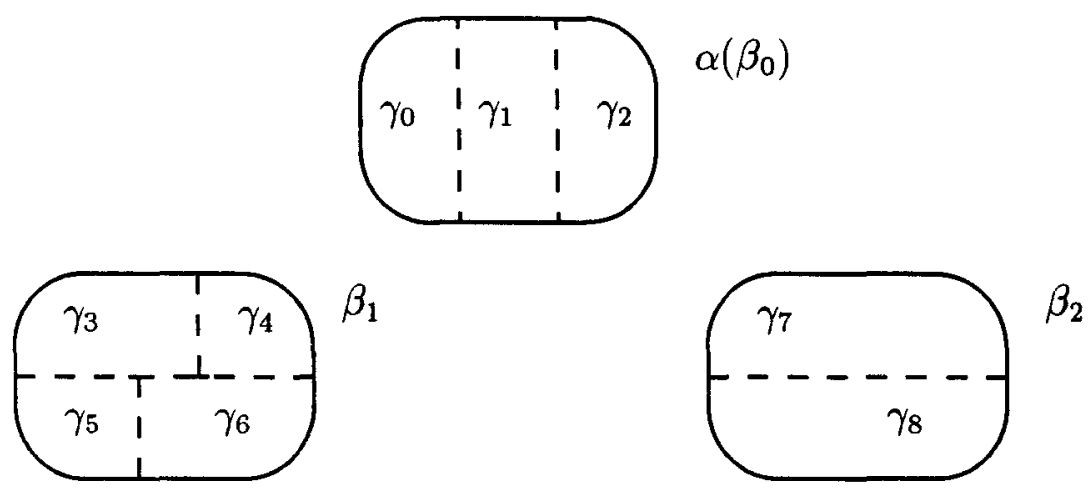

Figura 2.24: A divisão de um sistema em regiões para uma subclasse

uma visão de classe para uma classe A cujo tipo seja um subtipo ou supertipo de $T$. Esta restrição previne uma variável global de receber, em uma atribuição, um objeto da classe A em uma região $\alpha$ que interpreta esta classe corretamente e imediatamente receber uma mensagem em uma região $\beta$ que interpreta esta classe incorretamente. Esta variável será usada na região $\beta$ sem se referir ao objeto filtro, pois não houve nenhuma atribuição para esta variável nesta região. Portanto, não haverá nenhuma translação da mensagem para sua semântica correta. Esta mesma restrição se aplica às variáveis da seção share de uma classe, que são apenas variáveis globais manipuladas por meio do nome da classe.

Nem todas as divisões do programa em regiões são válidas. Assumindo que as regiões $\beta_{1}, \ldots \beta_{q}$ interpretam a classe $\mathrm{B}$ incorretamente e $\beta_{0}$ é a região que interpreta esta classe corretamente, a divisão do sistema deve obedecer às seguintes regras:

- $\mathrm{B} \in \beta_{0}$, o que também é válido para qualquer subclasse de $\mathrm{B}$. Isto é, uma classe não pode interpretar ela mesma incorretamente nem o podem suas subclasses. É possível modificar visão de classe para permitir que subclasses possam interpretar incorretamente a semântica da superclasse, embora isto não seja feito nesta tese;

- $\beta_{i} \cap \beta_{j}=\{\}$ para $i \neq j, 0 \leq i, j \leq q$. Um pedaço de código não pode interpretar a classe $\mathrm{B}$ de mais de uma maneira;

- uma subclasse $\mathrm{C}$ de $\mathrm{B}$ pode ter sua própria visão de classe, mas a divisão do programa em regiões deve ser feita quebrando-se cada região $\beta_{i}$ de $\mathrm{B}$ em um ou mais pedaços que serão as regiões para $C$.

Formalmente, sejam $\gamma_{0}, \gamma_{1}, \ldots \gamma_{k}$ as regiões para C. Então, para cada $\gamma_{i}$, $0 \leq i \leq k$, existe $0 \leq j \leq q$ tal que $\gamma_{i} \subseteq \beta_{j}$ e para cada $\beta_{j}, 1 \leq j \leq q, \beta_{j}=$ $\left\{\gamma_{j_{1}}, \gamma_{j_{2}}, \ldots \gamma_{i_{m}}\right\}, 0 \leq j_{n} \leq k, 1 \leq n \leq m$.

Para uma representação gráfica desta regra, veja Figura 2.24. 
Quando um programador constrói um filtro para uma classe, ele deve definir todos os métodos definidos nos filtros para as superclasses desta classe. A razão disto é que, se uma superclasse foi interpretada incorretamente, assim o foram suas subclasses.

A linguagem permite enviar uma mensagem para o valor de retorno de um procedimento/método, como em a.m().n(1). Neste caso, podemos estar interpretando o método $\mathrm{n}$ usando uma semântica incorreta, sem nenhuma atribuição. Para impedir este erro, o compilador criará uma variável temporária para armazenar qualquer valor intermediário, de tal forma que uma mensagem será sempre enviada através de uma variável:

$$
\begin{aligned}
& \operatorname{tmp}:=a \cdot m() ; \\
& \text { tmp.n(1); }
\end{aligned}
$$

\subsection{Solução dos Problemas}

Tendo definido visão de classe completamente, usá-la-emos para resolver os problemas apresentados no começo deste capítulo. O primeiro problema é a interpretação incorreta da semântica de duas classes, StringR e StringE. Portanto, visão de classe deve ser usada duas vezes.

Admita que estas classes são usadas pelo programa mostrado na Figura 2.25. Os procedimentos $\mathrm{P}$ e main assumem que o tipo type (StringE) usa a semântica da classe StringE para a sinalização de erros, enquanto que a classe A assume a semântica da classe StringR para isto.

Devem ser criados filtros para converter objetos da classe StringR para objetos que usam a semântica da classe StringE e vice-versa. Isto é feito na Figura 2.26. Quando o programa for compilado, o compilador transformará algumas atribuições em chamadas para PutFilters que testarão se os objetos estão sendo interpretados incorretamente em tempo de execução. O programa com o código inserido pelo compilador é mostrado na Figura 2.27.

Uma análise cuidadosa pode diminuir o número de chamadas a PutFilters no programa. Por exemplo, uma atribuição $a:=b$, onde ambas as variáveis pertencem a uma mesma região, não precisa ser modificada. É somente necessário fazer a referir-se ao objeto ou objeto filtro a que b se refere. Há outras situações similares a esta que não serão analisadas aqui, mas que poderão ser assunto de pesquisas futuras.

Um compilador otimizado não inseriria chamadas a PutFilters para a atribuição 3 do procedimento main mostrado na Figura 2.27. Ambos os procedimentos main e P possuem a mesma interpretação das classes string e o parâmetro real para $P$, que é $s$, já foi corretamente inicializado algum tempo antes. $O$ compilador apenas inseriria código para fazer o parâmetro formal de P, ps, referir-se a qualquer coisa a que s se refere (objeto filtro ou objeto), o que é uma atribuição normal.

O segundo problema apresentado no começo deste capítulo é relacionado à interpretação incorreta da unidade de medida usada por objetos da classe Box. 


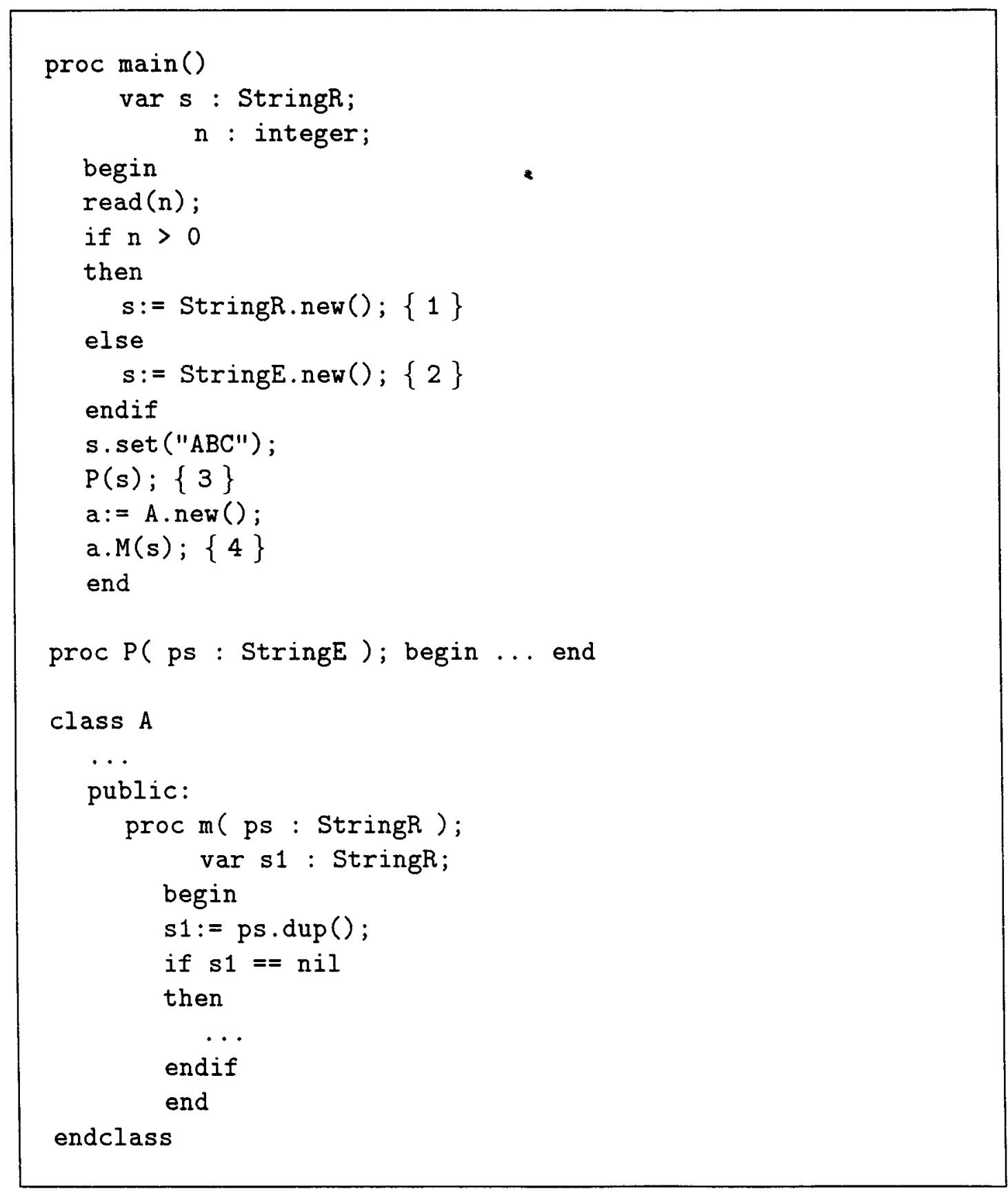

Figura 2.25: Programa que usa as classes StringE e StringR 


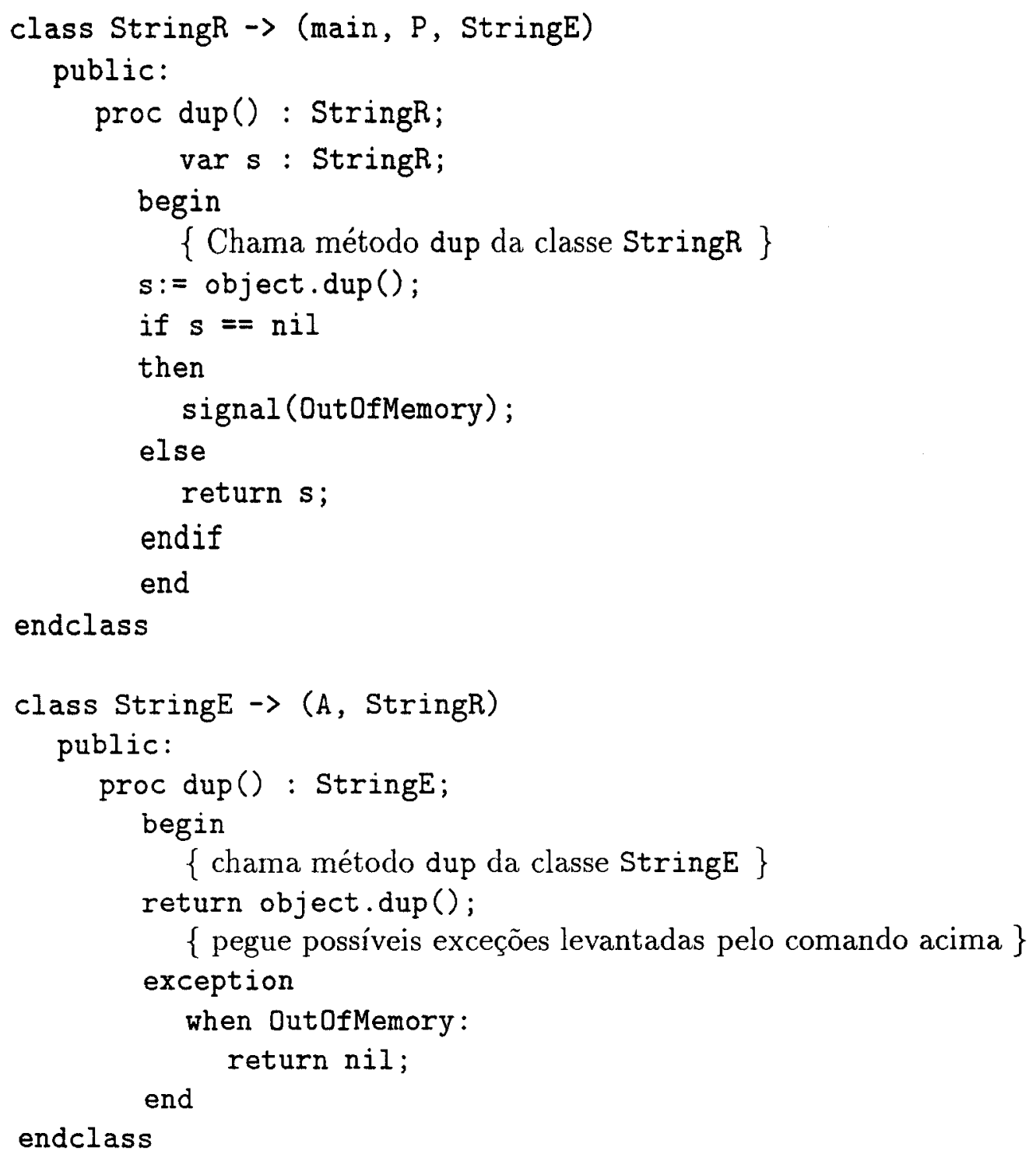

Figura 2.26: Classes filtro para classes StringR e StringE 


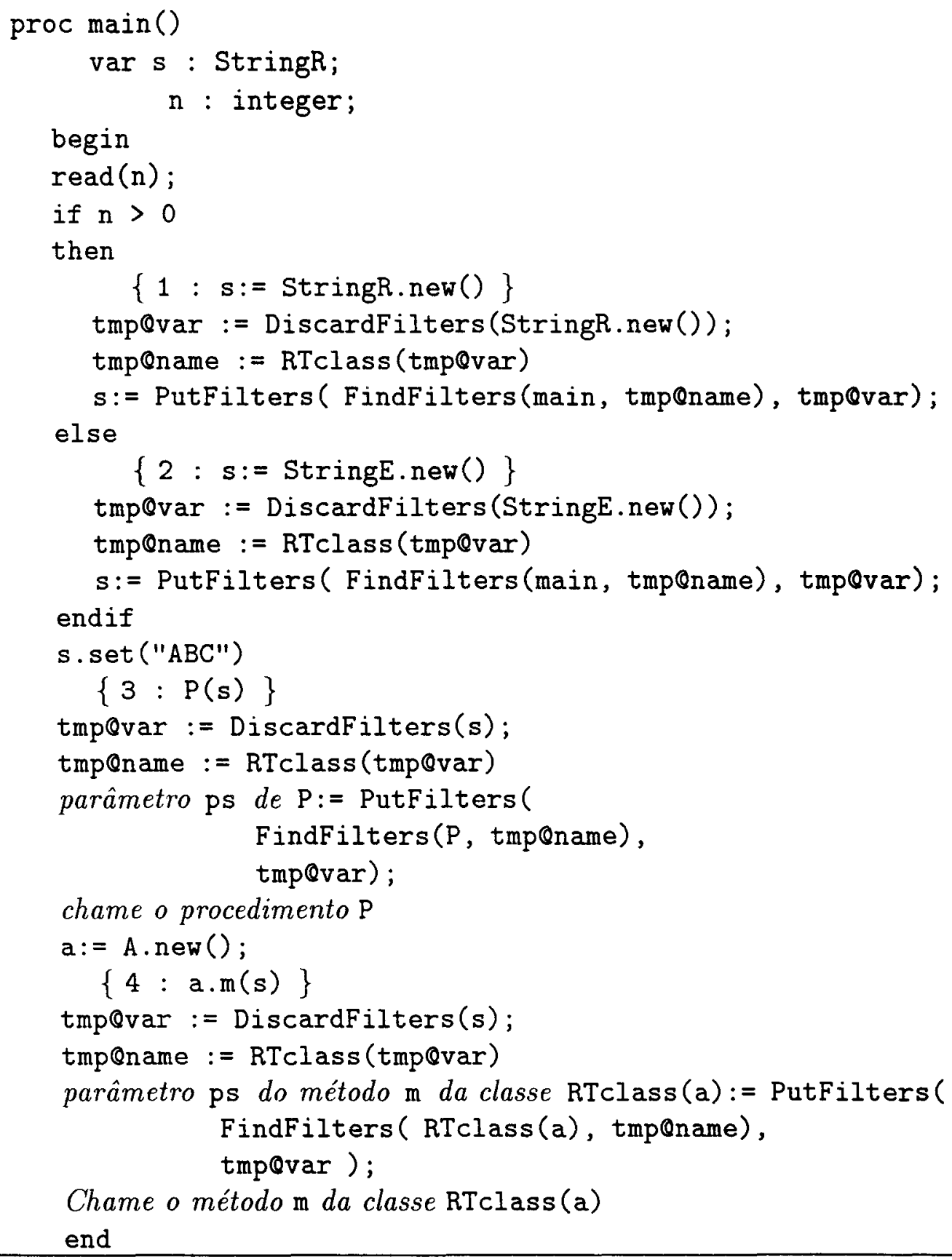

Figura 2.27: Programa com testes inseridos pelo compilador 


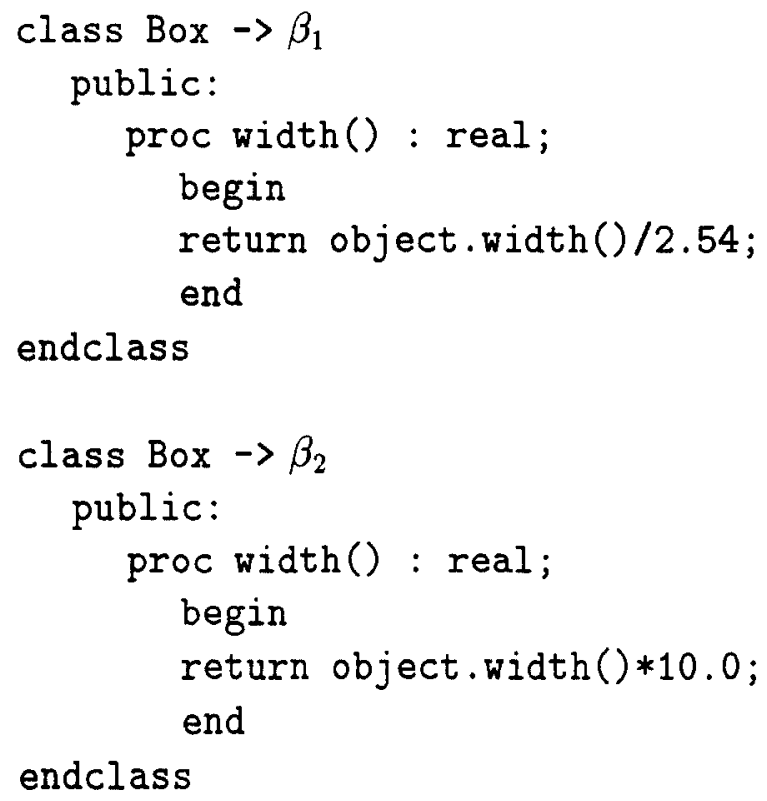

Figura 2.28: Filtros para a classe Box

Sejam $\alpha, \beta_{1}, \beta_{2}$ os conjuntos das classes que assumem que Box usa centímetros, polegadas e milimetros, respectivamente. Então precisamos de filtros para converter objetos Box para a semântica de polegadas e milímetros, respectivamente. Estes são apresentados na Figura 2.28.

\subsection{Implementação}

Uma implementação simples de visão de classes usaria a representação de objetos e o algoritmo de busca por método definidos no Apêndice A. Um objeto da classe B que herda da classe A é representado como um subobjeto que possui todas as variáveis de instância/métodos definidos na classe B mais um objeto da classe A. A busca por método é feita procurando-se o método em cada um dos subobjetos que compõem o objeto.

Esta representação torna a implementação de visão de classe fácil. Quando um filtro da classe Box $\rightarrow \beta$ deve ser inserido entre uma variável $\mathrm{x}$ e um objeto $\mathcal{Q}$, o sistema de tempo de execução criará um objeto de Box $\rightarrow \beta$ (o objeto filtro) e fará a sua variável de instância "super (Box)" referir-se a $\mathcal{Q}$. Então o objeto filtro será atribuído a $\mathrm{x}$. Todos os envios de mensagens para "object" dentro de Box $\rightarrow \beta$ serão transformados em envio de mensagens para "super(Box)". Embora simples, esta implementação é ineficiente. A implementação de shell dinâmico, definida no capítulo 5, une em um único objeto o filtro e o objeto ao qual ele é associado. Isto não pode ser feito com visão de classe porque pode haver uma variável que se refere a um objeto através de um filtro e outra que se refere ao objeto diretamente. Assim, o compilador deve permitir estes dois casos. É necessário um estudo mais profundo para obter uma maneira eficiente 
de implementar visão de classe.

\subsection{Trabalhos Relacionados}

Não encontramos nada na literatura que desempenhe o mesmo papel que visão de classe. Contudo, há algumas propostas que são de algum modo relacionadas a ela.

Xavier Pintado [24] define gluons, que são objetos usados para mediar a cooperação entre componentes de software. Um objeto gluon faz a comunicação entre dois outros objetos ${ }^{8}$ que podem ser acoplados dinamicamente ao gluon. No caso mais simples, um dos objetos acoplado ao gluon envia uma mensagem a este, que redireciona a mensagem para o outro objeto, possivelmente fazendo conversão de parâmetros e/ou do nome da mensagem. Então, um gluon pode converter os dados obtidos de um objeto no formato esperado pelo outro objeto, corrigindo incompatibilidades semânticas entre os objetos. Conclui-se que gluons podem desempenhar um papel semelhante a visão de classe. A diferença em relação à nossa proposta é que a cooperação através de gluons deve ser planejada. Esta técnica não permite alterar a funcionalidade de código já existente, como visão de classe.

Shilling e Sweeney [25] propuseram views, um conceito de linguagem que permite a manipulação de um objeto por diferentes interfaces em diferentes partes do programa. Uma interface pode possuir variáveis de instância privadas não compartilhadas com outras interfaces. De acordo com os autores, views reduz a complexidade do sistema porque os programadores podem lidar com uma interface restrita de cada objeto. Visão de classe não altera as interfaces dos objetos, mas permite que diferentes partes do programa manipulem as variáveis de instância de um objeto através de diferentes métodos.

Visão de classe de algum modo relaciona-se com refactorings [26] [27]. Esta técnica pode mudar o código de um programa sem alterar sua funcionalidade. Refactorings podem mudar nomes de variáveis/métodos, mover métodos para superclasses/subclasses [28], adicionar classes no meio da hierarquia, transformar herança em agregação ${ }^{9}$ e assim por diante. Eles são o tipo de tranformação que usualmente um programador faz usando um editor de texto. Contudo, as modificações feitas por refactorings não introduzem erros no programa nem modificam sua funcionalidade.

Um tipo de refactoring que não preserva a funcionalidade do programa poderia ser usado para simular algumas das características de visão de classe. Se uma classe $\mathrm{B}$ fosse interpretada incorretamente em uma região $\beta$, o refactoring criaria uma classe $B^{\prime}$ com a semântica correta e trocaria todas as referências a $B$ em $\beta$ por $\mathrm{B}^{\prime}$. Então o código de $\beta$ criaria objetos de $\mathrm{B}^{\prime}$, que seriam usados com a semântica correta. Contudo, uma simulação completa de visão de classe não é possível porque esta construção toma algumas decisões em tempo de execução que não podem ser tomadas por uma ferramenta de refactoring, que é executada

\footnotetext{
${ }^{8}$ Este é o caso mais simples. Há outros mais complexos.

${ }^{9}$ Agregação é o relacionamento entre uma classe e suas variáveis de instância.
} 
antes da compilação do programa. Neste exemplo, a região $\beta$ não manipularia corretamente os objetos da classe B que são referenciados em $\beta$ em tempo de execução. 


\section{Capítulo 3}

\section{Adaptadores}

\subsection{Introdução}

Suponha que um método requeira um parâmetro do tipo $T$ e alguém queira passar como um parâmetro real um objeto do tipo $U$. O tipo $U$ apresenta a mesma funcionalidade que $T$, mas não é um subtipo deste. Os métodos de $T$ e $U$ com funções semelhantes possuem diferentes nomes e/ou tipos de parâmetros. Para se usar um objeto do tipo $U$ como parâmetro onde se espera um objeto de $T$, deve ser projetado um código que converta este objeto para um outro do tipo $T$, como é descrito na próxima seção. Este código é definido pelo programador e deve ser explicitamente chamado na passagem de parâmetros. Adaptadores permitem a conversão de um objeto de um tipo para outro automaticamente, sem nenhuma chamada explícita a um procedimento de conversão. Adaptadores são especificados pelo programador através de uma classe adaptadora; além disto, objetos adaptadores são adicionados e removidos automaticamente pelo sistema de tempo de execução.

\subsection{Alguns Exemplos de Problemas}

Suponha a existência de classes Person e Pessoa que sejam funcionalmente compatíveis, mas incompatíveis quanto a tipos. O método de Pessoa com a mesma função do método print de Person chama-se imprime. Se alguém queira usar um objeto de Pessoa quando um objeto Person seja requerido, deve-se usar um filtro.

Por exemplo, suponha que se pretenda passar um objeto Pessoa para

proc Report ( $x$ : Person);

begin

$x \cdot \operatorname{print}()$;

end;

Então, deve-se codificar uma classe filtro para converter objetos de Pessoa em objetos de Person, como aquela mostrada na Figura 3.1. ${ }^{1}$ Este filtro deve ser usado como no código abaixo.

\footnotetext{
${ }^{1}$ Para simplificar o exemplo, admita que o único método de Person é print.
} 


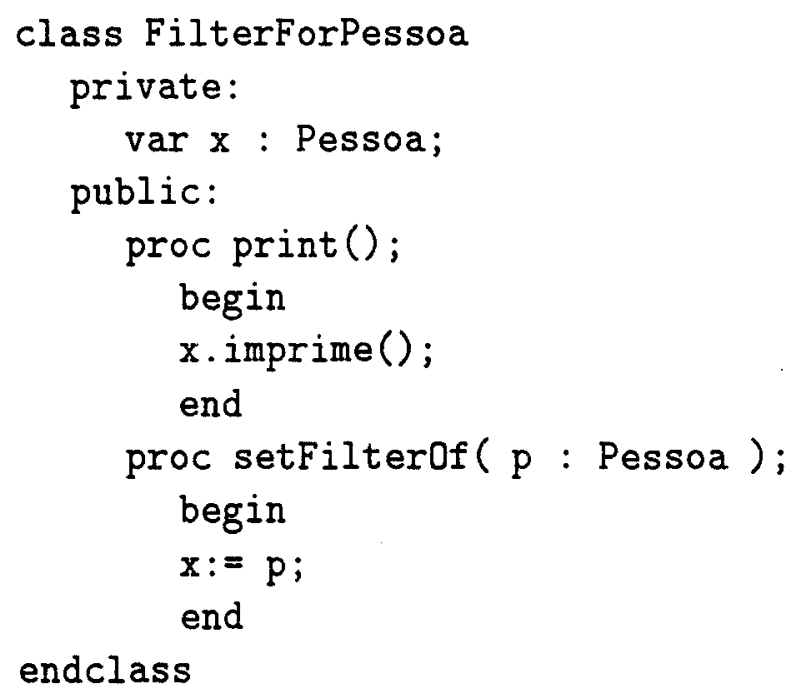

Figura 3.1: Um filtro para transformar objetos Pessoa em objetos Person

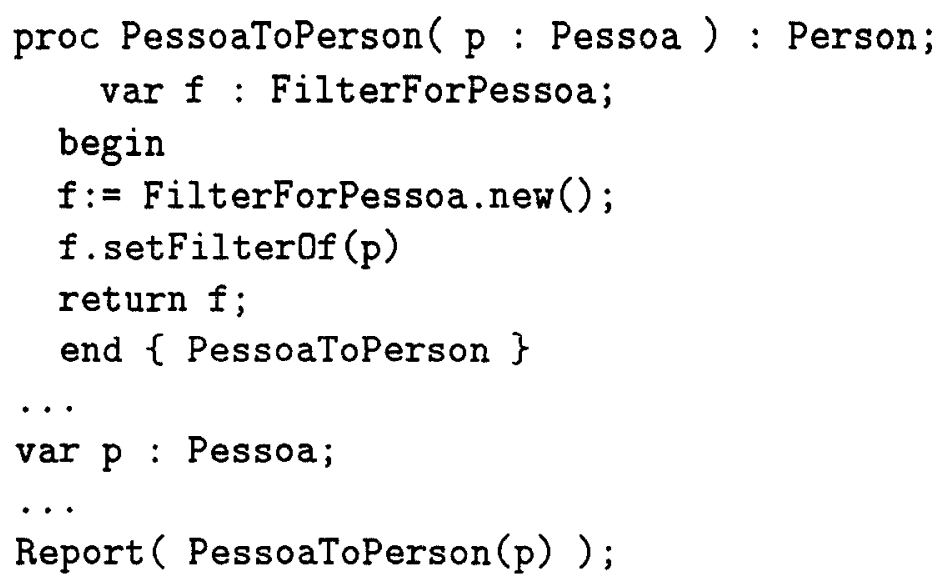

Suponha uma classe Estudante subtipo de Pessoa que defina um método imprime2, além de imprime. Estes dois métodos estão relacionados à classe Estudante, assim como print está relacionado à classe Person. A semântica subjacente é "imprima todos os dados do objeto". Para chamar o procedimento Report com objetos da classe Estudante, deve-se construir um filtro FilterForEstudante cujo método print é:

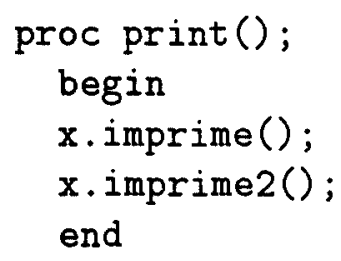

Embora os filtros para Pessoa e Estudante funcionem corretamente quando somente uma destas classes é usada no programa, eles não funcionam quando variáveis de Pessoa referem-se a objetos de Estudante em tempo de execução. Por exemplo, no código

$\operatorname{var} \mathrm{p}:$ Pessoa; 


\section{s : FilterForPessoa;}

begin

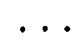

a variável p pode referir-se a objetos de ambas as classes em tempo de execução e, portanto, haverá um erro quando $p$ referir-se a um objeto Estudante ( $i<=0$ ). Neste caso, o método print de Pessoa será mapeado somente no método imprime do objeto Estudante, ao invés de ser mapeado em imprime e imprime2.

De fato, como não se pode prever o fluxo de execução do programa, não se pode afirmar em tempo de compilação qual o tipo de filtro que deveria ser usado em tempo de execução. Então, deveria ser usado o comando caseclass, que permite descobrir a classe de um objeto em tempo de execução e, portanto, permite descobrir o filtro apropriado.

Usando caseclass, o procedimento PessoaToPerson deveria ser modificado da seguinte forma para escolher o filtro correto em tempo de execução:

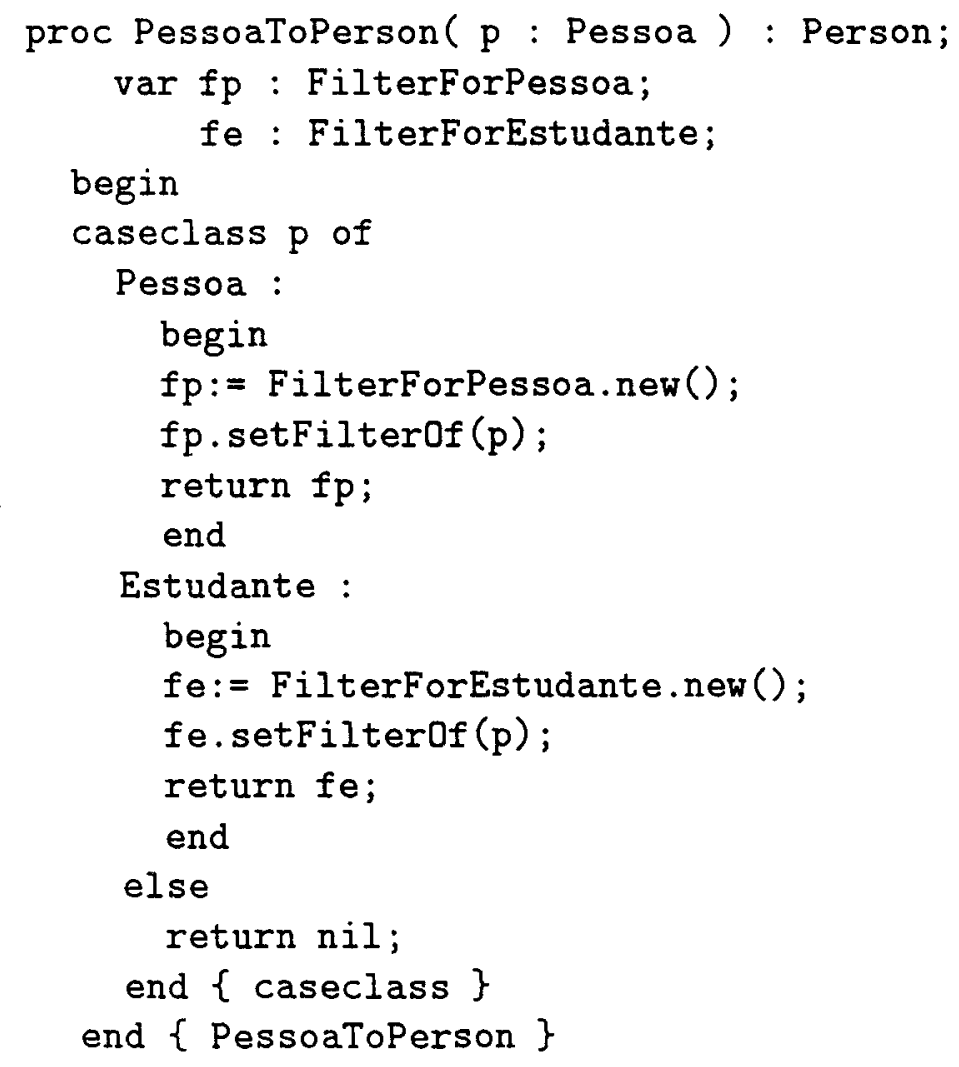


Se o código das classes Pessoa e Estudante estiver disponível e Estudante for subclasse de Pessoa, o programador poderá inserir um método ToPerson na classe Pessoa e redefini-lo em Estudante. Isto funciona se não existir nenhuma outra classe com o mesmo tipo que Pessoa ou Estudante.

A técnica descrita acima funciona razoavelmente bem; contudo, é uma tarefa repetitiva e, portanto, sujeita a erros. Além disto, todos os métodos de Person devem ser definidos na classe filtro (ou adaptadora). Se Person e Pessoa forem funcionalmente compatíveis, provavelmente eles possuem algumas assinaturas de métodos em comum. Seria interessante se não fosse necessário se preocupar com estas assinaturas comuns na definição de um filtro.

Embora estas restrições não sejam muito severas, escolhemos criar um novo tipo de filtro, chamado adaptador, para fazer o mesmo trabalho que os filtros dos parágrafos anteriores. Adaptadores são definidos como construção da linguagem, embora possa ser melhor implementá-los como uma ferramenta de software como um pré-processador. $\mathrm{O}$ uso e a definição de adaptadores permanecem inalterados se eles forem incorporados na linguagem ou implementados por uma ferramenta de software.

Adaptadores são definidos como uma construção de linguagem, ao invés de uma técnica de programação, porque:

- eles são coerentes com a "filosofia filtro". A experiência tem mostrado que programadores usam uma facilidade quando a linguagem ou ambiente de programação fornecer esta facilidade, mesmo quando seria melhor usar uma outra ferramenta. Este é o motivo mais forte para que a linguagem suporte adaptadores. Pelo fato de adaptadores serem apenas mais um tipo de filtro, eles são fáceis de entender e se integram perfeitamente ao resto da linguagem. Isto é válido mesmo se adaptadores forem implementados como um pré-processador, porque este seria fornecido com o compilador;

- a construção de adaptadores pelo programador é um problema real na prática. Uma técnica para facilitar a sua construção é descrita por Gamma et al [5];

- Hölzel [29] propôs alguns melhoramentos para adaptadores, tais como

- criar apenas um filtro para cada objeto. Na descrição desta tese, se um mesmo objeto precisar de dois filtros para convertê-lo para um outro tipo durante a execução do programa, deverão ser criados dois filtros adaptadores. Hölzel propôs criar apenas o primeiro e reusá-lo nas situações seguintes;

- permitir que as comparações de igualdade entre dois filtros sejam a comparação entre os objetos referenciados pelos filtros.

Estes melhoramentos podem ser acrescentados a adaptadores em um trabalho futuro. Neste caso, todo o código existente se beneficiaria deles, sem necessidade de modificações; 


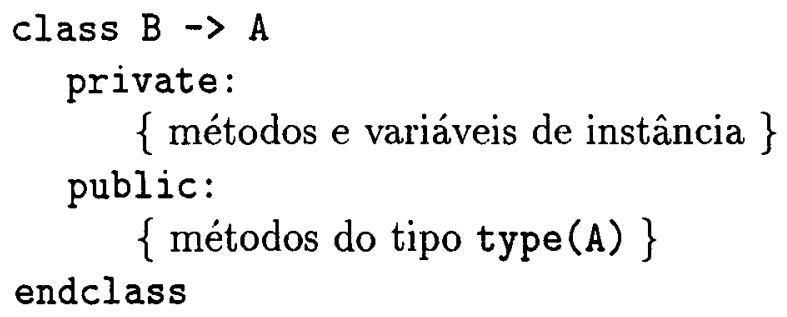

Figura 3.2: Um adaptador para converter objetos do tipo B para objetos do tipo A

- adaptadores não são muito difíceis de implementar e apresentam certas características, descritas nas próximas seções, que são difíceis de simular com programação.

\subsection{O Esboço de uma Solução}

Veremos agora uma descrição informal de adaptadores. Suponha que exista um método ou procedimento

$$
\operatorname{proc} P(\mathbf{x}: A) \text {; }
$$

e que queiramos passar como parâmetro a ele um objeto do tipo type(B) tal que type (B) não seja um subtipo de type (A). Podemos construir a classe adaptadora mostrada na Figura 3.2 na qual:

- há uma variável de instância implícita do tipo type(B), que pode ser referenciada nos métodos do adaptador com a palavra chave object, como em todas as construções filtro;

- o programador consegue declarar outras variáveis de instância na classe adaptadora. A classe adaptadora será denominada "classe filtro", sendo representada como $B \rightarrow A$;

- o tipo de $B \rightarrow A$ é igual a type(A), embora não seja necessário redefinir em $B \rightarrow A$ os métodos que possuem as mesmas assinaturas em A e B. Quando uma mensagem for enviada ao objeto filtro, mas sem que ele possua $o$ método correspondente, a mensagem será redirecionada ao objeto referenciado pelo objeto filtro.

Após a construção do filtro $B \rightarrow A$, o programador poderá utilizar objetos do tipo type (B) sempre que for esperado um objeto do tipo type(A). Neste caso, o compilador percebe que type(B) não é um subtipo de type(A) e insere o código para criar, em tempo de execução, um objeto filtro. $O$ objeto filtro referir-se-á ao objeto do tipo type(B). Portanto, não haverá um erro de tipos. Se existir um adaptador $\mathrm{A} \rightarrow \mathrm{B}$, o contrário será também verdadeiro e poderemos usar um procedimento 
Algoritmo CreateNewAdapter(B, A, IVs, Ms)

$\{$ Este algoritmo cria uma classe normal $B Q A$ cujo corpo é essencialmente aquele da classe adaptadora $B \rightarrow A$. O corpo de $B \rightarrow A$ é copiado para $B Q A$ e os métodos retornados por FillClass ( $B \rightarrow A$ ) são adicionados a esta classe.

A classe $B Q A$ é, então, retornada por este algoritmo \}

\{ adicione a variável de instância object $\}$

IVs' $\mathbf{s}^{\prime}$ IVs $\cup\{($ object, $B)\}$

$M s^{\prime}=$ Ms $\cup$ FillClass $(B, A, M s)$

return $\left(B \otimes A,\{\}, I V s^{\prime}, M s^{\prime},\{\},\{\}\right)$

Figura 3.3: Algoritmo para criar uma classe normal a partir de uma classe adaptadora

$\operatorname{proc} \mathrm{P}(\mathrm{x}: \mathrm{A}): \mathrm{A}$;

em uma expressão como

$\mathrm{b}:=\mathrm{P}(\mathrm{b})$;

onde o tipo declarado de $\mathrm{b}$ é B. Quando $\mathrm{b}$ for passado como um parâmetro, o sistema de tempo de execução usará o filtro B $\rightarrow$ A. Por "usará", queremos dizer que o sistema de tempo de execução criará um objeto filtro da classe $B \rightarrow A$, fazendo-o referir-se a b. Então uma referência para o objeto filtro é passada ao procedimento. Diremos também, neste caso, que um filtro é colocado no objeto.

Quando o objeto retornado por $\mathrm{P}$ for atribuído $\mathrm{a} \mathrm{b}$, será usado o filtro $\mathrm{A} \rightarrow$ $B$. Veremos que, se o objeto retornado por $P$ for um objeto filtro que se refere a um objeto do tipo type (B), então a classe filtro A $\rightarrow$ B não será usada. Ao invés disto, o sistema de tempo de execução remove o objeto filtro, resultando em um objeto do tipo B e, portanto, a atribuiçâo torna-se correta quanto a tipos.

\subsection{A Definição de Adaptadores}

\subsubsection{A Análise da Classe Adaptadora}

Uma classe adaptadora, como mostrado na Figura 3.2, será representada como (NomeFonte, NomeDestino, VariaveisDeInstancia, Metodos)

onde VariaveisDeInstancia e Metodos possuem o mesmo significado que na representação de uma classe normal - veja Seção A.2. Este adaptador converte objetos do tipo NomeFonte em objetos do tipo NomeDestino. Na Figura 3.2, NomeFonte $=\mathrm{B}$ e NomeDestino $=\mathrm{A}$.

Quando o compilador encontrar um adaptador (B, A, IVs, Ms), ele

- chamará o algoritmo CreateNewAdapter da Figura 3.3, que retornará uma classe

$$
\left(\mathrm{BQA},\{\}, \mathrm{IVs}^{\prime}, \mathrm{Ms}^{\prime},\{\},\{\}\right)
$$




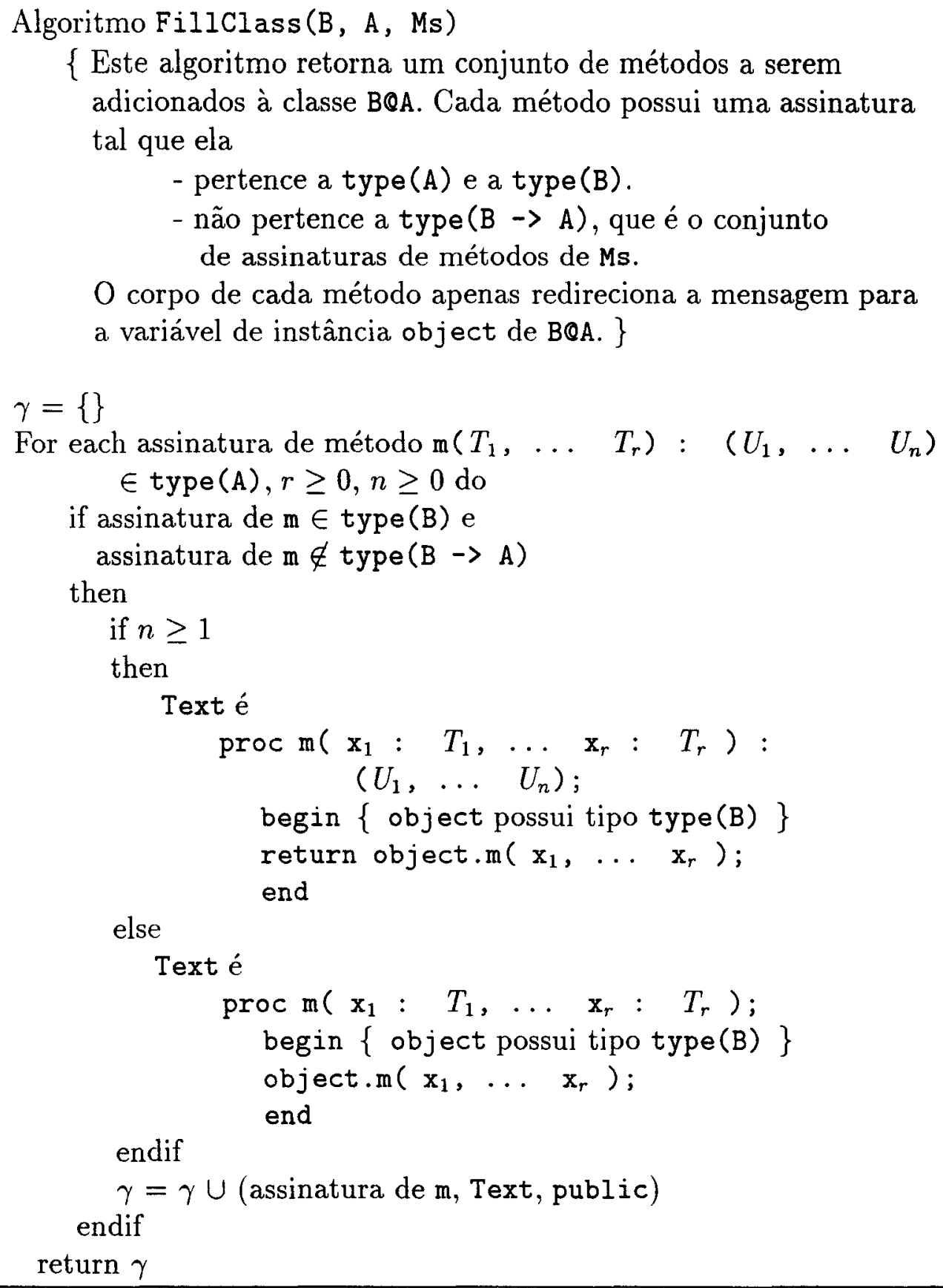

Figura 3.4: Algoritmo para encontrar métodos a serem adicionados a uma classe adaptadora 
Este algoritmo usa o algoritmo FillClass da Figura 3.4;

- compilará BQA, que é uma classe normal. A classe BQA será considerada correta se não ocorrerem erros em sua compilação e type $(B Q A)=$ type $(A)$.

O nome BQA é permitido pelo compilador, mas não pela linguagem, pois $\bullet$ não é um caracter válido para identificadores. Assuma que este nome identifique precisamente as classes A e B.

A próxima seqüência de proposições prova que qualquer erro na compilação de $B @ A$ não foi introduzido por CreateNewAdapter. Se houver um erro, este estará na classe $B->A$, codificada pelo programador.

Proposição 3.1 Seja type( (B $\rightarrow$ A)) o conjunto de assinaturas de métodos retornado por uma chamada a FillClass(B, A, Ms) no algoritmo CreateNewAdapter. Então, type $(\sim(B \rightarrow A))=(\operatorname{type}(B) \cap \operatorname{type}(A))$ $-\operatorname{type}(B \rightarrow A)$.

Prova: $O$ algoritmo FillClass percorre todos os métodos $m \in$ type(A) e adiciona um novo método $\mathrm{m}^{\prime}$ ao conjunto $\gamma$ se $\mathrm{m} \in$ type $(B)$ e $m \notin$ type $(B->A)$. Como $\mathrm{m}^{\prime}$ possui a mesma assinatura que $\mathrm{m}$, o conjunto de assinaturas de métodos retornados por este algoritmos é:

que é:

$$
\{m \mid m \in \operatorname{type}(A), m \in \operatorname{type}(B), m \notin \operatorname{type}(B \rightarrow A)\}
$$

$$
\{m \mid \operatorname{type}(A) \cap \operatorname{type}(B), m \notin \operatorname{type}(B \rightarrow A)\}
$$

que resulta em

$$
\begin{gathered}
\operatorname{type}(\sim(B \rightarrow A))=\{\mathfrak{m} \mid \mathfrak{m} \in \operatorname{type}(A) \cap \operatorname{type}(B)-\operatorname{type}(B \rightarrow A)\} \\
=\operatorname{type}(A) \cap \operatorname{type}(B)-\operatorname{type}(B \rightarrow A)
\end{gathered}
$$

o que prova a Proposição.

Proposição 3.2 Eventuais erros de compilação em métodos de BQA encontramse em métodos oriundos de $\mathrm{B}->\mathrm{A}$, que foram codificados pelo programador.

Prova: Não há erros nos métodos criados por FillClass ( $B->A)$ porque:

1. há somente uma instrução em cada método

$$
\mathrm{m}\left(T_{1}, T_{2}, \ldots T_{r}\right):\left(U_{1}, \ldots U_{n}\right)
$$

criado por este algoritmo e esta instrução é o envio de mensagem

$$
\text { object.m }\left(\mathbf{x}_{1}, \ldots \mathrm{x}_{r}\right)
$$

onde type $\left(\mathbf{x}_{i}\right)=T_{i}, 1 \leq i \leq r$;

2. este envio de mensagem é correto porque object possui tipo type(B) (por definição de CreateNewAdapter) e este tipo possui uma assinatura de método igual à assinatura de $m$ descrita no item 1 anterior (porque $m \in$ type(B)).

Então, este envio de mensagem é correto porque object possui um método m e os parâmetros reais $\mathrm{x}_{i}, 1 \leq i \leq r$ possuem tipos iguais aos parâmetros formais correspondentes de $\mathrm{m}$; 


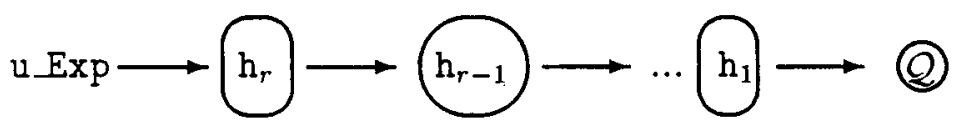

Figura 3.5: Objeto $\mathcal{Q}$ coberto por filtros $\mathrm{h}_{1} \ldots \mathrm{h}_{r}$, que é chamado $\mathcal{P}$

3. os valores de retorno de m não existem $(n=0)$ ou são valores dos tipos $U_{1}$, $U_{2}, \ldots U_{n}, n \geq 1$. Se $n=0$, o envio de mensagem será considerado uma instrução normal ao invés de uma expressão e, portanto, não haverá erro. Se $n \geq 1$, uma mensagem será enviada e o resultado será retornado pelo método. Não haverá erros de tipo porque os tipos dos valores retornados (tipos dos valores de retorno do método $m$ do tipo type(B)) sâo os mesmos tipos esperados pelo método m criado por Fillclass.

Os itens acima provam a Proposição.

Proposição 3.3 Não há colisão de métodos em CreateNewAdapter entre os métodos de $\mathrm{B}->\mathrm{A}$ e aqueles retornados por $\mathrm{FillClass.}$

Prova: CreateNewAdapter faz a união dos métodos de $B->A$ e aqueles retornados por FillClass. Haveria uma colisão de métodos se um método de $B->A$ também pertencesse ao conjunto retornado por FillClass. Entretanto, isto nunca acontece porque, de acordo com a Proposição 3.1, os métodos retornados por FillClass excluem aqueles de type $(B->A)$.

$O$ fato de que $B Q A$ possua uma variável de instância chamada object, do tipo $B$, significa que um objeto filtro da classe $B->A$ refere-se a um objeto do tipo type (B) em tempo de execução. $O$ fato de que os métodos retornados por FillClass redirecionam mensagens para object significa que as mensagens não entendidas pelo objeto filtro são redirecionadas ao objeto referenciado pelo objeto filtro. Exatamente como na descrição de adaptadores do início deste capítulo.

\subsubsection{Quando um Objeto Filtro Deve Ser Adicionado}

Um filtro será colocado em um objeto quando for esperado um objeto de um outro tipo. Isto somente acontece em atribuições e passagem de parâmetros, que também pode ser considerada uma atribuição. Então, estudaremos as instruções do tipo:

$t:=u_{-} \operatorname{Exp}$

onde o tipo declarado de $t$ é $T$ e o de u_Exp é $U$.

u_Exp pode ser uma referência para uma seqüencia de filtros em tempo de execução, pois um filtro pode ser colocado sobre outros objetos filtro. Por enquanto, assuma que u_Exp resulta em tempo de execução na seqüência de objetos 


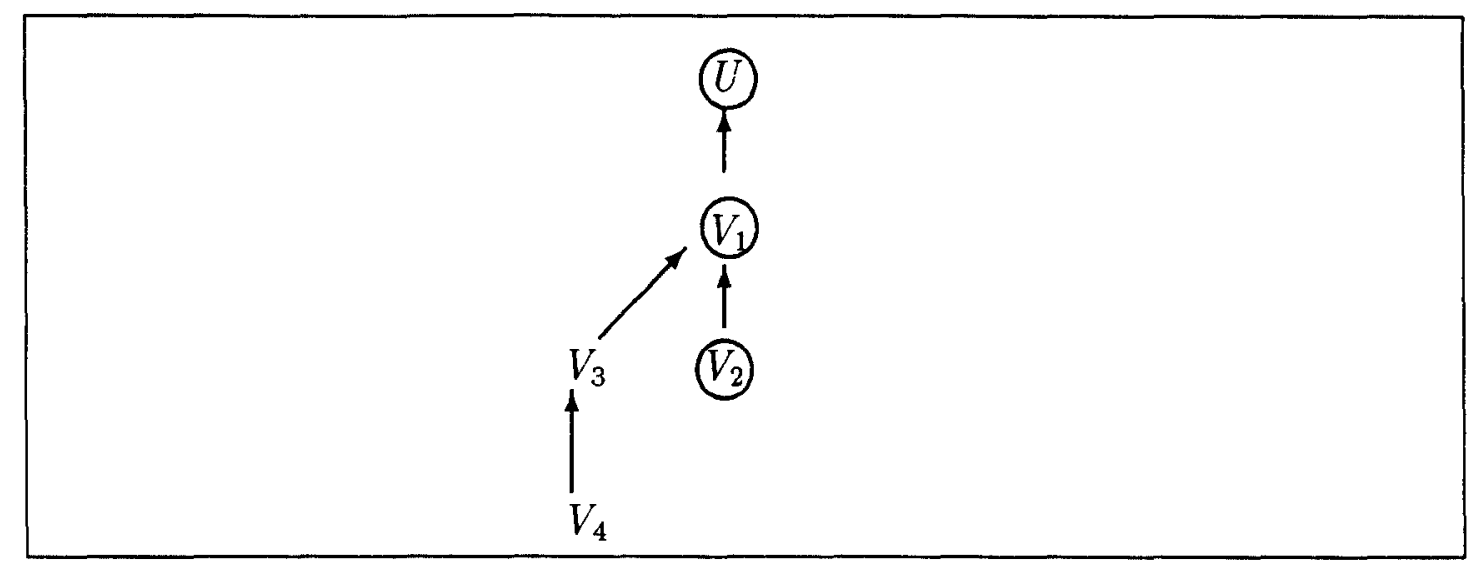

Figura 3.6: Hierarquia de tipos com filtros para converter objetos do tipo $T$

filtro $h_{r}, h_{r-1}, \ldots h_{1}$. Um objeto filtro $h_{i}$ refere-se $a h_{i-1}$, u_Exp refere-se a $h_{r}$ e $h_{1}$ refere-se ao objeto $\mathcal{Q}$ - veja Figura 3.5. A combinação de $\mathcal{Q}$ com os seus objetos filtro será chamada de $\mathcal{P}$.

Em tempo de compilação, é possivel decidir se esta atribuição necessita de um filtro ou não. Se $U \prec T$, não haverá necessidade de filtro, já que a regra Tipo:= Subtipo será obedecida. Se $U \nprec T$, haverá dois casos a serem considerados. No primeiro, não há nenhum adaptador $U \rightarrow T$ e, portanto, esta atribuição será considerada ilegal.

O segundo caso ocorre quando este adaptador existe. Neste caso, o compilador inserirá código para converter tipos nesta atribuição. Este código colocará um filtro sobre $\mathcal{P}$ e/ou removerá alguns objetos filtro em tempo de execução. Os algoritmos usados por este código são descritos nos parágrafos seguintes. Assumimos que $U \nprec \mathrm{T}$.

Seja $S$ o tipo de $\mathcal{P}$ em tempo de execução. Então $S$ é um subtipo de $U$, pois assume-se que o programa seja corretamente tipado considerando a avaliação de u_Exp. Portanto, uma variável, parâmetro ou valor de retorno do tipo $U^{2}$ pode referir-se a um objeto de um subtipo de $U$.

Deve existir um filtro $U \rightarrow T$, pois $U$ não é um subtipo de $T$. Isto é conferido pelo compilador. No caso geral, há outros filtros $W \rightarrow T$ no programa tal que $W$ $\prec U$. Um exemplo desta situação é mostrada no gráfico da Figura 3.6, onde

- vértices representam tipos;

- existe uma flecha de um subtipo para cada um de seus supertipos diretos. Veja definição de "supertipo direto" no Apêndice C;

- haverá um círculo ao redor do tipo $X$ se existir um adaptador $X \rightarrow T$.

Se $S=V_{1}$, o filtro $U \rightarrow T$ poderá ser usado para converter $\mathcal{P}$ para o tipo $U$ (porque objetos de $S$ são também objetos de $U$ ), mas esta não é a ação mais lógica a tomar. Há um filtro mais específico que pode ser usado, $V_{1} \rightarrow T$. O adaptador $V_{1} \rightarrow T$ foi definido precisamente porque $U \rightarrow T$ não era adequado

\footnotetext{
${ }^{2}$ Note que uma expressão que resulta em um objeto ou é uma variável/parâmetro ou um valor de retorno de algum método.
} 
para converter objetos de $V_{1}$ para o tipo $T$. Lembre-se dos exemplos com Pessoa e Estudante da Seção 3.2.

Do mesmo modo, se $S=V_{2}$, o filtro $V_{2} \rightarrow T$ deve ser usado. Se $S=V_{3}$ ou $S=V_{4}$, o filtro $V_{1} \rightarrow T$ será empregado.

De fato, o filtro colocado no objeto $\mathcal{P}$ é encontrado em tempo de execução pelo algoritmo Specific apresentado na Figura 3.7. Este algoritmo encontra um tipo $W, S \prec W \prec U$, tal que $W$ seja o tipo mais próximo de $S$ que possui um filtro para $T$ na hierarquia de tipos. A garantia de que $W$ é o tipo mais próximo que obedece a esta restrição é fornecida no item 3 do algoritmo. Assim, nenhum filtro é mais específico do que $W \rightarrow T$ para converter objetos de $S$ para $T$. Este algoritmo retorna false se houver dois (ou mais) tipos $W_{1}$ e $W_{2}$ tal que filtros para ambos existem, $S \prec W_{1} \prec U, S \prec W_{2} \prec U$ e $W_{1} \nprec W_{2}, W_{2} \nprec W_{1}$. Neste caso, o filtro para $W_{1}$ não é mais específico do que o filtro para $W_{2}$ (e vice-versa). Portanto, nenhum filtro pode ser considerado o "melhor" filtro para objetos de $S$. Este exemplo é mostrado graficamente na Figura 3.8.

Quando tentamos converter um objeto de $S$ para o tipo $T$, devemos usar $W_{1}$ $\rightarrow T$ ou $W_{2} \rightarrow T$ ? Qualquer um destes filtros poderia ser usado com objetos de $S$, mas ambos causariam perda de informação - o modo como $W_{2} \rightarrow T$ trata os métodos comuns a $W$ e $U$ pode ser diferente da forma como $W_{1} \rightarrow T$ os trata. Além disto, $W_{1} \rightarrow T$ não mapeia os métodos de $T$ possuídos por $W_{1}$, mas não por $W_{2}$. Como Specific retorna um filtro $W \rightarrow T$ (ou false) tal que $S \prec W$, este filtro pode ser usado para converter objetos de $S$ para objetos de $T$.

$O$ algoritmo é chamado em tempo de execução para a atribuição $t:=u_{\_} \operatorname{Exp}$ como

Specific $(S, U, T)$

retornando o filtro escolhido ou false, se nenhum filtro ideal existir. Este último caso ocorre na hierarquia da Figura 3.8. Contudo, é garantido que este algoritmo nunca retornará false em tempo de execução. Isto porque ele é executado em tempo de compilação usando todas as possíveis combinações de parâmetros reais. Se ele retornasse false em tempo de execução, ele retornaria false em tempo de compilação. Por isto, a linguagem permanece estaticamente tipada.

O algoritmo ShellTypeSafe da Figura 3.9 executa $\operatorname{Specific}(S, U, T)$ com todos os valores possiveis para os parâmetros reais $S, U$ e $T$ em tempo de execução. Os valores assumidos por $T$ são selecionados dentre um conjunto que contém todos os tipos $X$ tal que existe um adaptador para converter algum tipo (qualquer um) para $X$. O tipo $U$ assume todos os tipos tal que $U \rightarrow T$ seja definido, e $S$ assume todos os subtipos de $U$. Lembre-se de que o algoritmo $\operatorname{Specific}(S, U, T)$ pode ser usado sempre que $U \rightarrow T$ existir e $S$ for um subtipo de $U$.

\subsubsection{Quando Filtros Redundantes são Removidos}

Esta seção expõe um exemplo onde objetos filtro são removidos de $\mathcal{P}$ (seqüência de objetos filtro) em uma situação que exigiria o uso de adaptadores. Assuma que o sistema possua os tipos $U, V$ e $W$ e os adaptadores representados no grafo da Figura 3.10, onde uma flecha de $U$ para $V$ revela que existe um adaptador $U \rightarrow V$. Devido ao ciclo no grafo, os tipos $U, V$ e $W$ podem ser considerados 
Algoritmo Specific $(S, U, T)$

$\{$ Retorne a classe filtro mais específica que pode ser usada para converter objetos do tipo $S$ em objetos do tipo $T$. Se $W \rightarrow T$ for a classe filtro retornada, $W$ deverá ser subtipo de $U$ e supertipo de $S$. $O$ tipo $S$ é um subtipo do tipo $U$ e garante-se a existência da classe filtro $U \rightarrow T$. Este algoritmo retorna false se nenhum filtro for considerado melhor que os outros (ambigüidade). \}

if $S=U$

then return $U \rightarrow T$ else

Seja $G=(V, E)$ um grafo onde:

- V é o conjunto de tipos que são subtipos de $U \mathrm{e}$ supertipos de $S$. Visto que $Y \prec Y$ para qualquer tipo $Y, S$ e $U$ pertencem a V;

- há uma aresta dirigida em $E$ de cada subtipo para cada um dos seus supertipos diretos considerando-se o conjunto V. Veja a definição de "supertipo direto" no Apêndice C. A relação de "supertipo direto" é usada para garantir que o grafo possui um número mínimo de arestas. Os supertipos indiretos de um tipo em particular podem ainda ser atingidos seguindo-se um caminho no grafo.

Então, é escolhido um tipo $W \in \mathrm{V}$ tal que

1. $S \prec W \prec U(W$ pode ser $S)$

2. $W \rightarrow T$ existe

3. Não há subtipo $X$ de $W$ em V tal que $X \rightarrow T$ existe.

Se existir mais de um tipo que obedece às regras acima, retorne false. Caso contrário, retorne $W \rightarrow T$. endif

Figura 3.7: Algoritmo para encontrar o filtro mais específico para $S$ 


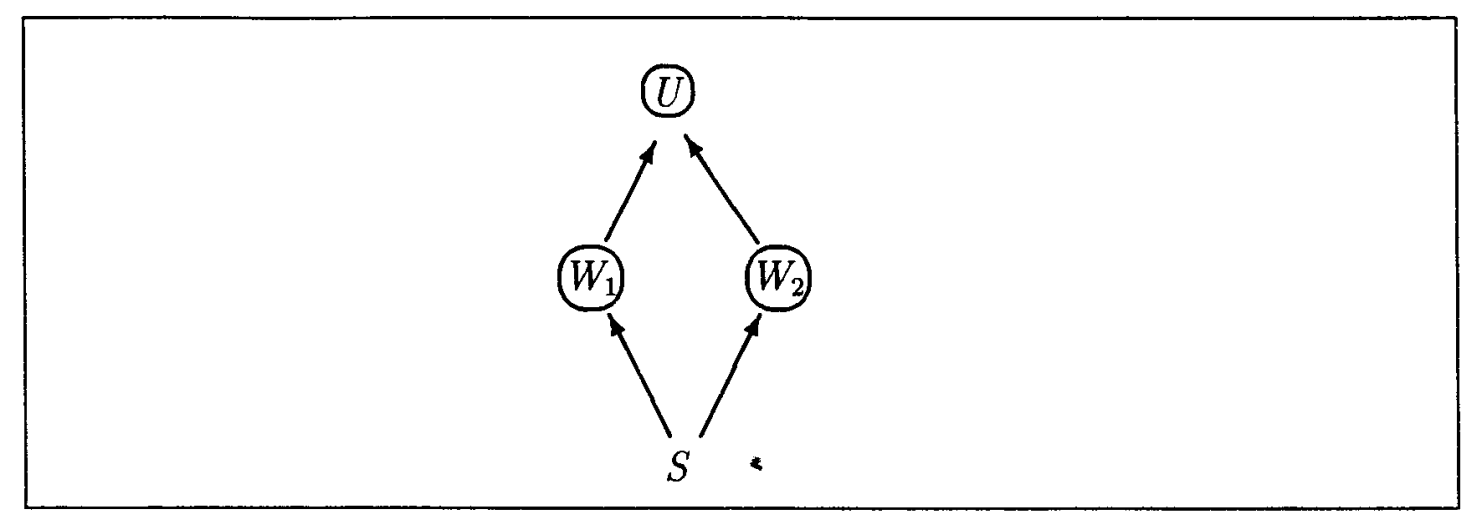

Figura 3.8: Ambiguidade na escolha do filtro para $S$

\section{Algoritmo ShellTypeSafe()}

$\{$ Retorna false se alguma ambigüidade com relação aos adaptadores for possivel em tempo de execução \}

Seja $\gamma=\{X \mid U \rightarrow X$ existe para algum tipo $U$ do programa $\}$ for each tipo $T \in \gamma$, do

for each tipo $U$ tal que $U \rightarrow T$ existe, do

for each subtipo $S$ de $U$, do

if Specific $(S, U, T)=$ false

then

return false

endif

return true

Figura 3.9: Algoritmo ShellTypeSafe

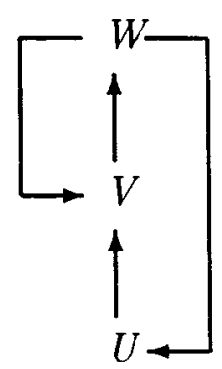

Figura 3.10: Alguns tipos e seus adaptadores 


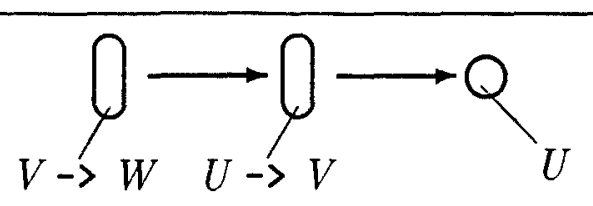

Figura 3.11: Seqüência de objetos filtro para um objeto do tipo $U$

"equivalentes" no sentido de que um objeto de qualquer um destes tipos pode ser convertido para um objeto de qualquer outro tipo neste conjunto.

Se um objeto do tipo $U$ for usado onde um objeto do tipo $V$ era esperado, o filtro $U \rightarrow V$ será colocado sobre o objeto, resultando em um objeto do tipo $V$. Se este objeto, por sua vez, for fornecido onde um objeto do tipo $W$ era esperado, o filtro $V \rightarrow W$ será usado, resultando na configuração mostrada na Figura 3.11, chamada de objeto $\mathcal{P}$, cujo tipo $W$.

$\mathrm{O}$ objeto $\mathcal{P}$ pode ser usado quando:

1. um supertipo de $W$ for esperado. Neste caso, nenhum filtro será necessário e o número de objetos filtro de $\mathcal{P}$ permanecerá constante;

2. um objeto do tipo $V$ for esperado, pois um filtro $W \rightarrow V$ existe. Entretanto, ao invés de usar este filtro, o sistema de tempo de execução removerá o último objeto filtro de $\mathcal{P}$ (cuja classe filtro é $V \rightarrow W$ ), resultando em um objeto do tipo $V$ e reduzindo o número de objetos filtro de um;

3. um objeto do tipo $U$ for esperado, pois um filtro $W \rightarrow U$ existe. Entretanto, ao invés de usar este filtro, o sistema de tempo de execução removerá ambos os objetos filtro de $\mathcal{P}$, resultando em um objeto do tipo $U$. O número de objetos filtro é reduzido de dois.

Pelo exemplo acima, percebe-se que um ciclo no grafo dos adaptadores, como $U \rightarrow V \rightarrow W \rightarrow U$, não permite um crescimento ilimitado no número de objetos filtro de $\mathcal{P}$. Veja os casos 2 e 3 .

Se não houvesse ciclos no grafo dos adaptadores (ex: não houvesse $W \rightarrow V$ e $W \rightarrow U$ ), o número de objetos filtro de $\mathcal{P}$ não poderia ser aumentado, pois há somente uma alternativa para conversão de tipo de objetos do tipo $W$ (como $\mathcal{P}$ ), que seria a conversão por subtipo - veja o caso 1 . Formalizaremos esta ideia usando a atribuição $t:=u_{-}$Exp onde:

- o tipo declarado de t é $T$;

- o tipo declarado de u_Exp é $U, U$ não é um subtipo de $T$ e o adaptador $U$ $\rightarrow T$ existe. Isto significa que um objeto filtro deveria ser usado para esta atribuição;

- O objeto resultante de u_Exp em tempo de execução é uma seqüência de objetos $\mathrm{h}_{r}, \ldots \mathrm{h}_{2}, \mathrm{~h}_{1}, \mathcal{Q}$, onde cada um refere-se ao próximo e $\mathrm{h}_{i}$ é um objeto filtro. Esta seqüência será chamada $\mathcal{P}$. O objeto $\mathcal{Q}$ será representado como $\mathrm{h}_{0}$ a fim de uniformizar o texto para o objeto e seus objetos filtro. 
Seja $h_{i}$ o primeiro elemento da seqüência $h_{0}, h_{1}, \ldots h_{r-1}$ tal que

1. type $\left(h_{i}\right) \prec T$

ou

2. $\exists$ type $\left(h_{i}\right) \rightarrow T$.

é válido.

Se 1 for válido, os objetos filtro $h_{i+1}, \ldots h_{r}$ não serão considerados. $O$ sistema de tempo de execução fará a variável $t$ referir-se ao objeto do tipo $\mathrm{h}_{i}$. Então, a atribuição transformar-se-á em uma atribuição correta do tipo "Tipo:= Subtipo". Portanto, se 1 for válido, nenhum filtro será colocado sobre $\mathcal{P}$. Melhor que isto: alguns objetos filtros não serão usados e poderão ser eliminados pelo coletor de lixo se nenhuma outra variável referir-se a eles.

Se 2 for válido, o sistema de tempo de execução desconsiderará os objetos filtro $h_{i+1}, \ldots h_{r}$ e colocará o filtro type $\left(h_{i}\right) \rightarrow T$ sobre o objeto resultante $h_{0}$, $\mathrm{h}_{1}, \ldots \mathrm{h}_{i}$. A atribuição resultante é do tipo "Tipo:= Tipo", que é correta.

Ambos os casos, 1 e 2, desconsideram alguns objetos filtro de $\mathcal{P}$, fazendo o envio de mensagens mais rápido ${ }^{3}$ e não permitindo um crescimento ilimitado no número de objetos filtro.

Se 1 e 2 forem falsos, então a classe filtro retornada por Specific (type $\left(h_{r}\right)$, $U, T$ ) será colocada em $\mathcal{P}$, capturando a semântica dos adaptadores apresentada previamente.

Note que os itens 1 e 2 não podem ocorrer ao mesmo tempo, pois uma classe filtro type $\left(h_{i}\right) \rightarrow T$ é proibida se type $\left(h_{i}\right) \prec T$.

\subsubsection{Caso Geral}

Esta seção reune todos os algoritmos. Um adaptador é um mecanismo para converter um objeto de um tipo para um outro objeto de outro tipo. Ele é usado somente em atribuições, incluindo passagem de parâmetros para procedimentos e métodos.

Então estudaremos as instruções do tipo $t:=u_{-}$Exp onde o tipo declarado de $t$ é $T$ e o de u_Exp é $U$. O compilador conhece os tipos de $t$ e $u_{-}$Exp porque a linguagem exige que o tipo de cada expressão ou variável seja determinado em tempo de compilação.

Se $U \prec T$, a atribuição já será correta com relação a tipos e será compilada normalmente. Se $U \nprec T$, o compilador testará se o adaptador $U \rightarrow T$ foi definido no arquivo shell. Se ele não foi, haverá um erro de compilação. Se ele foi, a atribuição $t:=u_{-}$Exp será trocada por

$t:=\operatorname{Convert}(T, U, \mathrm{u} \operatorname{Exp})$

e compilada. Convert é o algoritmo da Figura 3.12.

As pré-condições do algoritmo Convert são $U \nprec T$ e a existência do adaptador $U \rightarrow T$, satisfeitas pelos parágrafos acima. Agora provaremos que esta substituição é correta com relação a tipos.

Proposição 3.4 O algoritmo Convert e a atribuiçãot:= Convert ( $T, U$, u_Exp) são corretamente tipados.

\footnotetext{
${ }^{3}$ Isto depende da implementação. Talvez a velocidade de execução não seja modificada.
} 


\section{Algoritmo Convert $(T, U, \mathcal{P})$}

$\{$ Existe uma atribuição $t:=u$ Exp onde o tipo declarado de $t$ é $T$ e o de uExp é $U, U \nprec T$ e o adaptador $U \rightarrow T$ existe. $\mathcal{P}$ é o resultado da avaliação de u.Exp em tempo de execução, e pode ser representado como $h_{r}, \ldots h_{1}, h_{0}(r \geq 0), \mathrm{e} \mathrm{h}_{i}$, $r \leq i \leq 1$, é um objeto filtro; e $h_{0}$ é o objeto original.

Este algoritmo retorna um ponteiro newFilter para um objeto $\mathcal{R}$ tal que type $(\mathcal{R}) \prec T$ e, portanto, newFilter pode ser atribuído a t. $\}$

I Seja $h_{j}$ o primeiro elemento da sequência $h_{0}, h_{1}, \ldots h_{r-1}$ tal que

$$
\text { 1. type }\left(h_{j}\right) \prec T
$$

ou

2. $\exists \operatorname{type}\left(h_{j}\right) \rightarrow T$

if 1 for válido then

II

$$
\text { newFilter }=h_{j}
$$

else

if 2 for válido

then

Seja $W \rightarrow T$ o adaptador type $\left(\mathrm{h}_{j}\right) \rightarrow T$. Então, o compilador criou uma classe WQT.

newFilter $=$ WQT.new ()

$\left\{\right.$ faça-o referir-se $\left.a h_{j}\right\}$

newFilter.object $=h_{j}$

else

IV

\{Crie objeto filtro da classe retornada por Specific

Seja $W \rightarrow T$ o adaptador retornado por Specific (type $\left.\left(\mathrm{h}_{r}\right), U, T\right)$

Então, o compilador criou a classe wQT.

newFilter $=$ WQT. new ()

$\{$ Faça-o referir-se a $\mathcal{P}$ \}

newFilter.object $=h_{r}$

endif

endif

return newFilter

Figura 3.12: Algoritmo que encontra o modo correto de converter $\mathcal{P}$ para o tipo $T$ 
Prova: $\mathrm{O}$ algoritmo Convert sempre retorna um ponteiro newFilter, independentemente de qual ramo do comando if tenha sido executado. Se os comandos da parte then número II forem executados, newFilter receberá $h_{j} \mathrm{e}$, portanto, type (newFilter) $\prec T$.

Se os comandos da parte then número III forem executados, um objeto filtro da classe $W Q T$ será atribuído a newFilter. Como $W \rightarrow T=\operatorname{type}\left(\mathrm{h}_{j}\right)$ $\rightarrow T$, type (newFilter) $\prec T$, por definição. De fato, type (newFilter) $=T$. Esta classe filtro possui uma variável de instância object do tipo type $\left(\mathrm{h}_{j}\right)($ de acordo com o algoritmo CreateNewAdapter), inicializada na próxima atribuição, newFilter. object $=h_{j}$, o que está corretamente tipado.

Se os comandos da parte else número IV forem executados, a newFilter será atribuído um objeto filtro recém-criado da classe filtro $W \rightarrow T$. Esta classe filtro foi retornada por Specific $\left(\operatorname{type}\left(h_{r}\right), U, T\right)$. Portanto, type (newFilter) $=$ $T$, o que significa que type (newFilter) $\prec T$. O algoritmo Specific sempre retorna uma classe filtro em tempo de execução e não false. Isto é garantido por ShellTypeSafe, que executa Specific em tempo de compilação com todas as combinações de parâmetros possíveis em tempo de execução. Se uma das execuções retornar false, ShellTypeSafe sinalizará um erro em tempo de compilação.

Se $W \rightarrow T$ for a classe filtro retornada por Specific $\left(\operatorname{type}\left(h_{r}\right), U, T\right)$ em tempo de execução, então, segundo a definição deste algoritmo, type $\left(h_{r}\right) \prec W \prec U$. Isto é válido qualquer que seja o ramo do comando if do algoritmo Specific executado - veja Figura 3.7. Se a parte then for executada, type $\left(\mathrm{h}_{r}\right)=U, W=U$; portanto, type $\left(\mathrm{h}_{r}\right)=W=U$, o que significa que type $\left(h_{r}\right) \prec W \prec U$. Se a parte else for executada, esta propriedade será verdadeira por definição.

A variável de instância object de newFilter possui o tipo $W$ por definição do algoritmo CreateNewAdapter e para ela é atribuída o objeto $h_{r}$ do tipo type $\left(h_{r}\right)$. Esta atribuição é corretamente tipada porque type $\left(\mathrm{h}_{r}\right) \prec W$, como provado acima.

O objeto retornado por Convert ( $T, U$, u Exp) é newFilter, que é sempre um subtipo de $T$. Então, a atribuição $t:=\operatorname{Convert}(T, U$, u.Exp) é corretamente tipada porque $T$ é o tipo de $t$. Como já provamos que Convert não possui erros de tipos, provamos toda a proposição.

\subsubsection{Restrições nas Definições de Adaptadores}

Algumas definições de adaptadores são consideradas ilegais pelo compilador por causa do relacionamento delas com outros adaptadores e/ou tipos. A seguir, estão as restrições que adaptadores devem obedecer.

Restrição 3.1 Dadas as classes $\mathrm{B} e \mathrm{~A}$ tais que $\mathrm{B} \prec \mathrm{A}$, o conjunto de filtros $\mathrm{B} \rightarrow$ $\mathrm{C}_{1} \rightarrow \mathrm{C}_{2} \rightarrow \ldots \mathrm{C}_{n} \rightarrow \mathrm{A}$ e $\mathrm{A} \rightarrow \mathrm{C}_{1} \rightarrow \ldots \mathrm{C}_{n} \rightarrow \mathrm{B}$ não é válido para qualquer $n \geq 0$. O primeiro filtro seria redundante e ambiguo ${ }^{4}$ porque ele permite que um

\footnotetext{
${ }^{4}$ Ambíguo para o programador, mas não para o algoritmo Specific, que escolheria um único filtro (se necessário), mesmo se esta configuração fosse válida.
} 
objeto do tipo B seja convertido para um objeto do tipo A de uma forma diferente de conversão por subtipo. A segunda seqüência de filtros é ilógica, pois ela afirma que um objeto de um supertipo poderia ser considerado um objeto de um subtipo. Se $n=0$, B $\rightarrow$ A será ilegal. Portanto, nunca haverá ambigüidade entre os itens 1 e 2 no algoritmo Convert.

Restrição 3.2 Usaremos B $\hookrightarrow$ A para significar que existe B $\rightarrow$ A ou B $\prec$ A. Em outras palavras, há um meio de converter objetos do tipo $\mathrm{B}$ em objetos do tipo A. Então é proibido existir um ciclo

$$
\mathrm{C}_{1} \hookrightarrow \mathrm{C}_{2}, \mathrm{C}_{2} \hookrightarrow \mathrm{C}_{3}, \ldots \mathrm{C}_{n-1} \hookrightarrow \mathrm{C}_{n}, \mathrm{C}_{n} \hookrightarrow \mathrm{C}_{1}
$$

se existir $1 \leq i<n$ tal que $\mathrm{C}_{i} \prec \mathrm{C}_{i+1}$ ou $\mathrm{C}_{n} \prec \mathrm{C}_{1}$. Em um ciclo, cada tipo poderia ser convertido para qualquer outro tipo do ciclo. Se isto acontecesse, um supertipo (ex: $\mathrm{C}_{i+1}$ ) poderia ser tratado como se ele fosse um subtipo (e.g. $\mathrm{C}_{i}$ ).

\subsubsection{Limites no Número de Objetos Filtro}

O número de objetos filtro que podem ser colocados em um objeto possui um limite máximo no número de classes adaptadoras definidas no programa. Assim, se o programador definiu cinco classes adaptadoras, nenhum objeto em tempo de execução será embrulhado com mais de cinco objetos adaptadores. De fato, o número máximo de objetos filtro calculados em tempo de compilação pode ser menor que o número de adaptadores.

O limite superior do número de objetos filtro que podem cobrir um objeto em um programa é dado pela Proposição 3.5 abaixo, que usa um grafo cujos vértices são os tipos do sistema e haverá uma aresta $(B, C)$ de $B$ para $C$ se a classe filtro $B$ $\rightarrow C$ existir.

Proposição 3.5 Seja $K$ o número de arestas do maior caminho entre quaisquer dois vértices do grafo. Um caminho é uma seqüência $\left(v_{1}, v_{2}\right),\left(v_{2}, v_{3}\right), \ldots\left(v_{n-1}\right.$, $\left.v_{n}\right)$ tal que $v_{i} \neq v_{j}$ para $i \neq j, 1 \leq i, j \leq n$. Então, o número máximo de objetos filtro que podem ser colocados em qualquer objeto do sistema é menor ou igual a $K$.

Prova: Suponha que objetos filtro das classes filtro $\left(A_{1}, A_{2}\right), \ldots\left(A_{K}, A_{K+1}\right)$ foram colocados sobre um objeto $\mathcal{Q}$, nesta ordem, resultando em um objeto $\mathcal{P}$. $K$ é o tamanho de um dos maiores caminhos no grafo (pode haver mais de um caminho com tamanho $K$, mas nenhum com tamanho $>K$ ). Se o algoritmo Convert tentou colocar um filtro a mais $\left(A_{K+1}, B\right)$ em $\mathcal{P}$, uma de duas coisas aconteceu:

1. $B=A_{i}, 1 \leq i \leq K$. Há um ciclo no grafo e neste caso os objetos filtro das classes filtro $\left(A_{i}, A_{i+1}\right),\left(A_{i+1}, A_{i+2}\right), \ldots\left(A_{K}, A_{K+1}\right)$ são descartados, resultando em um objeto cujo objeto filtro mais externo já possui o tipo B. Nenhum objeto filtro é colocado sobre o objeto. Então, o número de objetos filtro se mantem $\leq K$. Uma configuração deste tipo é mostrada na Figura 3.13, onde há um ciclo $A_{3}, A_{4}, A_{5}, A_{6}$ e tipos $A_{1}$ e $A_{2}$ estão fora dele;

2. existe um caminho entre $A_{1}$ e B cujo tamanho é $K+1$, o que é contra a hipótese. 


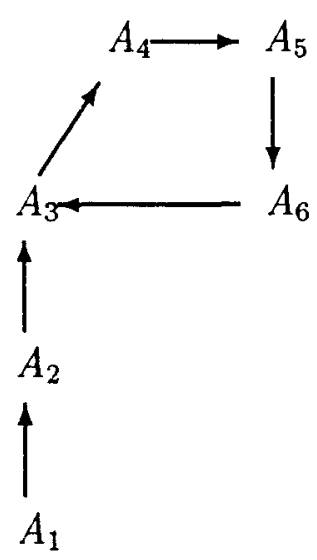

Figura 3.13: Um ciclo de tipos equivalentes

Na prática, o número máximo de objetos filtro pode ser um número $L, L<K$, por duas razões: primeiro, isto pode acontecer devido ao uso da conversão por subtipo, ao invés da conversão por adaptadores. Lembre-se de que, se um objeto deve ser convertido para um tipo que é subtipo do tipo de algum de seus objetos filtro, nenhum filtro é necessário. Veja item 1 da página 61 .

Segundo, alguns caminhos de execução do programa nunca serão executados, não importando a entrada do programa. Estes caminhos não podem ser descobertos em tempo de compilação. É possível que estes caminhos "proibidos" sejam exatamente aqueles caminhos que colocariam $K$ filtros nos objetos do sistema. Então, se eles não ocorrerem, o número máximo de objetos filtro sobre qualquer objeto em tempo de execução será menor do que $K$.

\subsection{Solução dos Problemas}

Agora os problemas apresentados no início deste capítulo podem ser resolvidos. É necessário um filtro para converter objetos Pessoa para objetos Person e outro para fazer o mesmo com objetos de Estudante. Estes dois filtros são apresentados na Figura 3.14.

Os nomes de classes usados na declaração de adaptadores significam, na prática, "tipos". Nomes de classes são usados, ao invés de nomes de tipos, porque a linguagem não possui nenhuma construção para definir tipos. $O$ mesmo acontece na declaração do tipo de uma variável. Colocamos o nome de uma classe, mas de fato o nome significa "o tipo da classe". A variável pode referir-se a objetos de qualquer classe que seja subtipo do tipo da classe com a qual ela é declarada. Adaptadores são usados para converter objetos de um dado tipo para outro tipo, nâo importando a classe dos objetos. 


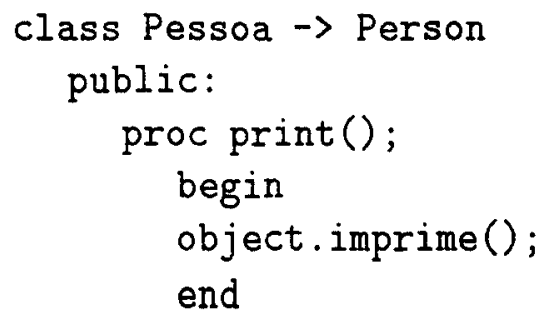

Figura 3.14: Filtros para tipos type(Pessoa) e type(Estudante)

\subsection{Implementação}

Adaptadores não possuem nenhum problema de implementação. Uma classe adaptadora simplesmente define alguns métodos que redirecionam suas mensagens para uma variável de instância. Nenhum algoritmo especial de busca por método é necessário. Todos os algoritmos necessários pelo compilador e sistema de tempo de execução para implementar adaptadores foram completamente especificados neste capítulo.

\subsection{Trabalhos Relacionados}

Strom e Yellin [30] propuseram uma técnica para construir adaptadores de modo semi-automático. Contudo, os adaptadores deles possuem algumas diferenças com relação aos adaptadores aqui propostos. O objetivo de Strom e Yellin é permitir a colaboração entre objetos de diferentes classes, mas obedecendo a algumas restrições de seqüência. Eles definem uma "especificação de colaboração" que consiste em um conjunto de mensagens que cada objeto da colaboração deve suportar, e na seqüência permitida em que as mensagens podem ser enviadas. Por exemplo, a mensagem Read somente pode ser enviada após Open. Os adaptadores de Strom e Yellin permitem usar uma classe em uma "especificação de colaboração" mesmo quando o tipo da classe não for exatamente o tipo requerido.

Honiden at al. [31] descrevem "adaptação de métodos". Em uma rede, quando um objeto $\mathcal{Q}$ é movido de um nó para outro, ele pode ter problemas ao enviar mensagens para os objetos do novo nó, pois os nomes das mensagens/tipos dos 
parâmetros podem ser diferentes no novo ambiente. Quando $\mathcal{Q}$ envia uma mensagem a um objeto no novo nó, o meta-objeto ${ }^{5}$ deste objeto traduz a mensagem em uma outra que o objeto pode responder. A tradução das mensagens é feita dinamicamente, o que é semelhante ao mapeamento de assinaturas de métodos feita por adaptadores. A diferença é que adaptadores fazem uma tradução estática das mensagens que um objeto pode receber, enquanto que "adaptação de métodos" faz tradução dinâmica de mensagens que um objeto pode enviar.

Gluons [24] são objetos que mediam a comunicação entre dois objetos (no caso simples). Então, eles podem desempenhar o mesmo papel que adaptadores. Uma mensagem enviada para um objeto de um gluon pode fazer com que o gluon envie uma outra mensagem com uma assinatura diferente para outro objeto.

\footnotetext{
${ }^{5}$ Veja Capítulo 8.
} 


\section{Capítulo 4}

\section{Extensão de Classe}

\subsection{Introdução}

Extensão de classe permite adicionar métodos a uma classe sem editar o código fonte da classe diretamente. Uma extensấo de classe pode ser acoplada a várias classes, adicionando os seus métodos e variáveis de instância a cada uma destas classes. O acoplamento de uma extensão de classe é feito por um comando do arquivo shell e não diretamente no arquivo do programa. Embora esta idéia pareça semelhante à herança, ela pode resolver problemas que herança não pode. Além disto, herança é usualmente limitada a expressar relacionamentos do tipo "é-um" (is-a) e extensão de classe, não. Portanto, a classe de problemas nos quais extensão de classe pode ser usada é, de certo modo, maior do que a classe de problemas nos quais herança pode.

A proposta de extensão de classe apresentada nesta tese foi baseada no trabalho de Ossher e Harrison [10] e em classes mixin [23], embora ela se pareça com enhancive types de Horn [40] e descriptive classes de Sandberg [41]. Antes de definir extensão de classe, serão apresentados alguns problemas que não podem ser resolvidos satisfatoriamente usando construções convencionais de orientação a objetos.

\subsection{Alguns Exemplos de Problemas}

Suponha que uma classe Car de uma biblioteca de classes seja usada em um programa. Precisamos trocar o método SpeedUp desta classe por um método nosso e adicionar o método GetMaxSpeed.

Esta modificação pode ser feita criando-se uma subclasse XCar de Car e trocando-se todas as ocorrências da classe Car no programa por XCar, o que é uma fonte de erros. Mesmo a redefinição de apenas um método da classe Car exigiria uma grande quantidade de modificações no código. A classe Car poderia ser modificada, mas isto nem sempre é possível, pois o seu código pode não estar disponível. Mesmo se temos acesso ao código de Car, esta classe deveria ser modificada a cada nova versão da biblioteca de classes.

Suponha que exista um programa com diversas classes para a manipulação de estruturas de dados (listas, filas, conjuntos, etc). É necessário acrescentar 
um método addall em todas estas classes. Este método deve somar todos os elementos (números inteiros) armazenados em um objeto de qualquer classe e retornar o valor obtido. Todas as classes possuem métodos iteradores ${ }^{1} \mathrm{com}$ os mesmos nomes e eles armazenam somente valores do tipo inteiro. Uma classe que define um iterador é, no máximo, o único tipo ou abstração comum às classes.

Os métodos iteradores são reset (), para inicializar o iterador, e next (): (integer, boolean) para obter o próximo elemento do conjunto. ${ }^{2}$

Não é aconselhável definir uma subclasse com um método addall para cada uma das classes para estruturas de dados. Isto duplicaria o código do método para cada classe.

Criar uma superclasse comum às classes é melhor. Podemos definir uma superclasse abstrata, digamos Eaddall, que possui os métodos reset, next e addall. As subclasses desta classe, que são as classes de estruturas de dados, deveriam possuir os métodos iteradores e elas herdariam o método addall.

Esta soluçâo não funciona quando:

1. o método a ser adicionado (neste caso, addall) deveria se sobrepor ao método de mesmo nome da classe; isto é, a busca por um método (por exemplo, addall) deveria começar em Eaddall e então, se ele não fosse encontrado lá, continuar na classe da estrutura de dados;

2. o método a ser adicionado possuir um valor de retorno cujo tipo deve ser a classe da estrutura de dados.

Se o item 1 for necessário, a criação de uma superclasse não será útil. A busca por um método começaria na classe da estrutura de dados e continuaria, se necessário, em Eaddall. Neste caso, a criação de uma subclasse seria melhor se esta solução não possuísse os problemas já apresentados.

Como um exemplo do item 2, suponha que seja necessário adicionar um método union para cada classe de estrutura de dados. O método union concatena duas estruturas de dados, retornando a estrutura resultante:

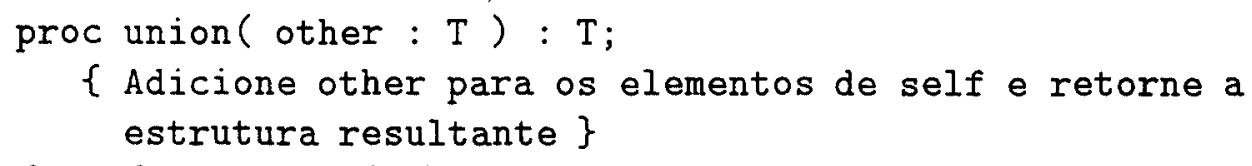

T é a classe de estrutura de dados para a qual union deve ser adicionado.

Então, para uma classe List deveria ser adicionado um método

proc union( other : List ) : List

Tentaremos criar uma superclasse para resolver este problema. Podemos definir uma superclasse abstrata Eunion com métodos reset, next e union. $O$ método union deveria ser

proc union( other : Eunion) : Eunion;

e as classes de estrutura de dados deveriam herdar Eunion, redefinindo os métodos iteradores.

\footnotetext{
${ }^{1}$ Métodos para obter os elementos de um conjunto qualquer, um a um.

${ }^{2} \mathrm{Um}$ método pode retornar mais de um valor.
} 


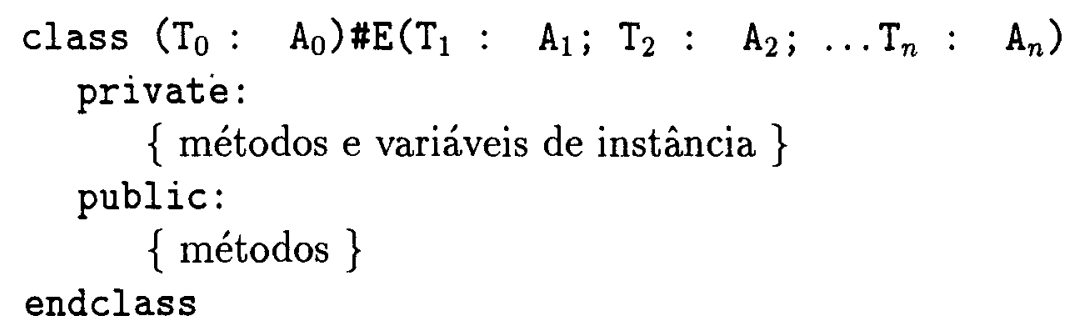

Figura 4.1: Sintaxe para uma extensão de classe

O problema com esta solução é que ele causa um erro de tipos. Suponha que List herda de Eunion. $\mathrm{O}$ código

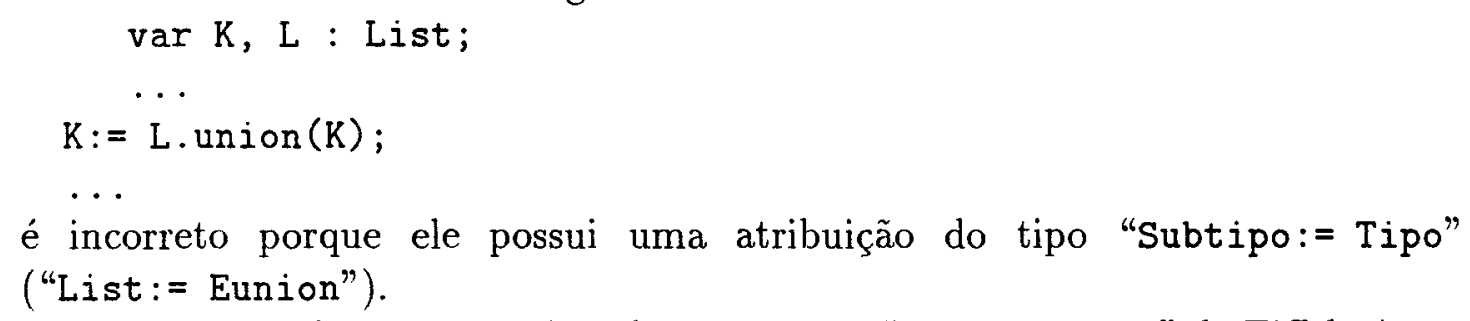

Este erro pode ser corrigido pela construção "like current" de Eiffel. A expressão "like $\mathrm{x}$ " resulta na classe com que $\mathrm{x}$ foi declarado. "Iike current" resulta no tipo da classe corrente, isto é, no tipo da classe onde esta expressão se encontra. Então, se union for declarado em Eunion como proc union( other : Eunion) : like current

ele possuirá a assinatura

union( Eunion) : List

na classe List e a atribuição recém-descrita tornar-se-á correta.

O compilador copiaria o texto do método union para a subclasse List, mudaria a sua assinatura e o compilaria novamente. Contudo, neste caso haveria um erro de tipos. Os tipos dos valores retornados por union em Eunion são subtipos de Eunion ${ }^{3}$ e union de List exige que eles sejam subtipos de List. Como pode existir uma classe subtipo de Eunion, mas não seja subtipo de List, o compilador sinaliza um erro de tipos.

\subsection{A Definição de Extensão de Classe}

Extensão de classe usa uma sintaxe semelhante a classes parametrizadas e é declarada como mostrado na Figura 4.1. A classe E é instanciada como uma classe parametrizada normal:

$$
\text { shell } \mathrm{B}_{0} \# \mathrm{E}\left(\mathrm{B}_{1}, \ldots \mathrm{B}_{n}\right)
$$

A declaração da classe e sua instanciação são colocadas no arquivo shell. A instanciação adicionará os métodos e variáveis de instância de $E$ à classe $B_{0}$.

Uma extensão de classe é representada como (Nome, PrimParametro, Parametros, VariaveisDeInstancia, Metodos)

\footnotetext{
${ }^{3}$ Os valores seriam provavelemente objetos de Eunion.
} 


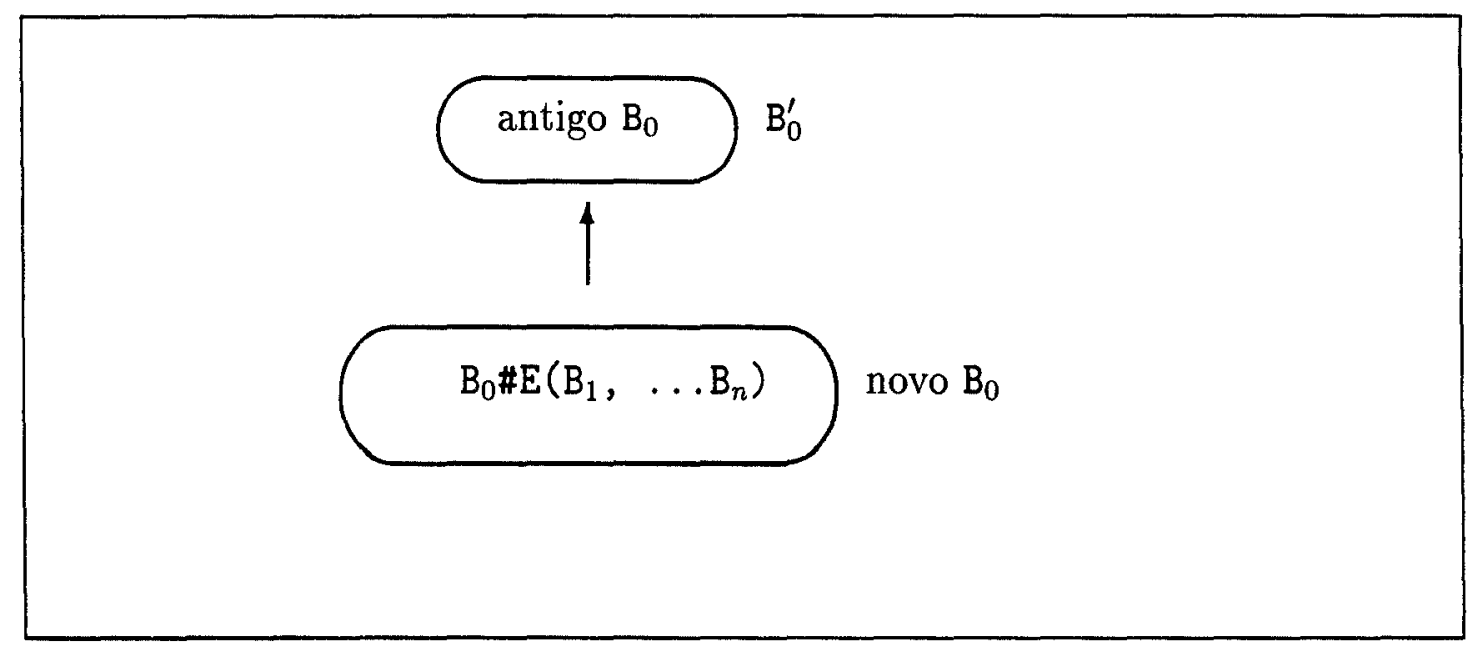

Figura 4.2: Representação da herança criada pela instanciação de uma extensão de classe

onde Nome, Parametros, VariaveisDeInstancia e Metodos possuem o mesmo significado que na representação de classes parametrizadas. PrimParametro é composto por um nome e um tipo - ele corresponde a $\left(\mathrm{T}_{0}, \mathrm{~A}_{0}\right)$ do exemplo da Figura 4.1.

A extensão de classe

$$
\left(\mathrm{E},\left(\mathrm{T}_{0}, \mathrm{~A}_{0}\right),\left(\left(\mathrm{T}_{1}, \mathrm{~A}_{1}\right),\left(\mathrm{T}_{2}, \mathrm{~A}_{2}\right), \ldots\left(\mathrm{T}_{n}, \mathrm{~A}_{n}\right)\right), \mathrm{IV} \mathrm{s}, \mathrm{Ms}\right)
$$

é transformada pelo compilador na classe parametrizada

$$
E^{\prime}=\left(E,\left(\left(T_{0}, A_{0}\right),\left(T_{1}, A_{1}\right), \ldots\left(T_{n}, A_{n}\right)\right),\{\}, I V s, M s,\{\},\{\}\right)
$$

e, quando o compilador encontrar a instanciação

$$
\text { shell } B_{0} \# E\left(B_{1}, \ldots, B_{n}\right)
$$

de $E$, ele:

1. instanciará $\mathrm{E}^{\prime}$ com $\mathrm{B}_{0}, \mathrm{~B}_{1}, \ldots \mathrm{B}_{n}$, criando uma nova classe $\mathrm{B}_{0}^{\prime}$;

2. renomeiará $\mathrm{B}_{0}$ como $\mathrm{B}_{0}^{\prime}$ e $\mathrm{B}_{0}^{\prime}$ como $\mathrm{B}_{0}$;

3. fará $B_{0}$ herdar de $B_{0}^{\prime}$;

4. trocará todos os símbolos "object" em $B_{0}$ por "super $\left(B_{0}^{\prime}\right)$ ";

5. inserirá a nova classe $B_{0}$ no arquivo do programa.

Uma representação gráfica da instanciação é mostrada na Figura 4.2. A instanciação requer a localização da classe $B_{0}$ no arquivo do programa, já que ela deve ser usada como um parâmetro para $E$ e o seu nome deve ser mudado. Não podemos considerar a localização da classe $B_{0}$ como possível sem discussão, pois algumas partes do programa foram feitas usando a nova classe $B_{0}$ e não foram compiladas ainda. Então, podem existir erros de sintaxe. Entretanto, garantimos que a classe $B_{0}$ pode ser localizada porque:

- se existir erros de sintaxe no programa, eles devem ser corrigidos antes que a instanciação continue; 
- se não existir erros sintáticos, a única regra da gramática da linguagem afetada pela adição de métodos a $B_{0}$ é "MessageSend : : = . .", a qual não impede o compilador de encontrar a classe $\mathrm{B}_{0}$ pela regra "ClassDec : := ..." - veja Apêndice B.

Agora, a linha

shell $\mathrm{B}_{0} \# \mathrm{E}\left(\mathrm{B}_{1}, \ldots \mathrm{B}_{n}\right)$

que causou a instanciação é removida do arquivo shell e a compilação começa novamente usando o novo programa criado pela instanciação.

Podem existir erros de tipo na classe $B_{0}$ e no código que usa esta classe, mas estes erros são descobertos em tempo de compilação, pois o programa é recompilado.

Um exemplo de erro ocorre quando:

- existe uma classe $S$ tal que type $(S) \prec$ type $\left(B_{0}\right)$ e $S$ não herda de $B_{0}$;

- variáveis do tipo $B_{0}$ são usadas para se referir a objetos do tipo $S$;

- uma extensão de classe adiciona métodos a $\mathrm{B}_{0}$ não pertencentes a type(S). Então, type (S) não é mais um subtipo de type $\left(B_{0}\right)$ e variáveis do tipo $B_{0}$ não podem se referir a objetos do tipo $\mathrm{S}$.

Pela definição de extensão de classe dada acima, a classe original $\mathrm{B}_{0}$ é substituída pela instanciação da classe $\mathrm{E}$, que herda a antiga classe $\mathrm{B}_{0}$. Quando uma mensagem for enviada a um objeto da classe $B_{0}$,

- se a extensão de classe $\mathrm{E}$ possuir um método m, este será executado;

- caso contrário, a busca por método m será feita na antiga classe $B_{0}$ e suas superclasses.

Isto significa que os métodos da extensão se sobrepõem aos métodos da classe $\mathrm{B}_{0}$ com os mesmos nomes.

Os métodos de $E$ podem invocar os métodos de $B_{0}$ através da palavra chave object. A instrução

object.m(...)

é transformada em "super $\left(B_{0}^{\prime}\right) \cdot m(\ldots)$ ", onde $B_{0}^{\prime}$ é a classe $B_{0}$ antiga. Então, a busca por $m$ será feita na classe original $B_{0}$. A classe $E$ pode referir-se a ela mesma usando a sintaxe class (self)

como qualquer classe parametrizada.

Não é permitido criar objetos de uma extensão de classe, pois os seus métodos podem se referir a métodos do tipo $\mathrm{T}_{0}$ e alguns destes métodos podem não estar definidos em $\mathrm{E}$.

Imagine que existam método $\mathrm{m}$ e $\mathrm{n}, \mathrm{m} \in \mathrm{E}, \mathrm{m} \in$ ao original $\mathrm{B}_{0}, \mathrm{n} \in$ ao original $\mathrm{B}_{0}, \mathrm{n} \notin \mathrm{E}$. Dentro de $\mathrm{n}$, há o envio da mensagem $\mathrm{m}$ para self. Se a mensagem $\mathrm{n}$ for enviada para um novo objeto de $B_{0}$ (veja a Figura 4.2), o método n na antiga classe $B_{0}$ será executado. Quando o código de $n$ enviar a mensagem m para self, a busca por m começará no novo $B_{0} e$, portanto, o método m de $E$ será executado. 
Concluimos que o método $m$ de $E$ realmente substitui o método $m$ do antigo $B_{0}$, mesmo do ponto de vista dos métodos antigos de $\mathrm{B}_{0}$, como $\mathrm{n}$.

Como resultado, os métodos da extensão de classe devem manter a semântica do tipo $\mathrm{T}$ (parâmetro formal), o qual é substituído pela classe $\mathrm{B}_{0}$ quando a associação de $E$ com $B_{0}$ acontece. Esta mesma regra se aplica à criação de subclasses. Os métodos da subclasse devem manter a semântica da superclasse.

\subsection{Solução dos Problemas}

Nesta seção usaremos extensão de classe para resolver os problemas propostos no começo deste capítulo.

O primeiro problema é substituir um método SpeedUp da classe Car e adicionar um método GetMaxSpeed. Isto é feito colocando-se a extensão de classe SlowCar da Figura 4.3 sobre a classe Car:

shell Car\#SlowCar

Quando o programa for compilado, o método SpeedUp de SlowCar cobrirá o método com o mesmo nome de Car. O método GetMaxSpeed e a variável de instância MaxSpeed serão adicionadas a esta classe.

A Figura 4.3 mostra uma classe BasicCar que declara os métodos que uma classe deve possuir para ser associada à extensão SlowCar. A classe BasicCar funciona apenas como uma interface e deveria ser definida no arquivo de programa. A classe SlowCar é definida no arquivo shell.

Esta extensão de classe pode ser reusada com outras classes. Não é necessário alterar os métodos de Car para modificar esta classe. Isto significa que qualquer seqüência de modificações é gravada nas extensões de classe. A liberação de uma nova classe Car não causa nenhum problema: o programa apenas deve ser compilado novamente.

O segundo problema é adicionar um método addall a várias classes de estruturas de dados. Isto é feito colocando-se a extensão de classe Eaddall da Figura 4.4 sobre as classes:

shell ListInt\#Eaddall

shell SetInt \#Eaddall

shell Collect\#Eaddall

O terceiro problema é adicionar um método

proc union ( other : $\mathrm{T}$ ) : $\mathrm{T}$

a várias classes de estruturas de dados, onde $\mathrm{T}$ deve ser substituído pelo nome de cada classe. Este problema é resolvido facilmente pela extensão de classe Eunion da Figura 4.5. Cada classe associada a esta extensão de classe deve possuir, além dos métodos iteradores, um método ins (para inserir elementos na estrutura de dados) e um método init (para inicializar o objeto). A extensão de classe é então acoplada às classes, como nos exemplos anteriores.

O problema resolvido acima pode ser generalizado permitindo-se: 


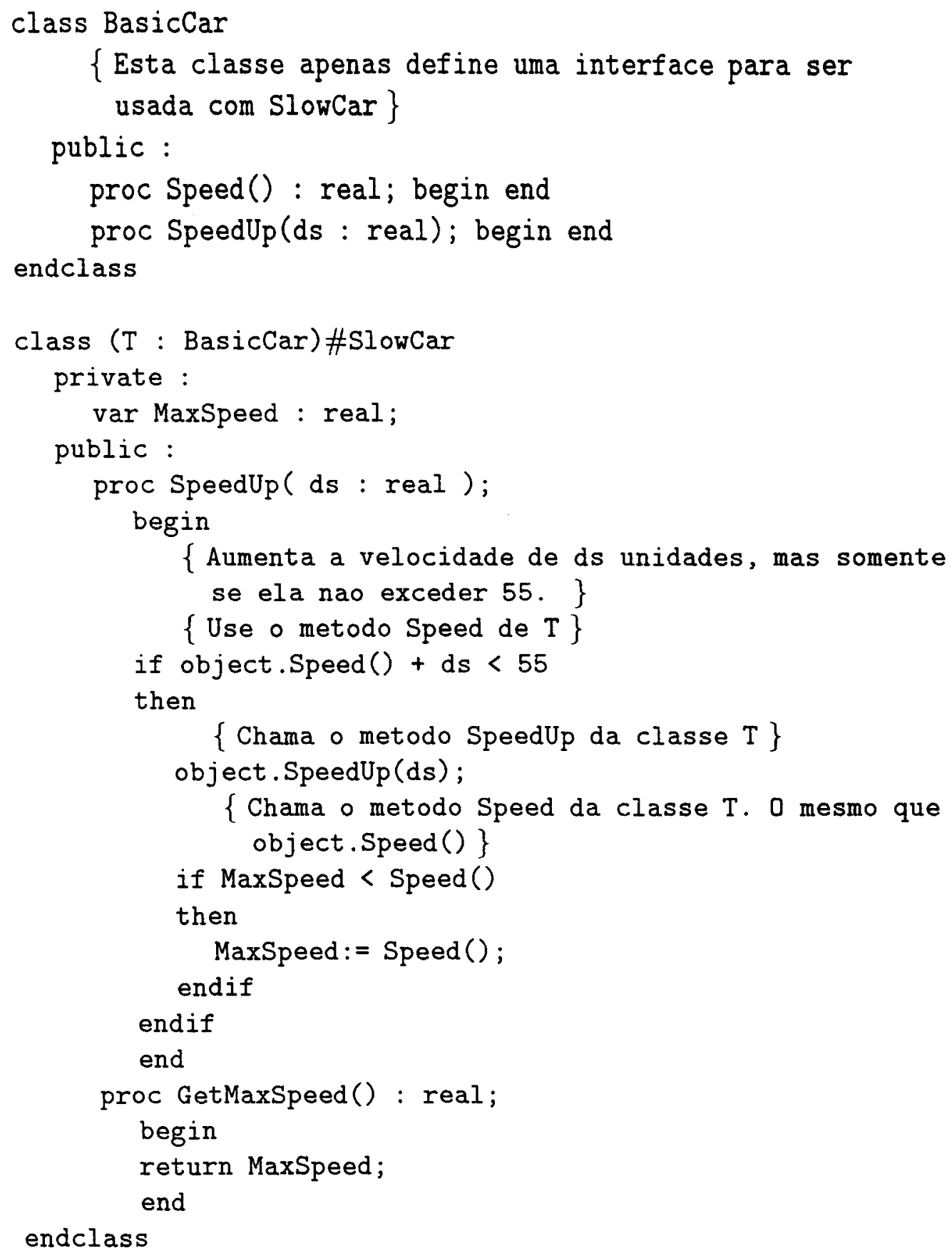

Figura 4.3: Extensão de classe para a classe Car 


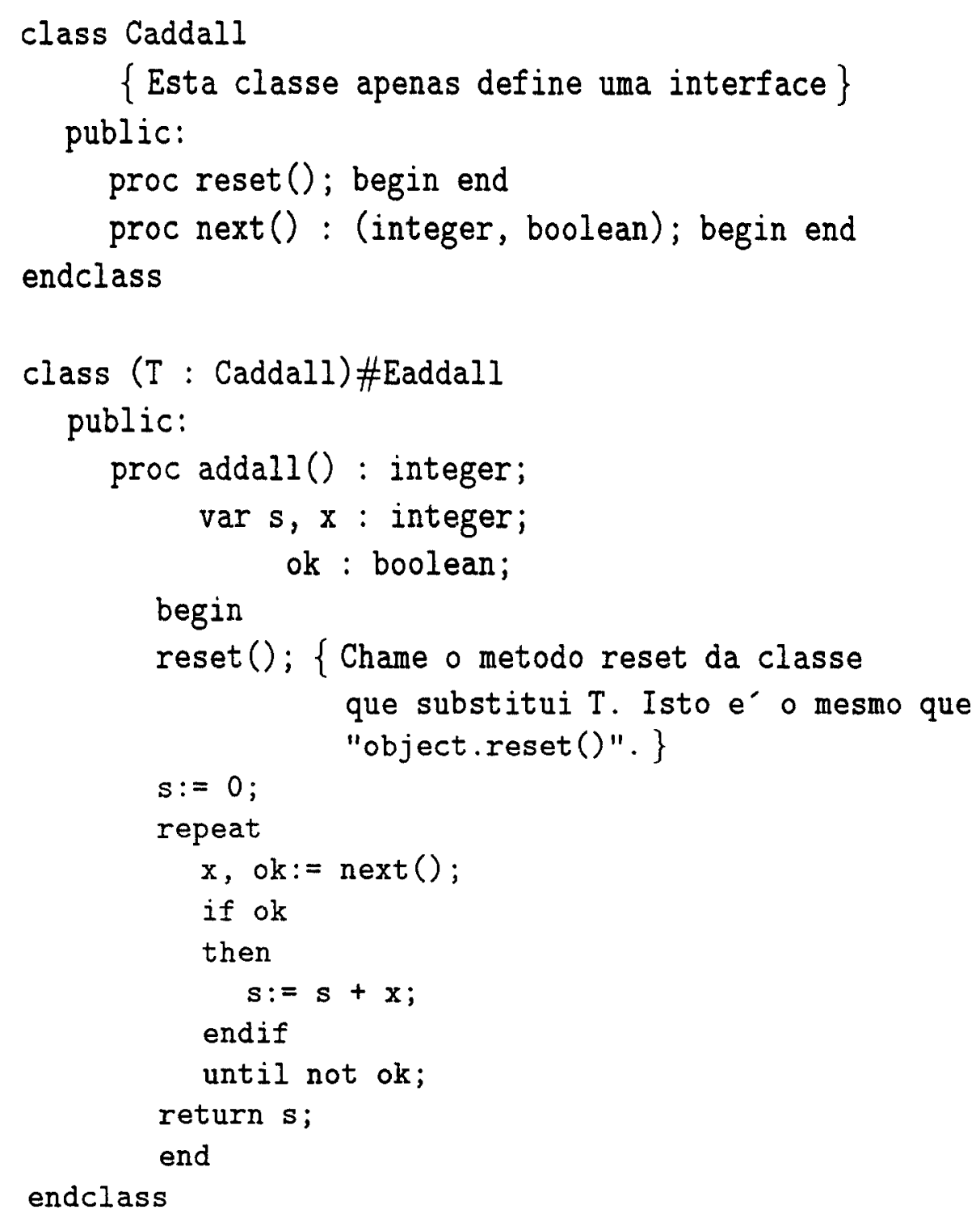

Figura 4.4: Extensão de classe Eaddall com método addall 


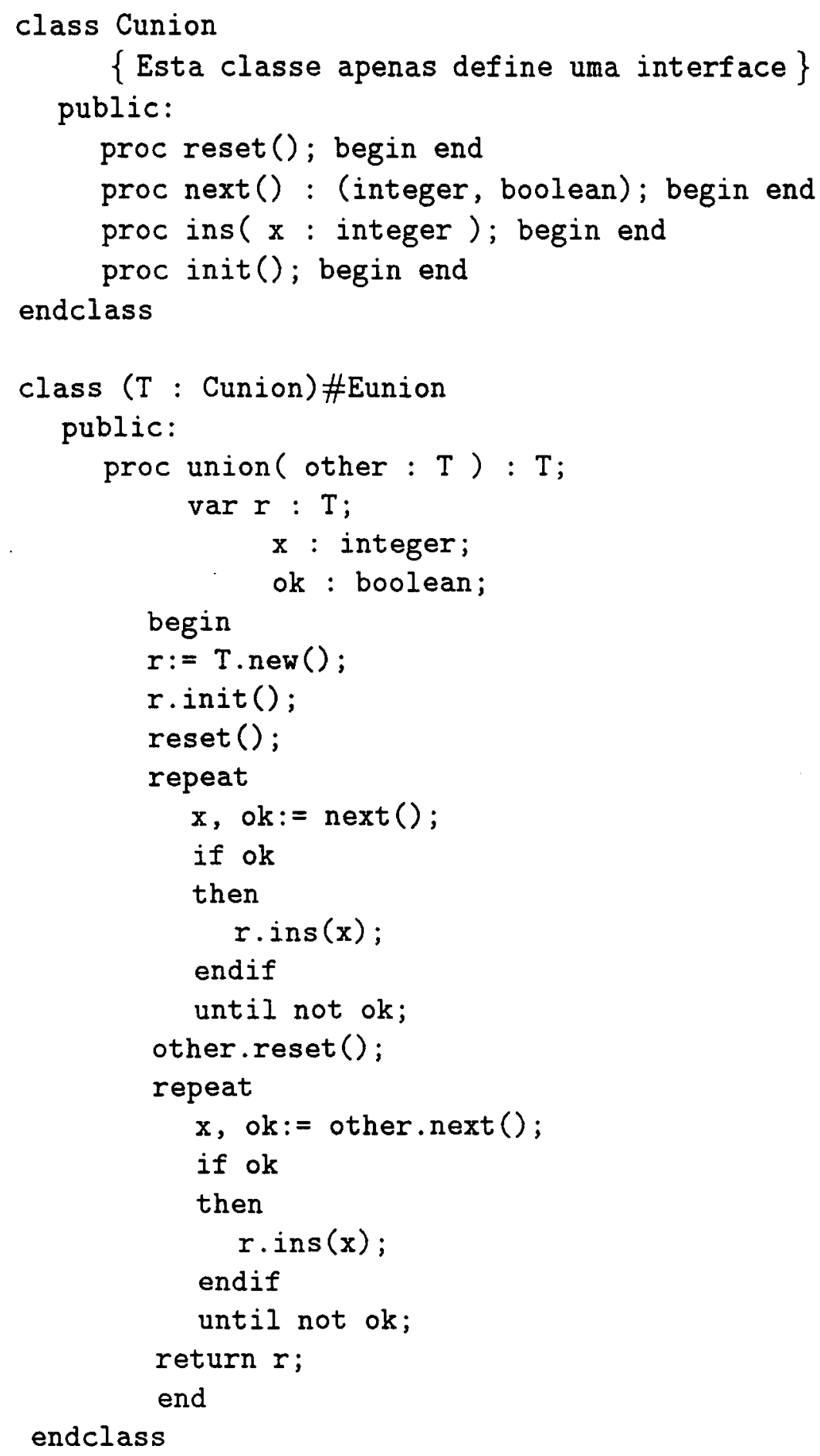

Figura 4.5: Extensão de classe Eunion com método union 


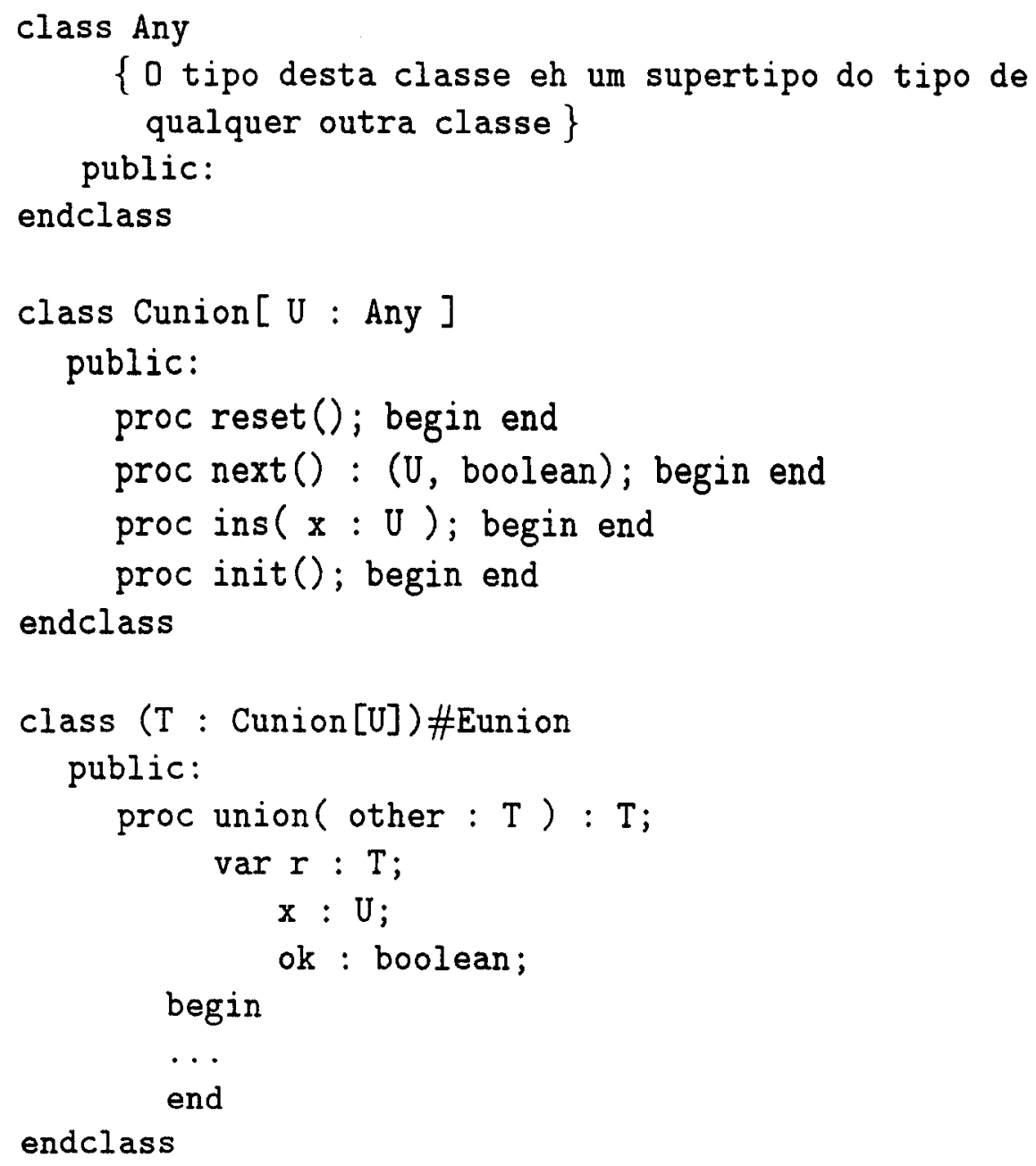

Figura 4.6: Extensão de classe Eunion para estruturas de dados que armazenam objetos de qualquer tipo

- acoplar Eunion a classes incompatíveis com type(Cunion). Estas classes seriam funcionalmente compatíveis com Cunion, mas teriam alguns métodos e tipos de parâmetros diferentes dos existentes nesta classe. Por exemplo, poderíamos acoplar Eunion a uma classe Queue que possui métodos initIter, getNext, insTail e setUp. ao invés dos métodos definidos em Cunion;

- armazenar objetos de qualquer tipo em objetos das classes para estruturas de dados. Nos exemplos acima, assumimos que somente valores integer poderiam ser armazenados.

A primeira generalização descrita acima não é possível no modelo corrente, embora esperemos introduzi-la em futuras versões de extensão de classe. Isto será feito combinando-se adaptadores com classes parametrizadas.

Para resolver a segunda generalização, podemos usar o fato de que uma classe parametrizada permite como parâmetro formal uma outra classe parametrizada. Assim, o tipo do parâmetro $\mathrm{T}$ da extensão de classe Eunion pode se tornar uma 
classe parametrizada cujo tipo é o tipo dos objetos a serem armazenados na estrutura de dados. Um exemplo é mostrado na Figura 4.6.

Então, Eunion pode ser acoplada à classe SetReal. Esta classe armazena números reais e possui o tipo

$\{$ reset (), next (): (real, boolean), ins(real), init(), empty() : boolean, isInSet(real) : boolean $\}$

Poderíamos fazer

shell SetReal\#Eunion

\subsection{Implementação}

Extensão de classe é implementada substituindo-se texto no arquivo do programa e no arquivo shell. Ela pode resultar em erros de compilação e isto é permitido pela construção. Não há nenhuma técnica especial para implementar extensão de classe. Isto pode ser feito usando-se a seqüência de comandos dada neste capítulo.

\subsection{Trabalhos Relacionados}

A proposta de extensão de classe apresentada nesta tese foi baseada em classes mixin [23] e extensões de Ossher e Harrison [10], embora ela se assemelhe a enhancive types de Horn [40] e descriptive classes de Sandberg [41]. Contudo, há algumas diferenças a serem discutidas.

Extensões, na forma definida por Ossher e Harrison [10], são separadas do código do programa, como extensões de classes. Diferente da nossa proposta, uma classe pode ser estendida sem a recompilação do seu código. ${ }^{4}$ Contudo, não é possivel existir um método como union do exemplo anterior no qual o tipo de um parâmetro é a classe na qual a extensão será acoplada.

Uma classe mixin pode ser adicionada a várias classes não relacionadas na hierarquia de herança. O mixin adiciona o seu código a todas elas. Contudo, classes mixin devem ser herdadas pelas classes em que elas são acopladas, o que significa que o seu uso deve ser planejado. Extensão de classe permite modificar o comportamento de uma classe existente sem nenhuma modificação do código. Editar o código fonte e alterá-lo diretamente é inseguro e usualmente introduz erros no programa.

Classes mixin têm sido utilizadas como uma técnica de programação em CLOS. Esta linguagem não é estaticamente tipada e permite o uso de mixins sem nenhum suporte pela linguagem. Bracha e Cook [23] propuseram uma versão estaticamente tipada de mixins para Modula-3 [32], semelhante a extensão de classe e à proposta de classes mixins deste capítulo. Na proposta deles, uma classe mixin conhece somente as assinaturas de alguns métodos das classes em que a classe mixin pode ser acoplada. Então, dentro de uma classe mixin podem existir chamadas a métodos destas classes e o compilador sabe estaticamente se o

${ }^{4}$ Isto pode ser feito por extensão dinâmica, definida no Capítulo 6 .

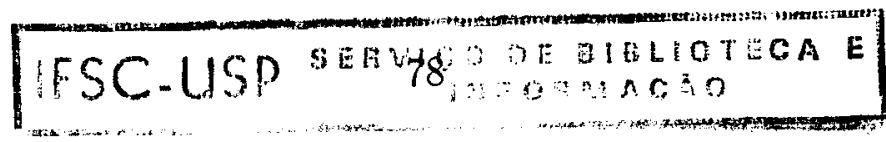




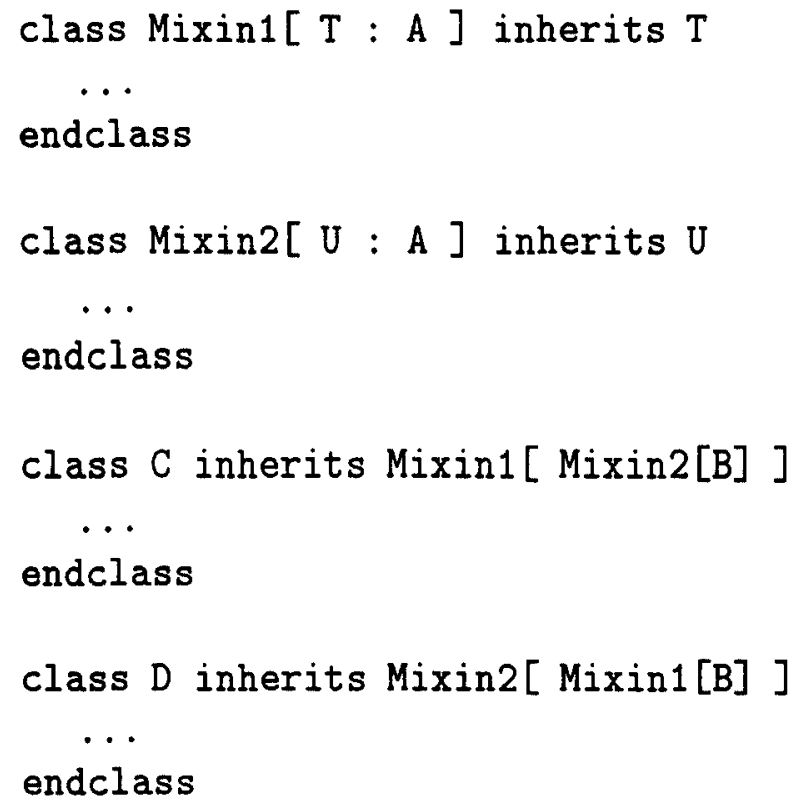

Figura 4.7: Classes mixins feitas com classes parametrizadas

acoplamento de uma classe mixin é correto. Ao contrário de extensão de classe, não há nenhum modo de uma classe mixin declarar uma variável cujo tipo é a classe na qual o mixin será acoplado.

É interessante notar que classes mixins podem ser implementadas usando o fato de que uma classe parametrizada pode herdar de um de seus parâmetros. Como exemplo, a Figura 4.7 mostra duas classes mixins Mixin1 e Mixin2 que podem herdar de classes conformantes a type (A). Estes dois mixins podem ser combinados em qualquer ordem, como ocorre com as classes C e D. Na classe C, os métodos de Mixin1 se sobrepõe aos métodos de mesmo nome de Mixin2. $\mathrm{Na}$ classe $\mathrm{D}$, ocorre o contrário.

Extensão de classe é muito semelhante a enhancive types de Horn [40], embora tenha sido desenvolvida independentemente desta construção. A principal diferença entre elas é no acoplamento de uma classe a outra. Com extensão de classe, isto se faz em um arquivo separado (arquivo shell), e o comportamento do código existente pode ser modificado sem editar o programa. Os enhancive types permitem acoplar uma classe a outra na declaração de uma variável. Isto é, uma nova classe é criada na declaração, a qual é composta pelo enhancive type acoplado à classe normal. Isto seria semelhante a instanciar a extensão de classe Eunion com Listint em uma declaração de variável:

$\operatorname{var} \mathrm{a}, \mathrm{b}:$ ListInt\#Eunion;

Apesar de enhancive types e extensões de classes possuírem funções semelhantes, esta última construção é mais fácil de entender. Enhancive types possuem regras complexas de subtipagem/conformidade e existem nada menos que quatro diferentes maneiras de usá-los: estática, dinâmica, temporária e protacted.

Sandberg [41] propôs descriptive classes, também semelhantes a extensões de classes. Uma classe descriptive é um tipo de classe parametrizada que pode ser 
acoplada a uma classe existente, o que faz da classe uma instância da classe descriptive. Isto é feito por uma instrução especial.

$\mathrm{O}$ acoplamento de uma classe descriptive a uma classe pode ser feita após a definição da classe (como extensão de classe) e a linguagem permanece estaticamente tipada com esta construção. Contudo, uma classe descriptive não pode chamar métodos da classe na qual ela é acoplada, como extensão de classe $\mathrm{e}$ enhancive types.

Raj e Levy [33] propuseram um modelo de composição para reutilização de software. Os métodos são definidos independentemente das classes e podem ser acoplados a elas. Um método m poderá ser acoplado a uma classe A se A fornecer o ambiente requerido por $\mathrm{m}$, o que pode inçuir variáveis de instância (com os seus nomes e tipos) e assinaturas de métodos. Então, o método m pode ser acoplado a várias classes diferentes que suportam o ambiente que ele requer. Isto é muito semelhante a definir uma extensão de classe com um único método e então acoplála a várias classes. A diferença é que uma extensão de classe não pode manipular as variáveis de instância da classe em que ela é acoplada.

Refactorings [26] [27] são técnicas para modificar o código fonte de um programa sem modificar a sua funcionalidade. Eles podem criar superclasses abstratas, mover variáveis de instância em uma hierarquia de classes, mudar relações de herança para relações de agregação ${ }^{5}$ e assim por diante. Um refactoring que não preserva a funcionalidade do código original pode fazer o mesmo trabalho que extensão de classe. Esta construção é, na verdade, definida como manipulação de texto, que é o mecanismo usado por refactorings.

Seria interessante construir uma ferramenta de software que produza a interface de uma classe (tipo), já considerando as extensões de classes definidas no arquivo shell. Esta ferramenta seria semelhante ao programa short fornecido com o ambiente de programação da linguagem Eiffel [34].

\footnotetext{
${ }^{5}$ Agregação é o relacionamento entre uma classe e suas variáveis de instância.
} 


\section{Capítulo 5}

\section{Shell Dinâmico}

\subsection{Introdução}

Shell dinâmico permite colocar um shell sobre um único objeto em tempo de execução. Todas as mensagens enviadas ao objeto através de qualquer variável são redirecionadas para o shell. Isto é similar a meta-objetos [20], que são objetos que controlam o comportamento de outros objetos. Shell dinâmico permite a criação de objetos especiais de uma classe. As caracteristicas especiais são colocadas no shell. Esta construção permite implementar traçadores, ${ }_{1}^{1}$ procuradores ${ }^{2}$ e mesmo actors [18]. Shell dinâmico é estaticamente tipado, fácil de entender e implementar. A relação de shell dinâmico com meta-objetos é examinada no Capítulo 8.

\subsection{O Problema}

Algumas vezes queremos modificar o comportamento (métodos) de alguns objetos em tempo de execução a fim de espelhar algumas mudanças no mundo real que não poderiam ser previstas quando as classes foram projetadas. Por exemplo, uma classe Client é usada em um programa de uma companhia de cartão de crédito e a companhia gostaria de aumentar o limite de crédito de algumas pessoas que obedecem a um certo perfil. Assuma que tal alteração foi planejada após esta classe ter sido liberada para uso, embora as idéias dadas neste capítulo sejam também adequadas quando mudanças forem requeridas antes que o sistema comece a ser construído. Há critérios para estudantes, cidadãos da terceira idade e várias outras classificações. Algumas pessoas de cada um destes grupos devem ser modificadas em tempo de execução no caso de elas obedecerem a um certo perfil.

Extensão de classe ou modificações no código poderiam ser usados para resolver este problema. Entretanto, neste caso todos os objetos $\mathrm{Cl}$ ient carregariam a carga de variáveis de instância que seriam utilizadas por uns poucos objetos.

\footnotetext{
${ }^{1}$ Objetos que fornecem dados, usualmente enviados ao vídeo, sobre o fluxo de execução do programa.

${ }^{2}$ Objetos que delegam as mensagens enviadas a ele para um outro objeto em outra máquina.
} 


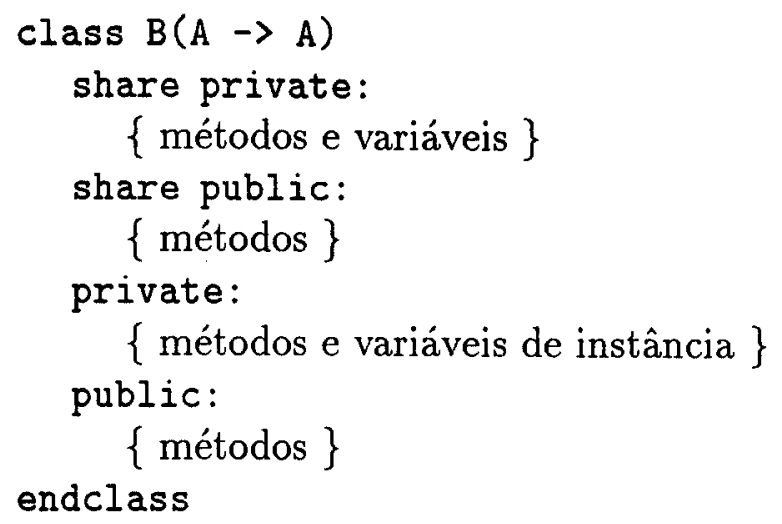

Figura 5.1: Sintaxe para um shell dinâmico

Além disto, métodos de $\mathrm{Cli}$ ent seriam "remendados" por uma grande quantidade de comandos if para separar os objetos normais dos especiais.

É preferível construir uma nova classe, uClient, com o mesmo tipo que Client, mas implementando os seus métodos de acordo com a nova política de crédito da companhia. Esta classe poderia herdar de Client.

Com uClient é possível criar objetos que podem ter o seu limite de crédito aumentado/diminuído, mas não é possível aumentar/diminuir o limite de crédito de objetos criados em outras partes do sistema, pois estes objetos pertencem à classe Client. Para alterar o limite de crédito de um objeto da classe Client, deve-se converter este objeto para um objeto de uClient. Pode-se efetuar tal conversão por um procedimento (ou método)

proc To_uClient ( $\mathrm{x}$ : Client ) : uClient;

da classe uClient que crie um novo objeto de uClient e copie os dados do objeto $\mathrm{Client}$ para ele. Cada classe semelhante à classe uClient (classe criada para ter um comportamento ligeiramente diferente de Client) deve possuir um procedimento/método como To_uClient. Além disto, talvez seja necessário construir métodos para converter objetos entre classes similares a uClient.

Suponha que a variável w refira-se a um objeto $\mathrm{Cl}$ ient e ela seja passada como um parâmetro para um método que usa To_uClient para converter o objeto à classe uClient. Agora há um objeto cujo limite de crédito pode ser modificado de acordo com algum critério. Entretanto, a variável w continua a referir-se a um objeto $\mathrm{Client}$. $\mathrm{O}$ código que chamou o método possui a mesma visão do objeto que antes, pois as operações executadas no novo objeto uClient criado por este método não modificaram os dados do objeto Client.

\subsection{O Esboço de uma Solução}

Este problema somente pode ser resolvido colocando-se um shell ao redor do próprio objeto. Quando uma mensagem for enviada ao objeto através de qualquer variável que se refira a ele, a mensagem será procurada primeiramente no shell e 


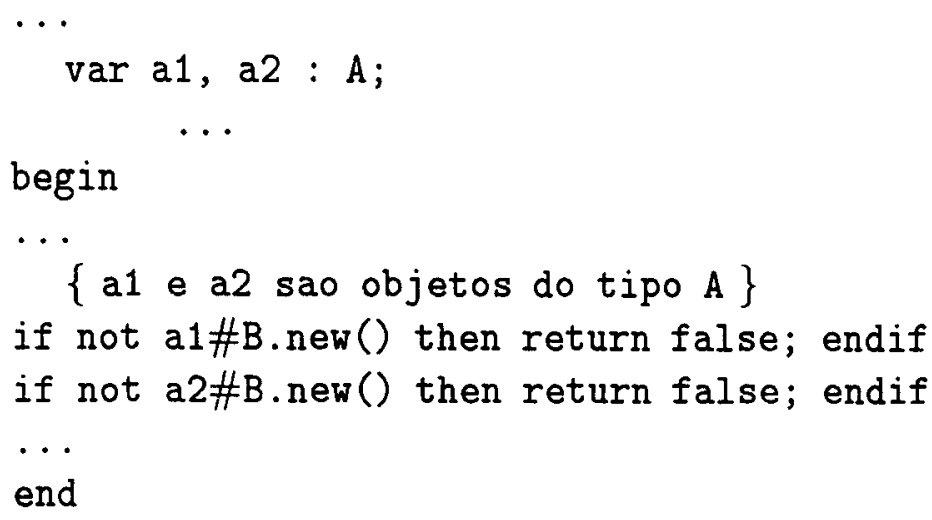

Figura 5.2: Shells são colocados sobre a1 e a2

depois no objeto. Isto é, o shell intercepta qualquer mensagem enviada ao objeto através de qualquer variável. Deste modo, todo o programa pode enxergar a nova semântica do objeto.

Isto é conseguido pela construção descrita neste capítulo, shell dinâmico. A sintaxe para definir este tipo de shell é mostrada na Figura 5.1, a qual define um shell com nome B que pode ser colocado ao redor de objetos que são subtipos de type (A), resultando em objetos deste mesmo tipo. Portanto, todos os métodos públicos definidos no shell devem pertencer ao tipo type(A), embora não seja necessário definir em $B$ todos os métodos do tipo type(A). Quando uma mensagem for enviada a um shell sem que ele possua o método apropriado, ele delegará a mensagem para o objeto que ele cobre.

$\mathrm{O}$ código da Figura 5.2 mostra como colocar um shell em objetos do tipo type (A). A expressão a1\#B. new() cria um objeto shell da classe B colocando-o sobre a1. Isto é, o sistema de tempo de execução faz o objeto shell referir-se ao objeto a1 e todas as variáveis que se referem a a1 referirem-se ao objeto shell. Esta expressão retornará false se não houver memória livre suficiente para criar o objeto shell. Caso contrário, ela retornará true.

Os métodos do objeto shell pertencentes à classe B podem chamar os métodos do objeto coberto pelo shell através da palavra chave "object", como nas construções shell anteriores.

A Figura 5.3 exemplifica a utilização de shell dinâmico. A figura mostra a configuração de dois objetos antes e depois da avaliação das expressões a1\#B. new() e a2\#B.new(). Depois, a1 e a2 referem-se a dois objetos shell diferentes, cada um contendo as variáveis de instância da classe B. Nesta figura, variáveis da seção share não estão representadas.

\subsection{A Especificação de Shell Dinâmico}

Um shell dinâmico como aquele da Figura 5.1 será representado como

(Nome, DePara, IVs, Ms, CIVs, CMs)

onde Nome, IVs, Ms, CIVs, e CMs possuem o mesmo significado que em uma classe 

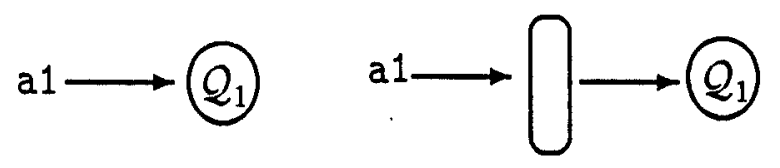

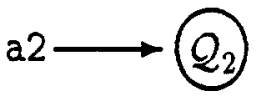

Antes

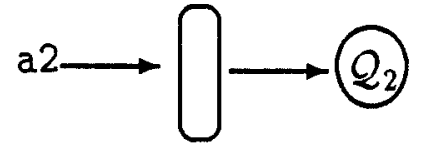

Depois

Figura 5.3: Antes e depois de um objeto shell ser colocado sobre um objeto da classe A

Algoritmo ReplaceObject (Ms, A)

$\{$ Este algoritmo substitui todos os símbolos "object" por

"super (A)" nos métodos do conjunto Ms. $\}$

$\mathbf{M s}^{\prime}=\{\}$

for each método (Sign, Text, Status) $\in$ Ms do:

Text' Text $^{\prime}$

Substitua todos os símbolos "object" em Text' por "super(A)"

$M s^{\prime}=M s^{\prime} \cup\{($ Sign, Text', Status $)\}$

return $M s^{\prime}$

Figura 5.4: Algoritmo para substituir "object" por "super(A)" 


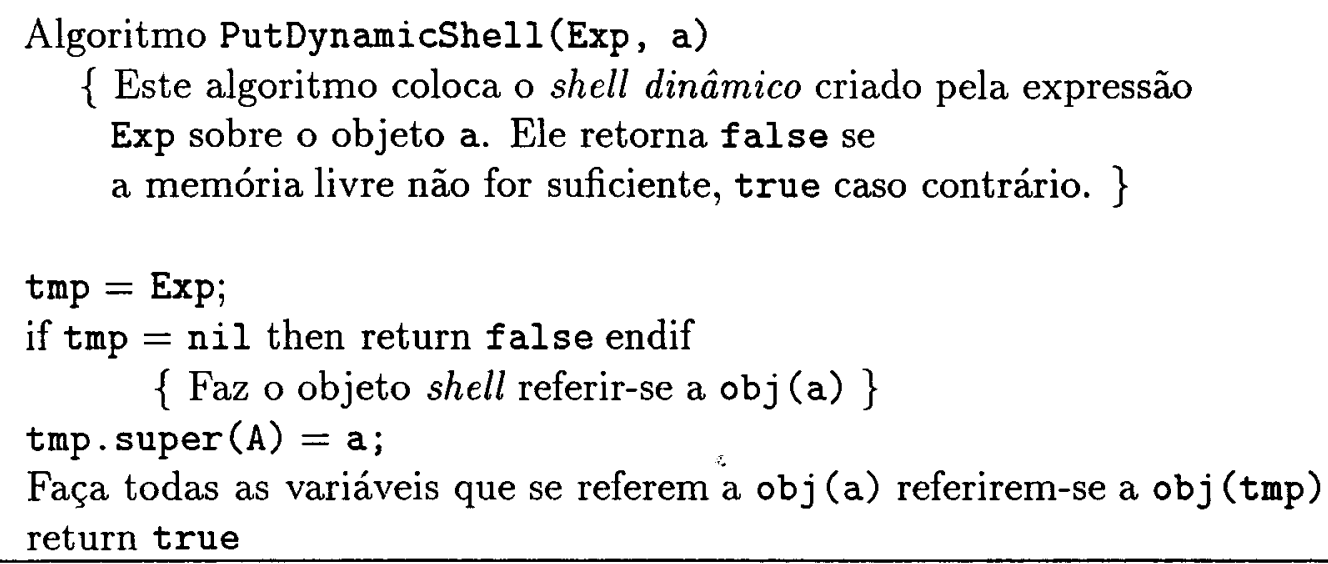

Figura 5.5: Algoritmo para colocar um shell dinâmico sobre o objeto a

normal e DePara é o nome de uma classe. Este shell pode cobrir objetos que são subtipos de type(DePara). Considerando-se a classe $B(A->A)$, Nome $=B$ e DePara $=$ A.

Ao encontrar a classe de um shell dinâmico

(B, A, IVs, Ms, CIVs, CMs)

(que é $B(A->A)$ ), o compilador criará a classe normal

(shell@B, \{A\}, IVs, Ms', CIVs, CMs)

onde Ms' é obtido por uma chamada ao algoritmo ReplaceObject da Figura 5.4. A classe shell@B herda $A$ e possui as variáveis de instância e métodos de $B(A \rightarrow A)$. Qualquer uso da classe B no programa será substituído por shell@B. Isto é, o nome B no programa significará shell@B.

$\mathrm{O}$ compilador usa a condição 5.1 para descobrir se a classe $\mathrm{B}(\mathrm{A}->\mathrm{A})$ está correta ou não.

Condição 5.1 A classe $\mathrm{B}(\mathrm{A}-\mathrm{A})$ está correta com relação a tipos se e somente se a classe shel1@B está corretamente tipada e type $($ shell@B $)=$ type $(\mathrm{A})$.

A expressão

a\#B.new ()

é considerada corretamente tipada se a condição 5.2 for válida.

Condição 5.2 A classe $\mathrm{B}(\mathrm{A}-\mathrm{A})$ existe e type(a) $\prec$ type(A), onde type(a) é o tipo declarado de a.

O compilador substitui a\#B.new() pela chamada de procedimento PutDynamicShell (B.new (), a)

Este algoritmo, mostrado na Figura 5.5, designa obj (a) como o objeto referenciado pela variável a. A Figura 5.6 exemplifica graficamente a última instrução deste algoritmo, "Faça todas as variáveis que referem-se a obj (a) referirem-se a obj (tmp)".

O comando

remove(a) 


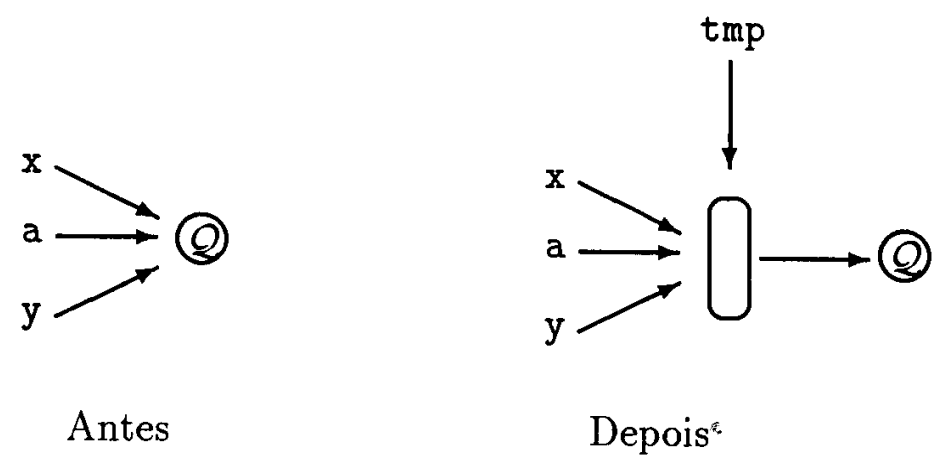

Figura 5.6: Faça todas as variáveis que se referem a obj(a) referirem-se a obj (tmp)

Algoritmo remove (a)

$\{$ Remove o último objeto shell do objeto a. Se a não possui um objeto shell, nada será feito. \}

if o objeto referenciado por a possuir um shell dinâmico then

Seja $\mathcal{R}$ o objeto shell do objeto a. Se a classe de $\mathcal{R}$ for shell@B, $\mathcal{R}$ possuirá um ponteiro super $(\mathrm{A})$ para o objeto coberto pelo objeto shell, que será chamado de $\mathcal{P}$. Note que $\mathcal{P}$ poderá ser composto por outros objetos shell — não importa. endif

Faça todas as variáveis que se referem a $\mathcal{R}$ referirem-se a $\mathcal{P}$.

Figura 5.7: Algoritmo para remover um objeto shell de um objeto

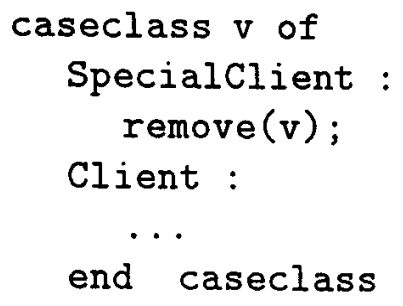

Figura 5.8: O comando caseclass usado conjuntamente com remove 
remove o último objeto shell de um objeto a, se existir algum. Ele é definido na Figura 5.7.

Aplicando-se a configuração da parte "Depois" da Figura 5.3, "remove(a1)" fará a1 referir-se a $\mathcal{Q}_{1}$. Este comando pode ser usado quando o objeto precisar retornar a um comportamento passado. Isto é, o novo comportamento introduzido pelo objeto shell não é mais necessário. remove pode ser usado com o comando caseclass, como mostrado na Figura 5.8.

\subsection{Prova da Correção Estática de Tipos}

Provaremos que os algoritmos PutDynamicShell e remove não introduzem erros de tipo em tempo de execução. Assumiremos que as condições 5.1 e 5.2 são verdadeiras. Caso contrário, haveria um erro de compilação. A prova é realizada através de uma seqüência de proposições. Assuma que um objeto shell foi colocado pela instrução

if $a \# B$.new() then ...

que é transformada em

if PutDynamicShell ( B.new (), a ) then ...

Proposição 5.1 As duas primeiras atribuições do algoritmo PutDynamicShell não introduzem erros de tipo.

Prova: A primeira atribuição do algoritmo PutDynamicShell (Figura 5.4), "tmp = Exp", é correta porque tmp pode ser considerada uma variável sem tipo. A segunda atribuição, "tmp. super $(A)=a$ ", é corretamente tipada porque type $(\operatorname{tmp} \cdot \operatorname{super}(A))=\operatorname{type}(A)($ pela definição de "super $(A) ")$ e type $(a) \prec$ type (A) pela Condição 5.2. A expressão Exp é o resultado de B.new(). Portanto, ela é um objeto da classe B e possui uma variável de instância chamada super(A), pois B é substituído por shell@B, que herda da classe A.

Seja $\mathcal{R}$ o objeto referenciado por tmp após todas as atribuições do algoritmo PutDynamicShell e $\mathcal{P}$ o objeto referenciado por a antes de a\#B.new().

Proposição 5.2 type* (shell@B) $\subset$ type $(A)$

onde type*(shell@B) é o conjunto das assinaturas dos métodos definidos em shell@B, não incluindo os métodos herdados de A.

Prova: A prova é deduzida pela Condição 5.1 e por shell@B herdar de A.

Proposição 5.3 type $(\mathcal{R})=\operatorname{type}(\mathcal{P})$

Prova: Na atribuição "tmp = Exp", um objeto do tipo type(shell@B) é atribuído a tmp, pois a expressão Exp é B.new() na chamada de PutDynamicShell. A classe shell@B substitui qualquer uso da classe B. Então, tmp possui o tipo type (A) de acordo com a Condição 5.1. Na atribuição seguinte, "tmp. super $(A)=a$ ", a variável super $(A)$ de tmp é inicializada com $\mathcal{P}$. 


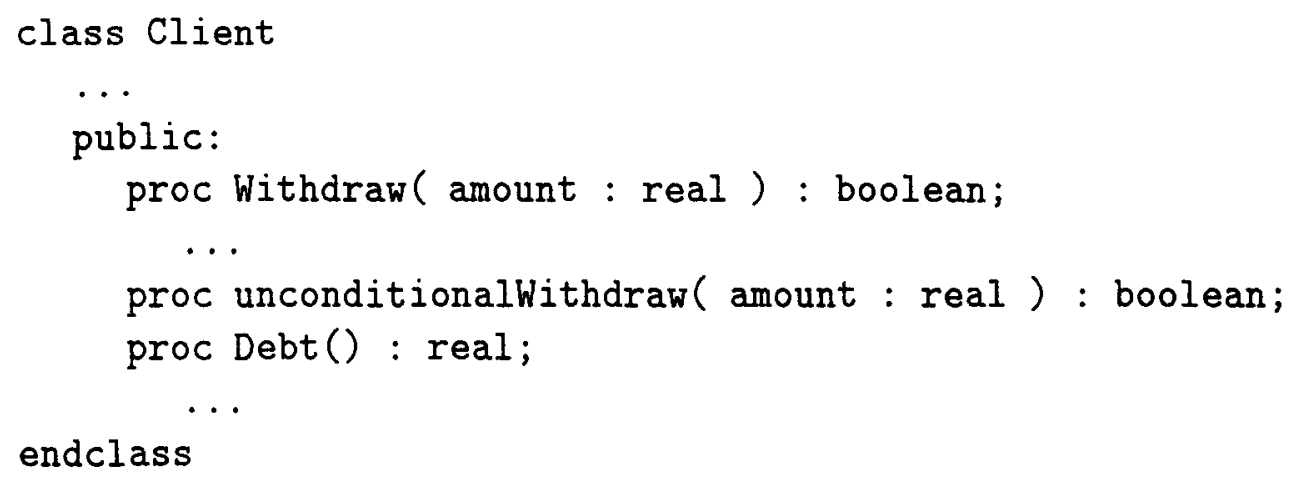

Figura 5.9: A classe Client

Depois de um envio de mensagem a tmp, o método adequado é procurado na classe shell@B e então no objeto referenciado por super $(A), \mathcal{P}$. Conclui-se que o tipo de tmp (que é o tipo de $\mathcal{R}$ ) é type* (shell@B) $\cup$ type $(\mathcal{P})$.

A linguagem é estaticamente tipada. Isto significa que uma variável referese a objetos que são subtipos de seu tipo declarado (type(Variável) $\prec$ type(objeto)). No exemplo acima, a variável a refere-se ao objeto $\mathcal{P}$ antes da avaliação de a\#B.new(). Como o tipo declarado de a é $A$, type $(A) \prec$ type $(\mathcal{P})$ e type $(A) \subset$ type $(\mathcal{P})$. Então, temos que:

1. $\operatorname{type}(\mathcal{R})=\operatorname{type} *(\operatorname{shell} @ B) \cup \operatorname{type}(\mathcal{P})$.

2. type* (shell@B) $\subset$ type(A) pela Proposição 5.2 .

3. type (A) $\subset$ type $(\mathcal{P})$

Logo, type* $(\operatorname{shell} \odot B) \subset \operatorname{type}(\mathcal{P})(\operatorname{por} 2$ e 3$)$ e type $(\mathcal{R})=\operatorname{type}(\mathcal{P})($ por 1$)$. 口

Proposição 5.4 A instrução "Faça todas as variáveis que se referem a obj(a) referirem-se a obj(tmp)" do algoritmo PutDynamicShell é corretamente tipada.

Prova: O tipo de obj(a) $(\mathcal{R})$ é o mesmo que o tipo de tmp $(\mathcal{P})$ conforme a Proposição 5.3. Então, esta instrução substitui um objeto por outro do mesmo tipo, não introduzindo erros de tipo.

Proposição 5.5 O comando remove não causa erros de tipos.

Prova: Segundo a Proposição 5.3, type $(\mathcal{R})=$ type $(\mathcal{P})$, onde $\mathcal{R}$ e $\mathcal{P}$ são os mesmos nomes de objetos empregados pelo algoritmo remove da Figura 5.7. Este algoritmo faz todas as variáveis que se referem a $\mathcal{R}$ referirem-se a $\mathcal{P}$. Como $\mathcal{R}$ e $\mathcal{P}$ possuem o mesmo tipo, remove é corretamente tipado. 


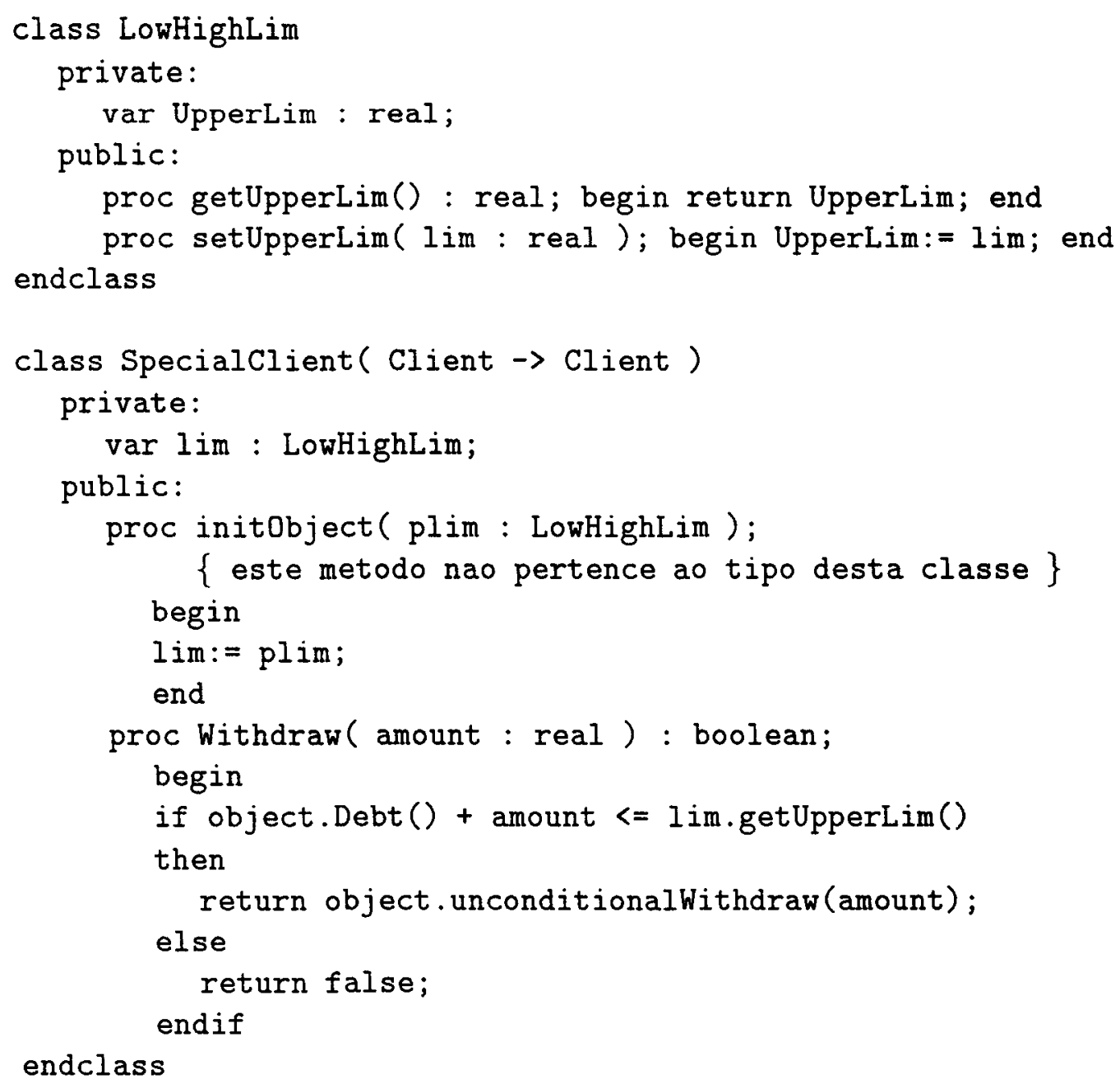

Figura 5.10: Um shell para objetos da classe Client 


\subsection{A Solução do Problema}

Agora o problema com a classe Client apresentado no começo deste capítulo pode ser resolvido. Suponha que esta classe seja aquela mostrada na Figura 5.9 e que seja necessário aumentar o limite de crédito de alguns estudantes e cidadãos da terceira idade. Isto pode ser obtido através do shell SpecialClient e da classe LowHighLim da Figura 5.10. A solução do problema é apresentada na Figura 5.11. Neste exemplo, cada objeto shell (classe Specialclient) possui uma referência para um objeto da classe LowHighLim com o limite de crédito. O objeto StudLim mantém o limite de crédito para todos os estudantes. $O$ objeto SeniorLim faz o mesmo para os cidadãos da terceira idade.

É possível a existência de várias classes de shell dinâmico sendo usadas com uma mesma classe. Isto permite a cada classe shell representar as diferentes mudanças de comportamento exigidas aos objetos da classe. Os diferentes tipos de transformações que um objeto deve sofrer durante a sua vida podem ser mapeados para diferentes classes shell.

Pode-se utilizar shell dinâmico para resolver o problema parte-todo descrito por Kusumoto e Murata [35] e Blake e Cook [36]. O todo (um objeto) usa as suas partes (variáveis de instância do objeto) enquanto executa os seus métodos. Um exemplo de problema [35] é um objeto "sinal de tráfego" que possui três lâmpadas: vermelha, amarela e verde. Para manipular o objeto "luz vermelha", deve-se enviar mensagens ao objeto "sinal de tráfego", que deve redirecionar estas mensagens à luz vermelha, armazenada no "sinal de tráfego".

É necessário criar métodos para manipular as luzes amarela e verde também, resultando em uma grande quantidade de métodos apenas para manipular as partes do objeto "sinal de tráfego". Uma solução alternativa seria permitir ao sinal de tráfego retornar suas luzes em resposta a envios de mensagem (por exemplo, getRedLight). Neste caso, as luzes poderiam ser manipuladas fora do objeto. Contudo, esta opção cria um problema porque as três luzes precisam ser sincronizadas - somente uma deve estar acessa a cada vez. Kusumoto e Murata resolvem este problema usando daemons, que são disparados quando certas mensagens são enviadas às luzes. Então, o daemon desliga as luzes amarela e verde quando a luz vermelha recebe a mensagem Turnon.

Shell dinâmico pode solucionar o problema parte-todo. O objeto "sinal de tráfego" precisa possuir métodos para retornar as suas luzes (como getRedLight), mas as luzes são previamente cobertas por shells dinâmicos. Se algum objeto receber uma luz vermelha através de getRedLight e enviar a ela uma mensagem Turnon, o shell que cobre esta luz enviará mensagens Turnoff às lâmpadas amarela e verde do sinal de tráfego e então redirecionará TurnOn para a luz vermelha. Para obter tais resultados, o shell dinâmico deverá possuir referências para as outras luzes do sinal de tráfego. Isto é conseguido através de um objeto comum que é compartilhado pelos shells que cobrem as luzes. Este objeto é também referenciado por uma variável do objeto "sinal de tráfego".

$\mathrm{O}$ código que implementa esta solução é mostrado nas Figuras 5.12 e 5.13. A classe TrafficLight possui uma variável de instância chamada control. $\mathrm{O}$ objeto referenciado por esta variável referencia as três lâmpadas da classe 


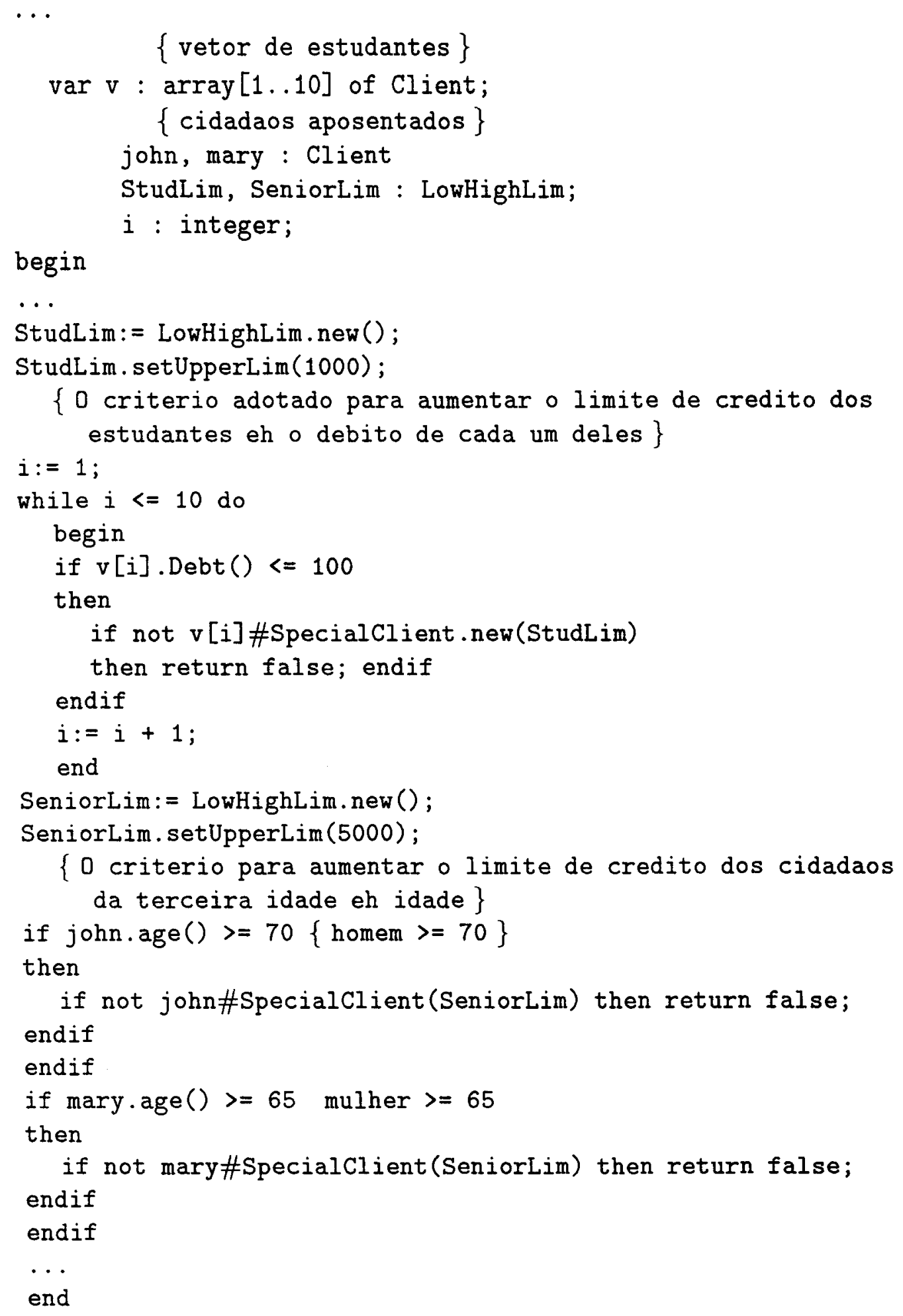

Figura 5.11: Um exemplo de uso de shell dinâmico 


\section{class Light}

...

public:

proc Turnon(); ...

proc Turnoff ()$; \ldots$

endclass

class Controllight

private:

var red, yellow, green : Light;

public:

proc setAll ( $r, y, g$ : Light );

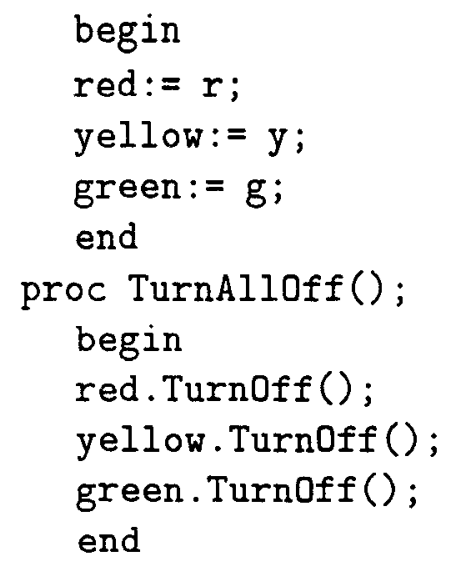

endclass

Figura 5.12: Classes Light e Controllight 


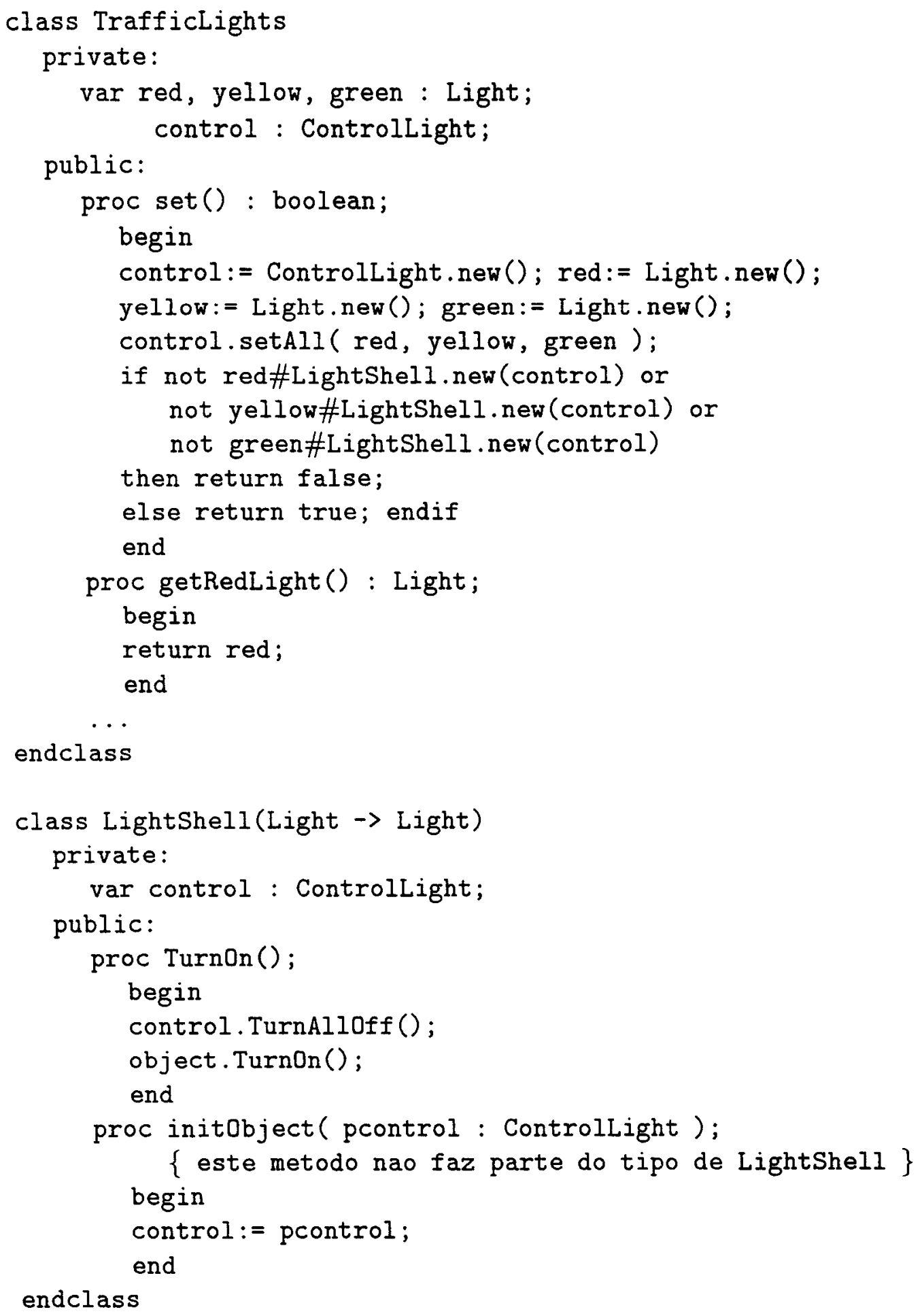

Figura 5.13: Solução do problema parte-todo com shell dinâmico 
TrafficLights. Veja a instrução

control.setall (red, yellow, green)

no método set de TrafficLights. Neste mesmo método são criados três shells, um para cada lâmpada. Cada um destes shells referencia a variável control veja método initobject ${ }^{3}$ de LightShell e a criação dos shells no método set de TrafficLights. A lâmpada vermelha do sinal de tráfego pode ser obtida pelo método getRedLight de TrafficLights. Quando uma mensagem Turnon for enviada a esta lâmpada, o método Turnon de LightShell será executado. Este método desliga todas as lâmpadas do sinal de tráfego (control. TurnAlloff()) e depois chama o método Turnon da luz vermelha.

\subsection{Implementação}

Shell dinâmico é implementado fazendo-se cada variável um ponteiro para um ponteiro para um objeto, ao invés de apenas um ponteiro para um objeto, como nas implementações normais. Se várias variáveis se referirem a um objeto $\mathcal{Q}$, elas de fato apontarão para o mesmo ponteiro (digamos, p), o qual apontará para $\mathcal{Q}$. Um objeto shell é colocado ao redor de $\mathcal{Q}$ criando-se dinamicamente de uma subclasse, como explicado adiante.

Suponha que as classes do objeto shell e $\mathcal{Q}$ sejam B e A, respectivamente. $O$ sistema de tempo de execução cria uma classe dinâmica $B^{\prime}$ com os mesmos métodos de B e que herda a classe A. Os envios de mensagens para "object" dentro dos métodos de $B^{\prime}$ são mudados para envios de mensagens para "super(A)". Naturalmente, se um shell dinâmico da classe $B$ foi colocado sobre um objeto da classe $A$ anteriormente, a classe $B^{\prime}$ já foi criada uma vez e será reusada.

Um objeto da classe $\mathrm{B}^{\prime}$ é criado e as variáveis de instância de $\mathcal{Q}$ são copiadas para ele usando cópia rasa. ${ }^{4}$ Isto significa que o objeto shell (classe B) e $\mathcal{Q}$ (classe A) são unidos em um único objeto da classe B'. Então, o ponteiro p é modificado para apontar para este objeto.

Explicaremos estas operações em detalhes a seguir. Para isto, será necessário entender como o algoritmo de busca por método funciona. Cada classe possui uma tabela de pares

(nome do método, ponteiro para o método)

contendo todos os métodos da classe, incluindo aqueles herdados. Cada objeto possui um ponteiro para a tabela de sua classe. Quando uma mensagem for enviada a um objeto, o nome ${ }^{5}$ da mensagem será usado como uma chave para recuperar o endereço do método da tabela de métodos da classe do objeto, usando uma função de espalhamento (hash).

Para criar a classe $\mathrm{B}^{\prime}$, o sistema de tempo de execução

\footnotetext{
${ }^{3}$ Este método é chamado na criação de um objeto por new - veja Apêndice A.

${ }^{4}$ Cópia rasa significa que as variáveis de instância do objeto da classe $B^{\prime}$ recebem as correspondentes variáveis de instância de $\mathcal{Q}$ através de atribuições. As variáveis de instância do objeto da classe $\mathrm{B}^{\prime}$ e $\mathcal{Q}$, após a cópia, passarão a se referir aos mesmos objetos.

${ }^{5}$ Dizemos "nome" mas de fato é usado um número inteiro associado com este nome.
} 


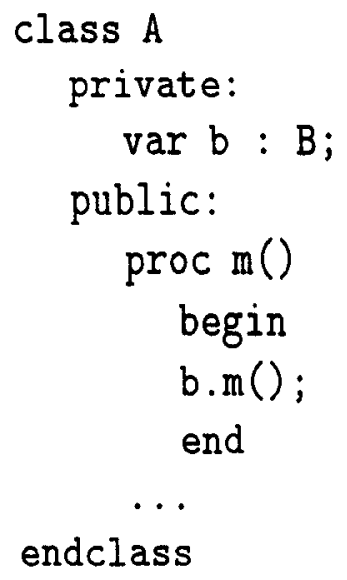

Figura 5.14: Uma simulação de shell dinâmico

1. faz uma cópia dos métodos da classe B. Cada envio de mensagem para "object" dentro destes métodos é mudado para uma chamada do correspondente método da classe A. Isto resulta em ligação estática, como em qualquer mensagem para "super" na linguagem que usamos (e na maioria das linguagens). Como os métodos da classe B são compilados em código de máquina, este passo modifica código objeto e não código fonte. Os métodos criados acima serão chamados de "os métodos da classe B";

2. cria uma tabela de métodos para a classe $B^{\prime}$ como se ela herdasse da classe A. O sistema de tempo de execução aloca memória para esta tabela, copia a tabela de métodos para a classe A para ela e atualiza as entradas desta tabela correspondentes aos métodos da classe $\mathrm{B}^{\prime}$. Uma entrada nesta tabela correspondente a um método definido em ambos $\mathrm{A}_{\text {e }} \mathrm{B}^{\prime}$ aponta para o método da classe $B^{\prime}$. A classe $B$ (e portanto $B^{\prime}$ ) não pode definir qualquer método não definido na classe $A$.

\subsection{Trabalhos Relacionados}

Davis [37] propôs uma técnica aplicável a qualquer linguagem orientada a objetos que permite a um objeto "mudar" o seu tipo. Uma classe, por exemplo A, é definida com um ponteiro para uma classe base, por exemplo B. Os métodos de A simplesmente redirecionam todas as mensagens para o ponteiro da classe B veja a Figura 5.14.

A classe B é supertipo de várias classes e a variável de instância b pertencente à classe A pode apontar para objetos de cada subtipo de B. Fazendo b apontar para objetos de diferentes subtipos de $\mathrm{B}$, estamos simulando a mudança de tipos do objeto da classe A em uso. Seu comportamento dependerá da classe do objeto b. Esta técnica simula algumas propriedades de shell dinâmico.

Shell dinâmico foi projetado após uma sugestão de Traina ${ }^{6}$ sobre mudar o tipo

\footnotetext{
${ }^{6}$ Traina Junior, Caetano. Comunicação pessoal, 1993.
} 
de um objeto em tempo de execução. Este foi o ponto de partida desta idéia, que evolui para não mudar o tipo, mas apenas os métodos do objeto.

Shell dinâmico é uma versão estaticamente tipada de meta-objetos [19] [20], embora ele não tenha sido baseado nesta facilidade. 0 relacionamento entre shell dinâmico e meta-objetos é discutido no Capítulo 8, que apresenta alguns trabalhos relacionados ao assunto. 


\section{Capítulo 6}

\section{Extensão Dinâmica}

\subsection{Introdução}

Extensão dinâmica possui algumas das características de meta-classes, as quais são usadas para representar as estruturas das classes e mudá-las dinamicamente.

Extensão dinâmica permite colocar um shell sobre uma classe em tempo de execução, o que significa que um objeto shell é colocado sobre cada objeto desta classe que existe agora ou que será criado (com new) mais tarde. Uma variável que se refere a um objeto desta classe referir-se-á ao objeto shell o qual, por sua vez, referir-se-á ao objeto. Esta situação é representada na Figura 6.1. Esta Figura mostra as referências antes e depois de uma extensão dinâmica ser colocada sobre a classe A, à qual pertencem todos os objetos da figura. Os objetos das extensões dinâmicas são representados por retângulos com bordas arredondadas. Uma mensagem enviada a uma variável é procurada no objeto shell e, se ela não for encontrada lá, será procurada no objeto.

\subsection{A Definição de Extensão Dinâmica}

A sintaxe para declarar uma extensão dinâmica (Figura 6.2) é exatamente igual à sintaxe para uma extensão normal, com a restrição de não se permitir variáveis de

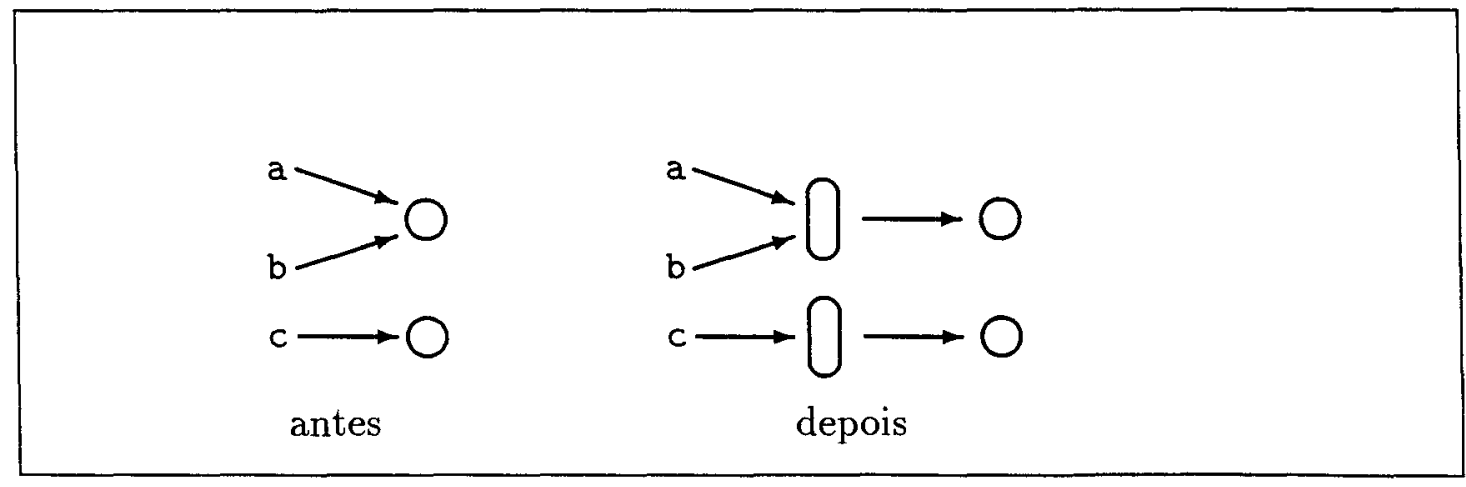

Figura 6.1: Antes e depois de uma extensão para a classe A ser criada dinamicamente 


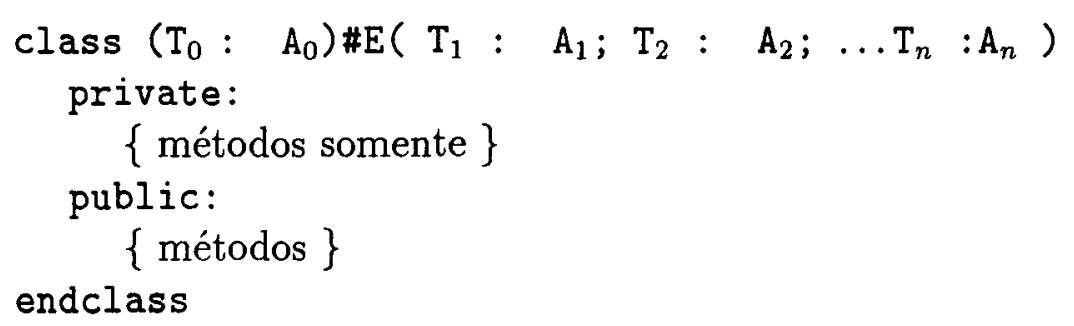

Figura 6.2: Sintaxe para extensão dinâmica

instância. Sem esta limitação, as variáveis de instância de cada shell deveriam ser inicializadas após a colocação do shell dinâmico sobre a classe, gerando problemas de desempenho.

Uma extensão dinâmica pode ser colocada sobre uma classe através da sintaxe if $B_{0} \# E\left(B_{1} \ldots B_{n}\right)$ then $\ldots$ else ... endif

onde a expressão $B_{0} \# E\left(B_{1}, \ldots, B_{n}\right)$ retornará false se não existir memória disponível suficiente para criar dinamicamente os objetos shell para todos os objetos da classe $\mathrm{B}_{0}$ ou qualquer estrutura auxiliar. Caso contrário, esta expressão retornará true. Uma implementação típica de shell dinâmico não criaria nenhum objeto shell, mas ela poderia necessitar de algumas estruturas de dados dinâmicas e talvez não haja memória disponível suficiente para fazer isto. Naturalmente, se a expressão retornar false, a extensão não será colocada sobre a classe.

Uma extensão dinâmica como aquela da Figura 6.2 é representada como

(Nome, PrimParametro, Parametros, Metodos)

onde Nome, Parametros e Metodos possuem o mesmo significado que na representação de classes parametrizadas (Seção A.3). PrimParametro é composto por um nome e um tipo - ele corresponde a $\left(\mathrm{T}_{0}, \mathrm{~A}_{0}\right)$ do exemplo da Figura 6.2.

Uma extensão dinâmica

$\left(E,\left(T_{0}, A_{0}\right),\left(\left(T_{1}, A_{1}\right), \ldots\left(T_{n}, A_{n}\right)\right), M s\right)$

é transformada pelo compilador na classe parametrizada

$$
E^{\prime}=\left(E,\left(\left(T_{0}, A_{0}\right),\left(T_{1}, A_{1}\right), \ldots\left(T_{n}, A_{n}\right)\right),\{\},\{\}, M s,\{\},\{\}\right)
$$

A extensão dinâmica, como qualquer outro shell, deve ser colocada no arquivo shell.

Quando o compilador encontra a expressão

$$
B_{0} \# E\left(B_{1}, B_{2}, \ldots B_{n}\right)
$$

no arquivo do programa, ele:

1. instancia $E^{\prime}$ com $B_{0}, B_{1}, \ldots B_{n}$, criando uma nova classe $B_{0}^{\prime}$;

2. faz $B_{0}^{\prime}$ herdar de $B_{0}$;

3. substitui todos os símbolos "object" em $B_{0}^{\prime}$ por "super $\left(B_{0}\right)$ ";

4. compila $B_{0}^{\prime}$ e testa se type $\left(B_{0}\right)=\operatorname{type}\left(B_{0}^{\prime}\right)$. Isto é, a extensão dinâmica não deve adicionar nenhum método novo a $B_{0}$; 
Algoritmo PutDynamicExtension $\left(B_{0}^{\prime}, B_{0}\right)$

$\left\{\right.$ Este algoritmo coloca a extensấo dinâmica $\mathrm{B}_{0}^{\prime}$ em objetos da classe $B_{0}$. Ele retornará false se não existir memória disponível suficiente $\}$

if não existir memória livre suficiente then

return false;

endif

for each objeto $\mathcal{Q}$ da classe $B_{0}$ do programa, do:

newShell $=B_{0}^{\prime}$. new ();

$\{$ newShell possui uma variável de instância

chamada super $\left(B_{0}\right)$, pois $B_{0}^{\prime}$ herda de $B_{0}$.

newShell. super $\left(B_{0}\right)=\mathcal{Q}$;

Faça todas as variáveis que se referem a $\mathcal{Q}$ referirem-se a newShell return true

Figura 6.3: Algoritmo para colocar uma extensão dinâmica sobre uma classe

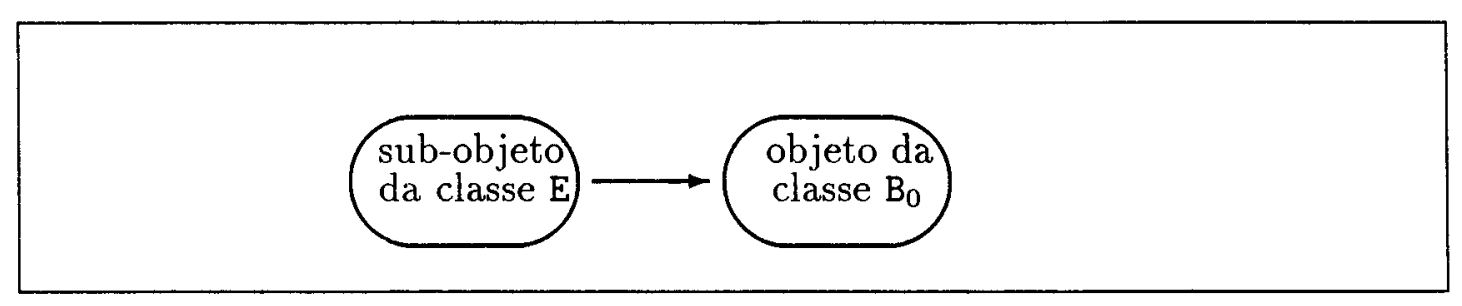

Figura 6.4: Um objeto da classe $\mathrm{B}_{0}^{\prime}$

5. substitui a expressão $B_{0} \# E\left(B_{1}, B_{2}, \ldots, B_{n}\right)$ pela chamada de subrotina PutDynamicExtension $\left(B_{0}^{\prime}, B_{0}\right)$

Esta subrotina é definida na Figura 6.3 (explicada posteriormente).

A classe $B_{0}^{\prime}$ é composta pelos métodos da classe $E$ e por uma herança de $B_{0}$. Segundo a representação de objetos da Seção A.2, um objeto da classe $B_{0}^{\prime}$ é composto por um sub-objeto que possui os métodos da classe $\mathrm{E}$ e por um objeto da classe $B_{0}$. O sub-objeto refere-se ao objeto da classe $B_{0}$ através de um ponteiro chamado "super $\left(B_{0}\right)$ ", como mostrado na Figura 6.4.

Para cada objeto $\mathcal{Q}$ da classe $B_{0}$ existente neste instante no programa, o algoritmo PutDynamicExtension da Figura 6.3 cria um objeto da classe $\mathrm{B}_{0}^{\prime}$ e faz newShell referir-se a ele. Depois, ele faz o sub-objeto da classe E, pertencente ao objeto da classe $\mathrm{B}_{0}^{\prime}$, referir-se a $\mathcal{Q}$ através de sua variável de instância "super $\left(\mathrm{B}_{0}\right)$ " na instrução "newShell. super $\left(B_{0}\right)=\mathcal{Q}$ ". Em seguida, o algoritmo faz com que todas as variáveis que se referem a $\mathcal{Q}$ passem a se referir a newShell, que se refere a um sub-objeto da classe E.

Uma representação gráfica do que acontece a $\mathcal{Q}$ antes da instrução

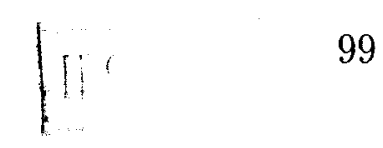




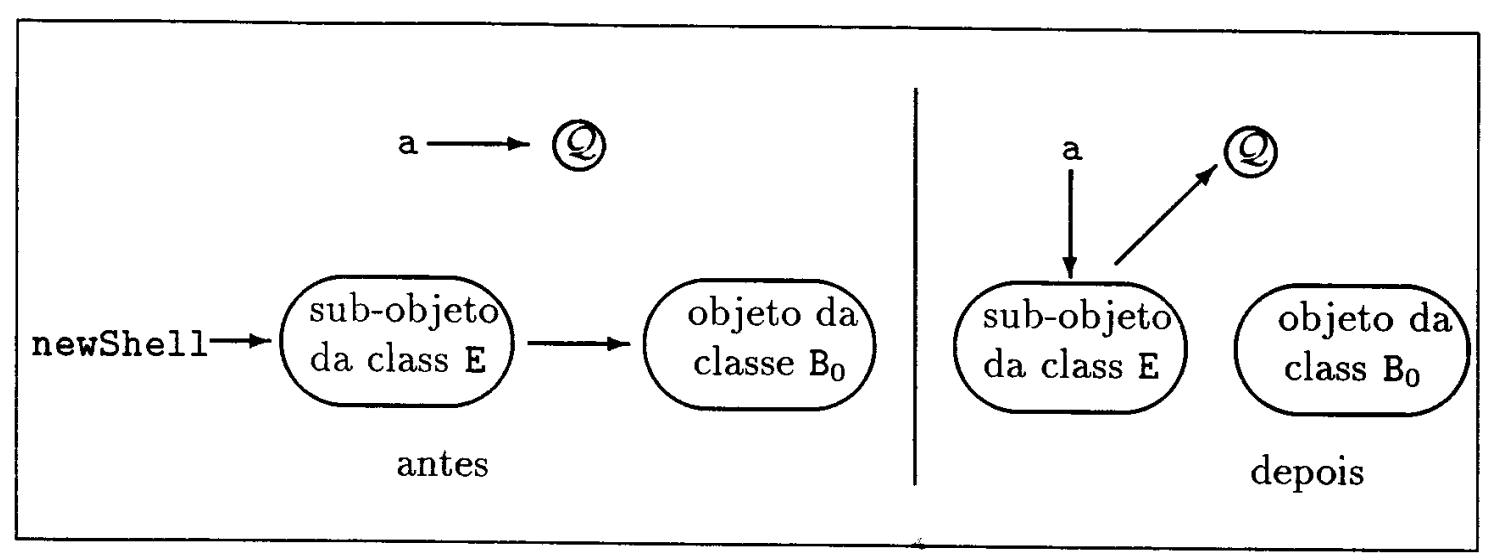

Figura 6.5: Antes e depois de um shell ser colocado em $\mathcal{Q}$

"newShell. super $\left(B_{0}\right)=\mathcal{Q}$ " e depois da instrução "Faça todas as variáveis ... newShell" é mostrada na Figura 6.5. Note que o objeto da classe $B_{0}$ deixa de ser referênciado por qualquer variável depois destas instruções.

\subsection{A Prova de Correção de Tipos}

Agora será provado que o algoritmo PutDynamicExtension não introduz erros de tipo em tempo de execução. Cada instrução do algoritmo será examinada.

Proposição 6.1 O algoritmo PutDynamicExtension é correto com relação a tipos.

Prova: A primeira instrução (o comando if) não possui atribuições ou envios de mensagens e, portanto, é corretamente tipada. A atribuição "newShell = $\mathrm{B}_{0}^{\prime}$. new ()" é corretamente tipada porque newShell pode ser considerado sem tipo.

A variável de instância "super $\left(B_{0}\right)$ " de newShell possui tipo type $\left(B_{0}\right)$ e refere-se a um objeto da classe $B_{0}$. A atribuição "newShell. super $\left(B_{0}\right)=\mathcal{Q}$ " inicializa "super $\left(B_{0}\right)$ " com outro objeto da classe $B_{0}$ e, portanto, é correta. Dentro dos métodos do objeto newShell, podem existir envios de mensagens a "super $\left(B_{0}\right)$ " que poderiam resultar em erros em tempo de execuçâo por causa da atribuição à variável "super $\left(B_{0}\right)$ ". Contudo, não haverá erro porque o tipo de "super $\left(B_{0}\right)$ " não é modificado na atribuição.

No algoritmo PutDynamicExtension, type (newShell) $=$ type $\left(B_{0}^{\prime}\right)$ e $\operatorname{type}(\mathcal{Q})=\operatorname{type}\left(\mathrm{B}_{0}\right)$. Pela definição de extensão dinâmica, type $\left(\mathrm{B}_{0}^{\prime}\right)=$ type $\left(B_{0}\right)$ e, portanto, a instrução "Faça todas as variáveis que se referem a $\mathcal{Q}$ referirem-se a newShell" é corretamente tipada porque $\mathcal{Q}$ e newShell possuem o mesmo tipo.

Ao contrário de extensões de classes, a extensão dinâmica E da Figura 6.2 não pode possuir nenhum método público que não pertença ao tipo $A_{0}$. Isto impede erros de tipo, como aquele da Figura 6.6. Em tempo de compilação, B é subtipo de $\mathrm{A}$, mas quando $\mathrm{A} \# \mathrm{E}$ for avaliado, o método $\mathrm{n}$ será adicionado à classe $\mathrm{A} \mathrm{e}$, portanto, a classe B não será mais um subtipo de A. Após o objeto de B ser passado como 


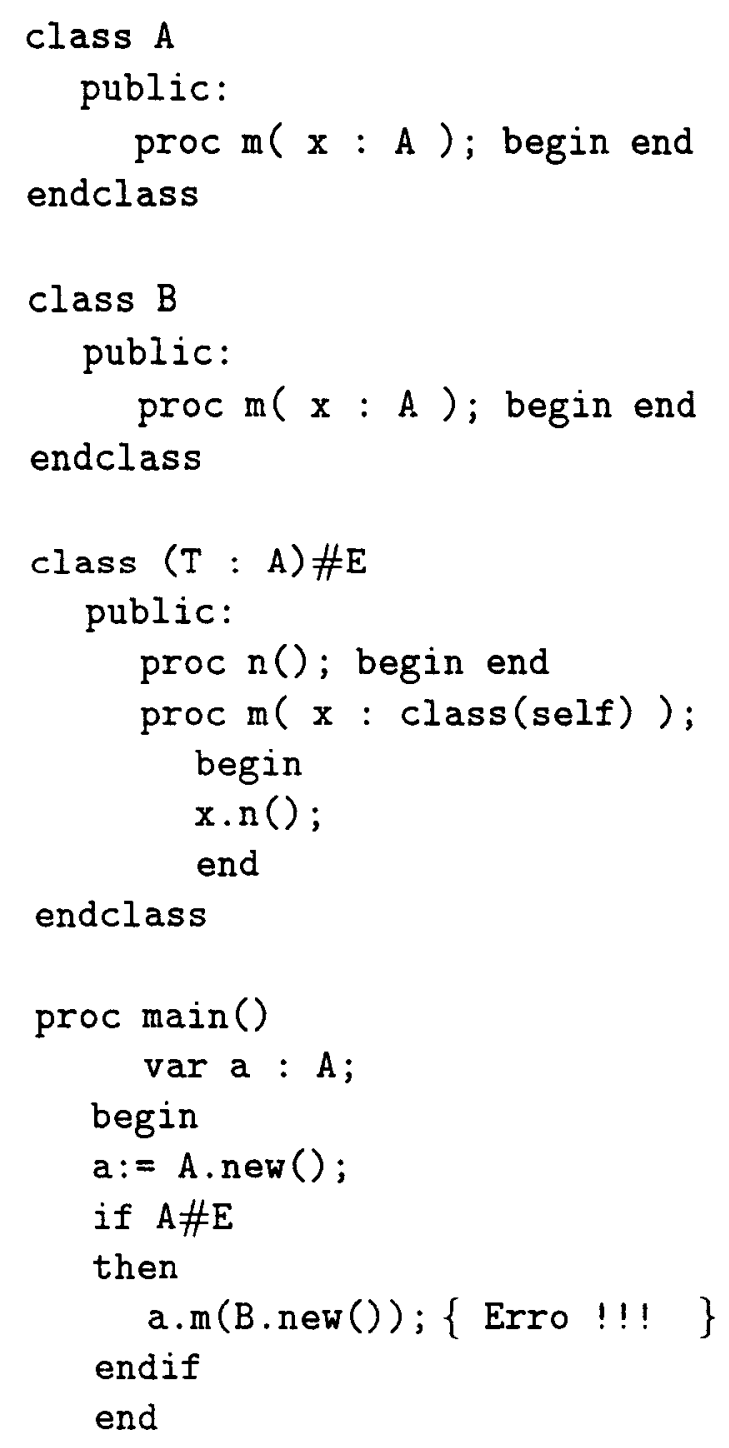

Figura 6.6: Um erro em tempo de execução

um parâmetro para o método $m$ na instrução a.m(B.new()), ele recebererá uma mensagem n cujo método correspondente ele não possui, provocando um erro em tempo de execução.

Note que a instanciação da extensão dinâmica seria válida se ela fosse uma extensão de classe. Neste caso, o compilador detectaria que a nova classe A não é um supertipo de B, sinalizando um erro na instrução a.m(B.new()).

\subsection{Implementação}

A implementação de extensão dinâmica é semelhante à de shell dinâmico. Para explicá-la, assumiremos que cada classe possui uma tabela de pares

(nome do método, ponteiro para o método) 
contendo todos os métodos da classe, incluindo aqueles herdados. Cada objeto possui um ponteiro para a tabela de sua classe. Quando uma mensagem for enviada a um objeto, o nome da mensagem será usado como uma chave para recuperar o endereço do método da tabela de métodos da classe do objeto, usando uma função de espalhamento (hash).

Quando uma classe B for colocada sobre uma classe A, o sistema de tempo de execução:

1. fará uma cópia dos métodos da classe B. Cada envio de mensagem para "object" dentro destes métodos será mudado para uma chamada do correspondente método da classe $A$. Os métodos criados acima serão chamados de "métodos da classe B";

2. atualizará as entradas da tabela de métodos da classe A com os métodos da classe $\mathrm{B}^{\prime}$ correspondentes. Uma entrada desta tabela correspondente a um método definido em ambos $A$ e $B^{\prime}$ apontará para o método da classe $B^{\prime}$.

Estas operações são equivalentes a criar dinamicamente uma subclasse de A e fazê-la substituir A.

Implementamos shell dinâmico e extensão dinâmica ${ }^{1}$ usando técnicas similares àquelas descritas acima e na seção 5.7. Foi utilizado um interpretador de um subconjunto da linguagem usada nesta tese. Estas construções foram adicionadas ao interpretador em menos de um dia de trabalho, incluindo a codificação, edição do programa, compilação e depuração dos erros.

\subsection{Trabalhos Relacionados}

Extensões dinâmicas possuem algumas das funções de meta-classes. Uma metaclasse é a classe de uma classe [21] [38] [19]. Uma classe é um objeto de sua metaclasse e, como qualquer objeto, ela pode receber mensagens. Na linguagem utilizada nesta tese, a meta-classe de cada classe possui automaticamente um método chamado new para criar instâncias não inicializadas da classe. Outras variáveis de instância e métodos podem ser adicionados a uma meta-classe colocando-as na seção share da classe correspondente. Para enviar uma mensagem a um objeto de uma meta-classe, deve-se enviar a mensagem para o nome da classe (por exemplo, "A. new ()"). O nome da classe funciona como uma variável representando o objeto que é a classe. Da mesma forma que em Smalltalk, nossas meta-classes não possuem nomes e existe exatamente uma meta-classe para cada classe. A ligação de mensagens enviadas para classes (como new) é feita em tempo de compilação, pois o compilador sabe qual método será executado em tempo de execução não há polimorfismo. Métodos de meta-classes não são herdados na linguagem empregada nesta tese. Isto introduziria um polimorfismo inútil com meta-classes e tornaria mais complexa a linguagem.

\footnotetext{
${ }^{1}$ Sem usar classes parametrizadas.
} 
Meta-classes em Smalltalk [21] e ObjVlisp [38] podem ser usadas para adicionar/remover métodos de instância ${ }^{2}$, mudar a superclasse de uma classe, informar quais métodos a classe possui e assim por diante.

A maioria das funcionalidades de meta-classes são inseguras quanto a tipo. Por exemplo, a remoção de um método de uma classe causará o erro "mensagem não entendida" se a mensagem correspondente for enviada a uma instância da classe. Um erro semelhante pode ocorrer se a superclasse de uma classe for removida ou trocada por outra. Contudo, meta-classes permitem algumas transformações seguras. Por exemplo, pode-se substituir o corpo de um método sem introduzir nenhum erro de tipos se a assinatura do método não for modificada. Outra transformação segura é substituir a superclasse por outra que suporte exatamente os mesmos métodos. ${ }^{3}$

Extensão dinâmica possui muitas das características seguras de meta-classes. Ela permite substituir vários ou todos os métodos de uma classe em tempo de execução. As classes de extensão dinâmica são parametrizadas e, portanto, podem se adequar a cada classe à qual elas são acopladas. Ao contrário de meta-classes de Smalltalk, extensões dinâmicas podem ser agrupadas em uma biblioteca e reusadas. Esta construção pode ser implementada sem diminuir a eficiência do envio de mensagens e sem introduzir erros de tipo. Uma discussão mais profunda da relação entre extensão dinâmica e meta-classes será apresentada no Capítulo 8.

\footnotetext{
${ }^{2}$ Métodos de instância são os métodos definidos na classe e são usados por instâncias da classe (objetos normais). Métodos de classe são definidos na meta-classe e são usados enviandose mensagens para o nome da classe.

${ }^{3} \mathrm{Em}$ Smalltalk, as subclasses podem manipular as variáveis de instância das superclasses. Neste caso, a nova superclasse da classe deveria também possuir as variáveis de instância que são usadas pelas subclasses.
} 


\section{Capítulo 7}

\section{Relacionamentos Entre Shells}

A presença de vários tipos de filtros/shells (de agora em diante, shells) na linguagem poderia resultar na seguinte situação: uma variável v refere-se, em tempo de execução, a um shell de algum tipo (ex: shell dinâmico), o qual, por sua vez, refere-se a um shell de um outro tipo (ex: adaptadores). Algumas situações como esta poderiam resultar em erros, como remover o adaptador sem fazer o mesmo com o shell dinâmico. Então, o shell dinâmico referir-se-á a um objeto que possui um tipo diferente do que ele espera.

Uma combinação de shells é proibida se ela puder fazer com que uma variável refira-se a uma seqüencia de shells na qual existam shells de mais de uma variedade. ${ }^{1}$ Nem todas as situações como esta poderiam resultar em erros de tipo, mas escolhemos proibir todas elas por simplicidade. Uma futura pesquisa poderia reduzir a quantidade de restrições sem danificar a segurança da linguagem.

$\mathrm{Se}$ todas as atribuições permitidas na linguagem fossem do tipo "Tipo:= Tipo", ${ }^{2}$, então deveríamos proibir o uso de duas construções shell que utilizassem objetos do mesmo tipo. Como a linguagem permite atribuições do tipo "Tipo:= Subtipo", é proibido existir dois shells que possam ser usados com objetos da mesma hierarquia de tipos. Isto é, dado um tipo $T$, dois shells quaisquer não podem ser usados com nenhuma classe cujo tipo pertence ao conjunto calculado pelo algoritmo all da Figura 7.1, onde Subtypes (T) (Supertypes (T)) é o conjunto de todos os subtipos (supertipos) de $T$ no programa em questão. all ( $T$ ) retorna todos os tipos que são relacionados de qualquer forma ao tipo $T$. Por exemplo, all $(T)=\{T, U, W\}$, onde a hierarquia de tipos do programa é aquela mostrada na Figura 7.2. Note que $U \in \operatorname{all}(T)$, embora $U$ não seja um subtipo ou supertipo de $T$.

É necessário encontrar os tipos que cada shell afeta aplicando-se os procedimentos seguintes.

- Em uma visão de classe para uma classe A, somente objetos da classe A serão usados com este shell. Assim, o tipo afetado por esta visão de classe é type (A).

O conjunto de tipos afetados por todas as visões de classe do programa é

\footnotetext{
${ }^{1}$ Estamos chamando "variedade" cada uma das cinco construções shell propostas nesta tese.

${ }^{2}$ Os tipos determinados estaticamente em ambos os lados da atribuição são iguais.
} 
Algoritmo all $(T)$

$\{$ Retorne o conjunto de tipos $R$ tal que :

1. $R$ contém todos os subtipos e supertipos de $T$

2. $R$ contém todos os subtipos e supertipos de qualquer tipo que pertença a $R$ \}

Seja $G(V, E)$ um grafo onde os vértices são os tipos do programa e existe uma aresta não dirigida entre um tipo e o seu supertipo.

Então, faça uma busca em profundidade em $\mathrm{G}$, começando em $T$, colocando no conjunto $R$ (inicialmente vazio) todos os vértices visitados. return $R$

Figura 7.1: Algoritmo para calcular todos os tipos relacionados a $T$

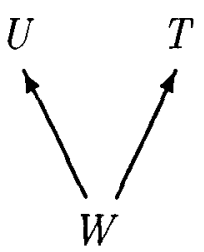

Figura 7.2: Uma hierarquia de tipos

CL $=\{U \mid \exists$ visão de classe para a classe A e $U \in \operatorname{all}($ type(A)) $\}$

- Um adaptador $B \rightarrow A$ converte um objeto do tipo type(B) em um objeto do tipo type (A). Portanto, os tipos relacionados a adaptadores são

$\mathrm{AD}=\{U \mid$ Há um adaptador $\mathrm{B} \rightarrow \mathrm{A}$ ou $\mathrm{A} \rightarrow \mathrm{B} \mathrm{e}$

$U \in \operatorname{all}($ type (A)) $\}$

- Um shell dinâmico $\mathrm{B}(\mathrm{A} \rightarrow \mathrm{A})$ afeta objetos do tipo type(A) e portanto o conjunto de tipos relacionados a este tipo de shell é

$\mathrm{DS}=\{U \mid \exists$ um shell dinâmico $\mathrm{B}(\mathrm{A} \rightarrow \mathrm{A})$ e $U \in \operatorname{all}(\operatorname{type}(\mathrm{A}))\}$.

- A instanciação de uma extensão dinâmica

if $\mathrm{A \# E}\left(\mathrm{B}_{0}, \ldots \mathrm{B}_{n}\right)$ then

afeta objetos do tipo type(A). Portanto, o conjunto de tipos que este shell afeta é

$\mathrm{DE}=\{U \mid \exists$ uma instanciação de uma extensão dinâmica para a classe A e $U \in \operatorname{all}($ type(A)) $\}$.

Não é necessário analisar extensões de classe. Quando uma extensão de classe for colocada sobre uma classe, a própria classe será modificada, o que equivale a modificações realizadas pelo próprio programador. Como o programador pode sempre alterar o seu próprio código, uma extensấo de classe sempre pode ser 
colocada sobre uma classe. Isto pode causar erros de compilação, mas não erros em tempo de execução.

As regras que se aplicam ao uso de vários objetos shell de uma mesma variedade em um programa foram discutidas nas seções que descrevem cada tipo de shell. Por este motivo, elas não serão repetidas aqui.

Para impedir que duas variedades diferentes de shell sejam usadas em uma mesma hierarquia de tipos, é necessário exigir que a intersecção dos conjuntos definidos acima seja vazia:

$\mathrm{CL} \cap \mathrm{AD} \cap \mathrm{DS} \cap \mathrm{DE}=\{\}$ 


\section{Capítulo 8}

\section{Reflexão Computacional e as Construções Shell}

\subsection{Introdução}

Um programa será reflexivo se ele:

- possuir dados descrevendo alguns aspectos de si mesmo;

- puder alterar alguns dos dados que o descrevem, causando mudanças no próprio programa.

Uma linguagem de programação será reflexiva se nela puderem ser escritos programas reflexivos. Dizemos que uma linguagem reflexiva suporta reflexão computacional.

Uma linguagem orientada a objetos reflexiva possibilita a um programa manipular os dados descrevendo as hierarquias de herança, os métodos suportados por uma dada classe, a classe de um objeto, e assim por diante [64] [68] [11]. Uma linguagem completamente reflexiva permite adicionar/remover métodos de uma classe em tempo de execução, mudar relações de herança e trocar o algoritmo de busca por método. Contudo, a maioria das linguagens adota somente um conjunto limitado de caracteristicas reflexivas, como Smalltalk [21], ObjVlisp [38], Open $\mathrm{C}++[11]$ e Oberon-2 [12].

Reflexão tem sido implementada principalmente em linguagens sem tipo como Smalltalk, ObjVlisp e 3-KRS [20]. Contudo, há algumas tentativas de introduzir reflexão em linguagens estaticamente tipadas, com Open $\mathrm{C}++$ e Oberon-2.

\subsection{Modelos Reflexivos Existentes}

De acordo com Ferber [19], características reflexivas de linguagens orientadas a objeto podem ser divididas em três categorias:

1. o modelo meta-classe;

2. o modelo meta-objeto; 
3. o modelo meta-comunicação.

O modelo meta-classe foi introduzido por Smalltalk [21]. Nesta linguagem, cada classe é uma instância de uma meta-classe sem nome que descreve a sua estrutura (variáveis de instância e métodos suportados). Uma meta-classe é criada automaticamente para cada classe do programa e há uma correspondência um a um entre classes e meta-classes. O programador não possui nenhum controle direto na criação de meta-classes.

O modelo de ObjVlips [38] remove as limitações das meta-classes de Smalltalk. Ele permite a criação explícita de meta-classes pelo programador. Um conjunto de classes pode compartilhar uma única meta-classe e as meta-ligações ${ }^{1}$ podem ser criadas indefinidamente.

Em Smalltalk e ObjVlisp, uma mensagem enviada para um objeto é redirecionada para a classe do objeto. Isto é, a busca pelo método apropriado ocorre na classe do objeto. Portanto, não há nenhum modo de mudar os métodos de um único objeto or fazer um interpretador de mensagens específico para ele.

O modelo meta-objetos foi introduzido por Maes [20] e permite métodos especializados para um único objeto. Cada objeto possui um meta-objeto associado que guarda informação sobre sua implementação e interpretação. Como existe uma correspondência um a um entre objetos e meta-objetos, um meta-objeto pode ser modificado para redirecionar as mensagens enviadas para o objeto, manter informações estatísticas sobre este objeto específico, etc.

O modelo meta-comunicação permite modificar todos os envios de mensagens. Quando uma mensagem for enviada, o sistema de tempo de execução criará um objeto da classe MENSAGEM e o inicializará com os dados da mensagem (seletor, o objeto que recebeu a mensagem, parâmetros). Então, a mensagem ENVIE será enviada a este objeto, o qual executará o algoritmo de busca por método apropriado. Subclasses da classe MENSAGEM podem ser definidas e usadas com uma sintaxe especial, então modificando o significado original de envio de mensagem. Objective-C [22] [71] permite redefinir a função que faz busca por método, que é uma função normal em C. Portanto, ele suporta o modelo meta-comunicação.

Reflexão pode ser suportada não somente por linguagens, mas também por outros sistemas, como bibliotecas. De acordo com Foote [68], X Window permite converter cadeias de caracteres para recursos ${ }^{2}$ em tempo de execução, simulando o acesso a dados que representam o programa. Silica [65] é um sistema de janelas portável escrito em CLOS que suporta o que o autor chama de "implementational reflection". Silica possui uma interface que permite trabalhar com objetos gráficos (janelas, botões, etc) e uma meta-interface que possibilita a criação de novos tipos de objetos não previstos pelos criadores originais de Silica. A meta-interface permite a um programador desempenhar o mesmo papel que os projetistas de Silica, o que é diferente do uso do sistema como um usuário normal. Por exemplo, a meta-interface permite que o programador faça o algoritmo para retornar a janela onde a seta do mouse se encontra.

\footnotetext{
${ }^{1}$ Uma meta-ligação é a ligação entre uma classe e sua meta-classe.

${ }^{2}$ Funções em C.
} 


\subsection{Alguns Exemplos de Uso de Reflexão}

Uma linguagem reflexiva permite que um programa escrito nela examine a si mesmo em tempo de execução e mude sua estrutura. O modelo meta-classe permite mudar classes, o modelo meta-objeto permite mudar um único objeto (inclusive o seu algoritmo para busca por método) e o modelo meta-comunicação permite mudar o algoritmo de busca por método para todos os objetos e classes. Maes [20] chama a habilidade de mudar uma classe de "reflexão estrutural" e a habilidade de mudar o algoritmo de busca por método de "reflexão computacional". Reflexão é usada para:

- criar ferramentas de software como depuradores. Um depurador simples pode ser construído simplesmente cobrindo-se todas as classes do programa com código executado pelo depurador. Quando uma mensagem for enviada, um método do depurador será chamado e então ele chamará o método original. O depurador pode exigir pré e pós-condições para cada chamada de método;

- manter estatísticas sobre chamadas de métodos e número de objetos criados;

- implementar construções não suportadas pela linguagem, como procuradores, futuros e actors [42]. Todas elas podem ser implementadas usando meta objetos. Um procurador é um objeto que delega as mensagens enviadas a ele a um outro objeto em uma outra máquina. Um objeto futuro representa um processo que está executando em paralelo com o processo no qual ele foi criado. Por exemplo, um objeto futuro f pode representar um processo que está calculando uma multiplicação de matrizes. Se uma mensagem for enviada a $f$, como

$$
\text { f.printResult () }
$$

para imprimir o resultado da multiplicação, o processo onde esta instrução se encontra irá parar e esperar a multiplicação terminar. Se nenhuma mensagem for enviada a $f$, os dois processos (multiplicação de matrizes e o processo que declara $f$ ) continuarão a executar em paralelo.

Um actor [18] é um objeto com uma fila de mensagens e um processo. Qualquer mensagem enviada ao actor será colocada na fila. O processo lê as mensagens da fila e as executa em seqüência;

- implementar persistência. Um objeto persistente sobrevive ao programa que o criou porque ele é gravado em disco. Persistência pode ser implementada se a linguagem permitir facilidades para examinar a estrutura interna das classes e objetos;

- visão de classe, adaptadores e mesmo extensão dinâmica poderão ser implementados por meio de um pré-processador se a linguagem fornecer ferramentas reflexivas para examinar e mudar a estrutura dos programas em tempo de execução. Os algoritmos que implementam adaptadores, por exemplo, precisam saber a classe de um objeto em execução. Extensões dinâmicas criam e modificam classes em execução.

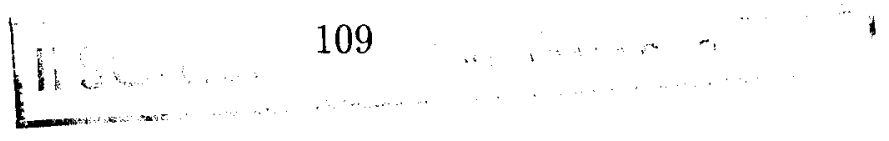




\subsection{Problemas com os Modelos Meta-classe e Meta Objeto}

Meta-classes são o conceito de programação orientada a objetos mais difícil de aprender [56]. Borning e O'Shea [60] propuseram que elas fossem eliminadas. $\dot{E}$ difícil entender as diferenças entre os relacionamentos criados por instanciações, herança e meta-classes. É difícil entender as responsabilidades de cada um destes relacionamentos em modelos complexos de herança/meta-classes como os de Smalltalk e ObjVlisp. Por exemplo, o que acontecerá a uma variável de instância da classe A se modificarmos a meta-classe de uma superclasse de A ? Como uma classe chamada Class pode herdar de uma classe Object se Object é uma instância de Class ? Uma superclasse não deveria ser criada antes de suas subclasses e uma classe antes de suas instâncias ? Meta-classes sofrem do problema da regressão infinita: uma classe deve possuir uma meta-classe, que deve possuir uma meta-meta-classe e assim por diante. Na prática, este problema é resolvido com criação preguiçosa de meta-classes ou pela introdução de hierarquias e meta-ligações incomuns (como a relação entre Object e Class), o que danifica $o$ aprendizado da linguagem.

De acordo com Maes [20], o modelo meta-objeto da linguagem 3-KRS é simples e uniforme porque há apenas um tipo de conceito: o objeto. Contudo, 3-KRS não é estaticamente tipada, o que dificulta uma implementação eficiente e a construção de programas seguros. Além disto, em 3-KRS ocorre o problema da regressão infinita de meta-objetos.

Os três modelos descritos na seção 8.2 podem causar erros de tipo. Eles permitem remover métodos de classes e objetos, mudar ligações de herança, modificar o algoritmo de busca por método e assim por diante. Eles podem causar erros de tipo em tempo de execução na maioria das linguagens reflexivas, com poucas exceções [12] [64]. Tudo indica que não há nenhum modo fácil de se fazer construções reflexivas que não causem erros de tipo sem remover algumas das suas facilidades. Do mesmo modo que nenhuma linguagem estaticamente tipada permite toda a flexibilidade de linguagens sem tipo.

\subsection{Discussão Sobre Shells e Reflexividade}

Shell dinâmico e extensão dinâmica possuem muitas características de metaobjetos e meta-classes, respectivamente. Embora eles não possam simular estas facilidades completamente, eles capturam a maior parte de suas características seguras e compõem um modelo reflexivo estaticamente tipado. Este modelo é elegante, fácil de entender e de implementar.

Um meta-objeto captura todas as mensagens enviadas ao seu objeto e pode redirecionar mensagens a outros objetos, coletar estatísticas sobre envio de mensagens, conferir pré e pós-condições, etc. No caso comum, o meta-objeto chamará o método correspondente para aquela mensagem. O comportamento de um objeto pode ser alterado mudando-se o seu meta-objeto. O novo meta-objeto pode chamar métodos diferentes daqueles chamados pelo meta-objeto anterior. Esta é 
exatamente a funcionalidade suportada por shell dinâmico. Os métodos de um objeto podem ser substituídos por outros colocando-se um shell dinâmico sobre o objeto.

Extensão dinâmica permite mudar os métodos de uma classe em tempo de execução. Os novos métodos podem chamar os métodos originais da classe através da palavra chave object. Embora extensão dinâmica não possa adicionar/remover métodos ou mudar hierarquias de classes, ela pode substituir meta-classes em muitos dos seus usos.

Shell dinâmico não foi baseado em outras construções de linguagens, embora ele seja essencialmente o mecanismo trap de KSL [43] [74] e a construção de meta-objetos de Foote e Johnson [42], introduzida em Smalltalk. Contudo, KSL e Smalltalk são linguagens sem tipo que permitem erros de tipo em tempo de execução. Shell dinâmico e extensão dinâmica podem ser suportados por uma linguagem estaticamente tipada sem danificar o sistema de tipos.

Classes predicado de Chambers [61] podem fazer um objeto herdar de algumas classes dinamicamente se ele satisfizer algumas expressões booleanas. A herança será removida sempre que a expressão booleana resultar em false usando o objeto. Então, classes predicado permitem mudar métodos de um objeto em tempo de execução e são relacionadas a shell dinâmico. Contudo, um shell dinâmico é colocado/removido ${ }^{3}$ pelo programador e a herança dinâmica de classes predicado é automaticamente gerenciada pelo sistema de tempo de execução.

Uma classe mixin [23] pode se referir às suas superclasses embora ela não herde de ninguém. Esta classe não é usada para criar objetos, mas para ser composta com outras classes que desempenham o papel de suas superclasses. $\mathrm{Na}$ composição de um mixin com uma classe $\mathrm{A}$, as referências às superclasses dos métodos do mixin são ligadas à classe A. Isto é similar a ter subclasses que podem ser acopladas a várias superclasses. Este é o motivo pelo qual classes mixins são chamadas de "subclasses abstratas".

A linguagem Agora [62] suporta a aplicação dinâmica de mixins. Uma classe pode ser criada dinamicamente pela combinação de um mixin com classes existentes. Isto é muito semelhante a extensões dinâmicas. Uma classe B definida como uma extensão dinâmica pode enviar mensagens (através da palavra chave "object") para a classe em que ela será acoplada. Se B for colocado sobre A, quaisquer mensagens enviadas através de "object" em métodos de B invocarão métodos da classe A. Extensấo dinâmica foi baseada em extensão de classe, que por sua vez foi baseada na proposta de Bracha e Cook [23] de mixins estaticamente tipados para Modula-3.

Open $\mathrm{C}++[11]$ é uma extensão reflexiva a $\mathrm{C}++$ que suporta meta-objetos. Seu objetivo é permitir que programadores estendam a linguagem com facilidades que não podem ser adicionadas facilmente a $\mathrm{C}++$, como suporte a programação distribuída. Em Open $\mathrm{C}++$, uma mensagem enviada a um objeto de uma classe reflexiva causa a execução de um método Meta_MethodCall do meta-objeto do objeto, não importando qual seja o seletor da mensagem. Isto é diferente de shell

\footnotetext{
${ }^{3} \mathrm{Um}$ shell dinâmico referenciado pela variável $\mathbf{x}$ pode ser removido pela instrução "remove(x)".
} 
dinâmico, no qual o método executado é sempre igual ao nome do seletor da mensagem.

Templ [12] introduziu reflexão na linguagem Oberon-2. Cada procedimento (o que inclui métodos) possui um meta-procedimento associado. Este sabe como chamar o procedimento. Agindo sobre o meta procedimento, o programa pode mudar o comportamento do procedimento. Por exemplo, o meta-procedimento pode chamar outro procedimento, ao invés do procedimento ao qual ele está associado. Se o procedimento for um método, isto será semelhante a colocar uma extensão dinâmica sobre uma classe, admitindo que apenas um método é definido na extensão. 


\section{Capítulo 9}

\section{Conclusão}

\subsection{Considerações Gerais}

As construções apresentadas nesta tese permitem modificar o comportamento/tipo de objetos. É relativamente fácil identificar as situações que requerem uma mudança no tipo/comportamento de objetos. Quando isto acontecer, o programador deve procurar o tipo apropriado de shell para usar, o que também não é difícil. A alternativa ao uso de shells é modificar o código, o que é inseguro e mistura o programa original com o código novo introduzido para corrigir/estender o programa. Com shells, o programa original e as modificações são mantidas separadas, o que significa que shells podem ser agrupados em uma biblioteca e reusados. O programa torna-se mais modular porque as abstrações representadas pelos shells são separadas das classes com as quais elas são usadas. Toda a experiência do grupo de programadores com o código original é preservada. Como shells não são misturados com o programa, eles podem ser facilmente removidos quando necessário. A definição completa das construções shell é difícil de entender, mas shells são relativamente fáceis de usar.

Se for necessário incluir shells em uma linguagem orientada a objetos estaticamente tipada, eles deverão suportar uma implementação eficiente. Portanto, analisaremos o desempenho destas contruções.

- Visão de classe requer um algoritmo de busca por método ineficiente porque um objeto filtro e o objeto a que ele se refere não podem ser agrupados em um único objeto, como é feito com shell dinâmico. A razão é que pode haver uma variável referindo-se ao objeto filtro enquanto que outra refere-se diretamente ao objeto. Assim, o objeto filtro e o objeto devem ser distintos.

- Adaptadores podem ser implementados eficientemente porque eles apenas enviam mensagens para uma variável de instância. Nenhum algoritmo especial de busca por método é necessário. Há uma degradação de desempenho mínima na criação de objetos adaptadores e na remoção deles, o que é feito para tornar correta uma atribuição incorreta em relação a tipos. De qualquer forma, esta degradação de desempenho ocorreria se o problema fosse solucionado por código feito pelo próprio programador. 
- Extensão de classe é aplicada antes da compilação e portanto não causa degradação do desempenho em tempo de execução.

- Shell dinâmico requer que cada objeto seja manipulado por uma indireção dupla. Então, cada chamada de método possui uma sobrecarga extra de uma indireção. Embora nós não tenhamos construído um compilador para uma linguagem que usa estas construções (somente um interpretador), podemos retirar algumas conclusões baseadas em $\mathrm{C}++$. Usando o compilador g++ (GNU) da Free Software Foundation executando em uma SPARC Station sobre SunOS, uma chamada a um método virtual com uma indireção de ponteiros a mais é $14 \%$ mais lenta que uma chamada normal. ${ }^{1}$ Assumindo que $50 \%$ do tempo de execução do programa é busca/chamada de métodos, a degradação total do desempenho causada por shell dinâmico será somente 7\%. Estamos considerando que todos os objetos são manipulados por dupla indireção. Uma otimização simples é manipular por indireção dupla somente aqueles objetos que podem ser afetados por shell dinâmico. Isto reduziria a degradação de desempenho drasticamente.

- Extensão dinâmica não altera o desempenho do programa na implementação sugerida por nós na seção 6.4 do Capítulo 6. Nesta implementação, cada objeto contém um ponteiro para uma estrutura de dados descrevendo a sua classe, que possui uma tabela com ponteiros para os métodos da classe. Quando uma mensagem for enviada a um objeto, o método apropriado será procurado na estrutura de dados que contém ponteiros para os métodos da classe deste objeto.

Contudo, extensẫo dinâmica poderá causar uma pequena degradação de desempenho se outras técnicas de implementação forem usadas. Por exemplo, Cox e Novobilski [22] sugerem que os métodos mais recentemente encontrados pelo algoritmo de busca por métodos sejam colocados em um cache, que é uma tabela hash cuja chave é uma composição do seletor do método com o nome da classe do objeto. Quando uma extensão de classe for colocada sobre uma classe A, dever-se-á retirar deste cache os métodos da classe A que foram substituídos pela extensão de classe. Contudo, a degradação do desempenho é miníma e corresponde a buscas pelos métodos da classe A que foram removidos do cache.

Pelas declarações acima, todos os shells, exceto visão de classe, possuem uma implementação eficiente. Isto pode ser mudado se delegação verdadeira não for usada por esta construção. Para explicar melhor este ponto, suponha que exista uma variável s que se refere a um filtro $\mathcal{F}$, o qual por sua vez refere-se a um objeto $\mathcal{Q}$. Quando uma mensagem for enviada para s e $\mathcal{F}$ não possuir o método apropriado, a mensagem será delegada a $\mathcal{Q}$. Como a linguagem é tipada estaticamente, $\mathcal{Q}$ possui o método correspondente, o qual será executado. Se este método enviar uma mensagem para self, a busca pelo método apropriado começará no filtro $\mathcal{F}$. Isto é, durante a execução de qualquer método chamado através de $\mathcal{F}$,

${ }^{1}$ Usando um método vazio. 
self é ligado a $\mathcal{F}$. Se a semântica de visão de classe for modificada para ligar self a $\mathcal{Q}$, teremos uma implementação eficiente para esta construção. O filtro $\mathcal{F}$ teria uma variável de instância chamada "object" que aponta para $\mathcal{Q}$. Qualquer mensagem enviada a $\mathcal{F}$ que ele não puder responder será redirigida para $\mathcal{Q}$.

Redirigir significa ter métodos em $\mathcal{F}$ que invocam os métodos de mesmo nome de $\mathcal{Q}$, como no exemplo abaixo:

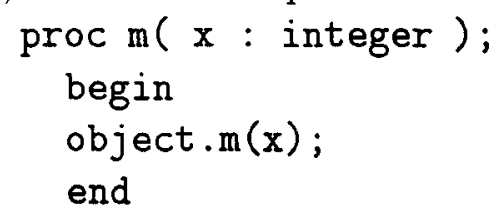

Isto é exatamente o que é feito por adaptadores. A implementação alternativa de visão de classe exposta acima muda a semântica desta construção, mas isto pode ser exatamente o que o programador quer em algumas situações. Por exemplo, suponha que $\mathcal{F}$ redefina o método print de $\mathcal{Q}$, que é usado para imprimir os dados do objeto. $O$ método print de $\mathcal{F}$ imprime em uma janela gráfica ao invés de no terminal como o método print de $\mathcal{Q}$. Neste caso, é desejável que quaisquer chamadas ao método print em $\mathcal{Q}$ invoquem o método print de $\mathcal{F}$. Delegação neste caso seria o ideal. Um outro exemplo seria a redefinição de um método copy de $\mathcal{Q}$, que aloca memória e retorna nil se não houver memória suficiente. Suponha que outros métodos de $\mathcal{Q}$ invoquem copy e testem o seu valor de retorno contra nil para descobrir se houve memória suficiente ou não. Se $\mathcal{F}$ redefinir copy para sinalizar uma exceção em falta de memória, então o envio da mensagem copy dentro de $\mathcal{Q}$ deve invocar o método copy de $\mathcal{Q}$ e não de $\mathcal{F}$. De outro modo, uma exceção seria sinalizada e não tratada. Por estes exemplos, vemos que delegar a mensagem (a semântica corrente) ou redirecioná-la (a semântica alternativa) são ambos úteis e poderiam ser suportados por visão de classe, embora isto fizesse esta construção mais complexa.

\subsection{Contribuições desta Tese}

Todos os shells foram criados independentemente de idéias semelhantes encontradas na literatura, exceto extensão de classe, que foi baseada em mixins [23] e extensions de Ossher e Harrison [10]. As contribuições desta tese são descritas abaixo, divididas por shell/construção.

- Visão de classe desempenha um papel, pelo nosso conhecimento, que não é diretamente relacionado com qualquer outra construção de linguagem ou ferramenta de software. Ela foi criada para resolver alguns problemas descritos por Berlin [39]. De acordo com ela, o maior problema na construção de um programa não são módulos mal projetados, mas incompatibilidades entre os módulos. Isto é, o que um módulo espera não é o que o outro módulo faz. A resolução deste tipo de problema é o objetivo de visão de classe, embora esta construção não possa resolver todos os problemas descritos por Berlin.

Visão de classe pode ser considerada como uma técnica para aplicação de meta-objetos em uma região específica do programa. Como exemplo, 
suponha que queiramos fazer uma estatística ${ }^{2}$ sobre as mensagens enviadas para objetos de uma dada classe, digamos $A$, em uma região $\beta$ do programa. Devemos construir uma visão de classe com uma classe $A \rightarrow \beta$ que coleta estes dados. Outras aplicações de meta-objetos podem também ser limitadas a uma certa região do programa usando visão de classe.

- Adaptadores têm sido usados como uma técnica de programação, de acordo com Johnson. ${ }^{3}$ Os adaptadores definidos pelo programador são similares àqueles descritos nesta tese. Contudo, os adaptadores descritos nesta tese são mais fáceis de se fazer do que aqueles feitos sem nenhuma ferramenta auxiliar. Como um exemplo disto, suponha a existência dois tipos, $T$ e $U$, que possuam algumas assinaturas de métodos em comum, fato freqüente na prática. Se o programador fizer um adaptador sem ajuda de nenhuma ferramenta, ele deverá definir todos os métodos da classe adaptadora, o que não será necessário se os adaptadores usados nesta tese forem utilizados. Os métodos com as mesmas assinaturas em ambos os tipos não precisam ser definidos. Os objetos adaptadores desta tese são também colocados e removidos automaticamente pelo sistema de tempo de execução.

Adaptadores estendem a definição de subtipo: Um tipo $U$ é um subtipo de um tipo $T$ se $T \subset U$ ou se existir um adaptador $U \rightarrow T$. Isto porque o compilador coloca automaticamente um procedimento de conversão de objetos de $U$ para $T$ no código. O programador usa $U$ como se ele fosse realmente subtipo de $T$.

- Extensão de classe foi baseada na extensão estaticamente tipada de classes mixin para Modula-3 proposta por Cook e Bracha [23] e na técnica extensão proposta por Ossher e Harrison [10]. Extensão de classe possui duas características não suportadas por mixins e extensões. Primeiro, um mixin ou extensão não pode declarar uma variável ou parâmetro de um método cujo tipo é a classe na qual o mixin/extensão será acoplado. Segundo, diferente de mixins/extensões, extensões de classe podem ser parametrizadas, o que significa que os parâmetros podem adequar uma extensão de classe a cada classe com que ela é usada.

Extensão de classe é muito semelhante a enhancive types de Horn [40] e descriptive classes de Sandberg [41] embora extensão de classe tenha sido desenvolvida independentemente destas construções. A principal diferença é que uma extensão de classe pode modificar uma classe (e portanto todo um programa) sem necessidade de nenhuma edição na classe ou no programa. Apenas um arquivo shell deve ser definido. Os detalhes do relacionamento de enhancive types e descriptive classes com extensão de classe são detalhados na seção 4.6 .

O programador pode alterar o código fonte de uma classe, digamos $\mathrm{A}$, ao invés de usar extensão de classe. Esta solução possui alguns problemas.

${ }^{2}$ Coletar dados estatísticos é uma das aplicações de meta-objetos - veja capítulo 8.

${ }^{3}$ Johnson, Ralph. Comunicação Pessoal, 1994. 
Primeiro, as alterações no código fonte devem ser feitas para cada nova versão da classe $\mathrm{A}$, se esta classe pertencer a uma biblioteca de classes não criada pelo programador ou seu grupo. Segundo, as modificações feitas na classe A podem ser as mesmas requeridas por outras classes. As alterações diretas no código fonte não são reutilizáveis, ao contrário de extensões de classe, que podem ser agrupadas em uma biblioteca.

Terceiro, alterar o código fonte diretamente usualmente implica em modificar o código de dentro dos métodos e usar as variáveis de instância e métodos privados das classes. Extensão de classe modifica uma classe usando apenas a sua interface pública, o que é muito mais seguro.

Esta tese também propõe uma técnica para construir classes mixins usando classes parametrizadas. Esta técnica resulta em classes mixins estaticamente tipadas e que podem declarar variáveis da classe na qual o mixin será acoplado.

- Shell dinâmico e extensão dinâmica juntos são a maior contribuição desta tese. Eles compõem um modelo reflexivo estaticamente tipado. Shells dinâmicos são semelhantes a meta-objetos embora existam algumas diferenças entre eles. Meta-objetos têm sido implementados em linguagens sem tipo por Maes [20] (3-KRS), Foote e Johnson [42] (Smalltalk) e Ibrahim et al. [43] (KSL). Chiba e Masuda [11] introduziram meta-objetos em uma extensão de $\mathrm{C}++$ chamada Open $\mathrm{C}++$. A linguagem é mantida estaticamente tipada embora uma chamada de método implementada por um meta-objeto seja cinco a oito vezes mais lenta que uma chamada de método normal de $\mathrm{C}++$. A sobrecarga de uma chamada de método quando se usa shell dinâmico é somente $14 \%$. E não é necessário usar um algoritmo de busca por método especial como em Open $\mathrm{C}++$. É somente necessário manipular os objetos através de uma indireção dupla.

Extensâo dinâmica permite substituir em tempo de execução alguns ou todos os métodos de uma classe por outros. Uma facilidade similar é suportada por Oberon-2 [12]. Nesta linguagem, cada procedimento possui um meta-procedimento associado que toma o controle quando o procedimento é chamado. Então, o meta-procedimento pode chamar outro procedimento ao invés daquele original. Isto significa que um procedimento pode substituir um outro procedimento em tempo de execução. Como métodos são procedimentos em Oberon-2, pode-se substituir um método de uma classe em tempo de execução, o que é semelhante a colocar uma extensão dinâmica sobre uma classe mudando apenas um método.

Embora Oberon-2 possua características similares a extensão dinâmica, elas são mais difíceis de entender, mais complexas e provavelmente menos eficientes. Nesta linguagem, existe uma função que insere procedimentos em uma lista circular mantida por cada meta procedimento. Quando o metaprocedimento receber uma mensagem requisitando a sua execução, ele executará todos os procedimentos da lista circular. Então, os parâmetros para um procedimento têm que ser passados para o meta-procedimento e 
depois para cada um dos procedimentos. Se existir apenas um procedimento na lista circular, o que é o caso mais comum, ${ }^{4}$ existirá uma passagem inutil de parâmetros do meta-procedimento ao procedimento, o que não acontece com extensão dinâmica, pois esta construção modifica diretamente as estruturas de dados que descrevem as classes em tempo de execução - os métodos são chamados diretamente, sem meta-procedimentos intermediários. Oberon-2 possui uma sintaxe para procedimentos normais e outra para meta-procedimentos. Extensão dinâmica utiliza uma sintaxe quase idêntica à sintaxe de classes normais, facilitando o seu uso.

Um interpretador de um subconjunto da linguagem utilizada nesta tese foi modificado para suportar shell dinâmico e uma versão de extensão dinâmica sem as facilidades de classes parametrizadas. A adição destas construções ao interpretador foi feita em menos de um dia de trabalho e com a adição de menos de 100 linhas de código em linguagem $\mathrm{C}$.

A diferença básica entre shells dinâmicos e meta-objetos (ou metaprocedimentos) é que os primeiros possuem apenas um mecanismo de busca por método, que é aquele fornecido pela linguagem. Uma mensagem enviada a um objeto não é primeiro analisada pelo seu meta-objeto e então delegada ao objeto. $O$ fato de shell dinâmico usar o algoritmo de busca por método da linguagem faz com que esta construção:

- seja fácil de entender, já que uma classe para um shell dinâmico é muito semelhante a uma classe normal;

- seja fácil de implementar, pois não existem desvios de mensagens para meta-objetos. Como conseqüência, shell dinâmico suporta uma implementação eficiente;

- seja estaticamente tipada, pois as regras de subtipo da linguagem são também empregadas para shell dinâmico.

Em resumo, shell dinâmico e extensão dinâmica formam um modelo reflexivo que pode ser colocado em uma linguagem orientada a objetos estaticamente tipada sem danificar o sistema de tipos. Este modelo é muito simples de entender, usar e implementar. A degradação do desempenho causado por estas construções é mínima. Do nosso conhecimento, ele é o primeiro modelo reflexivo orientado a objetos e estaticamente tipado projetado juntamente com a linguagem em que ele é usado.

\subsection{Pesquisas Futuras}

Esperamos projetar uma linguagem que suportará shell dinâmico, extensão dinâmica e adaptadores. Visão de classe e extensão de classe serão implementados por meio de pré-processadores. Esta linguagem será basicamente a descrita no Apêndice A com algumas pequenas modificações. Chamaremos esta linguagem

\footnotetext{
${ }^{4}$ É o equivalente a não usar meta procedimentos.
} 
de $\mathrm{X}$. Pensamos em projetar uma versão sem tipos de $\mathrm{X}$ e uma outra linguagem $\mathrm{Y}$ semelhante a $\mathrm{X}$, mas sem herança. $\mathrm{O}$ objetivo de $\mathrm{Y}$ é construir software com alto desempenho. Ela será baseada em classes (sem herança ou polimorfismo) e suportará operações de baixo nível (como fazer um ponteiro apontar para um número inteiro). Y não suportará coleta de lixo. A nossa intenção é fazer a maior parte do software em $\mathrm{X}$ e as partes mais críticas em Y. Esperamos que o interpretador para a versão sem tipos de $\mathrm{X}$ possa deduzir a maioria dos tipos de variáveis do programa, o que tornará parcialmente automática a conversão de um programa sem tipos para a linguagem $X$, que é estaticamente tipada.

Pretendemos também projetar uma linguagem de conexão de módulos que permitirá uma integração fácil entre X, Y e mesmo com outras linguagens.

Alguns melhoramentos podem ser feitos com as propostas desta tese. Abaixo estão alguns deles.

- Na linguagem X, devem ser acrescentados outros mecanismos de reflexão, como para permitir o exame da estrutura dos objetos e classes em tempo de execução. Esperamos também acrescentar em X mecanismos para persistência e programação distribuída.

- Poderia ser permitido herança com shells. Na proposta corrente, nenhuma classe shell pode herdar ou ser herdada.

- A combinação de adaptadores com classes parametrizadas poderia ser permitida. Assim, a classe

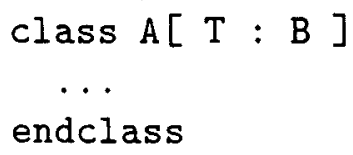

cujos parâmetros reais devem conformar-se $\mathrm{s}^{5} \mathrm{com} \mathrm{B}$, poderia ser instanciada com uma classe $\mathrm{C}$ que é funcionalmente compatível com $\mathrm{B}$ mas incompatível com relação a tipos com esta classe. Um adaptador para converter o tipo $B$ para $\mathrm{C}$ e vice-versa deveria ser construído pelo programador.

- A criação de subclasses poderia ser considerada como um mecanismo de shell.

- Classes de extensão dinâmica poderiam definir uma seção share. Isto permitiria mudar os métodos da seção share da classe (como new) em tempo de execução. A linguagem se tornaria mais uniforme e poderosa. Como exemplo desta facilidade, poder-se-ia redefinir em tempo de execução o método new de uma classe para implementar um mecanismo não padronizado de alocação dinâmica.

- A linguagem X deverá suportar classes como objetos de "primeira classe", embora não haverá herança de meta-classes ou criação dinâmica de classes (exceto por extensão dinâmica e shell dinâmico).

\footnotetext{
${ }^{5}$ Veja definição de conformidade na seção A.3.
} 
- Classes parametrizadas poderiam ter parâmetros que são constantes numéricas como no modelo descrito em [44].

- Visão de classe poderia ser modificada para poder ser usada com variáveis globais e variáveis de classe (aquelas definidas na parte share). Um modo simples de se fazer isto é examinar, em tempo de execução, todos os envios de mensagem em uma certa região do programa. Se o objeto empregado for de uma certa classe, então a mensagem será desviada para um outro objeto. Isto permitiria, por exemplo, modificar a entrada/saída de um módulo do programa. Suponha que um dado módulo faça algumas computações e envie sua saida para o vídeo. Queremos usar este módulo em nosso programa mas ele não deve enviar nenhum resultado para o vídeo. Utilizaremos apenas os resultados calculados por este módulo. Se a linguagem fizer todas as entradas/saidas através das variáveis globais cin e cout, como em $\mathrm{C}++$, este problema poderia ser resolvido por visão de classe. Bastaria redefinir o significado da classe de cout dentro do módulo para que ela não imprimisse nada. Da mesma forma, poderíamos desejar uma entrada e saída mais elaborada que a fornecida por cin e cout, talvez com o uso de janelas.

- O uso extensivo de visấo de classe e até mesmo extensão de classe certamente trará sérios prejuízos à clareza de um programa. É necessária uma comparação prática entre o uso destas construções e modificações diretas no código fonte. Alterações diretas no código também podem tornar um programa ilegível e de difícil manutenção, pois o código é "remendado" em diversos pontos, provavelmente com o uso de variáveis de instância/métodos privados das classes.

- Em versões anteriores desta tese, haviam dois outros shells: visão de tipo e extensão de tipo. Eles foram retirados porque não possuíam conceitos tão interessantes quanto os outros shells. Eles consideram um tipo como a coleção de todas as classes do programa que possuem aquele tipo. Assim, podemos usar visão de tipo para aplicar visão de classe a todas as classes que possuem um dado tipo. Esperamos implementar visão de tipo e extensão de tipo por meio de pré-processadores.

- O número de restrições ao uso de diversos shells em um mesmo programa pode ser diminuído. Em particular, acreditamos que shell dinâmico e extensâo dinâmica podem ser usados em um mesmo programa sem nenhuma restrição. É necessário construir provas, como as descritas nesta tese, que garantam que o uso de vários shells não resultará em situações ambígüas ou errôneas. 


\section{Bibliografia}

[1] LEWIS, John; Henry, Sallie; Kafura, Dennis; Schulman, Robert. An Empirical Study of the Object-Oriented Paradigm and Software Reuse. SIGPLAN Notices, v. 26, n. 11, p. 184-196, 1991. /OOPSLA 91/

[2] WILDE, Norman; Matthews, Paul; Huitt, Ross. Maintaining Object-Oriented Software. IEEE Software, v. 10, n. 1, p. 75-80, January 1993.

[3] TAENZER, David; Ganti, Murthy; Podar, Sunil. Object-Oriented Software Reuse: The Yoyo Problem. Journal of Object-Oriented Programming, p. 3035, September/October 1989.

[4] JOHNSON, Ralph; Foote, Brian. Designing Reusable Classes. Journal of Object-Oriented Programming, v. 1, n. 2, p. 22-35, 1988.

[5] GAMMA, Erich; Helm, Richard; Johnson, Ralph; Vlissides, John. Design Patterns. s.l., Addison-Wesley, 1995.

[6] MEYER, Bertrand. Tools for the New Culture: Lessons from the Design of the Eiffel Libraries. Communications of the ACM, v. 33, n. 9, September 1990.

[7] SNYDER, Alan. Encapsulation and Inheritance in Object-Oriented Programming Languages. SIGPLAN Notices, v. 21, n. 11, p. 38-45, 1986. /OOPSLA $86 /$

[8] SNYDER, Alan. Inheritance and the Development of Encapsulated Software Components. In: Shriver, Bruce; Wegner, Peter, eds. Research Directions in Object-Oriented Programming. s.l., MIT Press, 1987. p. 165-188.

[9] KNUDSEN, Jørgen. Name Collision in Multiple Classification Hierarchies. Lecture Notes in Computer Science, v. 322, p. 93-109, 1988. /ECOOP 88/

[10] OSSHER, Harold; Harrison, Willian. Combination of Inheritance Hierarchies. SIGPLAN Notices, v. 27, n. 10, p. 25-40, 1992. /OOPSLA 92/

[11] CHIBA, Shigeru; Masuda, Takashi. Open $\mathrm{C}++$ and Its Optimization. OOPSLA'93 Workshop on Reflection and Metalevel Architectures, 1993.

[12] TEMPL, Joseph. Reflection in Oberon. ECOOP'92 Workshop on ObjectOriented Reflection and Metalevel Architectures, 1993. 
[13] AMERICA, Pierre; Linden, Frank van der. A Parallel Object-Oriented Language with Inheritance and Subtyping. SIGPLAN Notices, v. 25, n. 10, p. 161-168, 1990. /ECOOP-OOPSLA 1990/

[14] UNGAR, David; Smith, Randall; Chambers, Craig; Hölzle, Urs. Object, Message, and Performance: How They Coexist in Self. IEEE Computer, v. 25, n. 10, p. 53-64, October 1992.

[15] UNGAR, David; Smith, Randall. Self: The Power of Simplicity. SIGPLAN Notices, v. 22, n. 12, p. 227-243, 1987. /OOPSLA 87/

[16] DONY, Christophe; Malenfant, Jacques; Cointe, Pierre. Prototype-Based Languages: From a New Taxonomy to Constructive Proposals and their Validation. SIGPLAN Notices, v. 27, n. 10, p. 201-217, 1992. /OOPSLA 92/

[17] LIEBERMAN, Henry. Using Prototypical Objects to Implement Shared Behavior in Object-Oriented Systems. SIGPLAN Notices, v. 21, n. 11, p. 214223, 1986. /OOPSLA 86/

[18] AGHA, Gul. An Overview of Actor Languages. SIGPLAN Notices, v. 21, n. 10, p. 58-67, October 1986.

[19] FERBER, Jacques. Computational Reflection in Class Based Object Oriented Languages. SIGPLAN Notices, v. 24, n. 10, p. 317-326, 1989. /OOPSLA $89 /$

[20] MAES, Pattie. Concepts and Experiments in Computational Reflection. SIGPLAN Notices, v. 22, n. 12, p. 147-155, 1987. /OOPSLA 87/

[21] GOLDBERG, Adele; Robson, David. Smalltalk-80: The Language and its Implementation. s.l., Addison-Wesley, 1983.

[22] COX, Brad; Novobilski, Andrew. Object-Oriented Programming - An Evolutionary Approach. s.l., Second Edition, Addison-Wesley, 1991.

[23] COOK, W.; Bracha, G. Mixin-based Inheritance, SIGPLAN Notices, v. 25, n. 10, p. 303-311, 1990. /OOPSLA 90/

[24] PINTADO, Xavier. Gluons: a Support for Software Component Cooperation. Lecture Notes in Computer Science v. 742, p. 43-60. /Object Technologies for Advanced Software, First JSSST International Symposium/

[25] SHILLING, John. Three Steps to Views: Extending the Object-Oriented Paradigm. SIGPLAN Notices, v. 24, n. 10, p. 353-361, 1989. /OOPSLA 89/

[26] OPDYKE, Willian. Refactoring Object-Oriented Frameworks. UrbanaChampaign, 1992. Tese (Doutorado) - University of Illinois at UrbanaChampaign. 
[27] OPDYKE, Willian; Johnson, Ralph. Refactoring and Aggregation. Lecture Notes in Computer Science, v. 742, p. 43-60. /Object Technologies for Advanced Software, First JSSST International Symposium/

[28] CASAIS, Eduardo. An Incremental Class Reorganization Approach. Lecture Notes in Computer Science, v. 615, p. 114-132, 1992. /ECOOP 92/

[29] HÖLZLE Urs. Integrating Independently-Developed Components in ObjectOriented Languages. Lecture Notes in Computer Science, v. 707, p. 36-56, 1993. /ECOOP 93/

[30] YELLIN, Daniel; Strom, Robert. Interfaces, Protocols, and the SemiAutomatic Construction of Software Adaptors. SIGPLAN Notices, v. 29, n. 10, p. 176-190, 1994. /OOPSLA 94/

[31] KISHIMOTO, Yoshinori; Kotaka, Nobuto; Honiden, Shinichi. Adapting Object-communication Methods Dynamically. IEEE software. v. 12, n. 3, p. 65-74, May 1995.

[32] CARDELLI, L.; Donahue, J; Glassman, L; Jordan, M; Kalsow, B; Nelson, G. Modula-3 Language Definition. SIGPLAN Notices, v. 27, n. 8, p. 15-42, August 1992.

[33] RAJ, R. K.; Levy, H. M. A Compositional Model for Software Reuse. The Computer Journal, v. 32, n. 4, p. 312-322, 1989.

[34] MEYER, Bertrand. Object-Oriented Software Construction. s.l., Prentice Hall, 1988.

[35] MURATA, Makoto; Kusumoto, Koji. Daemon: Another Way of Invoking Methods. Journal of Object-Oriented Programming. p. 8-12, July/August 1989.

[36] BLAKE, Edwin; Cook, Steve. On Including Part Hierarchies in Object0riented Languages, with an Implementation in Smalltalk. Lecture Notes in Computer Science v. 276, p. 41-50, 1987. /ECOOP 87/

[37] STEPHEN R. Davis. C++ Objects that Change their Types. Journal of Object-Oriented Programming, p. 27-32, July/August 1992.

[38] COINTE, Pierre. Metaclasses are First Class : the ObjVlisp Model. SIGPLAN Notices, v. 22, n. 12, p. 156-167, 1987. /OOPSLA 87/

[39] BERLIN, Lucy. When Objects Collide: Experiences with Reusing Multiple Class Hierarchies. SIGPLAN Notices, v. 25, n. 10, p. 181-193, 1990. /ECOOPOOPSLA $90 /$

[40] HORN, Chris. Conformance, Genericity, Inheritance and Enhancement. Lecture Notes in Computer Science, v. 272, p. 223-233, 1987. /ECOOP 87/ 
[41] SANDBERG, David. An Alternative to Subclassing. SIGPLAN Notices, v. 21, n. 11, p. 424-428, 1986. /OOPSLA 86/

[42] FOOTE, Brian; Johnson, Ralph. Reflective Facilities in Smalltalk-80. SIGPLAN Notices, v. 24, n. 10, p. 327-335, 1989. /OOPSLA 89/

[43] IBRAHIM, Mamdouh; Bejcek, W.; F. Cummins. Instance Specialization without Delegation. Journal of Object-Oriented Programming, p. 53-56, June 1991.

[44] GUIMARÃES, José de Oliveira. Suggestion for a Parametrized Class Model. OOPS Messenger, v. 5, n. 3, July 1994.

[45] DIXON, R.; McKee, T.; Schweizer, P.; Vaughan, M. A Fast Method Dispatcher for Compiled Languagues with Multiple Inheritance. SIGPLAN Notices, v. 24 , n. 10 , p. $397-406,1989$. /OOPSLA 89/

[46] DEMICHIEL, Linda; Gabriel, Richard. The Common Lisp Object System: An Overview. SIGPLAN Notices, v. 23, n. 11, p. 151-170, 1988. /OOPSLA $88 /$

[47] WOLF, Wayne. A Practical Comparison of Two Object-Oriented Languages. IEEE Software, v. 6, n. 5, p. 61-68, September 1989.

[48] CARDELLI, Luca. A Semantics of Multiple Inheritance. Lecture Notes in Computer Science n. 173, p. 51-67, 1984. /Colloquium on the Semantics of Data Types/

[49] STROUSTRUP, Bjarne. The C++ Programming Language. s.l., Second Edition, Addison-Wesley, 1991.

[50] LIPPMAN, Stanley B. C++ Primer. s.l., Addison-Wesley, 1991.

[51] MEYER, Bertrand. Eiffel: Programming for Reusability and Extendibility. SIGPLAN Notices, v. 22, n. 2, p. 85-94, February 1987.

[52] OMOHUNDRO, Stephen. The Sather Programming Language. Dr. Dobb's Journal, v. 18, n. 11, p. 42-49, October 1993.

[53] HENDERSON, Robert; Zorn, Benjamin. A Comparison of Object-Oriented Programming in Four Modern Languages. Software-Practice and Experience, v. 24, n. 11, p. 1077-1095, November 1994.

[54] HOFF, Arthur van. Java and Internet Programming. Dr. Dobb's Journal, v. 20, n. 8, p. 56-61, August 1995.

[55] WEGNER, Peter. The Object-Oriented Classification Paradigm. In: Shriver, Bruce; Wegner, Peter, eds. Research Directions in Object-Oriented Programming. s.l., MIT Press, 1987. p. 479-559. 
[56] O'SHEA, Tim, coord. Panel: The Learnability of Object-Oriented Programming Systems. SIGPLAN Notices, v. 21, n. 11, 1986. /OOPSLA 86/

[57] LISKOV, Barbara; Snyder, Alan; R. Atkinson; C. Schaffert. Abstraction Mechanisms in CLU. Communications of the ACM, v. 20, n. 8, p. 564-576, August 1977.

[58] LISKOV, Barbara; Atkinson, R.; Bloom, T.; Moss, E.; Schaffert, J.; Scheifler, R.; Snyder, A. CLU Reference Manual. Lecture Notes in Computer Science n. 114.

[59] RODRIGUES, Noemi; Rangel, José; Ierusalimschy, Roberto. Types in School. SIGPLAN Notices, v. 28, n. 8, p. 81-89, August 1993.

[60] BORNING A.; O'Shea, Tim. DeltaTalk: An Empirically and Aesthetical Motivated Simplification of the Smalltalk-80 Language. Lecture Notes in Computer Science v. 322, p. 1-10, 1988. /ECOOP 88/

[61] CHAMBERS, Craig. Predicate Classes. Lecture Notes in Computer Science v. 707 , p. 268-296, 1993. /ECOOP 93/

[62] STEYAERT, Patrick at al. Nested Mixin-Methods in Agora. Lecture Notes in Computer Science v. 707, p. 197-219, 1993. /ECOOP 93/

[63] RAJ, R. K.; Tempero, Ewan; Levy, Henry; Black, A. P. Emerald: A General Purpose Programming Language. Software Practice and Experience, v. 21, n. 1, p. 91-118, January 1991.

[64] BUSCHMANN, Frank; Kiefer, Konrad; Paulisch, Frances; Stal, Michael. A Runtime Type Information System for C++. OOPSLA'93 Workshop on Reflection and Metalevel Architectures, 1993

[65] RAO, Ramana. Implementational Reflection in Silica. Lecture Notes in Computer Science, v. 512, p. 251-267, 1991. /ECOOP 91/

[66] CANNING, Peter; Cook, Willian; Hill, Walter; Olthoff, Walter. Interfaces for Strongly-Typed Object-Oriented Programming. SIGPLAN Notices, v. 24, n. 10, p. $457-467,1989$. /OOPSLA $89 /$

[67] WIRTH, Niklaus. Programming in Modula-2. s.l., Springer-Verlag, 1983.

[68] FOOTE, Brian. Objects, Reflection, and Open Languages. OOPSLA'93 Workshop on Reflection and Metalevel Architectures, 1993.

[69] PORTER, Harry. Separating the Subtype Hierarchy from the Inheritance of Implementation. Journal of Object-Oriented Programming, p. 20-29, February 1992.

[70] MADSEN, Ole L.; Møller-Pedersen, Birger. Virtual Classes: A Powerful Mechanism in Object-Oriented Programming. SIGPLAN Notices, v. 24, n. 10, p. 397-406, 1989. /OOPSLA 89/ 
[71] LOZINSKI, Christopher. Why I need Objective-C. Journal of ObjectOriented Programming, p. 21-28, September 1991.

[72] MEYER, Bertrand. Genericity versus Inheritance. SIGPLAN Notices, v. 21, n. 11, p. 391-405, 1986. /OOPSLA 86/

[73] HENDERSON, Robert; Zorn Benjamin. A Comparison of Object-Oriented Programming in Four Modern Languages. Software-Practice and Experience, v. 24, n. 11, p. 1077-1095, November 1994.

[74] IBRAHIM, Mamdouh. Reflection in Object-Oriented Programming. International Journal on Artificial Intelligence, v. 1, n. 1, p. 117-136, 1992. 


\section{Apêndice A}

\section{Um Modelo de Linguagem}

\section{A.1 Introdução}

\section{A.1.1 Características Básicas}

Este apêndice descreve uma linguagem estaticamente tipada similar a POOL-I [13]. Nesta linguagem, classes são usadas para a criação de objetos e um tipo é apenas um conjunto de interfaces de métodos. A escolha de uma linguagem estaticamente tipada para ser usada nesta tese foi feita por duas razões. Primeiro, segurança. Todos os erros de tipo são descobertos em tempo de compilação, resultando em programas mais robustos. Segundo, eficiência. Linguagens estaticamente tipadas permitem a geração de código mais eficiente porque o compilador possui mais informações sobre o tipo de objetos a que cada variável pode se referir. Embora linguagens sem tipo como Smalltalk [21] e CLOS [46] permitam rápido desenvolvimento de protótipos, linguagens estaticamente tipadas produzem código mais útil a longo prazo porque erros de tipo são descobertos logo no início da codificação do sistema (em compilação) [47].

A sintaxe empregada para a declaração de uma classe é mostrada na Figura A.1. A sintaxe completa da linguagem está no apêndice B. Um método ou variável de instância privado pode somente ser usado dentro dos métodos da classe. Um método público é visto pelo código de dentro e fora da classe. Dentro de um método de uma classe $\mathrm{A}$, não se pode manipular uma variável de instância $\mathbf{x}$ de um parâmetro $\mathrm{p}$ que possui tipo $\mathrm{A}$, como em

$\operatorname{proc} m(p: A) ;\{$ método de $A\}$

begin

p.x:= 10;

end

A razão desta restrição é que $\mathrm{x}$ pode se referir, em tempo de execução, a um objeto que não pertence à classe $\mathrm{A}$ ou suas subclasses e, portanto, não possui uma variável de instância $\mathrm{x}$. Isto irá se tornar claro depois que tipos forem definidos.

A palavra chave share introduz métodos e variáveis de instância (componentes) que pertencem a todos os objetos da classe e não a uma instância específica. Estes componentes são manipulados pelo nome da classe:

NomeDaClasse.SetValue(100); 


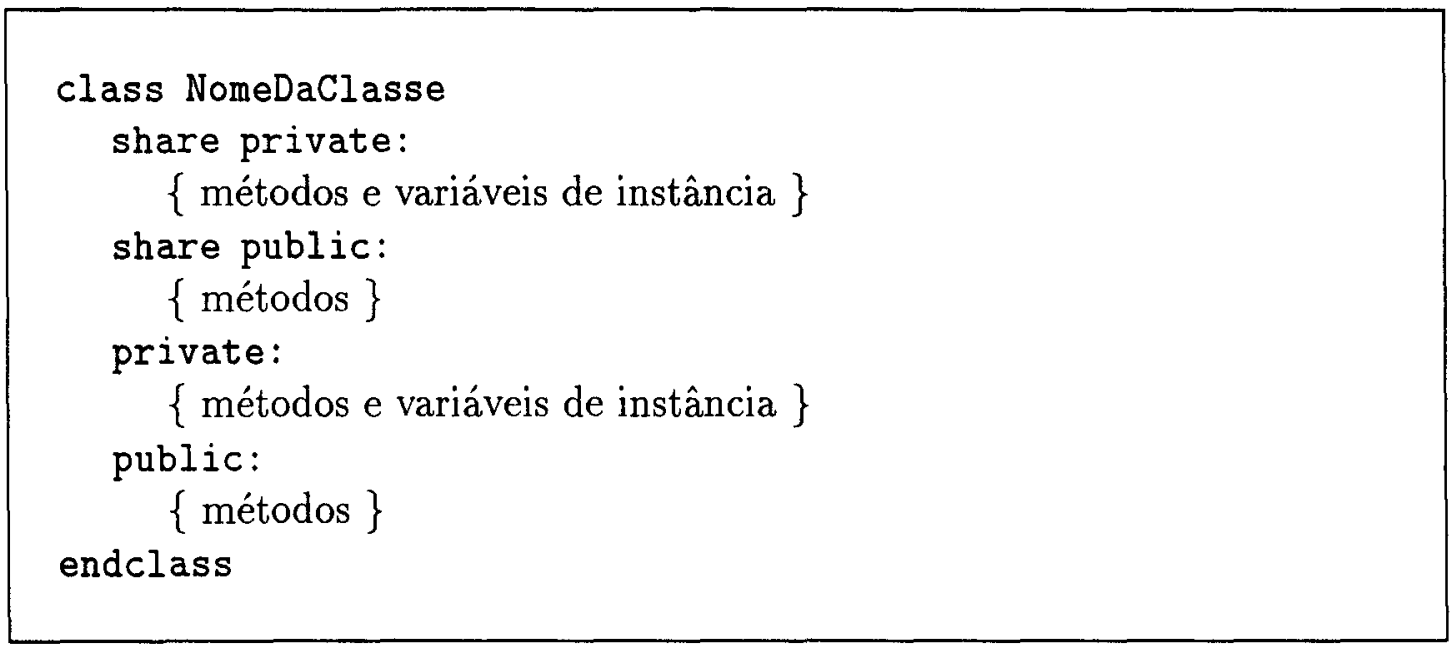

Figura A.1: Sintaxe para a declaração de uma classe

proc NomeMetodo ( lista-de-parâmetros) : TiposRetorno;

\{ Declaração de Variáveis Locais \}

begin

$\{$ Corpo de método $\}$

end

Figura A.2: Sintaxe para a declaração de um método

Eles são apenas variáveis e procedimentos globais que são manipulados através do nome da classe. Os componentes da seção "share private" podem ser usados somente dentro da classe e os métodos da seção "share public" podem ser usados em qualquer lugar. Os dados da parte share podem ser usados para armazenar informações comuns a todos os objetos da classe.

Um método é declarado como mostrado na Figura A.2, onde os tipos dos valores de retorno são opcionais. lista-de-parâmetros é uma seqüência de variáveis com seus tipos, como em Pascal, e toda passagem de parâmetros é por valor. A declaração de variáveis locais e variáveis de instância é precedida pela palavra chave var e os métodos são precedidos por proc. Um exemplo de declaração de classe é mostrado na Figura A.3.

A palavra chave return é usada para retornar os valores de um método, como em linguagem $\mathrm{C}$. Pode haver mais de um valor de retorno e, neste caso, os valores de retorno são dados entre parênteses. Um exemplo é mostrado na Figura A.4. $\mathrm{O}$ método ToHourMin é usado em atribuições múltiplas:

$\mathrm{h}, \mathrm{m}:=$ time.ToHourMin();

Uma atribuição múltipla

é definida como

$a_{1}, a_{2}, \ldots a_{n}:=\exp _{1}, \exp _{2}, \ldots \exp _{n} ;$

$$
\begin{aligned}
& a_{1}:=\exp _{1} ; \\
& a_{2}:=\exp ;
\end{aligned}
$$




\section{class A}

private:

$\operatorname{var} \mathrm{v}, \mathrm{k}$ : integer;

public:

$\operatorname{proc} m(x:$ Store $)$;

begin

$x \cdot \operatorname{put}(5)$;

$v:=x \cdot \operatorname{get}()$;

end

endclass

Figura A.3: Uma classe na linguagem usada nesta tese

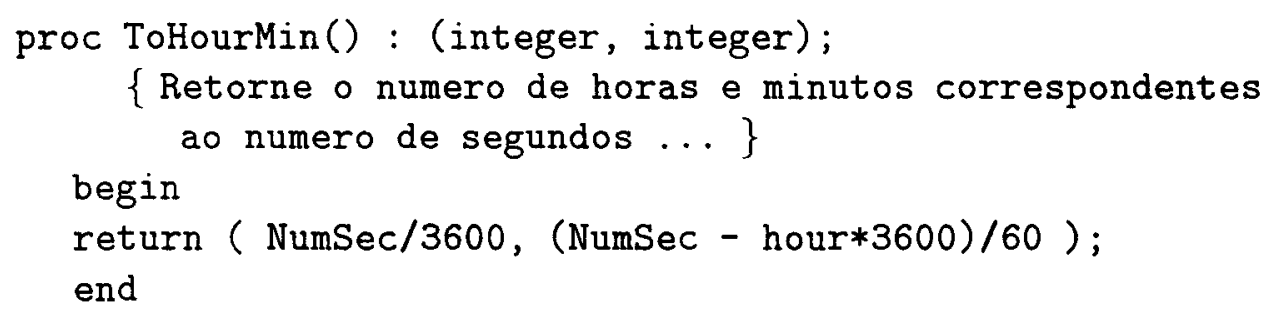

Figura A.4: Método que usa valor de retorno múltiplo

$$
\mathrm{a}_{n}:=\exp _{n} ;
$$

e uma função retorna para quem a chamou depois que o comando return é executado.

Letras maiúsculas e minúsculas são consideradas diferentes na linguagem. Variáveis e parâmetros referem-se a objetos e são similares a ponteiros em Pascal/C. Portanto, no código mostrado na Figura A.5, a declaração de a e b não conduz à criação de dois objetos da classe A. Estes são criados pela palavra chave new, usando alocação dinâmica de memória:

$$
\mathrm{b}:=\mathrm{A} \cdot \operatorname{new}() \text {; }
$$

Não há nenhum modo de desalocar memória, o que é feito automaticamente pelo coletor de lixo. A instrução $\mathrm{a}:=\mathrm{b}$ faz a e b referirem-se ao mesmo objeto, criando então um sinônimo. Qualquer alteração no objeto a por meio de um envio de mensagem será refletida no objeto referenciado por b, já que a e b referem-se ao mesmo objeto. A palavra chave nil representa um objeto nulo e o seu tipo é considerado subtipo de qualquer outro tipo em atribuições. Qualquer variável cujo tipo não é um dos tipos básicos (integer, real, boolean, char) pode receber nil em atribuições. Uma variável de qualquer um dos tipos básicos realmente contém um valor - ela não é um ponteiro.

Herança de uma classe A por uma classe B é sinalizada pela palavra chave inherits: 
$\cdot$

var $a, b: A$;

begin

- *

$b:=A \cdot \operatorname{new}()$;

$\mathrm{a}:=\mathrm{b}$;

...

end.

Figura A.5: Exemplo de uso de variáveis

$$
\left.\right|_{B} ^{A}
$$

A classe B herda da classe A

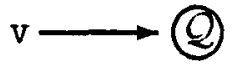

A variável v refere-se ao objeto $\mathcal{Q}$

Figura A.6: Herança de classes e referência a um objeto

\section{class B inherits A}

A herança de uma classe por outra será representada graficamente como mostrado na Figura A.6. Será usada uma flecha da subclasse para a superclasse. Assim, uma superclasse estará sempre acima de suas subclasses em uma Figura. Um objeto será representado como um pequeno círculo e uma referência de uma variável para um objeto é representada como uma flecha. Veja Figura A.6, onde variável v refere-se ao objeto $\mathcal{Q}$.

Herança múltipla é permitida, embora não possa haver colisão de métodos herdados. Esta decisão foi tomada porque há muitos problemas relacionados à colisão de nomes e a solução deles poderia ser incompatível com as propostas desta tese. Observe que não permitindo colisão de nomes, uma classe não pode ser herdada duas vezes por dois diferentes caminhos por uma subclasse, como

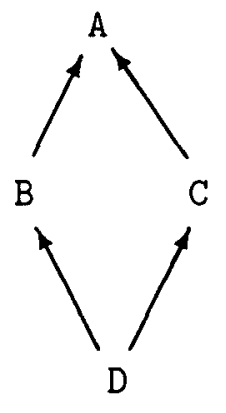

Figura A.7: A classe D herda A duas vezes 


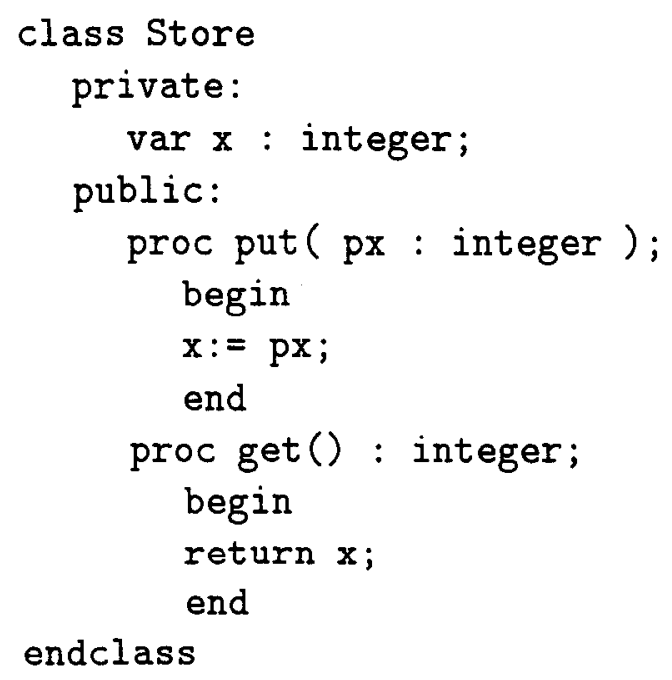

Figura A.8: Uma classe para armazenar objetos inteiros

mostrado na Figura A.7. Esta configuração resulta na questão: "As variáveis de instância da classe A devem ser duplicadas em objetos da classe D ?" A resposta depende da aplicação, embora a resposta "Não" cause violação do encapsulamento da classe $\mathrm{A}$ : os métodos das classes $\mathrm{B}$ e $\mathrm{C}$ poderiam manipular o mesmo conjunto de variáveis de instância (as da classe A) de modo não sincronizado [8] [7]. Por exemplo, suponha que um método print de $\mathrm{D}$ imprima os dados de $\mathrm{D}$ e invoque os métodos print de $\mathrm{B}$ e $\mathrm{C}$. $\mathrm{O}$ método print de $\mathrm{B}$ ( $\mathrm{e}$ o de $\mathrm{C}$ ) invoca o método print de A. Então, quando uma mensagem print é enviada a um objeto de D, os dados de A são impressos duas vezes. Este problema só pode ser resolvido alterando-se as classes B e C. Então, estas classes não podem ser usadas, neste caso, sem o conhecimento de suas heranças. Elas não podem ser usadas como "caixa preta".

Nesta tese, chamaremos "superclasses de A" todas as superclasses diretas e indiretas de $\mathrm{A}$.

\section{A.1.2 Tipos, Mensagens e Polimorfismo}

O tipo de uma classe é o conjunto de assinaturas de seus métodos públicos (métodos da seção share não são incluídos). A assinatura de um método é o seu nome, tipos dos valores de retorno (se ele é uma função), tipos dos parâmetros formais (nomes de parâmetros são descartados). Por exemplo, o tipo da classe Store da Figura A.8 é dado por

$$
\text { type (Store) }=\{\text { put(integer), get }(): \text { integer }\}
$$

Usamos type (A) para o tipo da classe A.

Um tipo $S=\left\{\mathrm{n}_{1}, \mathrm{n}_{2}, \ldots \mathrm{n}_{p}\right\}$ é igual ao tipo $T=\left\{\mathrm{m}_{1}, \mathrm{~m}_{2}, \ldots \mathrm{m}_{q}\right\}(S=T)$ se $p=q$ e $\mathbf{n}_{i}=\mathrm{m}_{i}, 1 \leq i \leq p$. A relação = para métodos é definida como se segue.

Sejam

$$
\begin{aligned}
& \mathrm{n}\left(T_{1}, T_{2}, \ldots T_{k}\right):\left(U_{1}^{\prime}, \ldots U_{l}^{\prime}\right) \\
& \mathrm{m}\left(T_{1}, T_{2}, \ldots T_{t}\right):\left(U_{1}, \ldots U_{r}\right)
\end{aligned}
$$


as assinaturas de dois métodos. Dizemos que $\mathrm{n}=\mathrm{m}$ se

- m e n possuem o mesmo nome.

- $t=k, r=l$.

- $T_{i}=T_{i}, 1 \leq i \leq t$.

- $U_{i}=U_{i}, 1 \leq i \leq r$.

Se necessário, as assinaturas dos métodos de $S$ e $T$ deverão ser organizadas em uma ordem tal que as relações acima tornam-se verdadeiras. Isto é, a ordem em que as assinaturas aparecem no conjunto não importa, embora a ordem dos tipos dos parâmetros/valores de retorno seja importante.

A igualdade de tipos é uma definição recursiva porque ela usa a definição de igualdade de métodos e vice-versa. Um algoritmo para testar se dois tipos são iguais poderia nunca terminar sua execução por causa de uma recursão sem fim. Contudo, isto nunca ocorre de acordo com a definição abaixo.

Proposição A.1 Um algoritmo que testa se dois tipos são iguais de acordo com a definição da linguagem sempre terminará sua execução.

Prova: Assuma que tipos são representados por vértices em um grafo dirigido e que há uma aresta do vértice $T$ para $U$ se $T$ usa $U$ em sua interface. Como um tipo deve ser definido antes que ele seja usado, $U$ foi textualmente definido antes de $T$ no programa.

Um algoritmo que testa se $S$ é igual a $T$ irá caminhar no grafo comparando os vértices atingidos a partir de $S$ com aqueles atingidos a partir de $T$. Como há um número finito de vértices, haverá uma recursão sem fim somente se houver um ciclo $U_{1} U_{2} \ldots U_{k} U_{1}$ no grafo. Isto significaria que $U_{1}$ vem textualmente antes de $U_{k}$ e vice-versa. Como isto é impossível, não haverá nenhum ciclo e o algoritmo sempre terminará.

Um tipo $S=\left\{\mathrm{n}_{1}, \mathrm{n}_{2}, \ldots \mathrm{n}_{p}\right\}$ é um subtipo de um tipo $T=\left\{\mathrm{m}_{1}, \mathrm{~m}_{2}\right.$, $\left.\ldots \mathrm{m}_{q}\right\}$ (Usaremos $S \prec T$ para esta relação) se $p \geq q$ e $\mathrm{n}_{i}=\mathrm{m}_{i}$ para $1 \leq i \leq q$. Por esta definição, $S \prec T$ implica $T \subset S$. Isto é, um subtipo tem pelo menos as mesmas assinaturas de métodos que o seu supertipo. Esta propriedade é fundamental para várias provas de correção do sistema de tipos feitas através desta tese. Como $X \subset X$ para qualquer tipo $X$, qualquer tipo é subtipo de si mesmo. Usualmente, dizemos "a classe B é um subtipo da classe A" ao invés de "o tipo da classe B é um subtipo do tipo da classe A".

Quando uma classe B herdar de uma classe A, B será uma subclasse de A. Assim, $B$ herdará todos os métodos públicos de $A$, implicando que $B$ será um subtipo de A. A classe B pode redefinir um método herdado de A, mas a sua assinatura deve ser a mesma que na superclasse. Pela definição de subtipo, qualquer subclasse é também um subtipo, mas é possível existir um subtipo que não seja uma subclasse.

Este sistema de tipos é uma restrição daquele da linguagem POOL-I [13]. Os programas que são corretamente tipados de acordo com o sistema de tipos 
definido acima são também corretamente tipados de acordo com o sistema de tipos de POOL-I, já que o primeiro possui mais restrições que o segundo. POOL-I segue as regras de Cardelli [48] para subtipos. Para explicar estas regras, suponha que a classe B seja subtipo da classe A, que define um método

$\operatorname{proc} m(x: C): D$

A classe $B$ pode definir um método

$\operatorname{proc} m\left(x: C^{\prime}\right): D^{\prime}$

tal que $C \prec C^{\prime}$ e $D^{\prime} \prec D$. Em nosso sistema de tipos, $C$ deve ser igual a $C^{\prime}$ e $D$ deve ser igual a $D^{\prime}$.

Algumas linguagens orientadas a objeto, como C++ [49] [50] e Eiffel [34] [51], associam subtipo com subclasse. Um subtipo de uma classe só pode ser criado por herança desta classe. Isto resulta em um sistema de tipos menos flexível que aquele usado nesta tese. Como exemplo, suponha que haja um método

$\operatorname{proc} m(x: A)$

de alguma classe (não importa qual). Em Eiffel e $\mathrm{C}++$, o método m aceita somente objetos da classe A e suas subclasses como parâmetros. Em nosso sistema de tipos, o método m aceita objetos de qualquer classe que seja subtipo de A. Como existem potencialmente mais subtipos que subclasses de $\mathrm{A}$, o sistema de tipos usado nesta tese suporta um grau de polimorfismo maior do que o de Eiffel $/ \mathrm{C}++$. A separação entre subtipo e subclasse resulta em uma flexibilidade próxima das linguagens sem tipos como Smalltalk. As linguagens POOL-I [13], Sather [52] [73], Java [54] e School [59] empregam sistemas de tipo similares a este. A linguagem Emerald [63] também usa este sistema de tipos embora ela não suporte herança.

Snyder [8] [7] afirma que há uma violação do encapsulamento se subtipo é atado a subclasse. Para mostrar isto, suponha que uma classe $B$ herde da classe A e um objeto da classe $B$ seja usado como parâmetro para o método m cuja assinatura foi mostrada no parágrafo anterior. Se a classe $\mathrm{B}$ for modificada para não mais herdar de A, embora mantendo sua interface, o código que passar objetos da classe B para m tornar-se-á incorreto. Isto significa que a herança de A por B não é privada a B: ela é pública e não pode ser alterada sem modificações no programa. A separação das hierarquias de subtipo e subclasse é recomendada por diversos autores, entre eles Porter [69] e Canning at al. [66].

Dado um conjunto de tipos $\delta$ e tipos $S, T \in \delta$, dizemos que o tipo $T$ é um supertipo direto de $S$ se:

- $S \prec T$

- $\nexists U \in \delta$ tal que $S \prec U \prec T$

Quando o conjunto $\delta$ não for especificado, ele será considerado como sendo composto por todos os tipos do programa.

A instrução

$$
\mathrm{aa}:=\mathrm{bb}
$$

faz as variáveis aa e bb referirem-se ao mesmo objeto. Os tipos declarados de aa e bb devem obedecer à relação

type (bb) $\prec$ type (aa)

Isto é, as atribuições do tipo 
Tipo:= SubTipo

são válidas.

A instrução

$$
\operatorname{a} \cdot m\left(p_{1}, p_{2}, \ldots p_{n}\right)
$$

envia a mensagem $m\left(p_{1}, p_{2}, \ldots p_{n}\right)$ para o objeto a que a se refere e será legal se:

- o método $\mathrm{m}\left(T_{i}, T_{2}, \ldots T_{n}\right):\left(U_{1}, U_{2}, \ldots U_{k}\right)$ pertencer a type (a), onde type (a) é o tipo declarado de a;

- para $1 \leq i \leq n, \operatorname{type}\left(\mathrm{p}_{i}\right) \prec T_{i}$, onde type $\left(\mathrm{p}_{i}\right)$ é o tipo declarado de $\mathrm{p}_{i}$.

O sistema de tempo de execução procura por um método com nome m na classe do objeto referenciado por a. Se nenhum método com este nome for encontrado, ele procurará nas superclasses do objeto, nas superclasses das superclasses e assim por diante. Se nenhum método $\mathrm{m}$ for encontrado, ocorrerá um erro de execução. ${ }^{1}$ Enviar uma mensagem para um objeto que não sabe respondê-la é um erro de tipos. Se um objeto possuir várias superclasses, não haverá nenhuma ambigüidade na escolha da superclasse para continuar a busca pelo método, pois duas superclasses de uma classe não possuem métodos em comum. $\mathrm{O}$ algoritmo para busca por método é definido na seção A.2.

A palavra chave self dentro de um método resulta no objeto que recebeu a mensagem que causou a execução do método. Ela não pode ser usada do lado esquerdo de uma atribuição.

Um envio de mensagem para self é considerado pelo sistema de tipos como um envio de mensagem normal no qual type (self) é o tipo da classe no qual a instrução se encontra.

$O$ envio de mensagem

$$
\text { super }(B) \cdot m\left(p_{1}, p_{2}, \ldots p_{n}\right)
$$

onde B é uma superclasse da classe onde esta instrução está, ordena ao sistema de tempo de execução que busque por método m na superclasse $\mathrm{B}$ da classe corrente. Ele será considerado corretamente tipado se o envio de mensagem

o for.

$$
(\text { B.new }()) \cdot m\left(p_{1}, p_{2}, \ldots p_{n}\right)
$$

A variável a usada acima pode se referir a um objeto cujo tipo é um subtipo do seu tipo declarado por causa das atribuições da forma Tipo:= Subtipo. Isto não causa nenhum erro, pois um subtipo possui todos os métodos do tipo, com as mesmas assinaturas de métodos.

O método m da classe A da Figura A.3 possui um parâmetro formal $x$ da classe Store. Usando as regras acima, o compilador confirma se:

- a classe Store possui métodos correspondentes aos envios de mensagem a $\mathrm{x}^{2}$ dentro do método $\mathrm{m}$, isto é, put e get;

\footnotetext{
${ }^{1}$ Embora as conferências feitas em tempo de compilação garantam que isto nunca ocorrerá em tempo de execução.

${ }^{2}$ Dizemos "envios de mensagens a $\mathbf{x}$ " significando "envio de mensagens ao objeto a que $\mathbf{x}$ irá referir-se em tempo de execução", já que uma mensagem é enviada a um objeto, não a uma variável.
} 
- Os tipos dos parâmetros reais/formais destas mensagens também obedecem à regra "Tipo:= Subtipo".

Em passagem de parâmetros para métodos/procedimentos, há uma atribuição implícita

parâmetro formal : = parâmetro real;

já que todos os parâmetros são passados por valor. 0 mesmo é válido para retorno de valores de métodos/procedimentos. Portanto, toda a análise de tipos pode ser restrita a atribuições, pois elas englobam passagem de parâmetros e retorno de valores.

Se uma classe $B$ for um subtipo de uma classe $A$, os métodos em comum entre $B$ e $A(B \cap A=A)$ deverão possuir a mesma semântica. Esta é a razão pela qual um objeto de B pode ser usado onde um objeto de A é esperado. Por "mesma semântica" queremos dizer que o resultado do envio de uma mensagem m para um objeto de $B$ é equivalente ao envio da mensagem m para um objeto de A. "Equivalente" significa que as operações abstratas executadas nos objetos de B e A podem ser consideradas como iguais. Esta definição não pode ser formal porque não se pode comparar os algoritmos de dois métodos e dizer se eles são equivalentes ou não no sentido computacional.

Quando uma variável for declarada, o programador deverá fornecer o nome de uma classe que representa o seu tipo, como em

var a : A;

Então, a variável a pode se referir a objetos de qualquer subtipo da classe A. De fato, A não representa a classe A mas o tipo type(A). Este é o motivo pelo qual algumas vezes é usado "A" como o tipo de uma variável ao invés de type(A).

Como esta variável pode se referir a objetos de classes que são subtipos de type (A), o compilador não sabe o tamanho do objeto a que esta variável irá se referir em tempo de execução. Esta é a razão pela qual a declaração de uma variável não aloca automaticamente memória para um objeto da classe A como em linguagens procedurais.

Este é também o motivo pelo qual um método de uma classe A não pode manipular uma variável de instância privada (ou método) $\mathrm{x}$ de um parâmetro cujo tipo é "A". O objeto a que o parâmetro irá se referir em tempo de execução pode ser de um subtipo de type(A) e ele pode não possuir um componente $\mathbf{x}$.

A linguagem não possui nenhuma sintaxe para a definição de módulos. Assim, devemos considerar que todo o programa está em um único arquivo. Isto não é uma limitação da linguagem porque os módulos apenas organizam o código. Embora o programa esteja em um único arquivo, pode haver outro arquivo com as classes shell. As definições de classes shell nunca são colocadas dentro do programa. Elas são sempre colocadas neste arquivo separado. Chamaremos este arquivo de "arquivo shell" e o outro de "arquivo do programa". A gramática do Apêndice $B$ define precisamente o que é legal em cada um destes arquivos.

Os tipos das classes definidas no arquivo do programa podem ser descobertas sem compilar este arquivo se não houver nenhum erro de sintaxe. Isto é possível porque o tipo de uma classe é apenas a sua interface. Ele não depende da correção semântica do código dos métodos da classe. Iremos usar na tese a

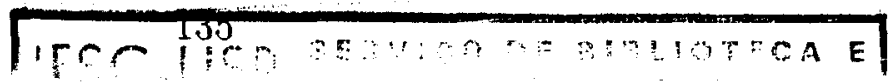


seguinte suposição:

Suposição A.1 É possivel encontrar os tipos de todas as classes que estão no arquivo do programa fazendo uma análise sintática nele se:

- não há nenhum erro sintático no programa;

- cada tipo de parâmetro e valor de retorno dos métodos seja definido antes que ele seja usado. Isto é, o nome de uma classe é usado somente nela mesma ou no código que a segue.

0 último item não é realmente necessário, mas ele é usado porque de outra forma haveria um erro de compilação e o programa deveria ser considerado incorreto. Assumiremos que existe um algoritmo que faz a análise do arquivo do programa e retorna os tipos de todas as classes. Ele usa a suposição A.1.

\section{A.1.3 Representação de Classes}

Representaremos os vários elementos da linguagem através de tuplas que são usadas nas definições dos shells.

Uma variável de instância de nome Nome e tipo Tipo é representada como (Nome, Tipo) e uma assinatura de método

Nome $\left(T_{1}, T_{2}, \ldots T_{p}\right):\left(U_{1}, U_{2}, \ldots U_{q}\right)$

é representada como (Nome, $\left.\left(T_{1}, T_{2}, \ldots T_{p}\right),\left(U_{1}, U_{2}, \ldots U_{q}\right)\right)$ e referenciada como Sign. Uma classe é uma tupla

(Nome, Superclasses, VariaveisDeInstancia, Metodos, IVsDaClasse, MsDaClasse)

onde:

- Nome é o nome da classe;

- Superclasses é um conjunto de nomes das superclasses;

- VariaveisDeInstancia é um conjunto de elementos da forma (Nome, Tipo);

- Metodos é um conjunto de elementos da forma

(Sign, Text, Status)

onde Sign é a assinatura do método (já descrita), Status será private se o método for privado ou public se o método for público e Text é o texto (em caracteres ASCII) do método, o que inclui tudo da palavra chave "proc" que começa o método até "end", que é a última palavra chave;

- IVsDaClasse é um conjunto de elementos do tipo (Nome, Tipo) e representa as variáveis de instância da seção "share" da classe;

- MsDaClasse é um conjunto de elementos (Sign, Text, Status) como em Metodos e representa os métodos da seção share da classe. 


\section{A.1.4 Outras Facilidades da Linguagem}

A palavra chave class, além de ser usada para declaração de classes, é uma função que retorna a classe de seu argumento (que deve ser um nome de variável ou self) avaliada em tempo de compilação. O valor de retorno desta função pode ser usada como o tipo de uma variável. Por exemplo, em

$\operatorname{var} \mathrm{x}: \mathrm{A}$;

$$
y: \operatorname{class}(x) \text {; }
$$

O tipo de y será A.

Como a avaliação da função class ocorre em tempo de compilação, a combinação

\section{class (self)}

é uma abreviação para o nome da classe onde esta expressão se encontra. Se a avaliação fosse feita em tempo de execução, o resultado de class(self) poderia ser uma subclasse da classe onde esta expressão está.

Variáveis e procedimentos/funções ${ }^{3}$ (fora de qualquer classe) são permitidos na linguagem. Isto permitirá que as construções propostas nesta tese sejam adicionadas facilmente a outras linguagens de programação. A execução do programa sempre começa em um procedimento chamado main e em um envio de mensagem/chamada de procedimento, parênteses serão usados mesmo se não houver parâmetro real, como na linguagem $\mathrm{C}$ :

$$
\text { a.m }() \text {; }
$$

Métodos e procedimentos com o mesmo nome, mas com número diferente de parâmetros, são considerados diferentes. $\mathrm{O}$ método new de uma classe não pode ser definido pelo programador. Se for necessário inicializar o objeto criado por new, isto deverá ser feito por um método cujo nome é initobject, qualquer que seja o nome da classe. Este método não pode ser chamado diretamente e não faz parte do tipo da classe. Conseqüentemente, ele não é herdado. Quando o método new for chamado, como em

$$
\text { A. new }\left(p_{1}, p_{2}, \ldots p_{t}\right)
$$

ele alocará memória para um objeto da classe A, inicializará algumas variáveis de instância "escondidas" e então enviará a mensagem

$$
\text { initobject }\left(\mathrm{p}_{1}, \mathrm{p}_{2}, \ldots \mathrm{p}_{t}\right)
$$

para o objeto criado.

A linguagem possui um comando que permite ao programa descobrir, em tempo de execução, a classe do objeto à que uma variável refere-se. Sua sintaxe é

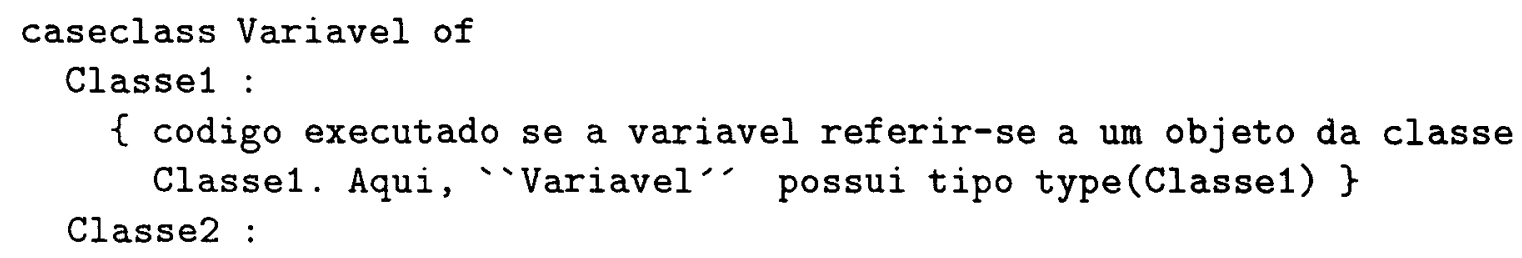

\footnotetext{
${ }^{3}$ Usaremos a palavra "procedimento" para significar rotinas que retornam ou não um valor. Então, procedimento é uma função em C ou um procedimento/função em Pascal.
} 


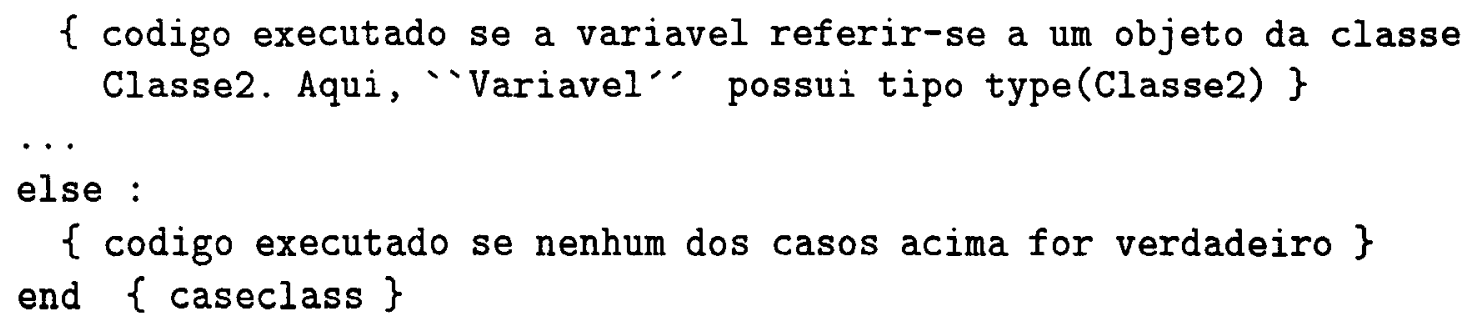

$\mathrm{O}$ código que se segue a $\mathrm{Cl}_{\text {asse }}$ pode usar Variavel como se ela tivesse o tipo type $\left(\mathrm{Classe}_{i}\right)$. Isto não causará erros de tipo porque este código será executado somente quando Variavel referir-se a um objeto da classe $\mathrm{Classe}_{i}$ e, portanto, ela terá o tipo type $\left(\mathrm{Classe}_{i}\right)$. Este comando é possivel porque cada objeto possui um ponteiro para a sua classe. Este ponteiro é inicializado na criação do objeto.

A linguagem suporta um mecanismo de exceções. Uma exceção é sinalizada por

signal (NomeExcecao)

e tratada pelo comando de exceções, que é colocado no fim de um procedimento ou método:

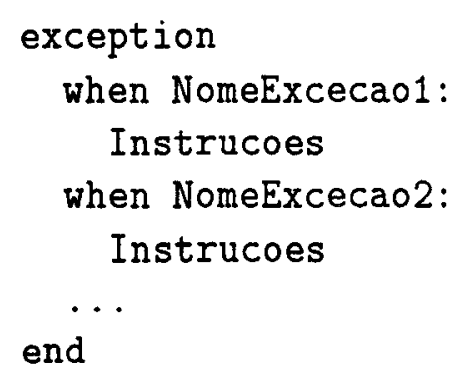

Uma exceção levantada pelo comando signal (E) ordena ao sistema de tempo de execução para procurar por uma instrução "when E" na pilha dos procedimentos/métodos chamados. Se algum for encontrado em um procedimento/método $\mathrm{m}$, todos os métodos/procedimentos antes de $\mathrm{m}$ serão desempilhados e a execução continuará nas instruções que se seguem a "when E" em m. O mecanismo de exceção não será completamente definido porque ele é usado somente em um (1) exemplo e sua importância é muito limitada.

Há quatro tipos básicos na linguagem: integer, real, boolean, e char. Eles não são classes mas podem ser considerados como tendo os seguintes tipos:

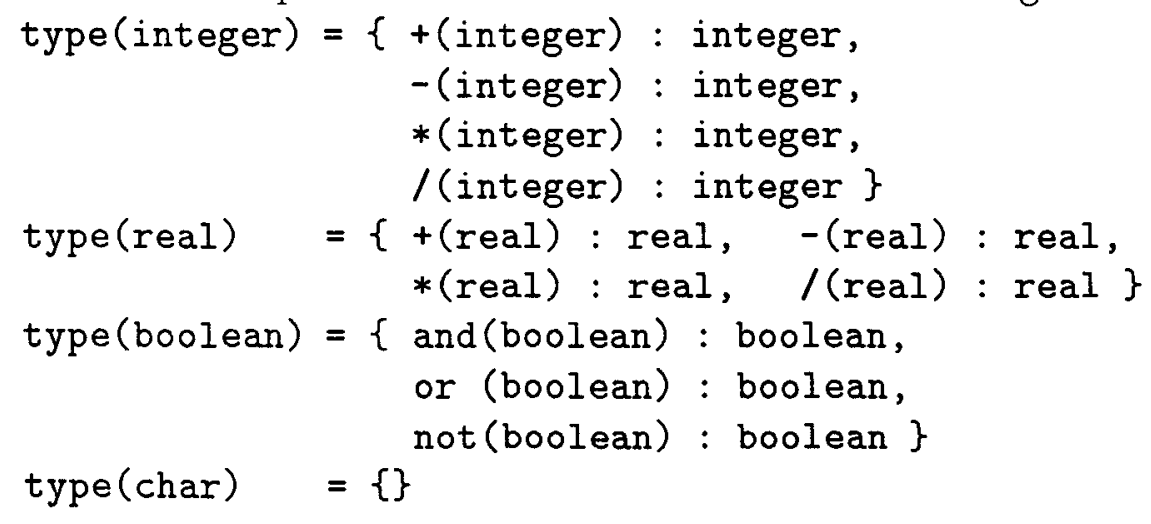




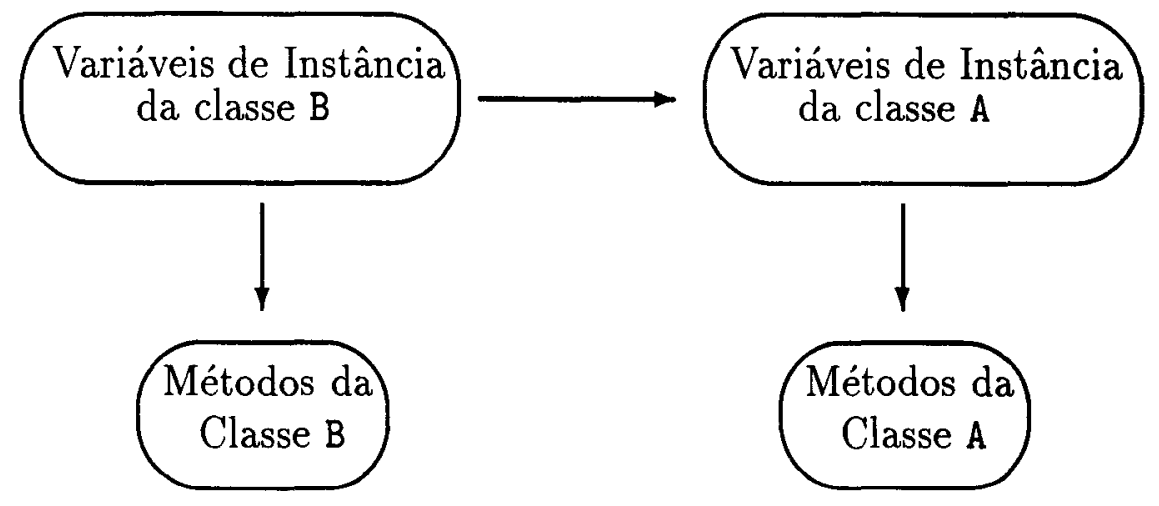

Figura A.9: Representação de um objeto da classe B. A classe B herda de A

\section{A.2 Representação de Objetos e Busca por Métodos}

Um objeto de uma classe B que herda de uma classe A (que não herda de ninguém) pode ser considerado como composto por dois sub-objetos. O primeiro possui todas as variáveis de instância de B e o segundo, todas as variáveis de instância de A. Há um ponteiro do primeiro para o segundo e cada um possui um ponteiro para o conjunto de métodos de suas respectivas classes. Esta situação é representada graficamente na Figura A.9.

Esta representação será definida mais precisamente agora. Um objeto de uma classe A que não possui superclasses possui todas as variáveis de instância definidas em A e uma referência para o conjunto de métodos de A. Este conjunto é retornado por uma função meth que toma como parâmetro uma referência para um objeto da classe A. Então, se a referir-se a um objeto da classe A, meth (a) será o conjunto de métodos de A. Este conjunto de métodos é organizado como procedimentos onde o primeiro parâmetro possui nome self e tipo A. Isto é, o método

$\operatorname{proc} m\left(\mathrm{x}_{1}: \mathrm{E}_{1}, \ldots \mathrm{x}_{r}: \mathrm{E}_{r}\right):\left(\mathrm{F}_{1}, \ldots \mathrm{F}_{q}\right)$

da classe A é considerado como o procedimento

$$
\begin{aligned}
\text { proc } m( & \left.\operatorname{self}: A ; x_{1}: E_{1}, \ldots x_{r}: E_{r}\right): \\
& \left(F_{1}, \ldots F_{q}\right)
\end{aligned}
$$

Cada envio de mensagem para self dentro de m é então o envio de uma mensagem para o primeiro argumento. $\mathrm{O}$ método m pode manipular as variáveis de instância do objeto a que self refere-se.

Um objeto de uma classe $B$ que herda de $A_{1}, A_{2}, \ldots A_{k}$ possui:

- todas as variáveis de instância definidas na classe B sem considerar as variáveis de instância herdadas. Este conjunto de variáveis é chamado de sub-objeto da classe B;

- um ponteiro para o conjunto de métodos da classe B. Isto é, os métodos 
definidos na classe B sem considerar os métodos herdados. Este conjunto é retornado pela função meth;

- um ponteiro para um objeto da classe $\mathrm{A}_{i}, 1 \leq i \leq k$. O nome deste ponteiro é super $\left(A_{i}\right)$ e, se b refere-se a um objeto da classe $B$, ele é manipulado como uma variável de instância normal: ${ }^{4}$

$$
\text { b. super }\left(A_{i}\right)
$$

Naturalmente, um objeto da classe $A_{i}$ será composto por outros sub-objetos se $A_{i}$ herdar de outras classes.

Então, um objeto da classe B é composto por um sub-objeto da classe B e por um sub-objeto de cada uma das classes herdadas direta ou indiretamente por $B$. Note que esta descrição de objetos não colide com o sistema de tipos ou com a definição da linguagem.

Usando a descrição de objetos dada acima, definiremos busca por método. Um envio de mensagem

$$
\text { a.m }\left(p_{1}, p_{2}, \ldots p_{r}\right)
$$

faz com que o compilador gere o código

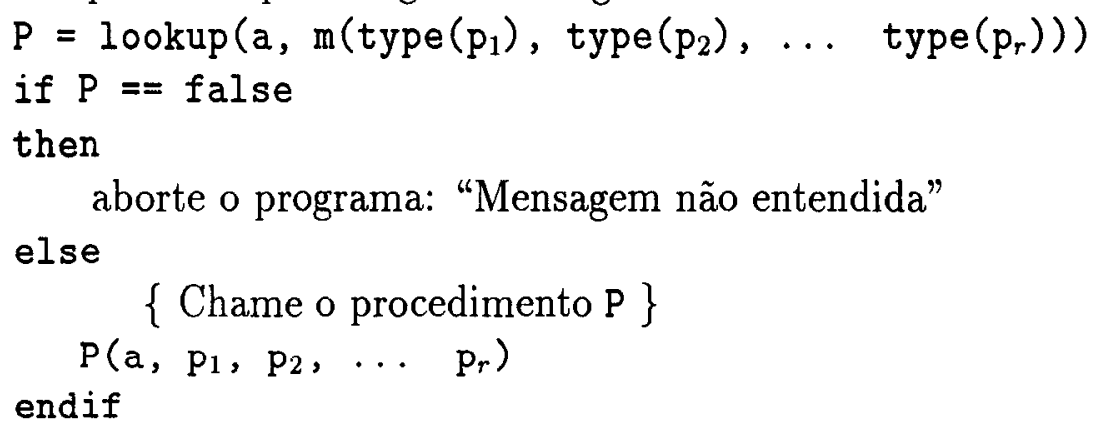

onde o algoritmo lookup é mostrado na Figura A.10. Um envio de mensagem usando super, como $\operatorname{super}\left(A_{i}\right) \cdot m\left(p_{1}, p_{2}, \ldots p_{r}\right)$

é transformada em uma ligação estática, pois o compilador sabe qual a classe onde a busca deve começar $\left(A_{i}\right)$.

Por esta descrição, se uma classe $B$ herdar de A, um objeto da classe B possuirá um ponteiro para um sub-objeto da classe A que é de fato um objeto normal desta classe e que será usado como tal por uma das construções filtros desta tese.

\section{A.3 Classes Parametrizadas}

\section{A.3.1 Definição}

A linguagem suporta uma forma simples de classes parametrizadas [72] que é baseada no trabalho de Guimarães [44]. Antes de apresentá-la, definiremos conformidade. Admita que existam dois tipos, $U=\left\{\mathrm{n}_{1}, \mathrm{n}_{2}, \ldots \mathrm{n}_{p}\right\}$ e $T=\left\{\mathrm{m}_{1}\right.$, $\left.\mathrm{m}_{2}, \ldots \mathrm{m}_{q}\right\}$. Todas as ocorrências do símbolo $U$ nos métodos $\mathrm{n}_{i}$ de $U$ são substituídas por $\square$, resultando em um tipo $U^{\prime}=\left\{n_{1}^{\prime}, n_{2}^{\prime}, \ldots n_{p}^{\prime}\right\}$. O mesmo é feito

\footnotetext{
${ }^{4}$ Embora a única operação suportada por ela seja envio de mensagem.
} 
Algoritmo lookup( $\operatorname{self}, \mathrm{m}\left(V_{1}, V_{2}, \ldots V_{r}\right)$ )

$\{$ Procura por procedimento $m$ no objeto a que self refere-se.

Se a classe deste objeto não possuir um método $\mathrm{m}$, a busca continuará em suas superclasses, superclasses das superclasses e assim por diante. Este algoritmo retornará o procedimento encontrado ou false se nenhum existir. Lembre-se de que os métodos de uma classe são transformados em procedimentos pela adição de self como primeiro parâmetro \}

if $\operatorname{self}==\mathrm{nil}$ then return false

else

if exitir um método $\mathrm{n}\left(T_{1}, T_{2}, \ldots T_{t}\right):\left(U_{1}, U_{2}, \ldots U_{l}\right)$ no conjunto meth (self) tal que

- $m$ e n possuem o mesmo nome.

- $r=t$ e $V_{i} \prec T_{i}$ para $1 \leq i \leq r$

then

return $n$

else

Sejam $A_{1}, A_{2}, \ldots A_{k}$ as superclasses do objeto self

if $k=0$

then

return false

else

for $i=1$ to $k$ do

begin

$\mathrm{n}=$ lookup ( self . super $\left(A_{i}\right)$,

if $n \neq$ false

$\left.\mathrm{m}\left(V_{1}, V_{2}, \ldots V_{r}\right)\right)$

then

return $\mathrm{n}$

endif

end

return false

endif

endif

endif

Figura A.10: Algoritmo para procurar por um método para responder a uma mensagem 


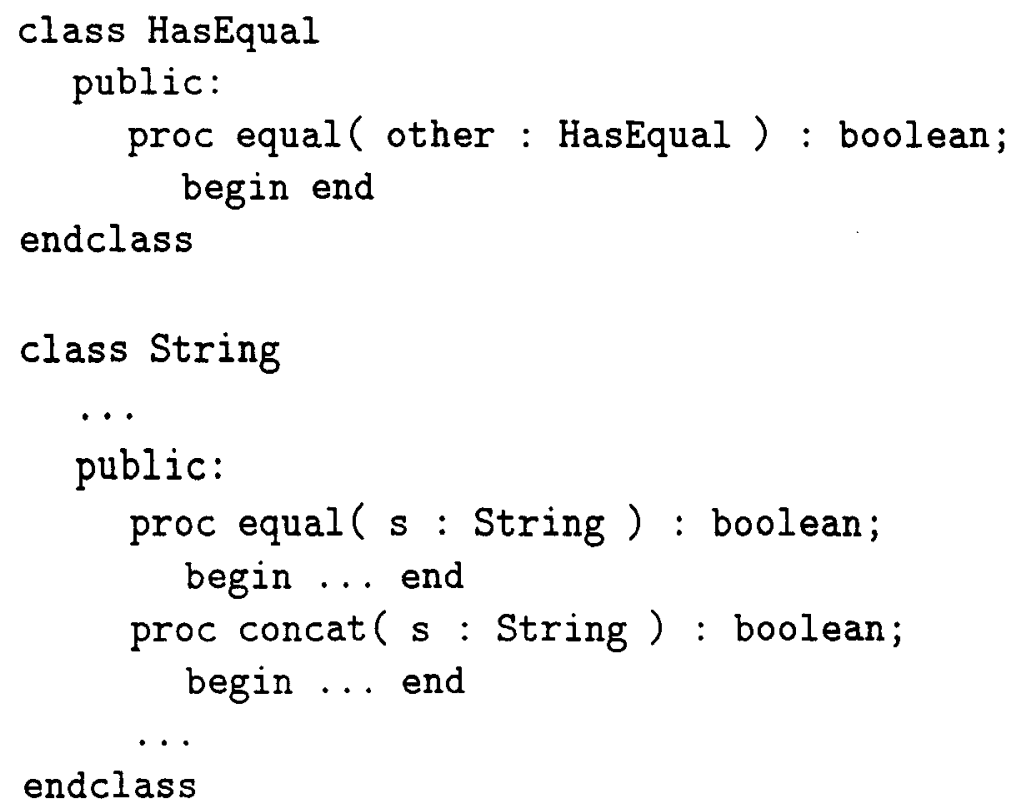

Figura A.11: Classe String conforma com HasEqual

com $T$, resultando em $T=\left\{\mathrm{m}_{1}^{\prime}, \mathrm{m}_{2}^{\prime}, \ldots \mathrm{m}_{q}^{\prime}\right\}$. O tipo $U$ conformará com o tipo $T$ se $p \geq q$ e $\mathrm{n}_{i}^{\prime}=\mathrm{m}_{i}^{\prime}$ para $1 \leq i \leq q$.

Diremos "a classe B conforma com a classe A" para significar "o tipo da classe B conforma com o tipo da classe A". Conformidade é diferente da relação de subtipo e é usada em School [59], CLU [57] [58] e em algumas construções de linguagem [40]. Como um exemplo desta relação, o tipo da classe String da Figura A.11 conforma com o tipo de HasEqual. Este exemplo foi retirado de [59].

A sintaxe para a declaração de uma classe parametrizada é mostrada na Figura A.12. Os parâmetros são especificados em uma lista separada por vírgulas e delimitada por colchetes, seguindo-se ao nome da classe no cabeçalho. Cada parâmetro $T_{i}: A_{i}$ é composto por um nome $T_{i}$ e o nome de uma classe $A_{i}$. O parâmetro real correspondente a $T_{i}$ deve conformar-se com $A_{i}$.

Uma classe parametrizada é representada como

(Nome, Parametros, Superclasses, VariaveisDeInstancia, Metodos, IVsDaClasse, MsDaClasse)

onde Nome, Superclasses, VariaveisDeInstancia, Metodos, IVsDaClasse, e MsDaClasse possuem o mesmo significado que na representação de uma classe normal. Parametros é um conjunto ordenado de elementos (Nome, Tipo), representando os parâmetros formais da classe.

Uma classe parametrizada pode ser usada em qualquer lugar em que uma classe normal também o possa, exceto em declarações de classes filtro/shell. Por exemplo, não se pode declarar um shell $B[X]->A[5]$ ou $B[X]->(A, B, C[5])$.

Para usarmos uma classe parametrizada

$\left(A,\left(\left(T_{1}, A_{1}\right),\left(T_{2}, A_{2}\right), \ldots\left(T_{n}, A_{n}\right)\right), \mathrm{S}\right.$, IVs, Ms, CIVs, CMs $)$

devemos fornecer a ela parâmetros reais que conformem com $A_{i}, 1 \leq i \leq n$. Isto é feito como uma chamada de procedimento: 


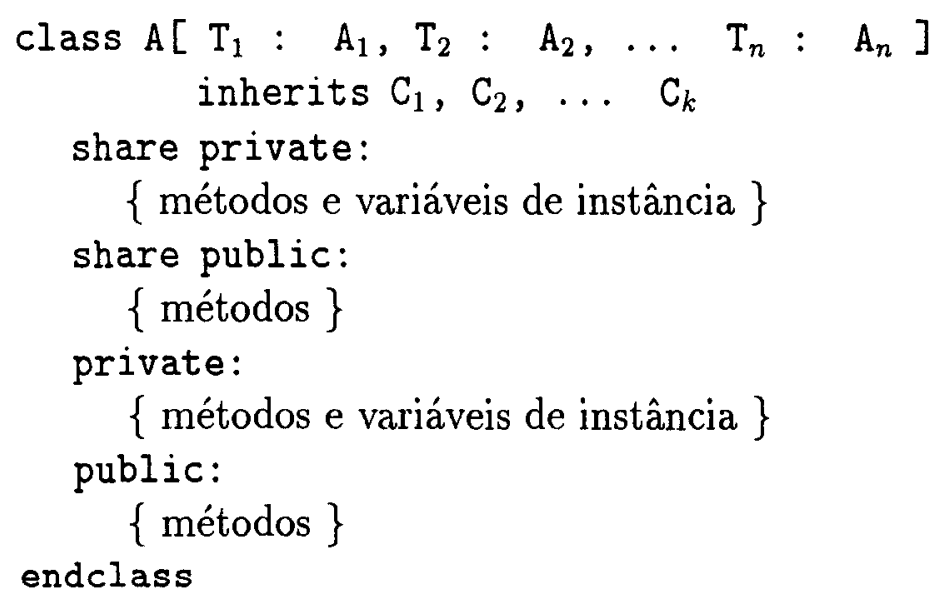

Figura A.12: Sintaxe para uma classe parametrizada

$$
\mathrm{A}\left[\mathrm{B}_{1}, \mathrm{~B}_{2}, \ldots \mathrm{B}_{n}\right]
$$

e é chamada de "instanciação da classe A". Quando o compilador encontrar esta instanciação, ele executará o algoritmo InstantiatePC da Figura A.13 com parâmetros $A, B_{1}, B_{2}, \ldots B_{n}$. Este algoritmo retornará false (se houver um erro) ou uma nova classe, que será então compilada. Se não houver erro de compilação, o nome desta nova classe, que é $\mathrm{N}^{\prime}$, substituirá $\mathrm{A}\left[\mathrm{B}_{1}, \mathrm{~B}_{2}, \ldots \mathrm{B}_{n}\right]$ e a compilação continuará. Diferente de classes virtuais de Beta [70], este modelo de classes parametrizadas não permite erros de tipo em execução.

$O$ nome $N^{\prime}$ é obtido pela concatenação do nome da classe parametrizada com os nomes de seus parâmetros reais usando o caracter ' $\bullet$ ' como separador. Como ' $@$ ' não é um caracter permitido na linguagem, $N$ ' é diferente de qualquer outro nome de identificador definido pelo programador e identifica precisamente a classe parametrizada e seus parâmetros reais. Uma instanciação de uma classe parametrizada pode ser usada em qualquer lugar onde se espera uma classe, pois ela é substituída por uma classe normal pelo compilador.

Há uma limitação no uso de classes parametrizadas: nem uma classe parametrizada A nem qualquer classe parametrizada que A usar (direta ou indiretamente) poderá instanciar a classe $\mathrm{A}$. Isto é, referências recursivas à classe $\mathrm{A}$ deverão ser feitas somente através do uso de "class(self)".

Podem ocorrer erros durante a compilação de uma classe retornada por InstantiatePC. Embora cada $\mathrm{B}_{i}$ deva conformar-se com cada $\mathrm{A}_{i}$, este fato sozinho não garante que a instanciação seja válida. Uma definição melhor de classes parametrizadas e uma prova formal poderiam garantir isto, mas esta prova não será feita nesta tese porque classes parametrizadas não são o ponto principal desta pesquisa.

\section{A.3.2 Uma Extensão a Classes Parametrizadas}

$\mathrm{Na}$ definição acima, não se pode colocar uma classe parametrizada no lugar reservado para o tipo de um parâmetro formal. Isto é, a classe parametrizada 
Algoritmo InstantiatePC $\left(A, B_{1}, B_{2}, \ldots B_{k}\right)$

$\{$ Este algoritmo retorna a classe criada pela instanciação da classe $A$ com $B_{1}, \ldots B_{k}$ ou false se ocorreu algum erro. $\}$

Seja

- $A=(N$, Ps, S, IVs, Ms, CIVs, CMs).

- $\mathrm{Ps}=\left(\left(\mathrm{T}_{1}, \mathrm{~A}_{1}\right),\left(\mathrm{T}_{2}, \mathrm{~A}_{2}\right), \ldots\left(\mathrm{T}_{n}, \mathrm{~A}_{n}\right)\right)$.

- $\mathrm{S}=\left(\mathrm{S}_{1}, \mathrm{~S}_{2}, \ldots \mathrm{S}_{v}\right)$

- IVs $=\left(\left(\mathrm{v}_{1}, \mathrm{~W}_{1}\right), \ldots\left(\mathrm{v}_{l}, \mathrm{~W}_{l}\right)\right)$.

- $\mathrm{Ms}=\left\{\left(\operatorname{Sign}_{j}, \operatorname{Text}_{j}, \operatorname{Status}_{j}\right) \mid 1 \leq j \leq p\right\}$

- $\operatorname{CIVs}=\left(\left(\mathrm{w}_{1}, \mathrm{Z}_{1}\right), \ldots\left(\mathrm{w}_{q}, \mathrm{Z}_{q}\right)\right)$

- $\mathrm{CMs}=\left\{\left(\operatorname{Sign}_{j}, \operatorname{Text}_{j}\right.\right.$, Status $\left.\left._{j}\right) \mid 1 \leq j \leq t\right\}$

if existir uma classe $\mathrm{A}^{\prime}$ cujo nome seja $\mathrm{AQB}_{1} \otimes_{2} @ \ldots \mathrm{B}_{n}$ e $n=k$ then

$\{$ Houve uma instanciação anterior desta classe com os mesmos parâmetros $\mathrm{B}_{1}, \ldots \mathrm{B}_{k}$. Assim, a classe instanciada previamente seja retornada $\}$ return $A^{\prime}$

endif

if $n \neq k$ ou $\exists i, 1 \leq i \leq n$ tal que $\mathrm{B}_{i}$ não conforma $\operatorname{com} \mathrm{A}_{i}$ then

return false

endif

Caso contrário, seja $\mathrm{A}^{\prime}$ a classe normal $\left(\mathrm{N}^{\prime}, \mathrm{S}^{\prime}, \mathrm{IVs}^{\prime}, \mathrm{Ms}^{\prime}, \mathrm{CIVs}^{\prime}, \mathrm{CMs}^{\prime}\right)$ na qual:

- $\mathrm{N}^{\prime}$ é o nome $\mathrm{A} \otimes \mathrm{B}_{1} \otimes \mathrm{B}_{2} @ \ldots \otimes \mathrm{B}_{n}$.

- $\mathrm{S}^{\prime}$ é obtido trocando-se cada $\mathrm{S}_{i}=\mathrm{T}_{i}$ no conjunto $\mathrm{S}$ por $\mathrm{B}_{i}$.

- $\operatorname{IVs}^{\prime}=\left(\left(\mathrm{v}_{1}, \mathrm{v}_{1}\right), \ldots\left(\mathrm{v}_{l}, \mathrm{~V}_{l}\right)\right)$ que é obtido trocando-se cada identificador $T_{i}=W_{i}$ dentro do conjunto IVs por $B_{i}$.

- $\mathbf{M s}^{\prime}=\left\{\left(\mathrm{Sign}_{j}^{\prime}\right.\right.$, Text $_{j}^{\prime}$, Status $\left.\left._{j}\right) \mid 1 \leq j \leq p\right\}$. Text ${ }_{j}^{\prime}$ é obtido substituindo-se cada símbolo $\mathrm{T}_{i}$ dentro de $\operatorname{Text}_{j}$ por $\mathrm{B}_{i}, 1 \leq i \leq n$. Sign' $\mathrm{Se}^{\prime}$ a assinatura do método resultante.

- As mesmas operações feitas com IVs e Ms são feitas com CIVs e CMs, resultando em CIVs' e CMs'.

return $A^{\prime}$

Figura A.13: Algoritmo para instanciar uma classe parametrizada A 


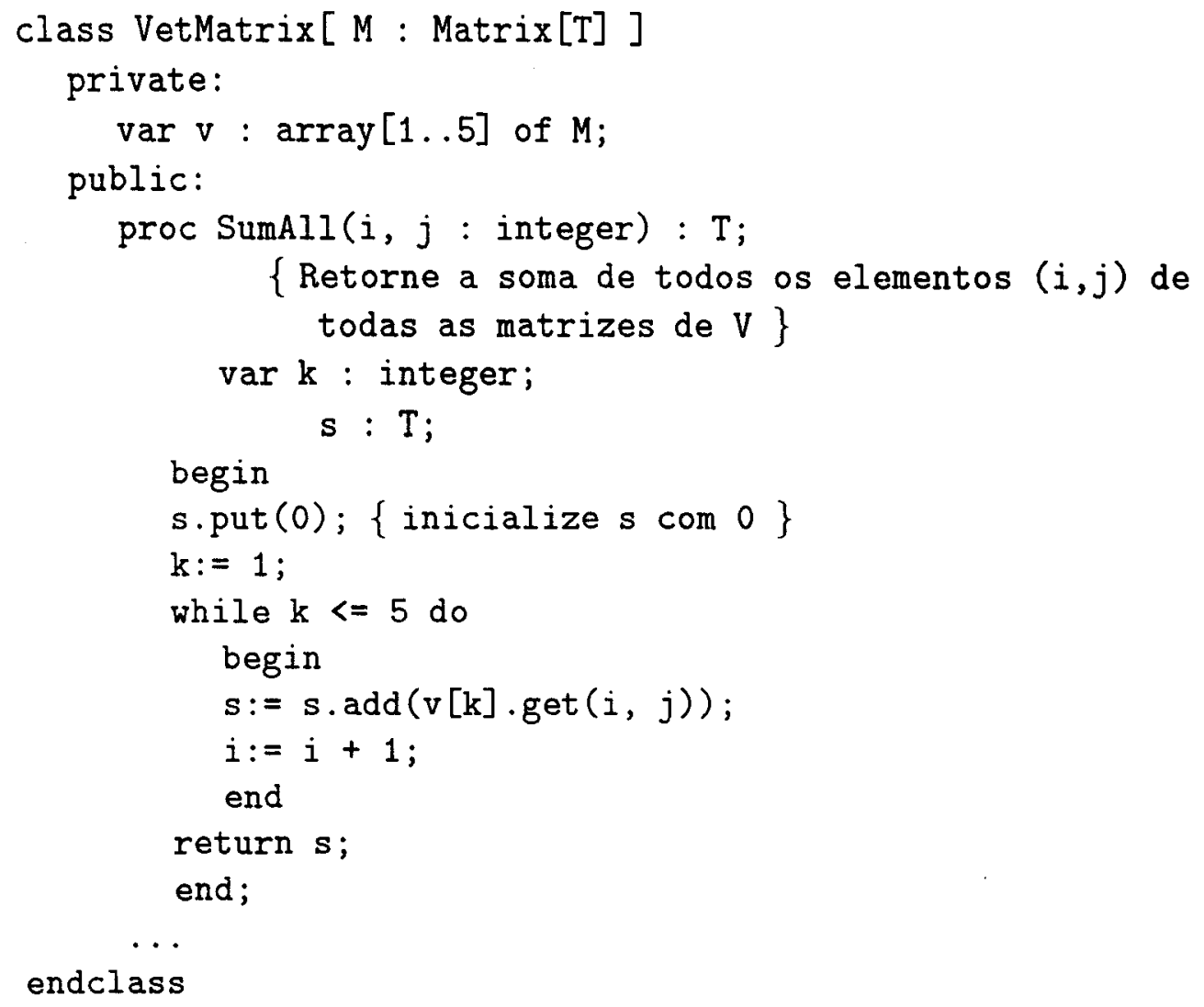

Figura A.14: Uma classe parametrizada que é um vetor de matrizes

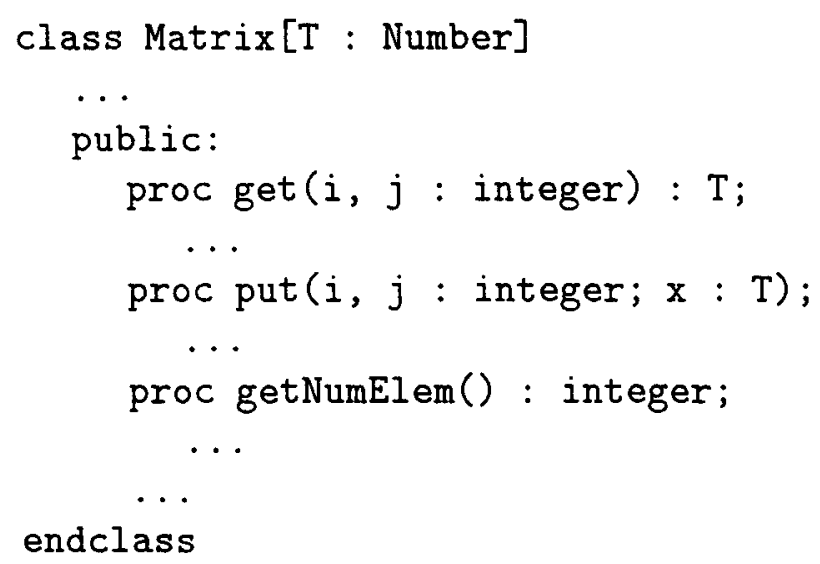

Figura A.15: Uma classe Matrix parametrizada com o tipo dos elementos da matriz 


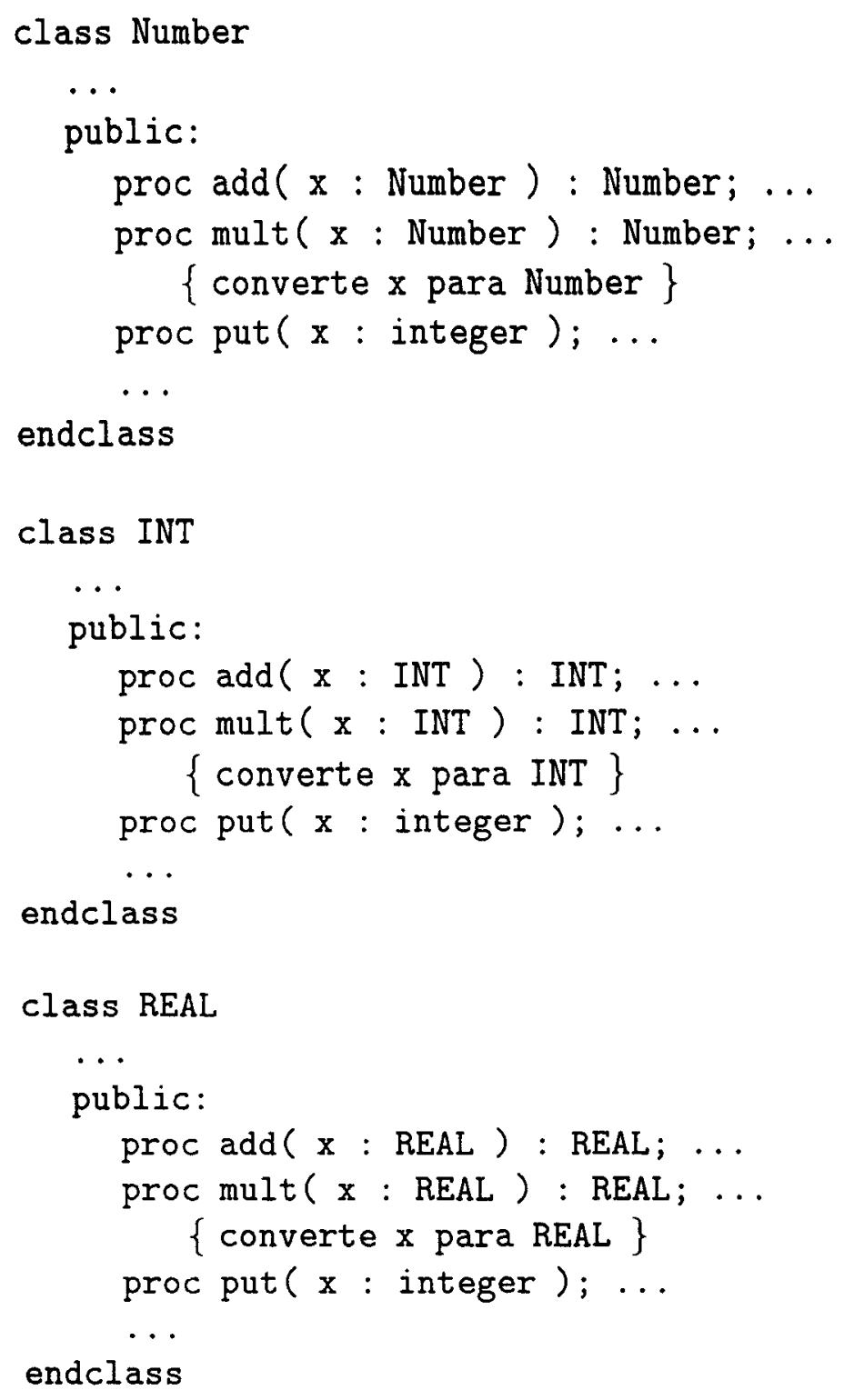

Figura A.16: Classes INT e REAL que conformam com Number 


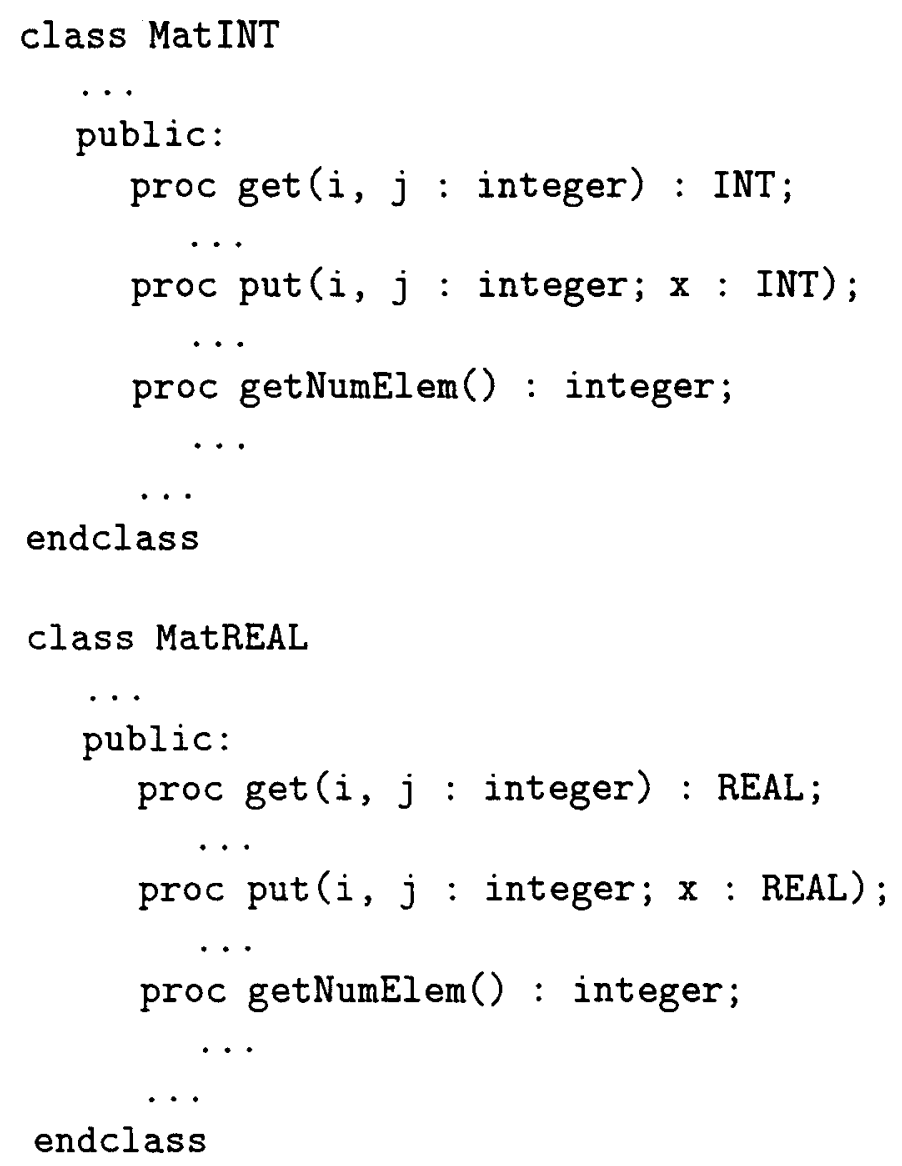

Figura A.17: Classes que conformam com Matrix [INT] e Matrix [REAL] 
VetMatrix mostrada na Figura A.14 não é permitida. O tipo do parâmetro M é a classe parametrizada Matrix da Figura A.15.

O modelo de classes parametrizadas será estendido para permitir isto. Assumindo que as classes INT e REAL definidas na Figura A.16 conformam com a classe Number desta mesma Figura, MatINT e MatREAL da Figura A.17 conformam com Matrix [INT] e Matrix [REAL] (respectivamente). Agora podemos usar MatINT e MatREAL para instanciar a classe VetMatrix:

var vmi : VetMatrix[MatINT];

vmr : VetMatrix [MatREAL];

O parâmetro T da classe Matrix é considerado como um parâmetro normal de VetMatrix cujo parâmetro real deve se conformar com o tipo type(Number).

$\mathrm{Na}$ instanciação de VetMatrix, como em VetMatrix[MatINT], é feito um emparelhamento entre MatINT e Matrix[T] para descobrir a classe T. Isto é necessário porque $\mathrm{T}$ é considerado um parâmetro normal da classe VetMatrix e, portanto, o compilador deve trocá-lo por uma classe real durante a instanciação. O emparelhamento revela que T é INT e então a instanciação de VetMatrix prossegue normalmente.

Se o emparelhamento não for possível, haverá um erro de compilação. Isto aconteceria na tentativa de emparelhar as duas classes abaixo.

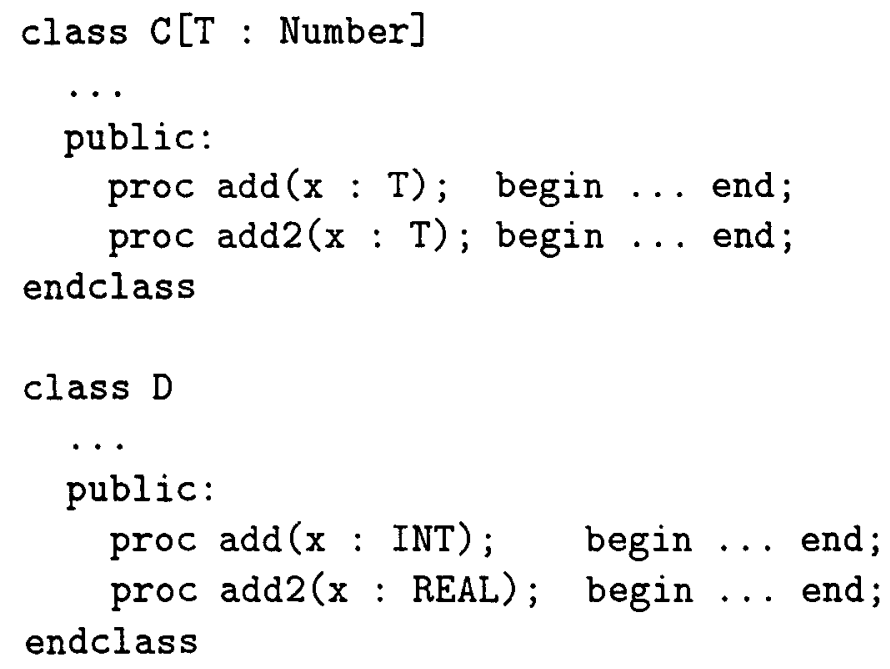

Se $\mathrm{T}$ for associado a INT, haverá um erro em add2. Se T for associado a REAL, o erro ocorrerá em add.

Esta idéia será melhor especificada agora. Serão usadas as classes parametrizadas

$$
\begin{aligned}
& \left(\mathrm{A},\left(\left(\mathrm{T}_{1}, \mathrm{~A}_{1}\right),\left(\mathrm{T}_{2}, \mathrm{~A}_{2}\right), \ldots(\mathrm{T}, \mathrm{B}[\mathrm{U}]),\left(\mathrm{T}_{j}, \mathrm{~A}_{j}\right), \ldots\left(\mathrm{T}_{n}, \mathrm{~A}_{n}\right)\right), \mathrm{S}, \mathrm{IVs},\right. \\
& \text { Ms }, \text { CIVs }, \mathrm{CMs})
\end{aligned}
$$

$\mathrm{e}$

$$
\left(\mathrm{B},((\mathrm{U}, \mathrm{X})), \mathrm{S}^{\prime}, \mathrm{IVs}^{\prime}, \mathrm{Ms}^{\prime}, \mathrm{CIVs}^{\prime}, \mathrm{CMs}^{\prime}\right)
$$

onde A possui somente um parâmetro que é uma classe parametrizada $(\mathrm{T})$ e $\mathrm{B}$ possui somente um parâmetro. Não definiremos uma forma mais geral desta facilidade porque isto não será necessário nesta tese. 
Algoritmo MatchClasses( C, B [U] )

$\{$ Descobre a classe correspondente a $U$ através do emparelhamento das classes C e B [U]. O algoritmo retorna esta classe ou false se houver alguma ambigüidade. \}

Seja

$\operatorname{proc} \mathrm{m}\left(\mathrm{x}_{1}: \mathrm{V}_{1}, \ldots \mathrm{x}_{n}: \mathrm{V}_{n}\right):\left(\mathrm{V}_{n+1} \ldots \mathrm{V}_{t}\right)$

um método de $\mathrm{B}$ onde o tipo $\mathrm{U}$ aparece como o tipo de um parâmetro ou valor de retorno. Isto é, $\exists j, 1 \leq j \leq t$ tal que $U=\mathrm{V}_{j}$. Se tal método não existir, retorne false. Não importa se existir mais de um tipo de parâmetro que seja igual a U. Se houver mais de um, o algoritmo poderá tomar qualquer um deles.

Seja

$$
\operatorname{proc} \mathrm{m}\left(\mathrm{y}_{1}: \mathrm{W}_{1}, \ldots \mathrm{y}_{q}: \mathrm{W}_{q}\right):\left(\mathrm{W}_{q+1} \ldots \mathrm{W}_{p}\right)
$$

o método da classe $\mathrm{C}$ com o mesmo nome do método $\mathrm{m}$ da classe $\mathrm{B}, n=q$, $p=t$ e, para $1 \leq i \leq t, \mathrm{~W}_{i}=\mathrm{V}_{i}$ sempre que $\mathrm{V}_{i} \neq \mathrm{U}$. Se este método não existir, retorne false

Agora a classe correspondente a $\mathrm{U}$ de $\mathrm{B}$ em C é $\mathrm{W}_{j}$ (pois $\mathrm{U}=\mathrm{V}_{j}$ no método $\mathrm{m}$ da classe $\mathrm{B}$ ) e temos os seguintes métodos $\mathrm{m}$ :

$$
\begin{gathered}
\operatorname{proc} \mathrm{m}\left(\mathrm{x}_{1}: \mathrm{V}_{1}, \ldots, \mathrm{x}_{j}: \mathrm{U}, \ldots \mathrm{x}_{n}: \mathrm{V}_{n}\right): \\
\left(\mathrm{V}_{n+1} \ldots \mathrm{V}_{t}\right)\{\operatorname{class} \mathrm{B}\} \\
\operatorname{proc} \mathrm{m}\left(\mathrm{x}_{1}: \mathrm{W}_{1}, \ldots, \mathrm{x}_{j}: \mathrm{W}_{j}, \ldots \mathrm{x}_{n}: \mathrm{W}_{n}\right): \\
\left(\mathrm{W}_{n+1} \ldots \mathrm{W}_{t}\right)\{\operatorname{class} \mathrm{C}\}
\end{gathered}
$$

Substitua todos os símbolos U na interface da classe B (type(B)) por $W_{j}$ resultando em uma classe $B^{\prime}$. Retorne false se $C$ não conformar com $B^{\prime}$. Caso contrário, retorne $\mathrm{W}_{j}$

Figura A.18: Algoritmo para emparelhar classes 
O compilador transforma a classe A em

$$
\begin{aligned}
& \left(\mathrm{A},\left(\left(\mathrm{T}_{1}, \mathrm{~A}_{1}\right),\left(\mathrm{T}_{2}, \mathrm{~A}_{2}\right), \ldots(\mathrm{U}, \mathrm{X}),(\mathrm{T}, \mathrm{B}[\mathrm{U}]),\left(\mathrm{T}_{j}, \mathrm{~A}_{j}\right), \ldots\left(\mathrm{T}_{n}, \mathrm{~A}_{n}\right)\right), \mathrm{S},\right. \\
& \text { IVs, Ms, CIVs, CMs })
\end{aligned}
$$

e em uma instanciação

$$
\mathrm{A}[\ldots \mathrm{C}, \ldots]
$$

da classe $\mathrm{A}$, onde $\mathrm{C}$ corresponde a $\mathrm{B}[\mathrm{U}]$, o parâmetro $\mathrm{C}$ deve ser uma classe real. Como o parâmetro U da nova classe A não é fornecido nesta instanciação, ele deve ser encontrado de alguma maneira. Isto é feito pelo algoritmo MatchClasses da Figura A.18, que é chamado como

$U^{\prime}=\operatorname{MatchClasses}(C, B[U])$

Se $U^{\prime}$ não for false, a classe A será instanciada com os parâmetros $U^{\prime}$ e C:

$$
\mathrm{A}\left[\ldots \mathrm{U}^{\prime}, \mathrm{C}, \ldots\right]
$$

Se o algoritmo retornar false, haverá uma ambigüidade e o compilador assinalará um erro.

Note, no algoritmo MatchClasses, que o tipo da classe $B[U]$ depois da substituição de símbolos (U por $W_{j}$ ), é type $\left(B\left[W_{j}\right]\right.$ ) e type $(C)$ conforma com type $\left(B\left[W_{j}\right]\right)$, pois ele conforma com type $\left(B^{\prime}\right)$.

A definição dada acima poderá ser estendida no futuro para lidar com mais de um parâmetro para uma classe B e com múltiplos níveis de aninhamento:

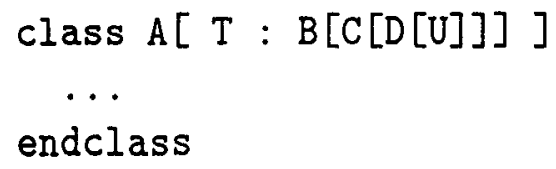

Então os símbolos $B[C[D[U]]], C[D[U]], D[U]$ e U poderiam ser usados dentro da classe A.

Este modelo de classes parametrizadas não é ideal porque não podemos dizer se uma classe será válida como parâmetro real para uma classe parametrizada apenas comparando o tipo do parâmetro real com o equivalente tipo do parâmetro formal. Este modelo foi escolhido para ser usado nesta tese não porque ele seja completo mas porque ele é simples e suficiente para os nossos propósitos. 


\section{Apêndice B}

\section{A Gramática da Linguagem}

Esta seção define a gramática da linguagem. As palavras reservadas e símbolos da linguagem são mostrados entre "e ". Qualquer seqüência de símbolos entre \{ e \} pode ser repetida zero ou mais vezes e qualquer seqüência de símbolos entre [e ] é opcional. O prefixo Un em um nome significa a união de duas ou mais regras. $\mathrm{O}$ arquivo do programa ${ }^{1}$ deve ser analisado pelo desdobramento da regra "Program" e o arquivo shell pelo desdobramento da regra "ProgramShells".

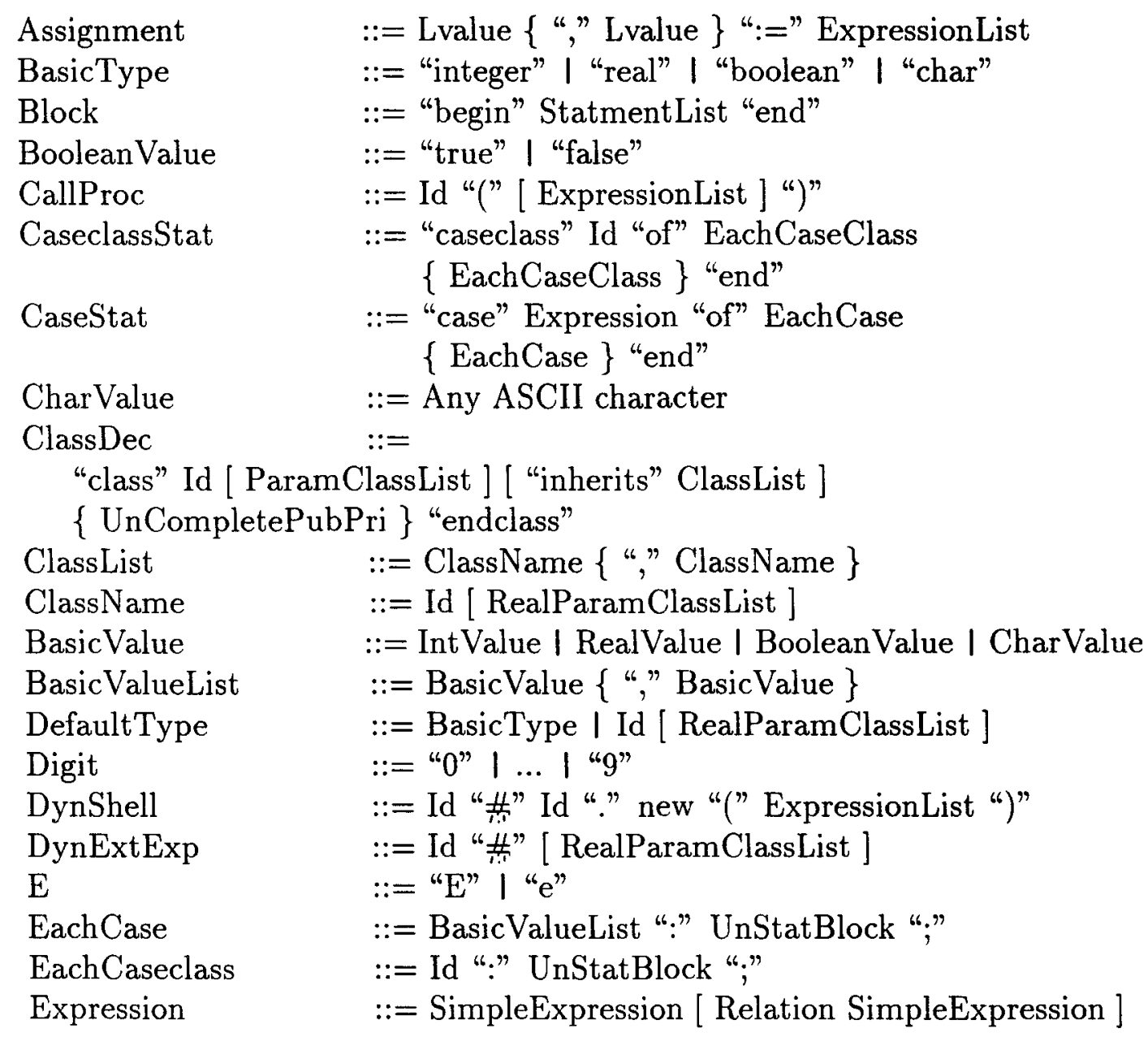

\footnotetext{
${ }^{1}$ Veja definição de arquivo do programa e arquivo shell no Apêndice C.
} 


\begin{tabular}{|c|c|}
\hline \multirow{5}{*}{$\begin{array}{l}\text { ExpressionList } \\
\text { Factor }\end{array}$} & $::=$ Expression $\{", "$ Expression $\}$ \\
\hline & $::=$ BasicValue | Id [ IndexList ] | CallProc | \\
\hline & MessageSend | DynShell | \\
\hline & "(" Expression ")" | "not" Factor I \\
\hline & DynExtExp | "self" | “nil" \\
\hline First & $::=$ Letter | "_" \\
\hline FormalParamDec & $::=$ IdList ":" Type \\
\hline FormalParamDecList & $::=$ FormalParamDec $\{$ "; FormalParamDec $\}$ \\
\hline GlobalDec & $::=$ "var" $\operatorname{VarDec}\{\operatorname{VarDec}\}$ \\
\hline HighOperator & $::=$ "*" | "/" | "and" \\
\hline Id & $::=$ First $\{$ Letter | Digit | "_" $\}$ \\
\hline IdList & $::=\operatorname{Id}\{“, " \operatorname{Id}\}$ \\
\hline IfStat & $\begin{aligned}::= & \text { "if" Expression "then" StatmentList } \\
& \text { ["else" StatmentList ] "endif" }\end{aligned}$ \\
\hline Index & $::=$ "[" Expression "]" \\
\hline IndexList & $::=\operatorname{Index}\{$ Index $\}$ \\
\hline IntValue & $::=$ Digit $\{$ Digit $\}$ \\
\hline Letter & $::=$ "A" | .. | "Z" | “a" | .. | "z" \\
\hline LocalDec & $::=" \operatorname{var} " \operatorname{VarDec}\{\operatorname{VarDec}\}$ \\
\hline LowOperator & $::=$ "+ | "-" | "or" \\
\hline Lvalue & $::=$ Id [ IndexList ] \\
\hline MessageSend & $\begin{aligned}::= & \text { ReceiverMessage "." MethodId "(" } \\
& {[\text { [ ExpressionList ] ")" }}\end{aligned}$ \\
\hline MethodDec & $::=$ ProcHeading ";" [ LocalDec ] Block \\
\hline MethodId & $::=$ Id | new \\
\hline ParamClass & $::=$ Id “:" TypeParamClass \\
\hline ParamClassList & $::=$ "[" ParamClass $\{$ ", ParamClass $\}$ "]" \\
\hline PrivatePart & $::=$ VarInstDecList | MethodDec \\
\hline ProcDec & $::=$ ProcHeading “;” [ LocalDec ] Block \\
\hline ProcHeading & $\begin{aligned}::= & \text { "proc" Id "(" [ FormalParamDecList ] ")" } \\
& \text { [ ":" ReturnTypeList ] }\end{aligned}$ \\
\hline Program & $::=\{$ UnDec $\}$ \\
\hline ProgramShells & $::=\{$ ShellDec $\mid$ ShellClassDec $\}$ \\
\hline RealParamClass & $::=$ ClassName \\
\hline RealParamClassList & $::=$ "[" RealParamClass $\{$ ", RealParamClass $\}$ "]" \\
\hline RealTypeParamClass & $::=$ RealParamClass I Id \\
\hline RealValue & $::=$ Digit $\{$ Digit $\} " . "\{$ Digit $\}[$ Scale $]$ \\
\hline ReceiverMessage & $::=$ "object" | "super" “(" Id ")" | Expression \\
\hline Relation & $::="=="|"<"| ">" \mid$ | $<=="|">="|$ | $<>"$ \\
\hline RemoveStat & $::=$ "remove" "(" Expression ")" \\
\hline RepeatStat & $::=$ "repeat" StatmentList "until" Expression \\
\hline ReturnStat & $\begin{array}{l}:=\text { "return" Expression I } \\
\text { "return" "(" ExpressionList ")" }\end{array}$ \\
\hline nTypeList & $::=$ Type I "(" Type $\{$ ", Type $\}$ ")" \\
\hline Scale & $::=\mathrm{E}[$ [+"| "-" ] Digit $\{$ Digit $\}$ \\
\hline
\end{tabular}




\begin{tabular}{|c|c|}
\hline \multicolumn{2}{|l|}{ ShellClassDec } \\
\hline \multirow{2}{*}{\multicolumn{2}{|c|}{ "class" Id "->" "(" IdList ")" \{ UnPubPri $\}$ "endclass" I }} \\
\hline & \\
\hline \multicolumn{2}{|c|}{ "class" "(" Id ":" TypeParamClass ")" “艼" Id [ ParamClassList ] } \\
\hline \multicolumn{2}{|c|}{ \{ UnCompletePubPri \} "endclass" | } \\
\hline \multicolumn{2}{|c|}{ "class" Id "(" Id "->" Id ")" \{ UnPubPriDynSh $\}$ "endclass" } \\
\hline \multirow[t]{3}{*}{ ShellDec } & $::=$ ShellClassDec | \\
\hline & "shell" Id “莒” Id [ RealParamClassList ] I \\
\hline & $\begin{array}{l}\text { "shell" "type" “(" Id ")" “艼” Id } \\
\text { [ RealParamClassList ] }\end{array}$ \\
\hline Signal & $::=$ "+ " " " " \\
\hline SimpleExpression & $::=[$ Signal $]$ Term $\{$ LowOperator Term $\}$ \\
\hline \multirow{3}{*}{ Statment } & $::=$ Assignment | CallProc | IfStat | WhileStat | \\
\hline & RepeatStat | CaseStat | CaseclassStat | \\
\hline & MessageSend | ReturnStat | RemoveStat \\
\hline StatmentList & $::=\{$ Statment ";" $\}$ \\
\hline Term & $::=$ Factor $\{$ HighOperator Factor $\}$ \\
\hline \multirow{3}{*}{ Type } & $::=$ "array" "[" IntValue ".." IntValue "]" "of" \\
\hline & Type I BasicType I \\
\hline & ClassName I "class" "(" UnVarSelf ")" \\
\hline \multirow[t]{3}{*}{ TypeParamClass } & $::=$ BasicType I Id I \\
\hline & Id "[" RealTypeParamClass \{ “," \\
\hline & RealTypeParamClass \} “]” \\
\hline \multirow[t]{2}{*}{ UnCompletePubPri } & $::=$ UnPubPri I \\
\hline & $\begin{array}{l}\text { "share" "public" ":" }\{\text { MethodDec }\} \text { I } \\
\text { "share" "private" ":" }\{\text { PrivatePart }\}\end{array}$ \\
\hline UnDec & $::=$ ClassDec | GlobalDec | ProcDec \\
\hline UnPubPri & $::=$ "public" ":" $\{$ MethodDec $\}$ I \\
\hline UnPubPriDynSh & $\begin{aligned} & \text { "private" “:" \{ PrivatePart }\} \\
::= & \text { UnCompletePubPri I }\end{aligned}$ \\
\hline & "shell" "public" ":" \{ MethodDec \} I \\
\hline & "shell" "private" “:" \{ PrivatePart $\}$ \\
\hline UnStatBlock & $::=$ Statment $\mid$ Block \\
\hline UnVarSelf & $::=$ Id | "self" \\
\hline VarDec & $::=$ IdList ":" Type “;” \\
\hline VarInstDec & $::=$ IdList ":" Type ";" \\
\hline VarInstDecList & $::=$ "var" VarInstDec $\{$ VarInstDec $\}$ \\
\hline WhileStat & $::=$ "while" Expression "do" UnStatBlock \\
\hline
\end{tabular}




\section{Apêndice C}

\section{Glossário}

Aplicar. Aplicar um filtro a um objeto referenciado por uma variável v significa que o sistema de tempo de execução:

- criará um objeto filtro e irá fazê-lo referir-se ao objeto;

- fará v referir-se ao objeto filtro.

Dizemos também "usar o filtro com o objeto/variável".

Arquivo do Programa. Um único arquivo contendo todo o código do programa, excluindo qualquer definição de shell/filtro. Veja também a entrada "Arquivo Shell".

Arquivo Shell. Um arquivo contendo todas as classes filtro/shell e outras declarações relacionadas com as construções shell.

Assinciturc. A assinatura de um método é o seu nome, tipo do valor de retorno (se ele for uma função) e tipos dos parâmetros formais. Por exemplo, a assinatura do método

é

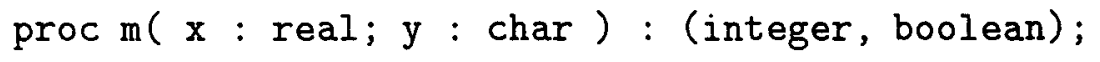

Clàsse. Uma classe é um esqueleto do qual objetos são criados. Ela é uma declaração que define um conjunto de dados chamados de variáveis de instância e um conjunto de procedimentos chamados métodos. Uma classe agrupa dados e comportamento (métodos) em uma mesma abstração. Todos os objetos de uma classe possuem o mesmo conjunto de variáveis e métodos, embora os valores das variáveis de instância difiram de objeto para objeto.

Clàsse Parametrizada. Uma classe parametrizada é uma classe com um ou mais parâmetros, fornecidos quando a classe for empregada no programa. Cada 
um deles deve ser uma classe. Veja Apêndice A para mais detalhes.

Cliente. Os clientes de uma classe são as classes/procedimentos que declaram variáveis e parâmetros daquela classe. Os clientes de um procedimento são as classes/procedimentos que chamam aquele procedimento.

Colocar um filtro. Colocar um filtro ao redor um objeto é criar um objeto filtro e fazê-lo referir-se ao objeto. Então o objeto filtro será usado como se ele fosse o objeto.

Conformar, Conformidade. Veja a definição na página 140. Uma classe poderá ser um parâmetro real para uma classe parametrizada se o seu tipo conformar com o tipo do parâmetro formal correspondente.

Erro de tipos. Um erro de tipo ocorre quando uma mensagem for enviada a um objeto que não possui um método apropriado para responder àquela mensagem. Erros de tipo são encontrados em tempo de compilação em linguagens estaticamente tipadas e em tempo de execução em linguagens fortemente tipadas.

Figurả. Para saber a representação gráfica de objetos, filtros e shells, veja as páginas 6 e 130.

Filtro. A palavra "filtro" significa "classe filtro", cuja definição está na página 6 .

Fortemente Tipada. Uma linguagem é fortemente tipada se nenhum erro de tipos puder ocorrer em tempo de execução. Um exemplo de linguagem fortemente tipada é Smalltalk [21]. Antes que um erro de tipos ocorra em tempo de execução, o programa é parado pelo sistema de tempo de execução ou interpretador.

Herança. Uma classe B herda de uma classe A usando a sintaxe class $B$ inherits $A$

...

endelass

Então, todos os métodos/variáveis de instância de A são adicionados a B. A classe B pode redefinir os métodos herdados de A e pode definir novos métodos por si mesma.

Instanciąçã̃o. É o processo de substituir os parâmetros formais por parâmetros reais em uma classe parametrizada. Então, quando o compilador encontrar uma declaração var a : $A[B]$;

ele criará uma nova classe instanciando a classe A com a classe B. 
Interface. A interface de uma classe é o seu tipo de acordo com a primeira definição de tipo (veja entrada "Tipo" neste glossário).

Mensagem. Uma instrução

a. $m\left(e_{1}, e_{2}, \ldots e_{n}\right)$

é o envio da mensagem $m\left(e_{1}, e_{2}, \ldots e_{n}\right)$ para o objeto referenciado por a. Um envio de mensagem causa uma busca por método na classe do objeto tal que a assinatura do método é a mesma de $\mathrm{m}$. Se o método apropriado não for encontrado na classe do objeto, a busca continuará nas superclasses, superclasses das superclasses e assim por diante. Não haverá nenhuma ambigüidade em qual superclasse continuar a busca (se houver mais de uma superclasse) porque uma classe não pode herdar dois métodos com o mesmo nome de duas superclasses.

Uma mensagem é somente enviada a um objeto em tempo de execução. Contudo, dizemos "mensagem enviada à variável v" ao invés de "mensagem enviada ao objeto ao qual a variável v irá se referir em tempo de execução".

Objeto. Um objeto é uma instância de uma classe. Como tal, ele só existe em tempo de execução, embora algumas vezes dizemos "objeto v" onde v é uma variável. Neste caso, queremos dizer "o objeto a que v irá se referir em tempo de execução".

Todos os objetos da mesma classe possuem o mesmo conjunto de variáveis de instância e métodos. Cada objeto possui o seu próprio conjunto de valores de variáveis de instância. Conceitualmente, um objeto possui seus próprios métodos também, mas na prática todos os objetos de uma mesma classe compartilham os mesmos métodos.

Objeto Filtro. Um objeto de uma classe filtro.

Objeto Shell. Um objeto shell é um objeto de uma classe shell.

Pálàvrâs Chàve. Abaixo estão algumas palavras chave da linguagem.

- class é uma função que retorna a classe do seu argumento avaliada em tempo de compilação. O argumento deve ser uma variável ou self. Por exemplo,

var $\mathrm{x}: \mathrm{A}$;

$y: c l a s s(x)$;

declara y como tendo o tipo A.

- new é a mensagem que, quando enviada para uma classe, criará um objeto desta classe:

$\mathrm{a}:=\mathrm{A} \cdot \operatorname{new}()$; 
- nil é uma referência para um objeto nulo, que não possui nenhum método. É um erro de tipos enviar qualquer mensagem para nil. Mesmo assim, o tipo de nil é considerado, em atribuições, subtipo de qualquer outro tipo. Qualquer variável cujo tipo seja uma classe pode receber nil em uma atribuição.

- object. Esta palavra chave somente pode ser usada dentro dos métodos de um filtro/shell. A expressão

$$
\text { object.m(...) }
$$

faz com que a busca por um método $m$ comece no objeto ou objeto filtro a que o shell/filtro refere-se. Um objeto shell/filtro sempre refere-se a um e somente um objeto ou filtro objeto. Esta palavra chave não pode ser usada como variável do lado direito ou esquerdo de uma atribuição, a não ser em envios de mensagens.

- private começa a seção privada de uma classe.

- public começa a declaração dos métodos públicos de uma classe.

- share. As variáveis e métodos da seção share são compartilhadas por todos os objetos da classe correspondente. Os métodos das seções share private e share public são manipulados usando a sintaxe

ClassName.MethodName (...)

e eles podem somente manipular as variáveis da classe.

- self é uma referência para o objeto que recebeu a mensagem que causou a execução do método corrente. Assim, self somente pode ser usado dentro de métodos e o seu tipo é o tipo da classe do método onde esta palavra chave está.

Procedimento. Um procedimento é uma rotina fora de uma classe. É o equivalente a funções da linguagem $\mathrm{C}$ ou procedimentos/funções de Pascal.

Referir-se. Variáveis são ponteiros para objetos, exceto quando o tipo das variáveis for um dos tipos básicos. Então, dizemos "uma variável refere-se a um objeto" ao invés de "uma variável contém um objeto". A declaração de uma variável não causa alocação de memória para o objeto ao qual ela irá se referir. $\mathrm{O}$ tipo do objeto será conhecido somente depois da atribuição. Lembre-se de que uma variável do tipo A pode referir-se a objetos de qualquer classe que é subtipo de A.

Regič̃̃o. Uma região é um conjunto de classes e procedimentos. Uma região é um pedaço de código que corresponde ao código de todos os procedimentos e todos os métodos de todas as classes do conjunto. 
Responder. Dizemos "um objeto pode responder a uma mensagem" quando o objeto possuir o método correspondente a esta mensagem. Isto é, este método será executado quando a mensagem for enviada ao objeto.

Shell. A palavra shell é usada para significar "classe shell", cuja definição está na página 4.

Símbolo. Um símbolo é qualquer identificador válido na linguagem ou qualquer sequiência de caracteres entre "e " na definição da sintaxe da linguagem dada no Apêndice B.

Sintåxe. Abaixo está a sintaxe para a declaração de cada shell/filtro. Veja Apêndice B para mais detalhes.

- Visão de classe:

class $\mathrm{B} \rightarrow\left(\mathrm{E}_{1}, \mathrm{E}_{2}, \ldots \mathrm{E}_{n}\right)$

- Adaptadores:

class B $\rightarrow$ A

- Extensão de classe, Extensão dinâmica:

class $\left(\mathrm{T}_{0}: \mathrm{A}_{0}\right) \# \mathrm{E}\left(\mathrm{T}_{1}: \mathrm{A}_{1} ; \mathrm{T}_{2}: \mathrm{A}_{2} ; \ldots \mathrm{T}_{n}: \mathrm{A}_{n}\right)$

Extensão de classe e extensão dinâmica são usados como

shell $B_{0} \# E\left(B_{1}, B_{2}, \ldots B_{n}\right)$

if $\mathrm{B}_{0} \# \mathrm{E}\left(\mathrm{B}_{1}, \mathrm{~B}_{2}, \ldots \mathrm{B}_{n}\right)$ then ...

respectivamente.

- Shell Dinâmico:

class $B(A \rightarrow A)$

Ele é usado como

a\#B. new ()

Onde o tipo de a é subtipo de type(A).

Subclàsse. Uma classe C será uma subclasse de B se C herdar de B. Neste caso, B será uma superclasse de C. Se B herdar de uma classe A, C será também uma subclasse de $\mathrm{A}$, que será superclasse de $\mathrm{C}$.

Em geral, dizemos "subclasse" ("superclasse") significando "subclasse (superclasse) direta ou indireta". Uma classe B será uma subclasse direta de uma classe A quando B herdar A. As subclasses (superclasses) não diretas são chamadas de "indiretas".

Subtipo. Um tipo $S$ é um subtipo de um tipo $T$ se $T \subset S$. Isto é, $S$ tem pelo menos as mesmas assinaturas de métodos que $T$. 


\section{Superclässe. Veja a entrada para "Subclasse".}

Supertipo direto. Dado um conjunto de tipos $\delta$ e tipos $S, T \in \delta$, dizemos que $T$ é um supertipo direto de $S$ se:

- $S \prec T$

- $\nexists U \in \delta$ tal que $S \prec U \prec T$

Quando o conjunto $\delta$ não for especificado, ele será considerado como composto por todos os tipos do programa.

Tipagem Estática. Uma linguagem é tipada estaticamente se nenhum erro de tipos puder ocorrer em tempo de execução e for possível garantir isto em tempo de compilação.

Tipo. Esta tese usa duas definições para "tipo". Na primeira, o tipo de uma classe é o conjunto de assinaturas de seus métodos públicos (os métodos da seção share não são incluidos). Por exemplo, o tipo da classe

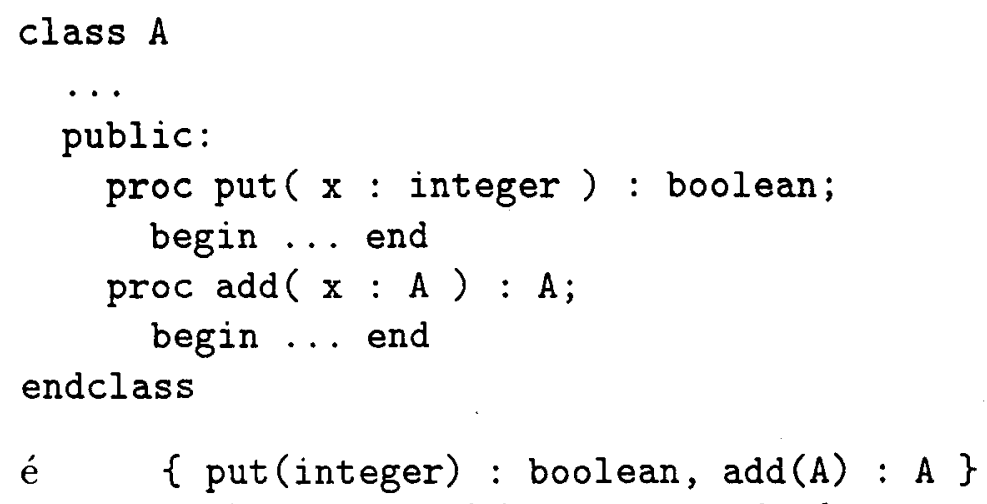

$\mathrm{Na}$ segunda definição, um tipo é um conjunto de classes de um programa que possuem o mesmo tipo de_acordo com a primeira definição. Então, o tipo de uma classe A é definido como

$$
\text { Type2 }(A)=\{C \mid C \text { é uma classe e type }(C)=\text { type }(A)\}
$$

A menos que haja alguma observação em contrário, usaremos a primeira definição. 